Social Media in an English Village 


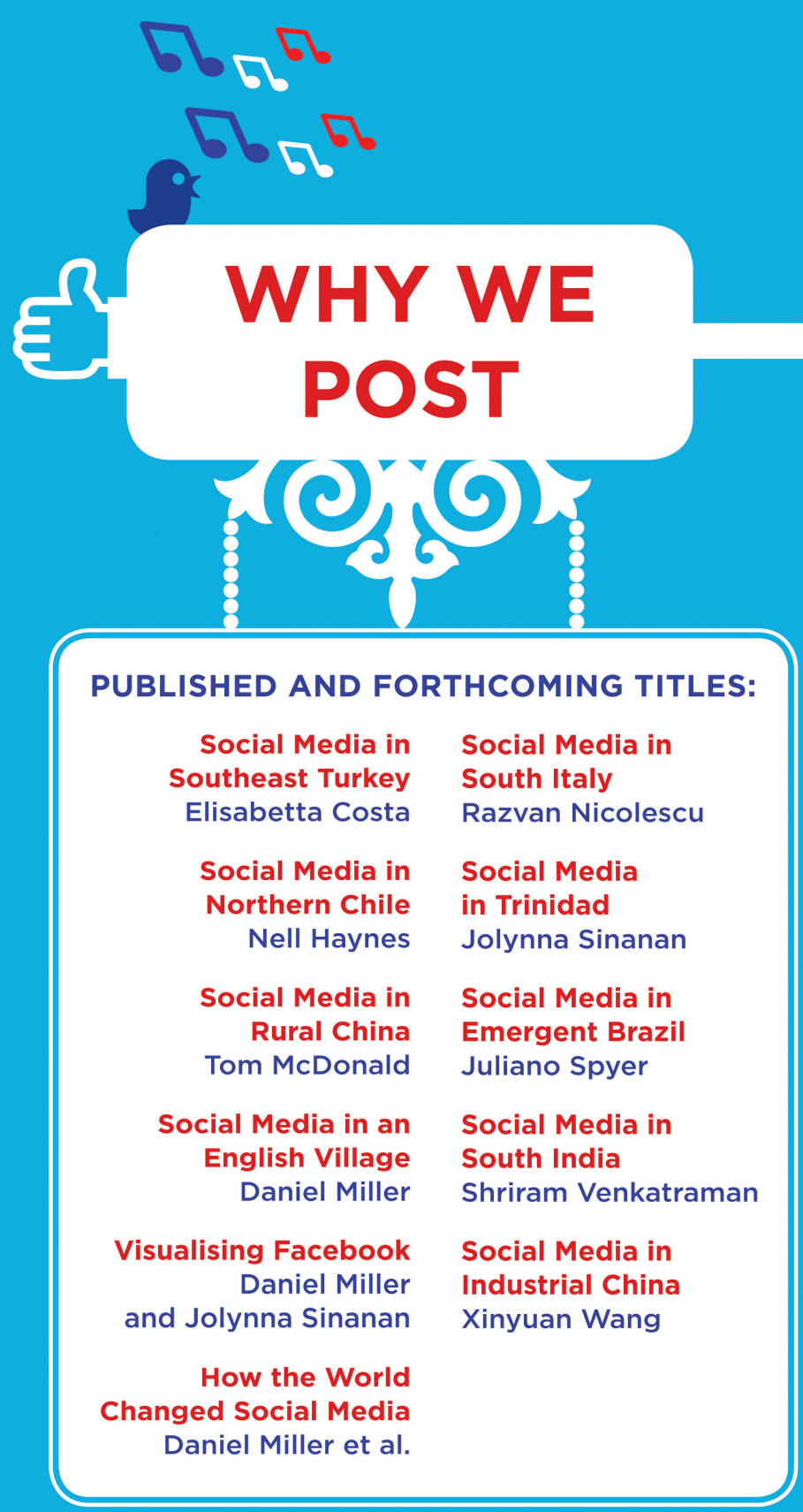

Find out more: www.ucl.ac.uk/ucl-press

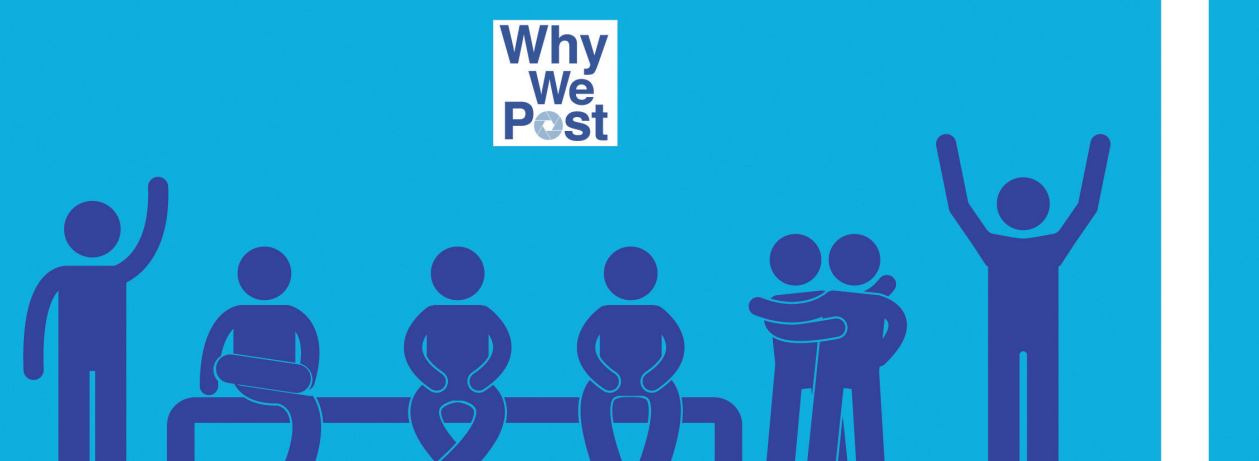




\section{Social Media in an English Village}

Or how to keep people at just the right distonce

Daniel Miller 
First published in 2016 by

UCL Press

University College London

Gower Street

London WC1E 6BT

Available to download free: www.ucl.ac.uk/ucl-press

Text (C) Daniel Miller, 2016

Images (C) Daniel Miller, 2016

A CIP catalogue record for this book is available from The British Library.

This book is published under a Creative Commons Attribution Non-commercial Non-derivative 4.0 International license (CC BY-NC-ND 4.0). This license allows you to share, copy, distribute and transmit the work for personal and non-commercial use providing author and publisher attribution is clearly stated. Further details about CC BY licenses are available at http://creativecommons.org/ licenses/by/4.0

ISBN: 978-1-910634-42-4 (Hbk.)

ISBN: 978-1-910634-43-1 (Pbk.)

ISBN: 978-1-910634-44-8 (PDF)

ISBN: 978-1-910634-45-5 (epub)

ISBN: 978-1-910634-46-2 (mobi)

DOI: $10.14324 / 111.9781910634431$ 


\section{Introduction to the series Why We Post}

This book is one of a series of 11 titles. Nine are monographs devoted to specific field sites (including this one) in Brazil, Chile, China, England, India, Italy, Trinidad and Turkey - they will be published in 2016-17. The series also includes a comparative book about all of our findings, published to accompany this title, and a final book which contrasts the visuals that people post on Facebook in this same English field site with those on our Trinidadian field site.

When we tell people that we have written nine monographs about social media around the world, all using the same chapter headings (apart from Chapter 5), they are concerned about potential repetition. However, if you decide to read several of these books (and we very much hope you do), you will see that this device has been helpful in showing the precise opposite. Each book is as individual and distinct as if it were on an entirely different topic.

This is perhaps our single most important finding. Most studies of the internet and social media are based on research methods that assume we can generalise across different groups. We look at tweets in one place and write about 'Twitter'. We conduct tests about social media and friendship in one population, and then write on this topic as if friendship means the same thing for all populations. By presenting nine books with the same chapter headings, you can judge for yourselves what kinds of generalisations are, or are not, possible.

Our intention is not to evaluate social media, either positively or negatively. Instead the purpose is educational, providing detailed evidence of what social media has become in each place and the local consequences, including local evaluations.

Each book is based on 15 months of research during which time most of the anthropologists lived, worked and interacted with people in the local language. Yet they differ from the dominant tradition of writing social science books. Firstly they do not engage with the academic literatures on social media. It would be highly repetitive to have the 
same discussions in all nine books. Instead discussions of these literatures are to be found in our comparative book, How the World Changed Social Media. Secondly these monographs are not comparative, which again is the primary function of this other volume. Thirdly, given the immense interest in social media from the general public, we have tried to write in an accessible and open style. This means we have adopted a mode more common in historical writing of keeping all citations and the discussion of all wider academic issues to endnotes. If you prefer to read above the line, each text offers a simple narrative about our findings. If you want to read a more conventional academic book that relates the material to its academic context, this can be done through engaging with the endnotes.

We hope you enjoy the results and that you will also read our comparative book - and perhaps some of the other monographs - in addition to this one. 


\section{Acknowledgements}

I am grateful to all the anonymous informants for this study, especially the patients at the hospice suffering from terminal illnesses who agreed to give their very precious time to these discussions. I would especially like to thank Ciara Green, my co-researcher on the entire village ethnographic study: she participated, discussed and helped throughout, and without her I could not have done this work. I am indebted to Kimberley McLaughlin, who worked with me on all the interviews of hospice patients, and to Dr Ros Taylor, the director of the hospice of St Francis. We received a good deal of assistance from a number of teachers who helped us establish our work in the four secondary schools. I am also grateful to Amelia Hassoun and Sabrina Miller, who worked as interns at an early stage in the project, and to Rickie Burman for all her help. I apologise that I cannot name others who assisted in this work for reasons of anonymity. I am also grateful to the two peer reviewers of the original manuscript and their many helpful suggestions for improvements. Finally I am very grateful for the excellent copy-editing by Catherine Bradley.

The volume forms one part of the Global Social Media Impact Study (www.gsmis.org), dedicated to understanding the use and consequences of new and social media. It consists of nine simultaneous 15-month ethnographies and is funded by the European Research Council grant ERC-2011-AdG-295486 Socnet. We devised the project as a team and discussed it continuously (incessantly) throughout. All the chapters of all the books were commented upon extensively by the other members of the team.

We obtained informed consent from all those who participated in our interviews. We also went through a secondary process of informed consent when we wished to use materials taken directly from people's own social media profiles, in instances where we had permission to follow these directly. This was also true for people who agreed to take part in the films we produced as part of our field work. These short films may be found on the Why We Post website (www.ucl.ac.uk/why-we-post), and 
I would strongly urge anyone taking the time and trouble to read this book also to view some of those films, especially if they have not themselves lived in England. It would not be hard in these days of 'Google Search' for readers to identify places and sometimes people. However, I would request that readers collaborate with me in trying to preserve anonymity as far as possible - a precondition if we want to share and understand people's personal lives and thereby educate ourselves. 


\section{Contents}

List of figures $\quad \mathrm{x}$

$\begin{array}{ll}\text { 1. Welcome to The Glades } & 1\end{array}$

2. The social media landscape 19

3. Crafting the look 45

4. Social media and social relationships 92

5. Making social media matter $\quad 122$

$\begin{array}{ll}\text { 6. The wider world } & 150\end{array}$

$\begin{array}{ll}\text { 7. How English is social media? } & 180\end{array}$

Notes 193

References $\quad 201$

$\begin{array}{ll}\text { Index } & 205\end{array}$ 


\section{List of figures}

$\begin{array}{lll}\text { Fig. 1.1 Terraced housing } & 11\end{array}$

$\begin{array}{lll}\text { Fig. } 1.2 \quad \text { Semi-detached housing } & 11\end{array}$

Fig. 1.3 Detached housing 12

$\begin{array}{lll}\text { Fig. } 1.4 \quad \text { Estate housing } & 12\end{array}$

Fig. 1.5 Carnival in Leeglade 14

$\begin{array}{lll}\text { Fig. 1.6 The annual gardening and produce show } & 15\end{array}$

$\begin{array}{lll}\text { Fig. 3.1 Typical visual joke tweet } & 47\end{array}$

$\begin{array}{lll}\text { Fig. 3.2 Typical visual joke tweet } & 47\end{array}$

Fig. 3.3 Typical visual joke tweet 48

Fig. 3.4 Typical visual joke tweet 48

Fig. 3.5 'Fake tan this morning was brilliant idea' 49

Fig. 3.6 'Can we all appreciate how ugly my knees are?' 49

Fig. 3.7 'I shall no longer wear cheap rings' 49

Fig. 3.8 'I saw this and thought of you' 50

Fig. 3.9 'This reminded me of you' 51

Fig. 3.10 'Sorry for eating your Wispa Gold bar' $\quad 51$

Fig. 3.11 'This is (...) He is single' 52

Fig. 3.12 'Sue, you got any nail varnish? Nah' 52

Fig. 3.13 'Russia borders Japan, like I said' 53

Fig. 3.14 'Is that yours, you c**t?' 53

Fig. 3.15 'Picture of Charlotte on beach' 54

Fig. 3.16 'I saw this and thought of you'

Fig. 3.17 Typical insulting tweet $\quad 55$

Fig. 3.18 Typical insulting tweet $\quad 55$

Fig. 3.19 'Felt rude not to accept every university' 56

Fig. 3.20 Overgrown BBQ 56

Fig. 3.21 'Joys of knowing someone that works at McDonald's, ordered medium got large plus two free burgers' $\quad 57$

Fig. 3.22 'This bath is just bliss' 57

Fig. 3.23 'Can't contain the excitement' 58

$\begin{array}{lll}\text { Fig. } 3.24 & 58\end{array}$ 
Fig. 3.25

'How I feel'

Fig. 3.26 'Bad day' 59

Fig. 3.27 'Even Lionel Messi wears bow ties' 59

Fig. 3.28 Tweeting involving sexual humour 60

Fig. 3.29 Tweeting involving sexual humour 60

Fig. 3.30 'Dilemma' 60

Fig. 3.31 Harry Potter tweet 61

Fig. 3.32 'My fortune cookie is freaky after this week' 62

Fig. 3.33 'He loves me not, that little f...' 62

Fig. 3.34 'Feeling festive' 63

Fig. 3.35 'Someone buy me this please' 63

Fig. 3.36 'I got an Aston Martin for Christmas woo woo' 64

Fig. 3.37 'Anyone want to buy me a ...' 64

Fig. 3.38 'I want' $\quad 65$

Fig. 3.39 'Wtf is this $\mathrm{s}^{* * \mathrm{t} \text { ?' }} 65$

Fig. 3.40 Lest we forget 66

Fig. 3.41 Political posting 66

Fig. 3.42 'Hope this hits the spot' 66

$\begin{array}{lll}\text { Fig. 3.43 School-related posting } & 67\end{array}$

Fig. 3.44 'Good morning Queen of Sass' 67

Fig. 3.45 'My mom is the cutist [sic], emergency basket and onesie' 68

$\begin{array}{lll}\text { Fig. 3.46 Cross platform visual posting } & 68\end{array}$

Fig. 3.47 Cross platform visual posting 69

Fig. 3.48 'We should be making these' 69

$\begin{array}{ll}\text { Fig. } 3.49 \text { Nails } & 70\end{array}$

$\begin{array}{lll}\text { Fig. 3.50 Home-made food } & 71\end{array}$

$\begin{array}{lll}\text { Fig. 3.51 Home-made food } & 72\end{array}$

$\begin{array}{ll}\text { Fig. 3.52 Commercial drink display } & 72\end{array}$

Fig. 3.53 Commercial food image 73

$\begin{array}{lll}\text { Fig. 3.54 Food as a photographic craft } & 73\end{array}$

Fig. 3.55 Holiday photograph 74

Fig. 3.56 Holiday photograph 75

Fig. 3.57 Holiday photograph 75

Fig. 3.58 Happy Birthday photograph 76

Fig. 3.59 Music festival photograph 76

Fig. 3.60 Wedding photograph 76

$\begin{array}{lll}\text { Fig. 3.61 Pet photograph } & 77\end{array}$

$\begin{array}{lll}\text { Fig. 3.62 Pet photograph } & 77\end{array}$

$\begin{array}{lll}\text { Fig. 3.63 Pet photograph } & 78\end{array}$

$\begin{array}{lll}\text { Fig. 3.64 Animal photograph } & 78\end{array}$

$\begin{array}{lll}\text { Fig. 3.65 Accessories } & 79\end{array}$ 
$\begin{array}{lll}\text { Fig. 3.66 Shoes } & 79\end{array}$

Fig. 3.67 Books and magazines 80

$\begin{array}{ll}\text { Fig. } 3.68 \text { Books and magazines } & 80\end{array}$

$\begin{array}{ll}\text { Fig. 3.69 Instagram as a photographic craft } & 81\end{array}$

$\begin{array}{lll}\text { Fig. 3.70 Instagram as a photographic craft } & 81\end{array}$

Fig. 3.71 Instagram as a photographic craft 82

$\begin{array}{ll}\text { Fig. 3.72 Instagram as a photographic craft } & 82\end{array}$

$\begin{array}{lll}\text { Fig. } 3.73 \text { Selfie } & 83\end{array}$

$\begin{array}{lll}\text { Fig. } 3.74 & \text { Selfie } & 83\end{array}$

$\begin{array}{lll}\text { Fig. } 3.75 & \text { Selfie } & 84\end{array}$

Fig. 3.76 Instagram image $\quad 89$

Fig. 3.77 Instagram image $\quad 89$

Fig. 3.78 Instagram image 90

Fig. 3.79 Instagram image 90

Fig. 5.1 Presence on social media by age at four secondary schools close to The Glades $\quad 127$

Fig. 6.1 Festive meals 155

$\begin{array}{lll}\text { Fig. } 6.2 & \text { Festive meals } & 155\end{array}$ 


\section{1 \\ Welcome to The Glades}

There are three primary arguments to this book. The first is that the study of social media ${ }^{1}$ suffers from a fundamental and mistaken preconception. Largely it has developed as a study of platforms such as Facebook and Twitter, and so tries to explain why and how people use these platforms on the basis of the properties or affordances (propensities) of such platforms. In Chapter 2 evidence will be presented to show that neither platforms nor affordances lie at the heart of what social media truly is. Platforms are merely the vehicles by which social media travels. To understand social media we need to focus instead upon content, which often migrates and switches easily between entirely different platforms almost regardless of their properties. Inevitably platforms remain as the units for discussion of social media, requiring frequent references to Instagram or Twitter, for example. Yet over the course of this volume it will become clear how the differences in platforms are exploited to express distinctions - a more private audience as opposed to a more public one, for instance, or a humorous style of communication as opposed to a serious one. The temptation to presume any causative relation between the nature of that platform and its content, however, will be shown to be often misleading and mistaken.

The second argument is that precisely because social media exists largely in the content of what people post, it is always local. Just as there will be Chinese or Trinidadian social media, the most important element in understanding social media in an English village is to appreciate how English it is. Indeed the study of social media will turn out to be just as revealing about the nature of Englishness as it will be about the nature of social media. The people who use social media may not share this conclusion. Generally they see their usage as 'natural' - in effect something

given by the nature of the medium or the company that owns it - but a project that compares usage across many different regions makes the 
local and specific character of that usage clear. In this case the spine of this volume that unites much of the content is the suggestion that there is a very particular alignment between what social media is and the traditional character of English sociality.

The third argument is that social media should never be considered as a place or world separated from ordinary life. Such a mistake perpetuated the early misconception of the internet as a virtual place. The best precedent is to consider social media as an elaboration of the traditional telephone. It is unimaginable that today we would consider a landline telephone call as taking place in another world, outside of all other conversations. Social media takes us beyond this analogy, however, since as the book proceeds we will come to appreciate that it has become more than a form of media and communication: in some ways it is now also a place where we live and where everyday life happens, but it is simply another place that could be compared with the way our lives are distributed between spending time at work, within the home or in a restaurant. It is in no sense virtual.

Perhaps the worst way to approach an issue of social science, although also one of the most common, is through semantics - to start, for example, with the dictionary definition of the terms. We really struggle if we take the words 'social media' too seriously or too literally. All media is to some degree social, even as all sociality involves some medium of communication, so it is hard to think of a more banal or tautologous expression than 'social media'. The situation was a little easier when this project began, because at that time the very same phenomena were called 'social networking sites'. Unfortunately we have no control over this terminology because in anthropology we mostly try to remain consistent with the everyday language of the peoples we study.

What is social media? ${ }^{2}$ Prior to social media we mainly had two forms of media. On the one hand we had the telephone or letters that were mainly used for one-to-one (dyadic) private communication. We also had public broadcast media such as radio, newspapers or television to which anyone could listen. The earlier social networking sites such as CyWorld, Friendster and QQ, followed later by Facebook and Twitter, were a kind of scaled-down public broadcast. An individual posted to a group rather than to everyone, and had some means of refusing people membership of that group. Often people in the group could also interact with each other. Social media begins largely as group media: more public than private, but no longer an entirely open public.

By contrast the recent rise of social media platforms such as WhatsApp and WeChat are more a scaling up from dyadic private 
conversation such as messaging services to create groups in which anyone can equally post to anyone else in that group - for example, a family sharing news about a baby. This is more private than public, but not as private as the traditional two-person conversation. We call the combination of these two trends 'scalable sociality'. What this means is that social media has created a range from private to public and from small to larger groups, replacing the traditional opposition between the private dyad and the public broadcast. It is the scalable group quality that is new and special about these platforms. ${ }^{3}$

The boundaries are permeable. Most of these sites also allow for more traditional dyadic communication, such as private messaging on Facebook. At the other end of the spectrum Twitter has some qualities of public broadcasting capacity, as long as you have not made your account private. It would be clumsy to suggest that WhatsApp is a social media site when messages are sent to groups, but not when messages are sent to an individual. Rather we should consider that social media includes both ends of this spectrum, the private conversation of two people and the posting to an open public. As long as there is also this group function, however, then that platform will be included here as a social media site, which will therefore now include gaming consoles such as Xbox and PlayStation. Not surprisingly, people in The Glades do not use the term 'social media' with complete consistency. While almost everyone seems to use this term for sites such as Instagram, Twitter, WhatsApp, Tinder and Facebook, they would probably not generally include gaming consoles, and would vary in their inclusion of webcam or YouTube.

There is another reason for regretting the decline of the term 'social networking sites'. Even if this too was a less than ideal description, it pointed to something essential to the anthropological study of these sites. One way of describing the difference between, for example, economics or psychology and anthropology is that the former disciplines generally study people as individuals while anthropologists study people as social networking sites. Starting from the study of kinship, anthropology has always defined people in terms of their relationships, not simply as individuals - an approach first developed because anthropologists mainly studied tribal and small-scale communities in which kinship was the main form of social organisation. Might this still be relevant to something like social media, used globally in huge metropolitan cities?

One of the joys of social media is it reminds us that human beings today remain rather more as conceived by anthropology than by psychology or economics. Even if we live within a metropolitan city, each of 
us is still in some ways a social networking site, not only an individual. There has also been a tendency to assume that every new innovation necessarily represents a shift from a supposedly more traditional situation, in which we were more socially defined, towards an increasing individualism and autonomy.

This book will argue against such an assumption. Using the case study of an English village, it will suggest that social media tends to have the reverse effect. It makes us less individualistic and less autonomous. In some ways social media returns us to older ways, in which our property as personal social networking sites shifts from the background back to the foreground of our lives. No doubt this is influenced by an anthropological bias here. It is rather a pleasure to be able to argue that just for once the world is becoming a little closer to, rather than further from, the purview of anthropology itself. One of the consequences of social media is to reinforce the individual's facility to network socially.

All of the above is argued to represent a general definition and approach to social media. However, in writing this volume it became increasingly apparent that it is particularly significant when we study social media in England: this study followed a path that led towards a definition of Englishness that was remarkably similar. Unfortunately not many studies try to examine what is particularly English about how people in England behave in social situations. The most popular recent account was probably Kate Fox's Watching the English, ${ }^{4}$ a book whose focus is on what she puns as the English 'social dis-ease'. Interestingly there is strong support for her characterisation of the English to be found on social media itself. Facebook contains many jokes about the publicly embarrassed English. Three typical examples would be: when one person bumps into another and both say sorry; when one belatedly realises a person was not waving at them; initiating a hug at the moment when another person initiates a handshake. All these seem to equate with the phrase 'social dis-ease'. Of course every English individual is in some ways unique, but the presence of these jokes on Facebook shows that making generalisations about the English is something that English people themselves do, including on social media.

In addition, historical accounts of the English as described by visiting foreigners suggest the longevity of these generalisations, stereotypes and characterisations. ${ }^{5}$ The argument will unfold gradually during the course of this book, but in essence much of the embarrassment that Fox calls social dis-ease concerns the boundaries between private and public realms. We will see that English people are friendly and charitable in the public domain, yet remain highly protective of 
their private domains. At the same time they create values and orders such as suburbia that try to preserve a middle ground, avoiding direct confrontation between these two domains. A good deal that the English see as characteristic of being English has to do with the complex relationship between public and private.

In this field site we have a population deeply concerned with the separation of the private and easily embarrassed within the public sphere confronted by a new set of communicative media that is defined precisely by the degree to which it creates a new space - neither private dyadic conversation nor public broadcast. The relationship between these two observations will be the 'story', and indeed the conclusion, of this book. We will find that at first social media is perceived as a problem, with the adult population becoming very concerned about this threat to their privacy. Over time, however, English users turn social media from being a problem into a solution. In Chapter 4 we discover how the English increasingly use social media as a means for keeping people at a distance rather than making them into closer relations. This is characterised as the 'Goldilocks Strategy', a mode in which English people exploit social media to calibrate the precise distance they desire for a given social relationship - neither too cold nor too hot but 'just right'.

Any generalisation such as 'Englishness' breaks down immediately when we start to differentiate men from women, working class from middle class, old from young. A reason this argument requires an entire book to develop is because we need to include the nuances of the particular as well as the overarching generalisation. To take the issue of age, the argument applies differently at each stage of life. For children it must mesh with the much more general problem of which each child becomes acutely aware: how he or she becomes an individual, with personal freedoms and choices, in response to the authority of parents and the incursion of peers. That is often an overwhelming concern for young people during their teenage years. One of the core studies within this research, discussed throughout this volume, was research among 16-18-year-olds, for whom these contradictions are particularly clear and often troubling. For adults the relationship between social media and Englishness blends into a more general contradiction of the modern world. ${ }^{6}$ On the one hand we may feel overwhelmed by information and communication, something now extended to our private lives through the bombardment of emails, texts and more conventional media. How do we negotiate this intensity of public and private lives? Yet this same contemporary world seems to facilitate new possibilities of loneliness, isolation and separation, a particular problem for the elderly. If this 
research was bracketed at one end by a study of school pupils, the other bracket was a study conducted in collaboration with a hospice, looking at the impact of social media on people diagnosed with a terminal illness. This resulted in a paper entitled 'The Tragic Dénouement of English Sociality'?

Similarly the definition of social media as 'scalable sociality' takes on specific implications as we match it to particular stages of life, for instance becoming a new mother. Partly because England has seen a rapid spread of social media to older age groups there is already a sense of its ubiquity, and it is possible to examine its impact across the age spectrum. Yet issues of Englishness and of scalable sociality also arise when we investigate the way in which social media has impacted on our relationship to almost every institution, from health and commerce to education and politics.

In the conclusion it will be suggested that social media has already been a vast social experiment. For example, the rise and success of Facebook in part came about because people felt they had lost something represented by a romantic vision of 'community'; they used Facebook and Friends Reunited to recreate this ideal of bringing people back together. When that happened, however, users also gained a growing realisation that this ideal of 'community' was actually a myth: in trying to recapture it they had brought people far too close and mixed them up far too much. This is another reason why the English have subsequently re-purposed social media into more of a tool for keeping people apart or at a distance.

This approach to social media as an anthropology of the English contrasts with conventional studies of social media that situate it within a trajectory. Such studies emerge largely from disciplines such as internet and computer studies, or from work on media and communication. There is a vast literature that perceives social media as the current station on this journey through new digital technologies. ${ }^{8}$ By contrast, in this book social media is regarded as a mode of social life and an aspect of relationships as studied within anthropology rather than as media. Nor is there any assumed continuity with prior uses of the internet. For example, when the internet first developed the overwhelming concern was with the consequences of anonymity, while with social media anxiety arises from the opposite problem of a lack of privacy. The internet fostered the bringing together of specialist groups such as fans of Star Wars; by contrast, Facebook has created the opposite effect of juxtaposing previously separated groups, for instance family, work and friends, in the same space. The approach here has thus been to examine social 
media in its own right rather than seeing it as the latest version of anything that preceded it.

Given the emphasis upon Englishness, much of this chapter is an extended description of the particular place in which the study was done and the variant of Englishness that it represents. It also includes a short discussion of the ways in which we carried out the research. In order to appreciate the arguments that develop through the course of this book we need not only to meet the people and the place, but also to be clear about the current range and usage made of social media. Chapter 2 introduces the concept of polymedia, intended to help us understand each social media platform, and indeed all other more traditional forms of media, as always in relation to each other. Evidence is presented that, rather than dealing with a fixed thing we can call, for example, Twitter, we seem to encounter platforms that have one set of properties at one stage and yet a few years later can be something with quite opposite effects. Rather than a single coherent Twitter we find a whole series of quite distinct genres of communication, which may today happily coincide in their use of this platform, but have nothing else in common. The evidence will be used to repudiate the current study of social media as the study of platforms and their affordances.

One of the other problems in the existing literature on social media is that we have been tardy actually in showing what we are talking about. Postings on social media have become increasingly visual. Young people in England today tend to start their social media lives on platforms such as Instagram and Snapchat, which are almost entirely visual. Yet often publications on the subject contain no visual material at all. If we fail to engage directly with this visual content we could properly be accused of 'missing the point' - or at least of missing most of the content. Chapter 3 of this volume consists of a direct comparison between young people's photographs and memes posted on Instagram with those posted on Twitter. ${ }^{9}$

Chapter 4 is concerned with the use of social media within relationships, whether of friendship, family or intimacy. The central argument will be about how the 'Goldilocks Strategy' is used to keep people at the appropriate distance. This may apply equally to friends and family, and perhaps even extend to the English version of intimacy. The chapter strives to give equal space to the instances where this proves not to be possible, and to explore what we can learn from these failures.

At first it might seem that Chapter 5 is off on an entirely different tangent since it is used to argue that our research is not solely academic, but can be used for applied purposes such as policy and 
welfare. Two examples are presented. The first argues for replacing the term 'cyber-bullying' with a more general understanding of the context of school interactions that could be called 'cyber-taunting'. The second reports on the two-year study of the potential of social media and other new media for improving the ways in which a hospice communicates with its patients. It also examines the wider social universe of people with terminal illness. In the event, the advice about how this social media might be used for policy and welfare purposes rests largely upon these same arguments about how social media can bridge private and public domains, and the specific issues raised by the context of English sociality.

This theme becomes still more entrenched through the final substantive Chapter 6, which explores three institutional settings for the use of social media: religion, politics and commerce. By comparing the sociality of the church with that of Facebook we are able to explore further the consequences of the English myth of community. By the end of the chapter the English dislike of intrusion into the private sphere becomes the foundation for a sceptical look at the currently dominant mode by which most internet activity is funded, that of targeted advertising. All of these themes are brought together in the conclusions of Chapter 7. First, however, the study must be understood in context and that is the task of the remainder of this chapter.

\section{The Glades}

The field site that I call The Glades ${ }^{10}$ is a dual village made up of the sites I call Leeglade, with a population of around 11,000, and Highglade, with around 6,500. Curiously The Glades is English in a way that is now quite atypical of England. The medical practice that covers Leeglade has 12,000 registered patients. They reveal that the entire Afro-Caribbean, African, Mixed and Asian population amounts to only two per cent of the total. On the High Street in the first few days I did not see a single person who seemed to be black or Asian, other than shopkeepers. In stark contrast to London, The Glades is largely homogeneous in population, White and middle class. It is also a relatively affluent area, chosen partly to repudiate the tradition of anthropology as one of 'us' studying 'them'. Many anthropology students at UCL, where I work, come from places very like The Glades. Despite the size and the fact that central London can be reached in less than an hour by train, everyone refers to them as villages. 
The Glades may more accurately be regarded as a suburb of a suburb of a suburb. The original London suburbs, such as Finchley or Wimbledon, have since been integrated within Greater London. Commuter belts, such as one here called Treedon, with a population of 100,000 , developed just beyond London, but today this too is almost joined to London and has a similar metropolitan and cosmopolitan feel. By contrast, The Glades could be considered the first ever true 'suburb': they are genuine villages surrounded by countryside, possessing all the accoutrements of a village, yet brought close to London by the facility of modern transport. As such they fully realise that suburban dream of enjoying 'the best of both worlds'.11

Historically these were farmlands, but the nineteenth and early twentieth centuries saw the growth of considerable industrial and service areas - to the extent that by the 1960s just four local companies/ institutions would have employed around 13,000 people. Partly in response to this came various private housing developments, joining up some of the earlier housing into larger units. Wealthier people tended to live close to the central Anglican churches. A novel by Marghanita Laski, The Village, ${ }^{12}$ written about a place similar to The Glades and published in 1952, principally concentrates on the scandal caused when two people want to marry across class lines.

From the 1970s there was a sharp decline in local industry, and over the next two decades all of the major employers in the area closed down. Yet The Glades never seems to have suffered major unemployment, and people living there today affirm that it is relatively easy to find work. With good transport links the area saw a rise in building and connected trades, as well as new service skills, for instance in the IT sector.

Jacob was born in the very room in which I met him. His mother's family had always lived in Leeglade and his father was born in Highglade. All of his schooling took place in the village, after which he worked as an electrician. Most of his work was in the local area, including maintenance of factory equipment in Treedon for 26 years - 'monstrous machines they were'. When that firm shut down Jacob got another job in Treedon repairing classic car engines, but he had to give this up when he was diagnosed with advanced cancer. He lived in a good sized private house in one of the more desirable sites within Leeglade, reflecting the decent salaries earned by families working in local industries prior to his birth.

Jacob recalled Leeglade and this particular area as having been a very friendly place, but most of the people he knew have moved on or died. He himself was a loner, interested in home improvements, 
and had never joined any of the village societies or sports clubs. Nor was he involved in the local church. People had difficulty in knowing how to respond to his recently diagnosed cancer, most making general offers of help, but nothing specific. Others had backed away, feeling they did not want to intrude into these private matters. One of his sisters had died; the other lived in the United States, but anyway, in his words they 'didn't get on'. His children mainly stayed in touch by phone, so he had few visitors. He used the internet extensively, both for shopping or information, but had increasingly become housebound. A few months after I met Jacob he died of his cancer, in the very same room in which he was born.

Jacob may represent one extreme in terms of identity with this locality. When the work started it seemed likely that this area could be characterised as a commuter belt for London, but this proved to be wrong. Many people in The Glades were born locally, not necessarily in the village itself, but in surrounding towns and villages; they typically work in places such as Treedon and a site to the north called Girming, so there is a genuine regional integrity to this area outside of London.

Although many people call themselves working class, most would be judged, at least by non-English observers, as middle class. ${ }^{13}$ The exception, amounting to less than ten per cent of the whole, is those who live in social housing ${ }^{14}$ this used to be owned by the local council, but is now run by housing associations. ${ }^{15}$ People worry that any further building might threaten the rural integrity of the villages and bring them closer to Treedon - a big issue in local elections. ${ }^{16}$ Class issues are also reflected in education, with a huge amount of parental concern over which primary school their child will be allocated to, and the consequent influence of this in determining entry to one of the four local secondary schools. These secondary schools vary from one to which entry depends entirely upon selection through examination to the school where parents told us they wept on hearing their children had been assigned there, believing it to be the end of their long-term prospects. This may in fact reflect more the problems of the past. We worked in all four schools and found a high standard of educational services throughout. ${ }^{17}$

Property prices are quite high. In 2012 at the start of field work average house prices were nearly $£ 400,000$ in Highglade and $£ 300,000$ in Leeglade, ranging from $£ 700,000$ for a detached property in Highglade to $£ 250,000$ for a terraced house in Leeglade. The most common house type is the terrace, which means a continuous row of joined houses (Fig. 1.1). 


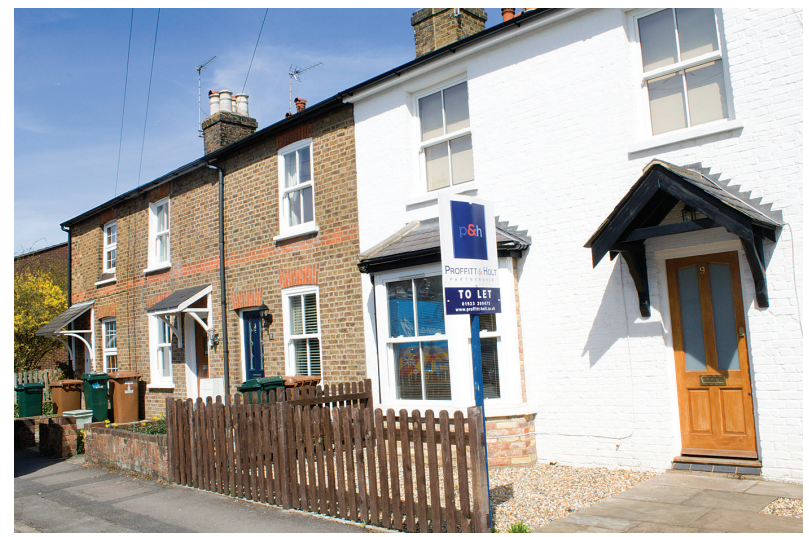

Fig. 1.1 Terraced housing

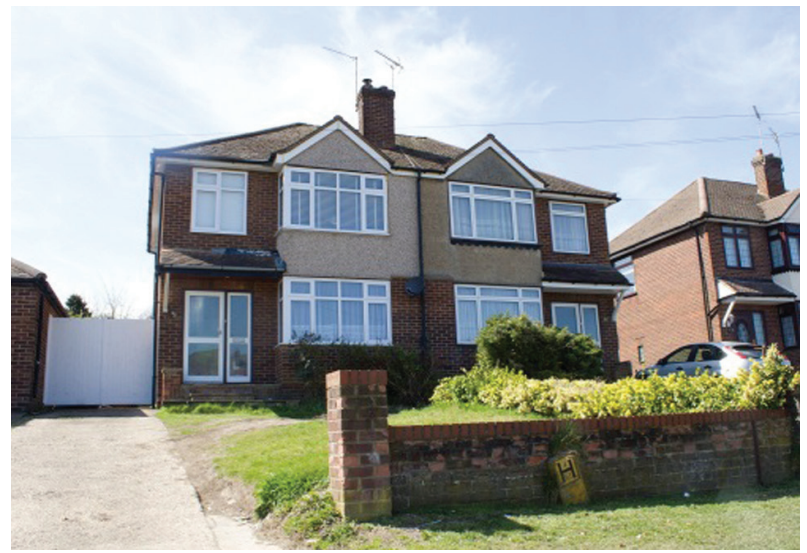

Fig. 1.2 Semi-detached housing

Semi-detached properties consist of two houses joined together, with a shared party wall. This is the housing type most clearly associated with suburbia (Fig. 1.2).

Less common are fully detached houses, though these dominate the roads climbing the hill of Highglade (Fig. 1.3).

There are relatively few flats other than for the elderly, the exception being social housing, or 'estates' as they are typically named. These tend to be smaller terraced properties characterised by small windows (Fig. 1.4).

Most houses are privately owned, but with households paying a mortgage to offset the high costs of purchase. Ironically the social 


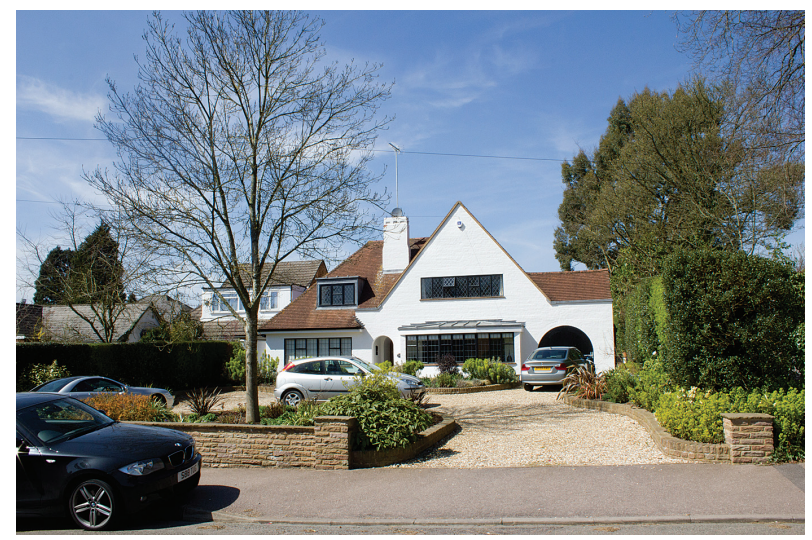

Fig. 1.3 Detached housing

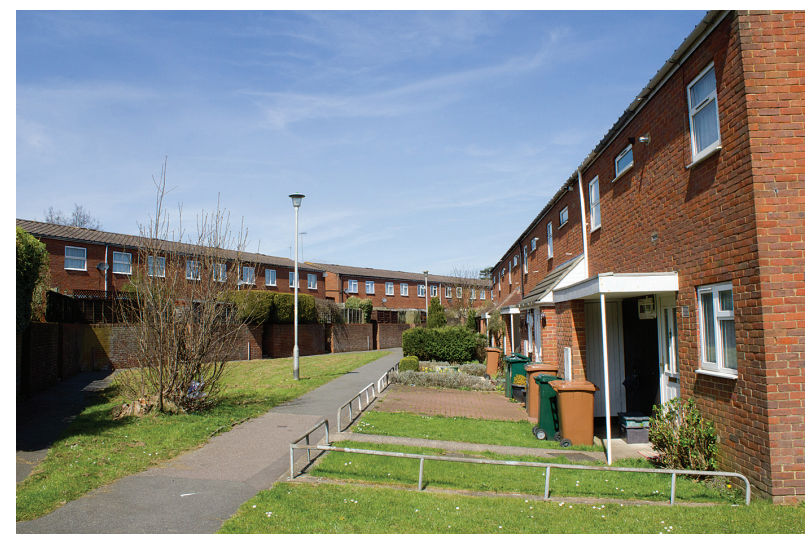

Fig. 1.4 Estate housing

housing units, about half of which have been privately sold, are often the only housing that people born in The Glades can now afford to buy. Otherwise they tend to move still further from London to towns such as Girming.

Tracey lives in one of the main blocks of social housing: her mother and sister also live in The Glades. Tracey has worked since she was 16 and been a mother since she was 17; she now has three children. The difference between the inside of her flat and the homes of The Glades' middle classes is palpable - possibly not helped by her beautiful caged husky dog in the middle of the main room, of which the entire family are inordinately fond - and there is simply not enough space for her 
family. Everywhere one looks things are piled high, from mattresses to schoolbooks.

Tracey really struggles to get by and ensure her children are educated, clothed and fed. She feels she lives on a fragile edge between two possible futures. Some of her family and those of her husband embrace an alternative culture, involved in constant confrontations with government authorities, but retain a strong sense of their own authenticity as a working-class community. She, however, aspires to move out of both the culture and conditions of her upbringing. She recently took on a leadership role in a village society that surprised the middle-class women who traditionally occupy these positions, but her main strategy is to use her husband's employment in the army to secure a better income and future. Before the end of our field work they had moved out of Leeglade to take up residence in an army barracks, offering not just more space and modern facilities, but better prospects for education, health care and for her family more generally.

Tracey is important in helping to represent the full spectrum of this population. As my forthcoming book Visualising Facebook, (UCL Press, 2017) reveals, she also represents a group that posts very different kinds of material on social media than the majority of the population.

Leeglade has the more functional High Street and is not on the road to anywhere else while Highglade, with its art galleries and wine shops, caters to people driving through its High Street from London. English families tend to be nuclear households consisting of parents and children. The most common single-person households are elderly. The most recent census suggests around a quarter of households are singleperson, but they are under-represented in our questionnaire. In this we found the following family sizes: one-person (12 per cent), two-person (38 per cent), three-person (26 per cent), four-person (14 per cent) and five-person (10 per cent). None were larger.

There is a small industrial estate between the villages. One company has 800 employees, but the average for local businesses is only 6 . The area would be characterised by what is now called the 'white van man', linked to building and associated trades, while many women work in the local schools and services.

Table 1.2 (p. 194) shows employment grades are as high in Leeglade as in London, and for Highglade are even higher. ${ }^{18}$ Highglade lies in the ten per cent of wards with the least deprivation in England. Life expectancy is 81.5 years, compared to the national average of $79.8,{ }^{19}$ but Leeglade would be more typical of the region as a whole. Yet there is certainly poverty associated with particular groups, for example single 
mothers in social housing (around six per cent of households in Leeglade are single mothers) or people with addiction and mental health problems, as evident in the very active local Citizen's Advice Bureau. Local politics, religion and commerce are discussed in Chapter 6. A free local monthly magazine is delivered to every home in The Glades. Crime is strongly featured, but focused on items such as an individual who has been banned from the pubs for rowdy behaviour, revealing a generally low crime rate.

From an ethnographic perspective the village makes most sense in terms of the life cycle of villagers. It matters most to children because this is where they are brought up and educated. In addition to family, most of their friends are likely to be those they go to school with or who live nearby. There is a host of children's sports and other activities, often with long waiting lists. There is also a successful annual carnival (Fig. 1.5). Teenagers, however, are generally bored, drifting to Treedon for Saturday night under-age drinking and parties, and then escaping to college or university.

For much of the middle part of life, post-school and prior to retirement, The Glades is likely to be relatively insignificant, even to the people who live there. People are largely absorbed by work and family. A major exception is new mothers, who join local antenatal and postnatal classes and toddler groups; many may well find this is the main time when they form core friendships, a few lasting for as long as they remain in The Glades or even for life. At this period of parenting they are intensely involved in their own locality. Otherwise the time

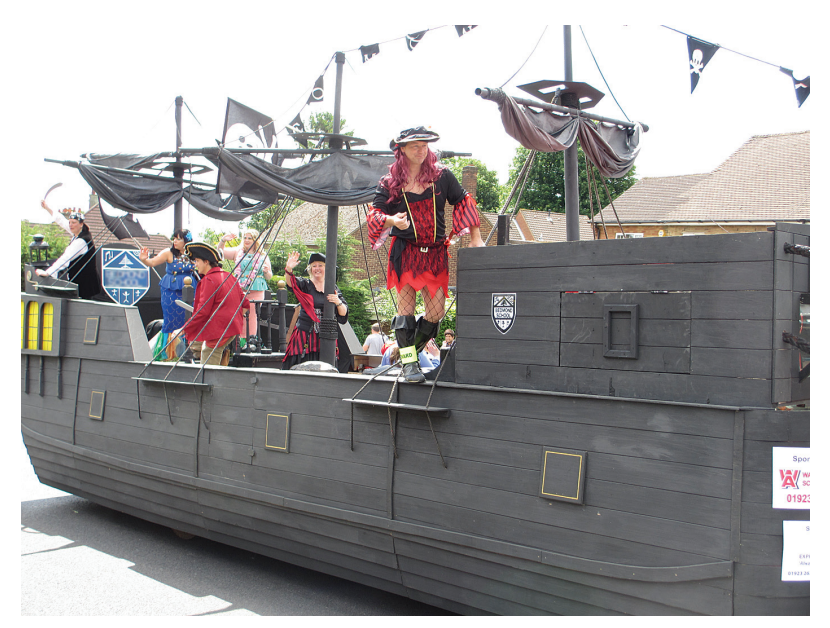

Fig. 1.5 Carnival in Leeglade 


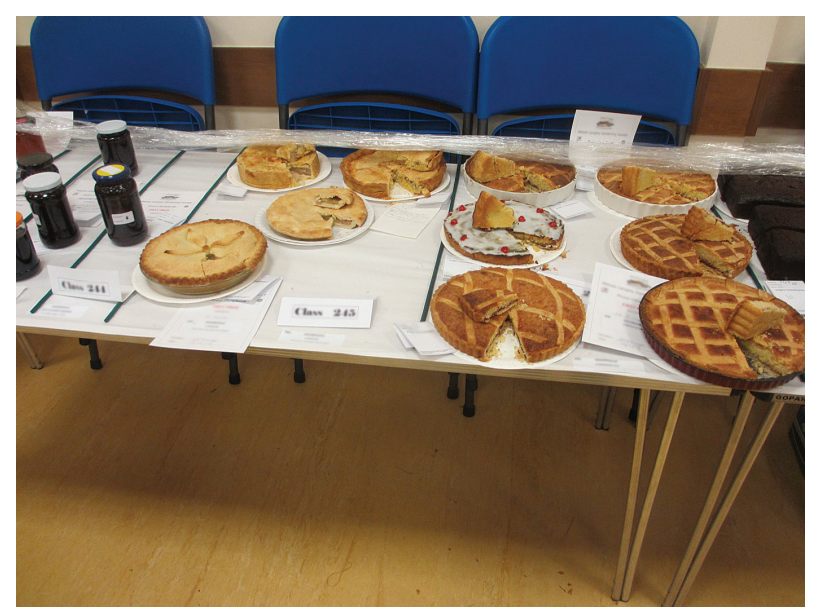

Fig. 1.6 The annual gardening and produce show

commitments of work and family result in detachment from the wider village. Men who would once have had more time for drinking in the pub and other local activities now spend more time in family-related leisure and household chores.

The Glades becomes important again at the time of retirement. As a result there is an astonishing number of societies, including half a dozen amateur dramatic groups, for example, some dedicated to Gilbert and Sullivan and other very 'English' musicals, Christmas pantomimes and also to more serious drama of remarkably high quality. There are also sports clubs, gardening shows (Fig. 1.6), bowls, the Women's Institute, philanthropic associations and so forth. Though few still attend church, there is a considerable amount of volunteer labour.

Grace is one of those who represent the 'life and soul' of Leeglade. She was probably the single most likely person you would meet at any society or village function, and she was always very friendly and helpful, as well as amazingly philanthropic. She taught computer courses to the elderly and of the 3,400 friends she has on Facebook she imagines about 2,000 of them are people she has taught. Grace also enjoys playing games on Facebook - whichever are current, from Candy Crush to Flappy Bird. Her intense relationship to social and other media reflects rather than detracts from her incredibly busy social life. At the heart of this is family. Her mother was one of 12 children and two of her uncles had 16 children each, so there are 82 close relations of her generation, 156 in her daughter's generation and 231 in her grandchildren's generation. There is also yet another generation, since she has one great-grandchild. 
Yet, in addition to family and her media relationships, Grace knows everyone (as in anyone-who-is-anyone) in Leeglade. She is very involved with the church and helped to develop 'messy church' for young mothers. She has also taken the main lead in developing a Credit Union so that the lowest income villagers do not have to pay the interest of credit loan sharks, but can instead use traditional forms of savings such as rotating credit schemes and Christmas savings clubs. She is also fairly notorious, being, as she would be the first to admit, open about topics such as sex and gossip - something not at all common for older people in Leeglade.

While Grace is exceptional, Bruce is not. Why does Bruce live in The Glades? 'It suited me, 'cos I worked from home. So it does not really matter where I am. I'm within easy distance to wherever I want to get to. I am based at home, but I do not work in the house. As long as I can get somewhere, and The Glades is very well placed.' Although Bruce now lives in The Glades, it is mostly an irrelevance to his life. 'I'm not sure the village thing is the thing that bothers me particularly. I would be happy here for location in relation to communications ... We've never had anyone in the street in for dinner. None of our close friends live in The Glades. My children weren't at school here.' There are hundreds of such people who live in The Glades because it is convenient for transport, but they join no local societies and could not tell you the full names of their immediate neighbours. It was the fact that there are far more people like Bruce than there are people like Grace that was to make this research project very difficult indeed.

\section{How we did this work}

The intention was to carry out a traditional anthropological ethnography alongside the other eight projects. Ideally this would have meant living in the village, participating in public events alongside other villagers and making close friends from whom one could gain a sense of their private lives, both within the family and more generally. However, it soon became apparent that there was no point living in the village: developing a relationship with one household in The Glades very rarely meant any kind of interaction with anyone else. It was as though each household was its own field work project. Getting to know people like Bruce did not bring us any closer to getting to know The Glades other than as an aggregate of people like Bruce. For these reasons I decided I might as well commute from my family home. 
What is ethnography? This may be defined as a commitment to contextual holism. Nobody lives within one topic or with only one role. No one lives only on social media, in the same way they do not live only with family or only at work or only with their religious beliefs. Ethnography is holistic because that is true of the lives of people, who live all of their contexts together. To understand any single aspect of a person's life, one wants to have at least some sense of all the rest. Furthermore you cannot predict which other elements and contexts are going to be most important in explaining the one that has been chosen as the focus of research, in this case social media. So the main reason anthropologists spend 15 months living with a population is in order to encounter all these potentially relevant contexts before deciding which ones are significant for their topic of study. The second main reason is in order to encounter the broadest possible range of people, spanning gender, income, education and all other parameters of difference. The third main reason is that people live increasingly private lives. If much of their time is within their own homes, how can we understand them if we cannot also be inside those homes? If much of social media now consists of quite private and intimate discussion on WhatsApp, then how long must we know someone for before he or she will trust us with that content? In anthropology the commitment is to observation of behaviour, not simply to the claims and accounts about people's behaviour that one would find from surveys, questionnaires and focus groups. So although ethnography was invented for the study of tribal and other small-scale societies, it may perhaps achieve its true potential in modern metropolitan society. It has become the only method that follows people into the private domains, which is where they live most of their lives.

This is the ideal. In practice it was more difficult conducting an ethnography in The Glades than any of our other field sites, and the result may be the least ethnographic of all our field site studies. English informants are simply not comfortable with the idea of someone just hanging out with them. One needs to have a purpose, such as an interview. In response, the study tried at least to secure breadth. Overall we interviewed over 370 individuals, many more than once. In addition there was much hanging about in public places such as community events, pubs and restaurants (especially pubs!). Fortunately one way we could accomplish the more conventional ethnographic method of participant observation was simply following (with their explicit permission) the social media platforms of our informants. Being able to follow 130 people on Facebook, 80 on Twitter and 50 on Instagram included many of the relatively private exchanges within families and between friends that was otherwise 
missing; sometimes we also asked to view WhatsApp or Snapchat. In this instance, rather than ethnography gifting us social media, it was often social media that helped gift us the ethnography.

Chapter 5 describes two subsidiary and more applied projects. One was carried out with patients from the Hospice of St Francis in Berkhamsted, many of whose patients came from similar villages to The Glades. This was carried out together with Kimberley McLaughlin, a senior hospice professional. The other was conducted with four local secondary schools; it included 80 interviews with the 16 to 18 age group and some teachers, as well as a general survey of social media use among 2,496 pupils aged 11 to 18 . This research in schools, along with much of the main ethnography, was conducted together with Ciara Green, then a student in the UCL Digital Anthropology programme. As a result this book refers to 'we' in conducting research.

Pilot research, along with two interns, began in April 2012. The main field work in The Glades lasted 18 months, from April 2013 through to the end of September 2014. During the first year Ciara and I concentrated on going door to door in streets that looked as though they would characterise the range from most to least expensive. We began by leafleting about the project, then calling to ask for a possible interview at some point in the future. Often people would agree to this and give contact details, but equally often they would fail to be present at the agreed time. We had the experience of some individuals cancelling five times without ever admitting that they did not really want to be interviewed. People in The Glades do not like to say no, even when they mean it. Nevertheless the bulk of our contacts with villagers came through this method, which required considerable perseverance.

The reasoning behind this method was that most studies of communities emphasise the people who actually join community groups. A truly representative study, however, would focus just as much on people who join no such activities and do not really want to be included in an ethnography, so this was the only method to ensure that this book is in some ways representative. Working with schools and the hospice helped in this respect, since everyone equally goes to school and will at some point die. Our additional book Visualising Facebook, which compares what people post on Facebook in The Glades as against Trinidad, has already been written and will be published in 2016. Together with the other volumes in the Why We Post series, it helps to sustain the arguments of this book with regard to the Englishness of English social media, but in that case through comparison and contrast. ${ }^{20}$ 


\section{2 \\ The social media landscape}

Typically, when they first arrive at the office for work, men talk about football. After work, when in the pub, they joke at each other's expense and talk about sex and football. Typically women going out in a group after work will talk about relationships. In both cases a major addition is conversation about what has passed by on the screens of their phones, and indeed what actually comes through to their phones during the course of those conversations. Typically parents at the family dinner try to ask their children about what they did at school that day, to which the children give typically unsatisfactory, laconic responses. At least at one time students typically had periodic conversations about the meaning and purpose of life, though one of the hospice patients remarked that it was only after he was diagnosed with terminal cancer that he realised that in his whole life he had never had a really deep conversation about anything. Meanwhile people meeting each other on the village High Street will typically still mention the weather.

The word 'typically' is the stuff of anthropology. It means that conversation is normative, which in turn means that we constantly judge each other as to whether the content of our communications is appropriate or inappropriate to the context we are in. The word 'typically' also refers to persons, place and circumstance. Following upon that word the relevant people were specified as women or men, children or parents, as well as the place they were in: around the dinner table or in the pub or at the office. The word is useful also because it recognises that many men do not behave as typical men. It also allows for the idea that social media can create and not just reflect typical behaviour. A typical female meme is clearly in part a product of social media that in turn impacts on our generalisations about what females do.

We can conclude that an analysis of conversations among English people would have to be quite specific. Firstly we would need to say 
which group of people we were generalising about - teenagers or the elderly, teachers or nurses - and then indicate the situation they were in - having breakfast or trying to pull someone at a party. The frame would be given by the title of this book, a village, rather than, for instance, London. Note that we have not yet started discussing social media. All of this pertains to face to face conversation.

A suitable colloquial word for this presumption that the content of any conversation is likely to be appropriate, both to the participants and to the situation, would be that of 'genre'. We expect that any given individual would be skilled at many such genres. They can easily switch to match the changing context. This does not only involve switching to different content; often the accent, speed and form of conversation will also change accordingly, as will the amount of swearing. The analysis of any individual genre can be rich and detailed: an example would be the analysis of pub banter by Fox. ${ }^{1}$ Genre is not just a mode of communication: it is a 'set of conventional and highly organised constraints on the production and interpretation of meaning. ${ }^{2}$ Frow takes his cue from the anthropologist Malinowski's discussion of language as dependent upon the context of situation. ${ }^{3}$

The trouble is that, once we turn to social media, the discussions make it seem as though communication is suddenly all about platforms, about Twitter or Instagram. Who uses them, where and when? We discuss communication in terms of a Facebook share or 'Twitter beef' (quarrel). The implication would be that platforms replace conversational genres as the foundations of communication. In this chapter we will review evidence that suggests all of this may be wrong. Actually it is the genres of conversation that are robust and develop - platforms are simply modes by which these are carried at a given time, and the choice of platform has far less consequence than we assume. It is just that this is the way we have become used to thinking about social media, as a set of platforms. It is not necessarily the best way, and certainly not the only way, to understand what social media is.

To approach social media we need to start with sufficient respect for what has preceded it because the complexity of communication and its content will provide much of the explanation for what social media then becomes. The argument will be developed in a series of stages. After introducing the idea of polymedia, we will meet an elderly person who does not use social media. The next example will illustrate how some media have come to dominate communication for certain individuals today. Reflections on the use of social media by schoolchildren are then employed to represent the current range and complexity of social 
media today, and a case study of a mother and her children demonstrates how this wealth of options has become naturalised for the young and problematic for their parents. We also start to see that social media is not just communication - it is also where these children now 'live'. The next stage demonstrates that as well as polymedia, seen as the complementary relationship between different platforms, any individual platform can be dissected for the myriad different genres into which it can actually be turned.

As a case study, the platform Twitter is broken into the multitude of different 'Twitters' that one actually encounters in The Glades. We will then look at Twitter within the lexicon of one particular individual in order to return to the point made about face to face conversations above. This suggests that within any given social media we still have to confront a wide range of genres that are specific to differentiated contexts. Finally a historical perspective is introduced that demonstrates the extraordinary dynamics of these new media. In conclusion, the initial discussion of these conversational genres that existed prior to the development of any communication technologies is developed and extended by the incorporation of new media technologies into the picture. We find that this poses considerable problems for the current discussions of social media, especially their reliance on platforms and affordances as the units of analysis.

The concept that guides this chapter is 'polymedia'. The term, coined by myself and Mirca Madianou, ${ }^{4}$ was based on a study we carried out of Filipino migrant mothers and the ways in which they communicated with their children left behind in the Philippines. For that study we worked first with the mothers in England before travelling to the Philippines and visiting their children, in order to see both ends of these conversations. What we realised was that it made little sense to study each individual platform/media in isolation. People now purposefully exploit this range of media. They text to see if it is a good time to Skype; they note something on Facebook, but send the details in an email. Children may prefer to use a platform based only on text if seeking to avoid a quarrel with their parents. As we will see in Chapter 4, people now differentiate 'email friends' from 'phone friends'. We were also indebted to Gershon's ${ }^{5}$ study of how young people in the United States end relationships. Here the emphasis was on the moral judgement of other people regarding the media used to dump their respective boy/girlfriends. Is being dumped by text message worse than being dumped by a change in Facebook status? We argued that polymedia represented a significant re-socialisation of media itself. Previously the 
main reason people used this or that media could be ascribed to issues such as cost or access, but now, in more affluent countries with internet and smartphone packages, cost had been relegated to infrastructure. As a result the decision of which media to use - whether a Facebook message or a webcam call, an email or a voice call - now represented a personal choice which could be subject to the judgement of others. The concept of polymedia did not therefore just refer to the relationship between media. It contends that the choice of media had become part of social interaction in its own right. Because people were being judged on the basis of these choices, polymedia represents the re-entry of morality as well as negotiated sociality into the task of understanding contemporary media.

This approach was devised in 2011. Yet already by 2015 one can see several ways in which it needs to be revised. When we first proposed this idea we considered social media as generic, i.e. just one thing, to be contrasted with other media such as the telephone or emails. Today, however, there are so many different social media platforms that we need to consider polymedia just as much for the study of the relationships within social media platforms as that between social media and other media. Twitter complements Facebook and Snapchat, even though all three are social media. As we shall see in Chapter 4, the ethnography of The Glades suggests that we should focus on the moral arguments concerning which is the most appropriate content for which media. What is acceptable to put on WhatsApp but not on Facebook, for example, or on Twitter but not on LinkedIn?

\section{Complementary and contrastive media}

Cyril, a hospice patient, was born in 1927 and moved to a rural area outside a village in 1954. He retired at the age of 65 after working in commerce. He and his wife have two sons and a daughter who lives nearby. His contact with the hospice is mainly by phone, but it is not something he is comfortable about. He feels that 'Somehow it doesn't click. You try to give additional explanation and the telephone conversation goes on and you get round to what you want to talk about. So it can be extraordinarily complicated.' By contrast he likes emails, which he feels have greater clarity, but he then worries whether people will read them properly. It turns out these attitudes were formed from earlier contrasts with letter writing. He liked to write long letters, but had bad handwriting and was afraid people did not read them through; 
such a fear has now transferred to the new medium of email, despite the fact that handwriting is no longer required. Cyril still receives three or four letters a year from a university friend now living in Paris and more rarely from others, including some ex-business colleagues and their wives. Email seems to be more for family use, including his son and goddaughter in the United States, partly because his son simply does not read letters. Since Cyril dislikes the phone, he ends up using it vicariously through his wife; she makes extensive phone calls to family and friends, telling him the ten per cent of the conversation he might want to know. Occasionally he uses his mobile phone and also Skype, especially during the period when his son worked in Hong Kong. He also writes postcards from his holidays. A very important use of the internet is online shopping, since he never wants to go to London again and is reluctant to leave even the local area.

This is a simple example, partly because Cyril is an elderly, rather uncommunicative male who does not use social media. However, it makes several points that will continue to resonate when we turn to social media. He clearly sees communication in terms of a series of alternative media, some of which he has turned into meaningful contrasts, for example the phone as opposed to email. Such contrasts may be sourced in the experience of prior media, in this case letter writing. They may also reflect other normative contrasts. For example, there are Cyril and his wife's joint gender stereotypes about what 'men' and 'women' are like. For them it is appropriate that a wife focuses upon social communication rather than her husband. So polymedia reflects this articulation between the differentiated media and the way these distinctions reflect, express, exacerbate or change other and prior social differences. Typically we found that people aged over 70 had a repertoire of postcards, letters, landline phones and, apart from the very elderly, also email. They also typically had mobile phones but did not necessarily text, and quite often also had webcam. Even prior to social media, therefore, we can see how the term polymedia helps us to perceive these as a package of options and contrasts, rather than entirely separate technologies.

This need not be a level playing field. For example Bella, another hospice patient born in 1957, has become devoted to texting, especially since being diagnosed with breast cancer: 'It's very non-intrusive isn't it? People can ask you how you are and you can quite quickly say "rubbish or well or whatever"; you've got to be well to speak on the phone, don't you, whereas texting is good.' Previously she felt that her life was 'overwhelmed with emails you need to answer, Ccd on things'. She worked a 
60-hour week, but with cancer she soon felt that she 'can't cope with that bombardment'.

So texting became Bella's communication hub. Not only all face to face visits, but also all phone calls were prearranged by texting, since people needed to know whether or not she felt 'up for it'. She managed to teach her mother how to text for precisely that functional reason, but she also values the content of texting: 'Just sending me texts, people telling me they are thinking about me. It's a bit boring lying in bed having chemo for six months. Quite nice getting little texts saying "how are you?" Bit of entertainment in a way, hearing a little bit about what other people are doing.' She could also text a friend to bring her a takeaway dinner when she was infectious, to organise her son's birthday party or to make sure that someone was feeding her guinea-pigs. In addition Bella has a texting relationship with someone else who had experienced chemotherapy and was happy to help her learn how best to cope with it. While she is using a wide range of media, therefore, it is clear that she has chosen just one, texting, to act as the control media for all the others. Such a decision provides another instance of polymedia, but one based on hierarchy rather than choosing between equal options.

\section{School pupils}

The group in The Glades that probably show most internal consistency in their social media usage are the school pupils aged 16 to 18 - partly because of the intensity of their interactions as a group. For example, when asking about the use of WhatsApp for groups the answers soon became quite repetitive. Almost everyone had one group that was single sex, for example girls had a girls' group in which they could talk and banter about their relationships with boys. However, they also had another WhatsApp group that was mixed and in which they could talk and banter with boys directly. Many also had temporary groups that might be created in order to organise a party, work on a school project, go paintballing and such like. Some also had family WhatsApp groups or belonged to groups devoted to particular interests.

Chapter 5 includes a chart of usage of social media by this age group. It shows that the majority of pupils use at least five out of BBM, ${ }^{6}$ Instagram, WhatsApp, Twitter, Snapchat and Facebook. In general girls have more accounts than boys. Instagram was especially popular among younger pupils, who saw it as more benign and free of the suspect content that circulated on Twitter. Facebook was in marked decline for peer 
interactions, though nearly everyone still had their Facebook profile; it was still seen as a useful site for organising parties and for some private messaging, but was mainly used to keep in touch with parents and other family members. Snapchat became particularly popular during the time of our field work. Some pupils used it pretty constantly during the course of the day - not just when they were bored or had seen something funny, but also as a minimal way of keeping up a visual conversation with friends to remind them every hour or so that they were best friends. A platform that we would not normally consider as a social media, but which was popular with many is YouTube. YouTube videos are often shared on social media such as Facebook, but may equally be used for specialist interests. For example, one girl learnt her ballet skills from YouTube and saw it as a means of connecting her with other ballet aficionados.

In general it should be acknowledged that the coverage throughout this volume is distorted towards those platforms that have a more public presence, for instance Facebook, Twitter and Instagram. Here in each case a good sample of villagers agreed to let me follow them online, which was not the case with more private platforms such as WhatsApp, BBM and Snapchat. It was far more difficult to engage with these latter sites, and the English study was less successful in this regard than the ethnographies carried out elsewhere. This is a problem, precisely because being private means they are used for many forms of communication that rarely appear on the more public media. These sites tend to be both more conversational and more transient. Snapchats are inherently transient in that they disappear after ten seconds, though everyone is aware of the potential for screen capture, which has made them more wary as to what they send. Fortunately the school pupils were comfortable with discussing their use of all these platforms in some detail, and occasionally showing us examples.

As well as the main platforms, quite a few others are used by a minority of pupils. These included Tumblr and to a lesser extent Pinterest or ask.fm, while a few 16-year-olds used PlayStation and Xbox as social media. No other platform registered as being used by more than two per cent of pupils. Tumblr seems to have become an important platform for blogging. Previously more comparable with a traditional diary, it has now, like Pinterest, become a collection point for images and items that interest the pupils. Several of them noted that they like the possibilities of anonymity it provides. One girl said 'Half the stuff I've put on Tumblr is so cringey, I couldn't put it on Twitter. I'd get it ripped out of me.' In some cases it was clear that the 
pupils' school friends did not know they had an active Tumblr account. Pinterest, on the other hand, is not really used as a social media. Many subscribe to Vine for making very short videos that might then appear on Twitter. For one group Imgur was becoming important. The wider ethnography suggested that various dating sites have been around for a considerable period, though they are more used by older age groups. Grindr is very well established for gay dating. Tinder was growing rapidly around the end of field work, and was starting to have a significant impact on contemporary dating.

None of these have anything like the general reach of platforms such as Twitter, Snapchat and WhatsApp, but there were individuals for whom they are the key site. For example, some boys devote their spare time to gaming and much of their social media is through PlayStation or Xbox. This represents a newly developed feature that has spread since gaming consoles came with voice and webcam connections. For Troy, quite a shy boy, his Xbox was the main way in which he had developed his social interactions. He had linked it up with Skype, though often without the webcam, but he does not link it with either Facebook or Instagram. He notes 'Whereas everyone else was partying, that's what I would spend my time doing, being on Xbox live talking to people. I didn't feel left out 'cos of that.' Within school Troy tended to socialise with other Xbox people. He recognised this was insular, but at least he felt they had something to talk about. Xbox was equally important for his family links, given that his parents were divorced. He did not see that much of his father, so his father set up an Xbox group with the two of them, the father's new girlfriend and a cousin in order to play games. This worked well and was clearly important and appropriate for Troy.

Another key and growing factor is the way companies as well as individuals want to create their own configuration of platforms as polymedia. An obvious case would be the Apple Corporation. There are those who organise their music on iPlayer, their visual communication on Facetime, use several apps from the iPhone store and make considerable use of their iPads or iPhones. Others are similarly wedded to their Android phones and the Google family. In the long term, however, companies seem to lose their attraction once they become powerful corporations who are seen by users as not just dominant but domineering - a shift that has happened in turn to Microsoft, Apple, Google and Facebook. By now there is very little sense of an emotional attachment to the products of any single company (apart from some latent regard for Apple); the examples just cited above tend rather to be viewed as packages of convenience that could easily be switched to another option. 
Thanks in particular to the ubiquitous presence of smartphones, social media is now seamlessly integrated with other media, to the extent that a text could equally come from WhatsApp, a private message on Facebook or just phone texting. During the first questionnaire it was quite amusing that the answer to one question became highly predictable. When asked 'Who do you contact through your landline?' the almost inevitable response was 'just my mother'. A couple of years previously everything had coalesced around Facebook, resulting in a messy blend of family, friends, colleagues and everything else, all in the same soup. Today polymedia has expanded choices and separated out niches. A school pupil could enjoy the public argy-bargy (arguments and banter) of Twitter, but then retreat to the private consolations of Tumblr. He or she could contemplate and admire images on Instagram and organise fun nights out on WhatsApp. As implied by the theory of polymedia, the pupil's decision about which media to use would be judged by others; it would be seen as reflecting the kind of person they were. The Xbox boy was thereby a typecast figure, but all this is very recent and not fully naturalised, even among those aged 16 to 18 . To encounter what may be the future degree of integration into people's lives, it is worth turning to a still younger group.

\section{Polymedia and parenting}

What the case study of Claudia will show is two simultaneous but opposite things. The first is the way in which the polymedia of social media itself becomes instantly natural to young children. The second is how this seems so confusing and unnatural to their parents.

Claudia has three children aged 7, 10 and 11 - otherwise she would probably not be telling us about Stampylongnose. However, trying to be an effective parent to her children meant taking a character called Stampylongnose seriously. It also meant appreciating that Stampylongnose sits within a configuration of social media that for her appears complex and dispersed, but for her children seems as natural as the relationship she assumes between the freezer and the microwave. At that moment two of the children were playing Minecraft, one on Claudia's iPod and the other on a tablet, but the way in which they played also involved using interactive videos on YouTube that are quite likely to have been posted by Stampylongnose. (They would not have encountered these through Stampylongnose's Facebook page simply because Claudia does not allow them access to Facebook.) Meanwhile 
her friend's child does much the same thing, but in his case through Xbox. Even Claudia became quite interested when Stampy grew from being just a cartoon cat, created by a 23-year-old barman, to something of a celebrity, possessing one of the most popular YouTube channels in the world. She rather enjoyed the Easter Egg challenge that he set for the children.

However, Claudia is concerned that this involves them in interactions with all sorts of people: some they know, some fictional and potentially some strangers. For her, polymedia is all about being a good parent whose responsibilities now include keeping up with all of these new social media as they are experienced, perhaps even inhabited, by her children. As she talks they build, 'because that is what, 100 per cent what they are doing up there now, so quiet, they are building their Minecraft'. What is particularly confusing to her is that when all the kids go out to one of their friends' homes, each takes his or her own iPad and they sit in the room, building together. Is this good socialising between children meeting face to face or, as Sherry Turkle $^{7}$ describes, are they 'alone together' being anti-social? Is this good working with their hands? Is it, as she puts it, 'the new Lego' - or a sign that children no longer build things by hand? If she compares her idealised memory of her own childhood, this all seems bad. Yet if she compares it with a few years ago when the kids were largely addicted to PlayStation, with a maximum of two playing together, this all seems good. The more such parents seek to understand these new media, the more moral dilemmas they give themselves. Another parent with a nine-year-old son can now see him searching for 'boys kissing girls' and 'fuck': 'So some of it, I've just taken the viewpoint, it's natural growing up, and it is strange not to be curious about certain things.'

Claudia's sense is that 'You've got to roll with these things because I think sometimes, as parents, when you were a kid and mum wasn't getting what you were doing and how frustrating that was, maybe how alienated you then felt from your parents 'cos they didn't get you.' Furthermore she understands that without the individual play you do not get the communal activity. When she was a child her parents stopped her watching a television programme that all the other kids in class watched, which would have led to her being ostracised unless she pretended that she had watched it too. While Claudia is thus conscious that whatever 'the' kids are doing, she needs 'her' kids to be doing also, she feels as well that she should monitor it, which is why she recently joined Instagram. 
Unfortunately, having previously worried about not knowing enough about her children's lives, she now feels uncomfortable with knowing too much. She realises that Instagram is not just pretty pictures: it is important for communication between her daughters and their friends, and now she can see all those associated comments and chats. Claudia may have banned Facebook, but now she realises that in so doing she had just displaced things to another place, owned by Facebook, where the children care just as much whether they will get 30 'likes'. Then she discovered that the children were going out to the park so that they could take photographs to put on Instagram. This was quite a blessing after all her complaints that they do not go outside anymore. For her, as for her friends, being a parent should be above all a moral project. Yet as soon as she has decided that one social media is bad, it turns out to have a good quality - and as soon as she has decided to favour another platform instead, it turns out to have problems associated with it. Polymedia has made it very difficult to hold any kind of consistent moral position. At a recent sleepover one of the girls would not help make the cakes; she just stayed on her phone and only got involved when taking pictures of the cakes to post on Instagram. Does that mean she was involved, or the reverse?

The fact that the children are so concerned about who is more popular and that banter quickly becomes fractious, with accusations circulating: are these the result of social media or exactly what she used to be like at that age? Yes, they can get nasty, but so did her friends at school. However, there does seem to be one clear difference: at least her quarrels in school stayed there.

Once texting came in, problems at school weren't over once the school hours were over. They were in your bedroom, they were sitting at your desk while you were doing your homework. A nasty person saying something to you over a text message. Whereas before it was contained within school hours of the day, and you had the evening to calm down, maybe make a landline phone call. Whereas now that seems like a period of the day that things can escalate even further.

Yet, as with some of the other parents, this was more a generic fear. When it came to their own children 'I don't feel, from what I can gather, that there has been any nasty stuff that has really affected them, although there's a lot of silly stuff in year 5. It's all BFF (Best Friends Forever) and you're my BFF and then you're not'. Her daughter's friends told her 
daughter that she should not be BFF with that other girl, so she split up and then instantly regretted it, but it was too late. Then there are other media that complicate the picture still further. 'They do Facetime each other as well. Quite a lot of that ... the most ridiculous chats. They'll be going oh yeah ... Oh mum has just brought me my dinner now, just eating my dinner now. And they say Oh yeah ... Just looking at a book. . . and it's like why, why are you bothering to have these conversations?' The Facetime worries Claudia because once when they were with their cousins it was discovered that an unknown boy was talking with them on Facetime - and with Facetime it is actually face to face. On the other hand, it is hard to claim the children are becoming less sociable, or less socially skilled, when they spend the entire day in endless chat, much of it visual. Then again perhaps it is better to be on Facetime, since any paedophiles who pretend to be children could not really do that on Facetime when they can be seen.

For Claudia, just as she is feeling that she cannot keep up, and that this is how a gulf will open up between the new generation and her generation, she starts to find the exact opposite. Thanks to Facetime the children have a real relationship with their uncle, her brother in Hong Kong, and also with his children, for which she is hugely grateful. Things have got even better with WhatsApp since he sends them little videos to share. She had thought her brother going to Hong Kong would make family life impossible, but actually all the kids seem close to all their cousins, wherever they are. Then, even more surprisingly, her father, who has split up with his second wife, started travelling a good deal more, including to Hong Kong, and himself took up all these media in order to stay in touch. To Claudia it seemed to happen overnight: 'Up to a couple of years ago he had an old brick of a phone and didn't have a laptop, and now he's got himself all connected, all part of the new Dad, and now he's really au fait with stuff when, you know, he's 67. So the kids now have a WhatsApp Grandad sending them pictures from all over the world and they love it.'

In fact Claudia feels sorry for the more technophobe mothers who try to deny what is going on and then are astonished to discover a stranger was chatting with their children - quite unaware that in certain genres such as gaming children simply do not necessarily expect to know one another. When the parents find this out they cannot decide if this means that some strangers are OK in some circumstances. Claudia insists that Instagram accounts are set to private, but the girls complain that as a result they get less 'likes'. 'The thing is all they need is 200 followers and they can feel they are famous, maybe that is good for their 
self-esteem? You could try to ignore all this, but what if something bad happened and you felt you had not been a good parent because you didn't realise this might happen?' Her sister's daughters are older, so Claudia knows things are going to get much worse. The bitchy comments that Claudia's nieces send each other, shown to her by her sister, really shocked her, and she knows this could happen on platforms such as Snapchat, to which she will not have access. Sooner or later she will lose her current measure of control. She hopes by then it will be clearer what she should be for and what she should be against. Right now it is just so confusing. ${ }^{8}$

So what does the example of Claudia, who I confess I regard as representing an exemplary parent, teach us? Her experience shows why from the start of this chapter it has been argued that polymedia is never just about a technical choice: it is always subsequently about the moral judgements made about media usage. Polymedia does not just re-socialise, it also 're-moralises' the media. In addition Claudia's story makes clear that, whatever her discomforts and dilemmas may be, her children seem entirely comfortable with their situation. While these children evaluate each other all the time, what is striking is that they not only use many media, but that they do not assume or expect any particular consensus about which ones to use. If one child is using Xbox and another his or her iPhone, if some like YouTube and others are excluded from Facebook, the children really do not care. However, there are two other things that they really do care about. The first is that whatever medium is used it should facilitate their relationship with Stampy. The second is that it should facilitate their relationships with each other, as people who share this interest and like to play together. What they are teaching us is that platforms and devices are often means rather than ends, though Minecraft itself is clearly significant.

All of this suggests that the way in which we have developed our internet studies and social media studies may possibly be rather misconstrued. Our units of analysis tend to be either the particular platforms, such as Twitter versus Instagram, or what have been called their affordances. Affordances refer to those properties of a platform that would lead people to use them in particular ways. For example, is the communication on that platform synchronic, such that both parties have to be present? Is it easy to store and retain messages? Which senses are employed, audio or visual or both? However, the evidence in this chapter will be used to suggest that both the platform and affordances are of rather more concern to academics and analysts than they are to users, and that may be increasingly true in the future. 
The question of affordances will be examined later. The next two sections provide the evidence for downgrading platforms as the determinants of their own usage. There is an increasing amount of literature on the use and consequences of Twitter: how it impacts on politics or privacy or many other areas of life..$^{9}$ But all of this rather begs the question of what Twitter actually is - the answer being that Twitter becomes whatever its users use it to do. Because of the way in which it developed people tend still to think of Twitter more as a source of information, in contrast to the social exchange mediums of Facebook and WhatsApp. Twitter is regarded as a platform for following the news, whether political or celebrity-focused. Yet the next section reveals that Twitter has actually already diversified into a wide range of sometimes highly specific and even quirky adaptations, some just as conversational as these other platforms. All of which becomes what Twitter is in The Glades.

\section{A medley of Twitters}

Trudy uses Twitter for two things and two things only. The first is to find work. It was her brother who set up her account. He has a signfitting business and he uses Twitter as part of his work. He knew Trudy is always short of money and struggling to make ends meet, what with looking after the two kids, so he explained that Twitter could help her get cleaning and other odd jobs. She could give herself a name, including for instance the term 'girlfriday' - effectively someone flexible who will do pretty much anything to help out. Then she could tweet that she was in a particular area if anyone had any cleaning they needed doing, or she could try \#gardening or \#ironing or pretty much \#anythingforwhichyouwillpayme£8anhour and hope people would find her through the hashtags. The result:

So yeah, not bad really. Building up the hours. That's it really. That's how I use Twitter. My mobile number is on there. They text me. It can be a bit daunting 'cos I got a text message from a lady, and she just said Hi would you come to Treedon to clean. As a woman you have to be careful that it's not a man contacting you. And you go to his house and then you're vulnerable aren't you? So I just replied Yes I would. I'm thinking is this a man, straight away. Just suspicious. On Twitter my name isn't on there (actually it is, but, she just doesn't realise this). So after a while they said their name was 'Naz' by the way. I still didn't know if it was a man or a woman. 
I was thinking. It could also be a sort of Arabic male name. After a while she said, 'my husband and I'. So that was really reassuring. And I went there, lovely couple, young professional, safe. This Naz, she's got two ladies on her road, friends, who want a cleaner, so this is word of mouth, more word of mouth.

Trudy's second usage is even more idiosyncratic. Apart from finding some way to earn money Trudy's real problem is her offensive and abusive ex-husband. They have not spoken for a year since he verbally abused her over the loudspeaker at school in front of their children, but she cannot get a legal constraining order on him since he has not actually been physically violent. She has at least prevented him from taking the children back to where he lives, a place he shares with other men she is very dubious about. The point is that her ex-husband started following her on Twitter, which meant that with her brother's help she could work out who he was on Twitter. As a result they could discover yet another side to him - not just that he could stalk and abuse on Twitter, but that he was basically also a Twitter idiot. He clearly did not get that it might not be wise to wind up Manchester City football fans to the degree that they were threatening to find out where he lived and beat him up. That if you did want to use prostitutes it might not be entirely sensible to follow them through Twitter, post their pictures and make pretty clear what was going on between you and them. Trudy's brother finds it hilarious, spying on her ex-husband and seeing all the mayhem he seems to enjoy causing and then watching how it all backfires on him: 'Oh another thing. Everyone takes the piss out of my ex. It's his spelling. His spelling is atrocious. He will insult someone online and they'll come back and say you can't even spell you idiot. No the funniest was, when he said to someone, "Oh you idiot you can't even spell" and in that very sentence he had about three spelling mistakes.'

Most accounts of Twitter, not surprisingly, do not really seem to have people such as Trudy in mind or either of the two ways in which she uses Twitter. However, the next three cases are further examples of people who use Twitter for one thing only. Keane uses Twitter for the sole purpose of following comedians, including Russell Kane, Chris Moyles and Alan Carr. Shannon follows Twitter mainly for keeping up to date on various feminist organisations, and likes the way she can click through to find out more about what is going on. Geraldine also has one primary use for Twitter, which is to make complaints about companies. She found that writing letters tended to be ignored, and making phone calls also got her nowhere because these are both private. Making a complaint on 
Twitter, however, is in the public arena and directly affects the company's reputation. As a result Geraldine now feels that the place to make a fuss over any issue she might have with any company is Twitter. It seems the only effective way to get a response.

Denise by contrast has two distinct uses, and at 17 a sophisticated policy of discrimination. She has an ordinary profile, which is where she behaves as a regular 17-year-old schoolgirl, but she also has another account that she keeps under careful lockdown because this is where she is trying to develop her musical career and where she wants people to take her seriously. So it is very important that this second account is not polluted by the first.

Lara is a journalist. We tend to think of Twitter as a key source of our news, but it has become just as important to those who publish news. For her the Twitter hashtag is a key means to find out what is happening locally. That month her 'scoop' had been a news item about an escaped peacock. She was able to track the story and the photographs people were putting up, and thereby the peacock itself. Through Twitter she also found the farm from which the peacock had escaped, and even the peacock's name.

Tobias is an example of a Twitter addict: 'Last thing I do before I go to bed is Twitter. First thing I do when I get up is look at Twitter.' He wants to go to bed, he waits and waits until it is late and for five minutes nothing has happened. He goes to the bathroom and then to bed, putting his phone on charge - then all of sudden he is looking at his tablet and some new thing has happened and it starts all over again.

Russell has two uses for Twitter. One is simply a place where, as he puts it, he can tweet 'absolute bollocks' and the other is sheer football fanaticism, which links to any and every possible site that has items about the team he supports.

Craig, more conventionally, uses Twitter as his news feed. He follows a thousand sites, but most of all things connected with the BBC such as technology news, political news and sports news. However, he also follows a BBC gardener and items on cricket, photography and airlines.

Another take on Twitter was represented by two people working in a shop who are quite techie. For them Twitter was important only at one moment during which it was new. They pride themselves in being in the vanguard, so that Twitter helped them confirm their skills when they became very early users. Yet once it became mainstream it held no such appeal, so they simply stopped using it.

This diversity in the use of Twitter across The Glades in part, of course, reflects the diversity of the village's population and their various 
interests. In one case it dominated that individual's life, becoming something of an obsession; in others it was a minor feature used for just one or two limited purposes. Yet all of this is what Twitter now is.

\section{Many Twitters in one}

In the following section we find that the point with which this chapter began about face to face conversation also works for Twitter. When a social media platform becomes dominant and central to an individual's life, there is a decent chance that it will have become effective in this role because in doing so it has been broken up into a series of overlapping but separate genres of usage, each related to a different context - thereby replicating face to face genres. The people for whom this is most true are the teenagers at school who have allowed Twitter to expand to colonise many fields, just as a few years ago Facebook expanded to resonate with many aspects of their lives. So we can take a single individual and trace through these different 'Twitters'. Once again we have polymedia, but now within one social media of one individual.

Twitter currently dominates teenage social media. I examined 50 cases of school pupils whom we had previously interviewed and had permission to follow. Of these the average number of tweets per person was 3,470 , though there are some who have posted up to 18,000 tweets and 17 who have fewer than 1,000 tweets. The average had 341 followers, though this was less varied with only six having under 50 followers and only three having over 1,000. These figures suggest that they are genuine followers. Younger children are known to use techniques to boost follower numbers artificially in competition with their peers. There was also some evidence that good-looking 'fit' males attract a much higher number of followers than most males. This was less evident with females, but then this is not a medium where women concentrate on sending out glamorous or sexy images.

Robin feels that irrespective of personal interest he would need to be on Twitter, since at his school the history department, as well as several others, have Twitter accounts; there is also a general sixth form account set up by the pupils. This is where teachers give advice about homework and deadlines, and may even tweet a picture of all the homework questions, which gets them over the 140-character limitation. The school seems to assume that all its pupils are on Twitter. Indeed the confirmation that Facebook had lost its prior importance for young people was clear when it was found that no school departments in any of these 
four schools used Facebook to connect with pupils; all used Twitter. Yet Robin also recognises that he is a particular Twitter type, the more occasional tweeter, and so rather different from some of his peers who tweet more than 15 times a day.

Robin's second usage is what makes him 'one of the lads'. This is mainly a genre of banter and jokes that depend above all upon football results. A third genre is local news that comes far more quickly through Twitter than any other source; for example, news about someone who got stabbed in Girming. A fourth usage would be an admission that school pupils do use Twitter competitively, though perhaps less so than the younger pupils. Nevertheless, people still notice who gets the most re-tweets and whose status update gets most discussion: 'Did you see so and so's status?' More complex are the judgements made on people's followers. A person with 1,000 followers seems more impressive than one with only 100, but less so if they themselves follow more people or if they post a prodigious number of tweets. The ranking of one's peers in terms of relative status is thus quite a complex calculation. By this age Robin also has a fifth usage that accords with what is often seen as the mature and 'proper' use of Twitter - that is, as a key source of news, including the BBC news app on his phone and notebook. His sixth usage is for a different kind of news, specifically related to football. There is some overlap, for example when the journalist Piers Morgan tweets about Arsenal alongside other news. The seventh usage is really more a bundle of minor aspects. Robin follows some music bands, but not very seriously. He notes comments by his peers about television programmes and might read them if he is watching the same programme, for instance The Only Way is Essex. He follows a few celebrities, but not as much as he used to, and like everyone else he is happy when good jokes and funny stories appear.

Robin's relationship to the eighth usage is also ambivalent; he claims that he never actually takes part, but readily admits that it is a major source of entertainment. In our school study we found many males making the same claim. The activity in question is 'Twitter beef' and is more associated with the girls. ${ }^{10}$

[This] is more used for confrontation. Arguing about boys and girls. Just like general, someone saying something behind someone's back. General teenage argument. A lot of indirect tweets. Hinting, so you've got, might say 'Oh I hate you' and then put in the person's Twitter name, saying reasons why, or you might say 'Oh I hate people who do this,' blahblahblah, and not mention them at 
all, but you can pretty much tell. I would say so yeah. Definitely. And it definitely divides opinion, groups, people who take sides. I'm sure that happens anyway. You sort of have the dance and the, that sort of thing, all the dancers on one side and all the people who didn't really think it was that great, both sides there. Maybe, a girl has had an argument with another girl about sleeping round, that sort of thing, one calling another a name. Just get the two groups that have completely split in school, whereas before between them two there had all been one group, take sides, two completely different friends groups.

This genre of 'indirects', where the posting does not state at whom it is directed, will be discussed in more detail in Chapter 5 .

\section{Historical evidence and the study of affordances}

The conclusions that are starting to emerge from this examination of synchronic ethnographic material are further reinforced when we start to examine historical materials - although the term historical is of course relative, since the period of interest is less than a decade. What we find is a quite extraordinary malleability in these platforms. Take, as an example, the medium that preceded social media as a huge transformation in communication - email.

Email had a radical impact upon my generation that has been analysed by Broadbent and others. ${ }^{11}$ What email achieved (a position then reinforced by subsequent media such as texting) was the overthrow of more than a century of infrastructural reinforcement of a strict division between work and non-work. As shown by feminist research on domestic labour, companies had made strenuous efforts to ensure that work matters stayed at work and domestic concerns should not intrude upon work. Yet, try as they might, companies have found it impossible to limit emailing to work matters, so within a few years these barriers broke down. Far from being merely a tool of capitalism, email had effectively demolished one of the most solidly entrenched rules of capitalist enterprise: the expulsion of the personal. For people of my age this property of email remains. I seamlessly move through emails concerned with family, leisure activities and work, all of which have a major place in my email inbox. In writing about email I would naturally have claimed that this was its main consequence. However, working with these young people today it soon became clear that email is now used for precisely the 
opposite purpose. They never use email for personal correspondence, but ensure that it is only ever employed for work, school or commercial purposes, thereby protecting their personal communication from such contexts. At this point the use of email by teenagers has become radically different. Once used to dissolve the separation of work from non-work, it is now the way these young people mark this same separation. For them, emails have performed a backflip to become the exact inversion of what I would have assumed they were destined to remain.

Of all the social media it is perhaps Blackberry's proprietary messaging service BBM that has been most neglected in writings on the topic. Few people realise that it provided an early example of the personal profile, or that WhatsApp is in many respects a copy of BBM, serving simply to make it available for all other phones. BBM was particularly important to young people because Blackberry phones were in effect the first really cheap smartphones. The fact that it was encrypted also made it ideal for the development of young people's private circles. This was first apparent from our study of Trinidadian youth. ${ }^{12}$ One of the key genres of their BBM usage was all sorts of quarrels and banter. In England, too, school pupils recognise that much of the initial negative social media, through which children were sometimes intensely nasty to each other, originally developed through BBM, where it remained largely under the radar of adult surveillance.

In Trinidad there was a fairly natural migration of this genre of usage from BBM to WhatsApp as people gave up their Blackberry phones for the more prestigious Androids and iPhones - natural because WhatsApp was such a similar platform. In The Glades, however, a quite different sequence emerges. As England is far more affluent than Trinidad, new Android and Apple smartphones had spread among young people in a period before WhatsApp was invented. As a result the entire culture of negative teenage usage migrated instead to the growing platform of Twitter (with a brief interlude for some on Facebook), which leads to the creation of 'Twitter beef'. The point of this example is that one would otherwise have argued that privacy was a crucial affordance of the encrypted BBM for this kind of behaviour.

Twitter, by contrast, looks entirely unsuitable for this purpose. It is one of the most open social media, especially as these young people never use their privacy settings. As a result Twitter is potentially much more open to adult surveillance. It is merely the current cultural happenstance that parents are not yet present on their children's Twitter accounts that makes this negative teenage usage possible at this point in time. Nevertheless, the consequences are dramatic. It is very hard to 
imagine an adult saying they prefer Twitter to Facebook because it is more personal and intimate. For them it is 'obvious' that Facebook is for more personal communication and Twitter is more for information. Yet many school pupils gave as one of their reasons for preferring Twitter to Facebook the fact that they regard Twitter as a more personal and intimate platform.

This is the history of social media. Again and again these examples of unpredictable and surprising shifts in the usage of social media demonstrate the extraordinary malleability of platforms. Instead of being able to match the platforms with particular usage, we find just when this seems clear the usage goes into reverse, demolishing our comfortable generalisation.

Such a combination of ethnographic and historical evidence is not just a problem for the study of platforms such as BBM and Twitter. It is perhaps even more a problem for the study of affordances - those characteristics of platforms that we have been using to explain why they have been chosen for a particular usage. ${ }^{13}$ Most of the academic analytical work that has tried to go beyond the reduction to platforms has done so on the basis of teasing out features that seem to be more constant, and about which it is thus possible to generalise. It has also focused upon situations where there is a clear rationale between usage and that particular affordance.

The best examples of this style of analysis are probably Baym and Broadbent. ${ }^{14}$ However, it is also employed in our theory of polymedia. For example, this approach was previously used to explain why people might use Facebook and more recently the implications of adding the visual affordance represented by webcam. ${ }^{15}$ The ability to see people as well as hear them is an affordance. Baym clearly defines the idea of an affordance as 'the social capabilities technological qualities enable'. ${ }^{16}$ None of these academics subscribes to any form of technological determinism, but equally all feel it would be foolish to ignore the influence of technology on what human beings do. In effect the argument is that, all other things being equal, we would expect people to use a platform for those things and in those ways which the properties of the platform facilitate and make easy. ${ }^{17}$ The trouble is that the evidence from our studies is that they do not. Instead of behaving in an orderly and sensible way that is respectful of affordances, people use social media in a disgracefully inappropriate and dysfunctional way, often with very little consistency. They treat us academics terribly.

There is also an additional layer between the analysis of platforms and that of affordances, since each platform may have several facilities 
and, as with polymedia, they may be used to complement one another. Skype is usually considered as a visual media based on the use of webcam. Yet you can also use it as a phone without the webcam, or even for just texting. In our book on webcam ${ }^{18}$ we examine the internal polymedia within Skype, noting for example that some people simultaneously type messages which contradict what they are apparently saying at that moment (for instance when there are children present to overhear them). Facebook is a social media, but it also has facilities for private messaging and live chat, which relate more to messaging services. WhatsApp to groups is different from WhatsApp to individuals. A selfie is an obvious example of a particular kind of content, but it is also trans-media. You can post a selfie on Snapchat, Instagram, Twitter or Facebook, for example, while continuing to call it a selfie.

Certainly we can find many examples where people look to a very specific communication channel in order to find a particular affordance that they require. An example was Ruth, a hospice patient who, being only in her thirties, is entirely comfortable with most social media, as well as with the various potentials of $i$ Phones and iPads. Her real embrace of social media came when she developed breast cancer. For any woman breast cancer and its treatment can be extremely embarrassing as well as traumatic. Ruth is concerned about what others might assume has happened to her breasts, and the only people with whom she is comfortable discussing this are other breast cancer patients. Even with these fellow patients, however, she prefers not to reveal her identity.

Fortunately she found that social media platforms exist which are designed entirely for anonymity, and one is specific to women experiencing breast cancer. There she felt free to remark 'OMG I have just lost my ladygarden' and ask what impact treatments had had on other women's pubic hair. She imagined men could well find equivalent support over issues such as sexual impotence, where anonymity might be essential for participation. She contrasts this with other people she knows who are suffering from breast cancer. One is a friend of a friend who is more extrovert and seems to want to put every detail of her illness on Facebook. Ruth uses her private forum daily because she finds it hugely helpful when, for example, people predict the potential impact of hormone treatments on one's own emotional state. Ruth is doing what we would have supposed a sensible person would do: carefully weighing up various affordances and choosing between them to help her deal with the situation. There is no doubt that on many occasions we can see a direct link between an affordance and the choice of that particular platform. It is simply that much of the time we cannot. 


\section{Living in a social media zoo}

This chapter started with a theoretical approach developed by myself and Madianou which we call polymedia. It was noted early on, however, that this is already in need of revision. For example, it needs to be clear that polymedia can exist within social media, and does not just refer to the relationship between social and other media. However, this chapter has suggested deeper problems - not only with our approach, but also with the way in which almost everyone in internet studies and social media studies tends to analyse social media. Take, for example, a recent edited collection of studies called The Internet and Societ ${ }^{19}$ which focuses on research by the Oxford Institute of Internet Studies. Several of the papers look at a particular platform and note that the dominant concern is whether that platform is having positive or negative social effects; it may conclude that we need more data to determine the result. The problem is that such an analysis assumes a relatively homogeneous beast called Facebook or Twitter or the selfie, about which we can generalise in this manner. Typically when a social media platform is established we decide what it 'is', based on the dominant form of usage we encounter. So we perceive Facebook as largely a network of sociality between individuals, or view Twitter, by comparison, as being more directed towards the dispersal of information. We (and I certainly include myself here) are then drawn towards the study of affordances, since we want to try to explain which particular features of that social media account for the evidence that it is predominantly used for this or that purpose.

The problem is that we never actually encounter a social media merely as a technology composed of affordances, and we never will. From the start we only actually see it in terms of that dominant usage of the time with respect to a particular population. We meet Twitter because it has already been adopted by millions of people who assume that it is largely something to be employed for these informational purposes. Yet in The Glades we then find a mass of young people who use Twitter for peer group banter; many of them are blissfully unaware that one is 'supposed' to use Twitter for obtaining information. Others such as Robin use it for both purposes, and many other genres besides. At this point, therefore, the only appropriate response by academic analysts ought to be 'Oops, we got it (at least partly) wrong'.

Had our first encounters with Facebook and Twitter been with these teenagers we would very likely have been writing a very different 
analysis: why the affordances of Facebook give it a propensity to be used for gaining information, for example, while those of Twitter make it ideal for banter and other forms of sociability. Again, however, we would be largely wrong. People do exploit affordances and so there is often a post hoc rationale for explaining a choice, but it is often not the one we expected or could predict. We cannot easily talk about Twitter because this chapter demonstrates that Twitter is not a single animal but rather a menagerie of extraordinarily different beasts that simply happen to be found in the same place. Some users have turned it into just one animal; others allow this zoo to proliferate within their own personal usage. For anthropologists acknowledging this descent into diversity is essential, simply because it is true; this text is intended to be an accurate record of what I encountered when I tried to study social media in The Glades. However, it does clearly pose a problem.

The reason, on reflection, is that the beasts/zoos with which we are dealing are actually in some ways more complex, but in another way much simpler than we have acknowledged. Twitter is simply a platform that permits you to make a statement or link with up to 140 characters, to follow and be followed. It is a very clear and simple device, which precisely for that reason can be used for pretty much anything. After a few years we discover in our medley of Twitters that, when actually given time to exploit it, people will indeed use Twitter for just about anything. Typically this is also differentiated in terms of the varied communities of users. Young people may, and do, use Twitter in entirely different ways from older people, simply because of their different stages in life. An example of this is how the changes brought by email were turned on their head, first bringing the spheres of work and leisure closer together and then firmly separating them. At this point any general argument as to whether a thing called 'email' or 'Twitter' is good or bad, which is what so many academic articles claim to be doing, becomes quite problematic, as does the claim that if only we had more data we could provide a better answer. Further evidence or 'data' will not lead to better answers, but might hopefully lead to an appreciation that these are the wrong questions to ask.

At this point the danger is that anthropology becomes once again no more than relativist critique - a statement that you can never generalise because 'my people', i.e. the ones I am studying, are different. If everyone does everything in their own way at any particular time, no generalisations will ever be made, or at least none that will last. This seems even more apt when we look at very young users, such as Claudia's children. 'Once upon a time', as we might say to them, we all 
used desktop computers and felt the transition to laptops was of considerable significance, but now, with tablets, phablets, phones and all the rest, the choice as to which device we use seems less significant than ever. 'Once upon a time' everyone used a single platform, and the movement from MySpace or Orkut to Facebook seemed of great significance. Yet now, with Twitters and Tumblrs, BBMs and WhatsApps, we may have been misled again into believing that platforms were causative of what we were seeing.

However, we do not want to throw the analytical baby out with the bathwater. These conclusions are intended to suggest more about what we need to add to, rather than to subtract from, the study of affordances and polymedia. The case of Ruth with breast cancer choosing a social media primarily because it supports anonymity, for example, was one of many in this chapter that illustrate how often we should ascribe significance to affordances. Furthermore, the question whether the reason is an affordance or simply a cultural consensus to use a platform in a particular way makes almost no difference to the subsequent capacity of platforms to be used contrastively within polymedia.

This is not a random mess at all. As noted at the beginning of this chapter, people used many genres of communication prior to social media; there were always many beasts in the zoo, but we could identify them and generalise about them. This is part of the solution to our problem. We need to recognise the habits of communication that existed prior to social media. Once we stop trying to reduce usage to platforms and affordances, and recognise that social media, just like face to face conversation, consists of a series of conventional genres, which often remain quite robust, we get back on to our analytical track. This will become clearer in Chapter 4, in which we see how genres of social media often associated with particular platforms are then used to differentiate between groups of friends and relationships. Twitter is where young people banter because Facebook is where their parents are. A hospice patient uses texting as a hub to organise the other media she employs. These arguments do not threaten the theory of polymedia, therefore, nor the trend to the re-socialisation and re-moralisation of media more generally.

Similarly we are not trying to replace technological with social determinism, which would be equally problematic. Each platform has consequences for its users and is likely to signify at least a degree of change in that genre of communication. There is historical continuity, but male banter within a pub, for instance, may be different when it is carried out on WhatsApp. Questions such as how to evaluate the impact of current Twitter use on ethnic relations among the youth of 
Wales, or how the rise of webcam may assist hospice patients in saying their farewells to relatives in Australia remain entirely valid. The problem does not lie in the desire to make judgements, but rather in the level of intended generalisation. The social genres of face to face communication discussed at the start of this chapter have always been dynamic, because societies change as well as technologies. This is why the first paragraph of this chapter remains so important. The study of social media in practice is the study of the continued dynamics of what was already a thoroughly variegated field. The genres of sociability and communication, including 'pub banter', 'family conversation at meal times', 'girl talk', 'office banter' and 'pedagogy' stood alongside the associated social groups. Young children's collective relationship to Stampylongnose matters considerably to them, irrespective of how that connection is achieved. So even with these new technologies we need to remain aligned to the analytical units of groups and genres that we encounter, and not to be too side-tracked by platforms and affordances.

An anthropological study is not just a study of what a generalised group of people such as Norwegian fisherwomen or Chinese accountants do. It is a study of what makes them in cultural terms typical while recognising that all of us will as individuals remain untypical in some respect or other. No one wakes up one day and decides to invent a genre called pub banter. We are all socialised into the norms of our particular society as children, and in learning about pub banter, for example, become examples of the society we are studying - in this case villagers of southeast England as opposed to those of southeast Turkey, the site of another of our volumes. In Chapter 4 we will start to engage not only with the relationship between people and these social media, but also with what makes these users distinguishable as English - a concept implying norms and genres which may have constantly changed but have been in formation sometimes for centuries. First, however, we need to address the question of what social media actually looks like. 


\section{3}

\section{Crafting the look}

The purpose of this third chapter ${ }^{1}$ is to address something that is surprisingly absent in studies of social media - a properly illustrated discussion of the visual material which often dominates what people actually post. We have been slow to appreciate that with digital technologies visual postings are no longer as costly or difficult to reproduce directly. Most books and journal articles, even where they do address visual postings, do not contain sufficient illustrations. Most of the chapters of this book relate to social media as communication, and therefore to the relationships between those who use it. By focusing upon the visual postings, however, this chapter also ensures that we pay proper attention to content, to the stuff people actually post and also to the practices that lie behind such posting.

If the last chapter tried to paint a whole landscape, this will be more a still life, focusing on the detail of just a couple of objects in that landscape: ${ }^{2}$ the visual postings of Instagram and Twitter. In The Glades Instagram is mainly used by young people; they are also the group who do most of the visual posting on Twitter, since adult Twitter is mainly textual. So this chapter returns to the research with 16-18-year-olds in the four secondary schools, but also the same young people as encountered more generally during the ethnography. The theme of polymedia is continued from the last chapter since Twitter and Instagram will be shown to act as complementary platforms that make sense only in relation both to each other and to other platforms such as Facebook. In many respects we can only understand Instagram and Twitter once we appreciate that they have been formed into the opposite of each other.

There is something, however, that transcends this opposition between Instagram and Twitter. As with all social media we need to stop thinking about this as trivia and focus on the visual more in the manner of any anthropological study of, say, the decoration of canoe prows or 
the use of colour in ritual. In scanning thousands of images we can soon discern clear patterns, and the analysis can quickly ascend from the idea that this is simply an individual doing something trivial to an appreciation that these are cultural genres in formation. Indeed one of our conclusions will be that such images do more than simply craft a look; they are a means by which young people change the frame through which they experience the world.

Facebook predates Instagram and Twitter, and was in retrospect the bridging platform that links older analogue photography with social media. On Facebook photographs are still organised by albums, which can be the site of traditional genres such as wedding or holiday photographs. Many of these may have been taken with a camera. At the same time, Facebook, alongside other new social media, introduced the idea of the photograph as a transient reflection of a particular day appearing on the wall, to be liked and commented upon. It also lent itself to images taken from the camera phone, a process consolidated in Instagram which for a long time only accepted images taken with phones rather than cameras. This chapter will demonstrate that in some respects Instagram and Twitter moved in quite opposite directions in their development from Facebook, while in other ways they seem to be similar and parallel. In the conclusion the analysis will be re-contextualised as polymedia alongside Facebook and Snapchat.

\section{Twitter}

For the 50 young people whom I followed in The Glades on Twitter ${ }^{3}$ the average total posting of visual images, including videos, was 142 , though there were 17 who posted fewer than 50 images. Since this represents over 7,000 images it is an important resource, and in raw numbers would be larger than Instagram though less than Facebook. If, however, we focused only on photographs Twitter would come a distant third, since it includes many more memes and fewer photographs. Photographs that include the person posting are much less common on Twitter. Furthermore, while the visual images stand more by themselves on these other media, within Twitter they are mostly more dependent upon the captions that accompany them.

An exception to this would be the large number of short videos that have been taken from another platform, Vine. Almost invariably, a Vine video is posted because it is considered funny in its own right. These are all 'shares' rather than videos that these young people had made themselves. 
Typical topics would be rather large people on the dance floor or an animal doing something amusing. Also acceptable are cute sequences such as a puppy or kitten pouncing on its sleeping owner. For some males almost all of their visual Twitter postings were Vine videos. These form part of what is the largest component of visual postings on Twitter, which comprise photographs and memes put up solely to amuse (Figs 3.1-3.4). These might be visual puns or juxtapositions, for example someone using baguettes for slippers or a dog pulling a particularly silly face.

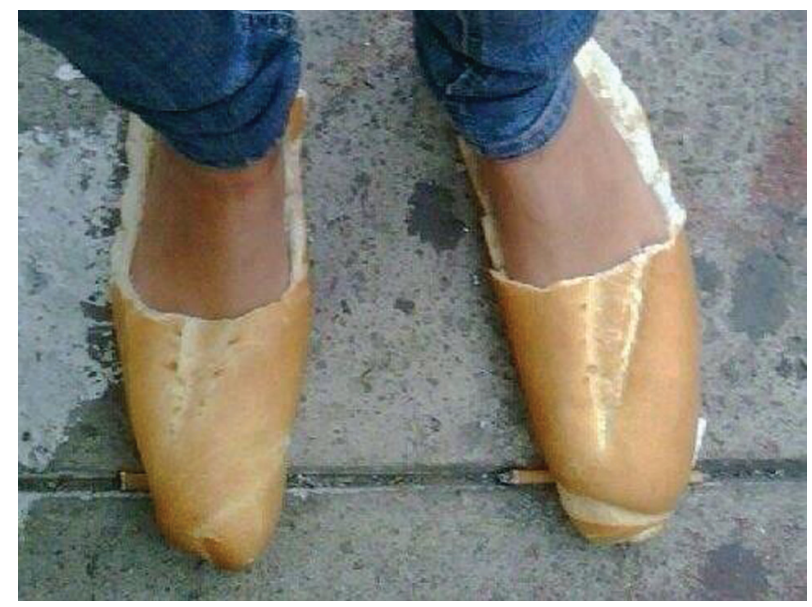

Fig. 3.1 Typical visual joke tweet

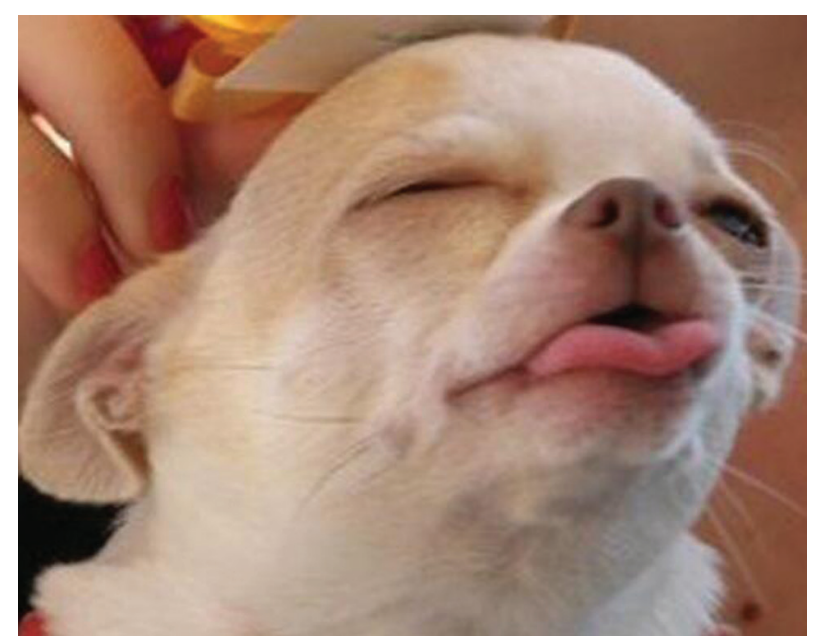

Fig. 3.2 Typical visual joke tweet 


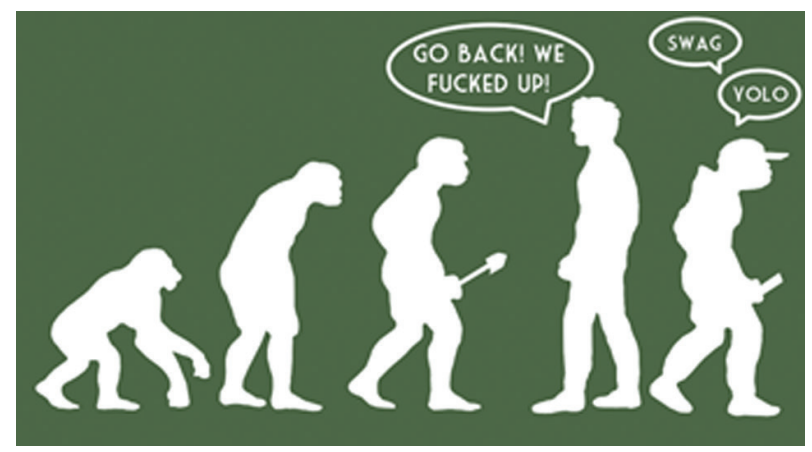

Fig. 3.3 Typical visual joke tweet

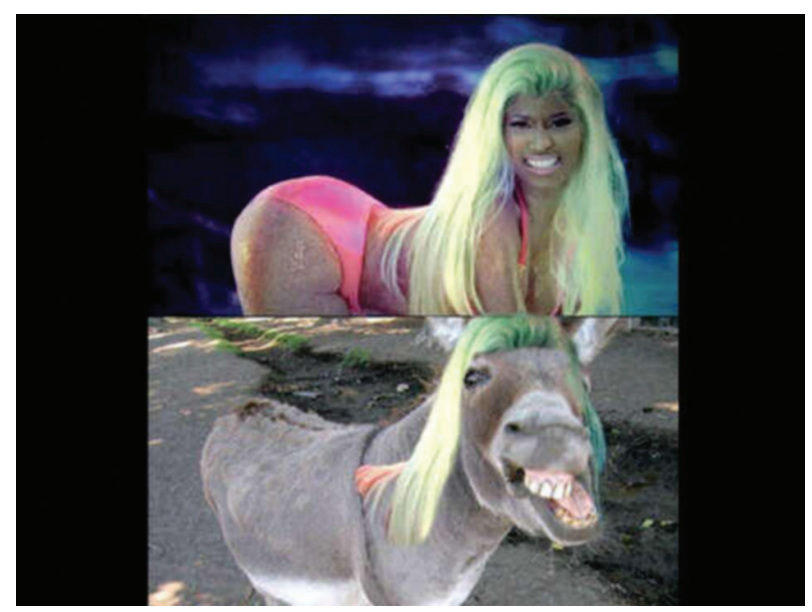

Fig. 3.4 Typical visual joke tweet

While many different varieties of humour can be found on social media, in Visualising Facebook ${ }^{4}$ we argue that the quintessential form of English humour is self-deprecation. Actually this was not common on Facebook for young people; it rather tends to develop as they get older. Self-deprecation does, however, seem reasonably common on Twitter, especially for female postings regarding personal appearance (Figs 3.5-3.7).

A second major category of posting is simply the use of visual imagery as part of direct banter with another individual. For these young people there had been a time when Facebook (and before that BBM) was the cool peer-to-peer platform for their own internal chat - some of which was benign and funny and some of which could 


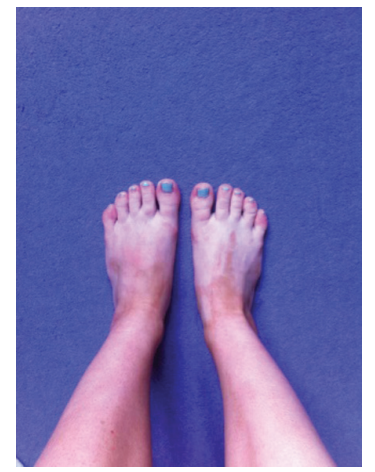

Fig. 3.5 'Fake tan this morning was brilliant idea'

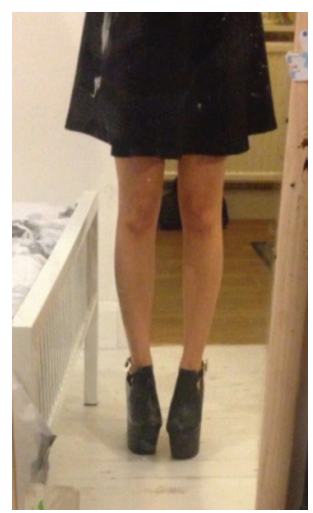

Fig. 3.6 'Can we all appreciate how ugly my knees are?'

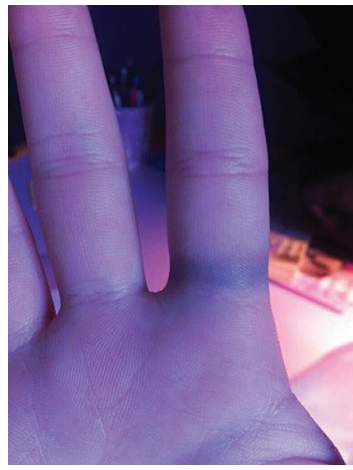

Fig. 3.7 'I shall no longer wear cheap rings' 
become quite nasty. As noted in the last chapter, these genres of peer interactions have now migrated to Twitter. Many of these are clearly directed to one particular person whose Twitter tag appears on the posting. Because Twitter is an open platform, everyone can see it. As a result it is generally assumed that these personal comments should also be in some way funny, otherwise there might be little point in sharing them.

One way of doing this is to make a comment on the supposed traits of one's friends. For example, two different people here associate a friend with their fondness for vodka (Figs 3.8 and 3.9).

Some of these personal references can be quite sweet or benign, such as the apology in Fig. 3.10 or the profiling of a friend in Fig. 3.11.

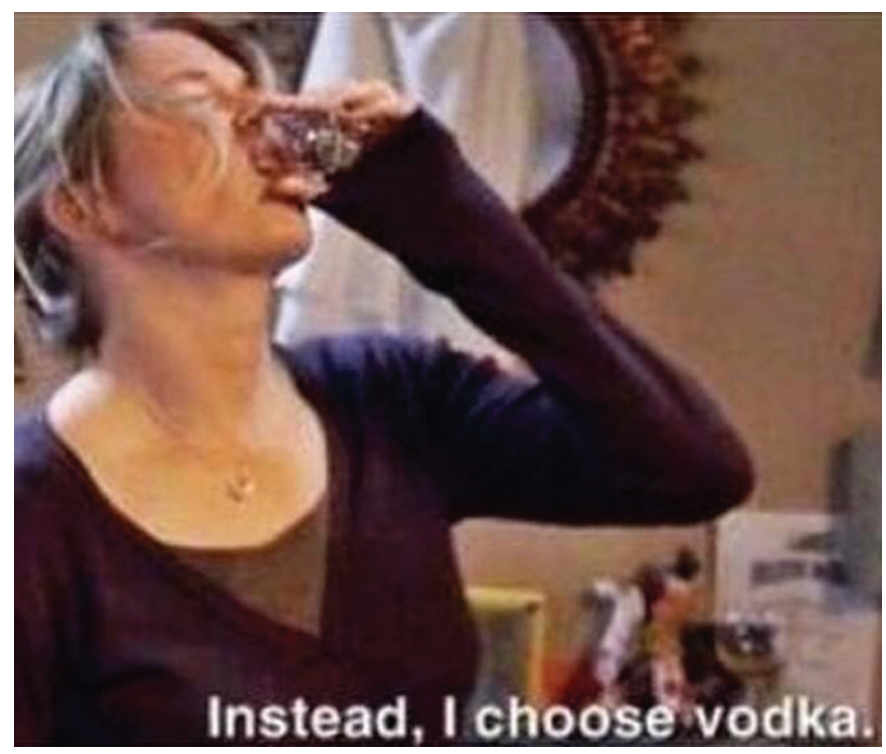

Fig. 3.8 'I saw this and thought of you' 


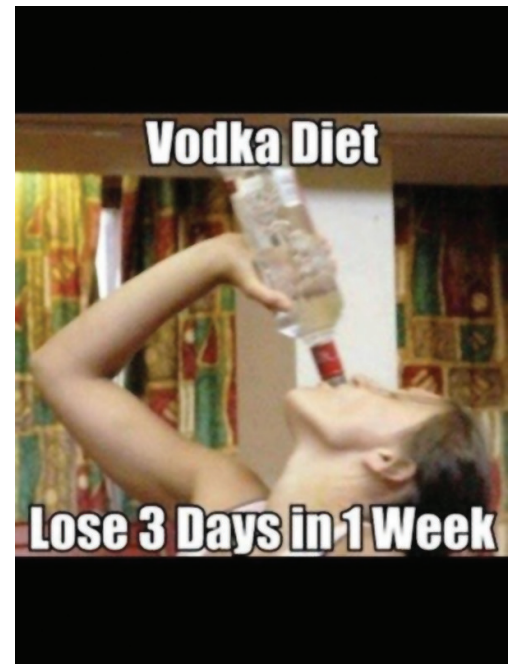

Fig. 3.9 'This reminded me of you'

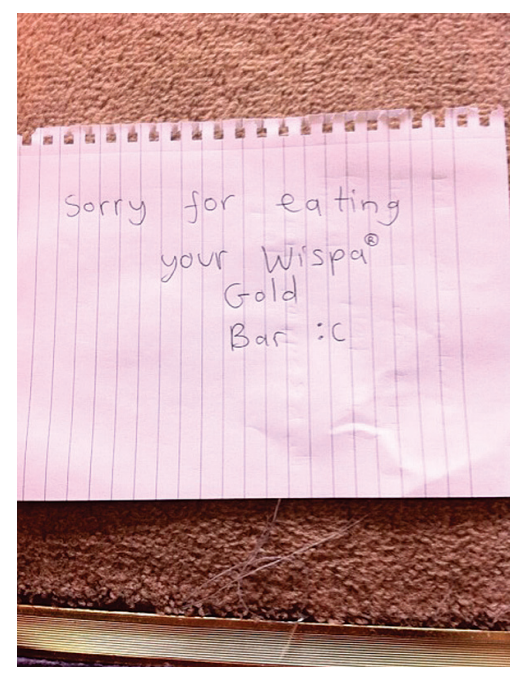

Fig. 3.10 'Sorry for eating your Wispa Gold bar' 


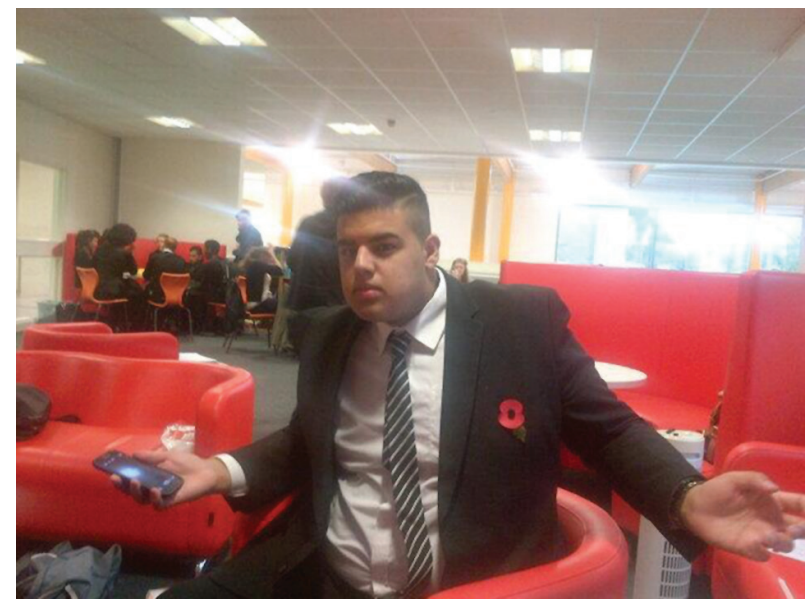

Fig. 3.11 'This is (. .) He is single'

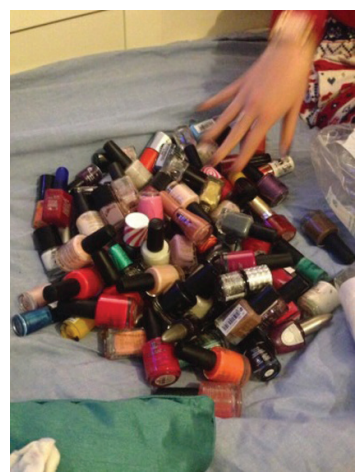

Fig. 3.12 'Sue, you got any nail varnish? Nah'

Or there is banter over, in this case, nail varnish (Fig. 3.12) or the proof that wins an argument (Fig. 3.13).

However, as with the banter more generally, such person-to-person posting can also be a joke at their expense, a taunt, an accusation or even a direct insult as in Figs 3.14-3.16. 


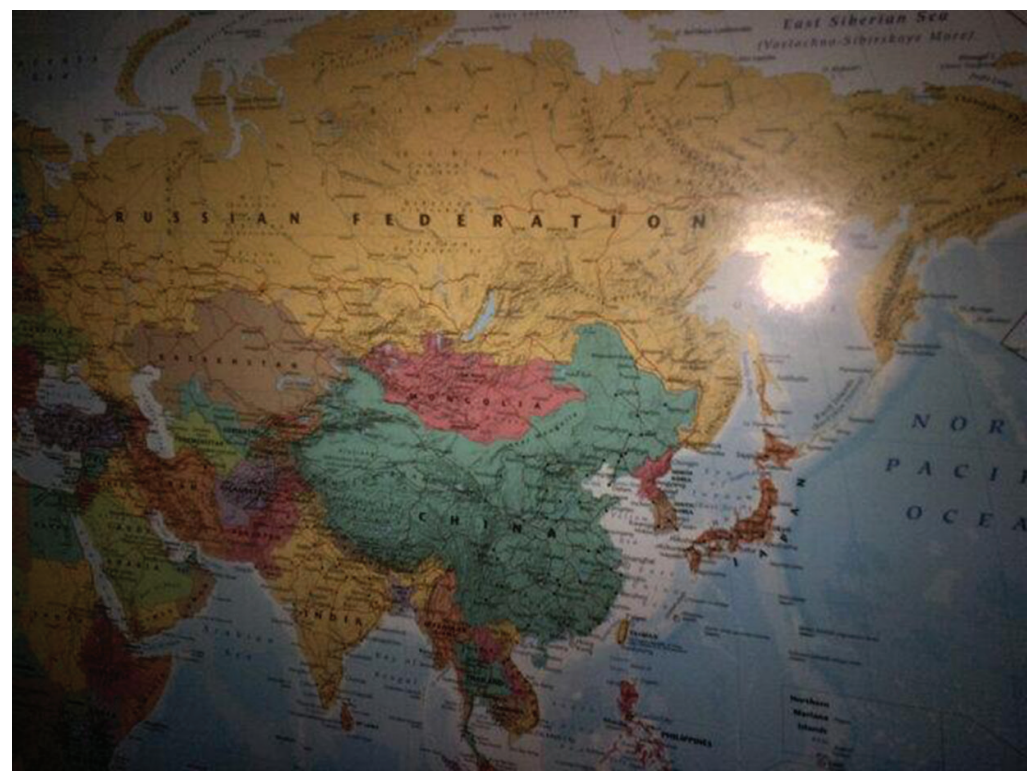

Fig. 3.13 'Russia borders Japan, like I said'

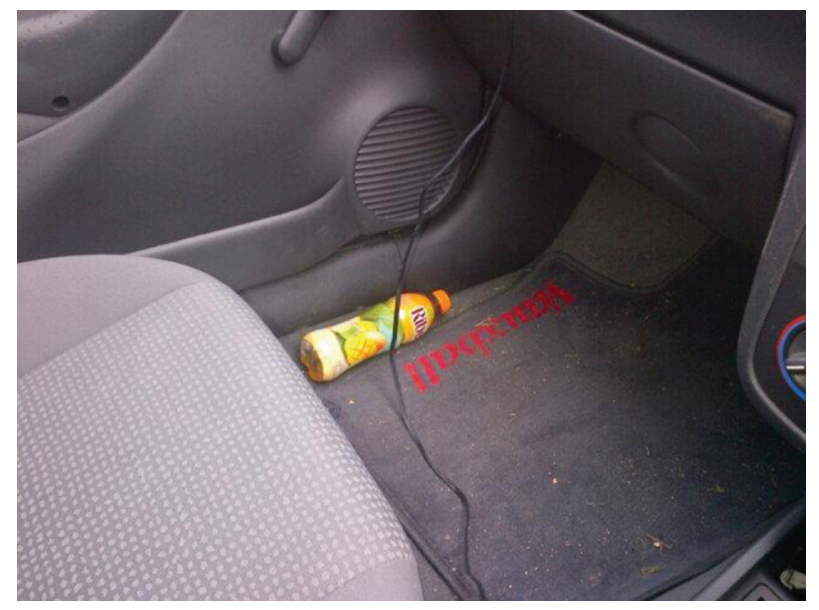

Fig. 3.14 'Is that yours, you c**t?' 


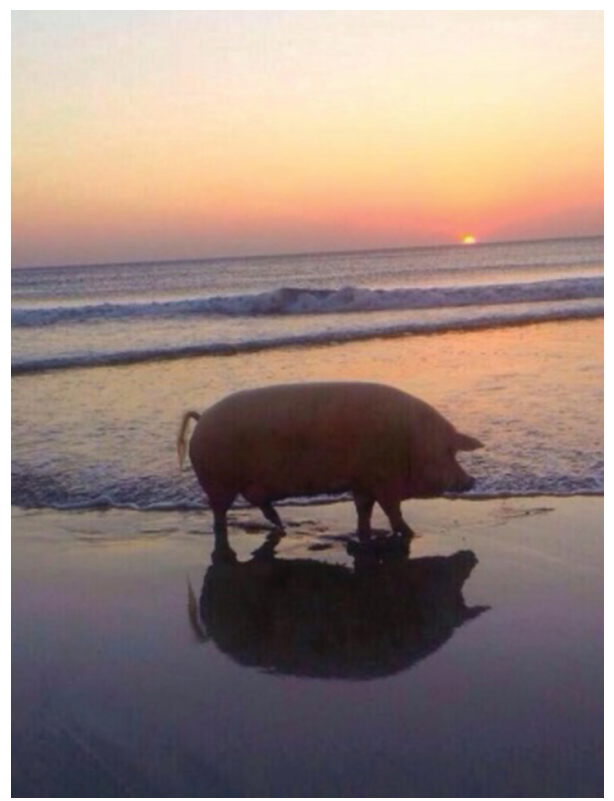

Fig. 3.15 'Picture of Charlotte on beach'

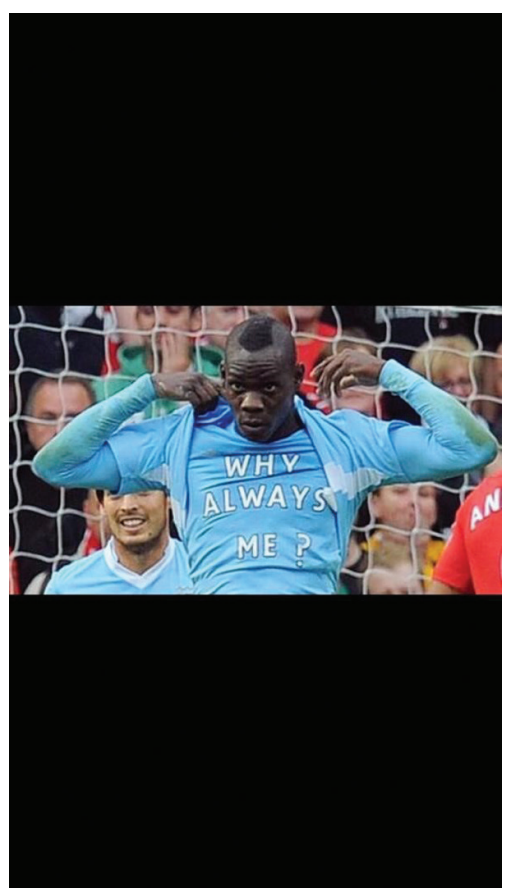

Fig. 3.16 'I saw this and thought of you' 
In every case insults are seen as acceptable as long as they are sufficiently funny to become part of a more public appreciation of the exchange, however negative (Figs 3.17 and 3.18). All of these images only make sense, therefore, if we perceive them as being simultaneously directed to a person and to everyone on the site.

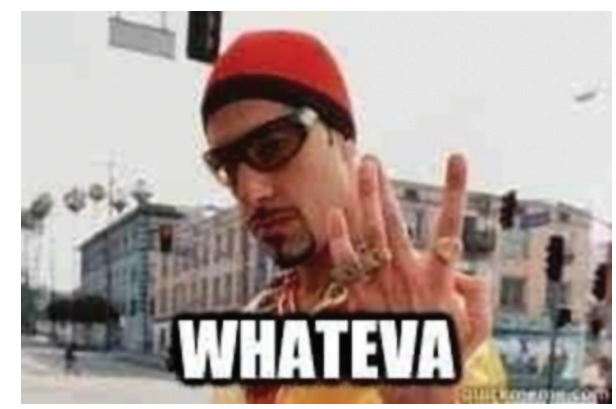

Fig. 3.17 Typical insulting tweet

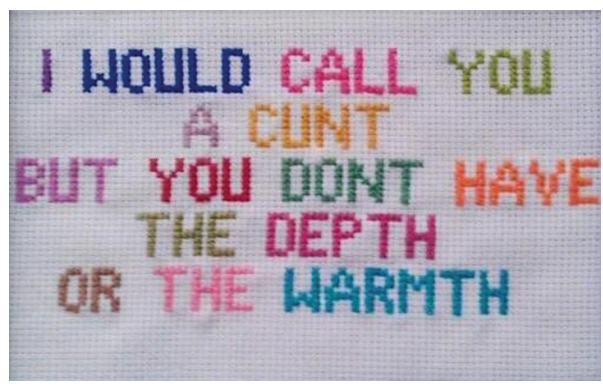

Fig. 3.18 Typical insulting tweet

Apart from humour and banter, the third major category of posting is more to do with happenstance - something curious that is seen during the day that strikes you as amusing and you want to share. These may include university prospectuses (Fig. 3.19) or a picture from the garden (Fig. 3.20) or a share (Fig. 3.21). 


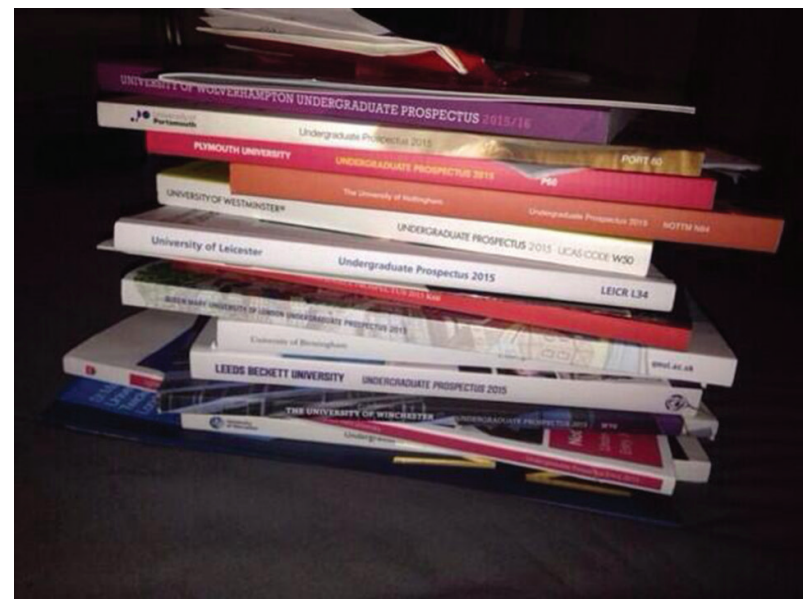

Fig. 3.19 'Felt rude not to accept every university'

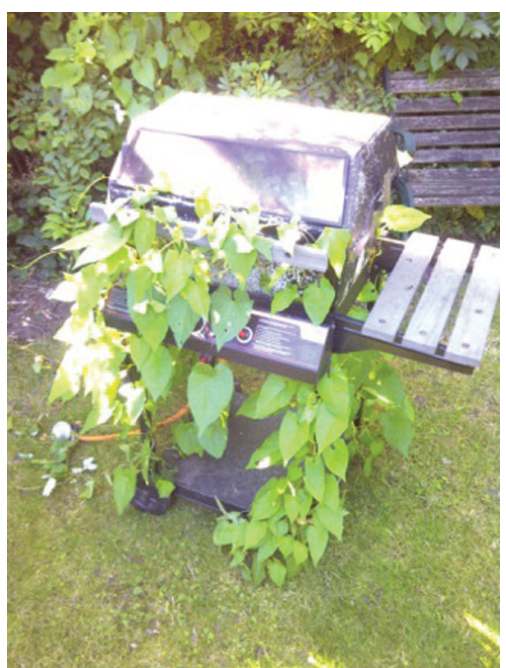

Fig. 3.20 Overgrown BBQ 


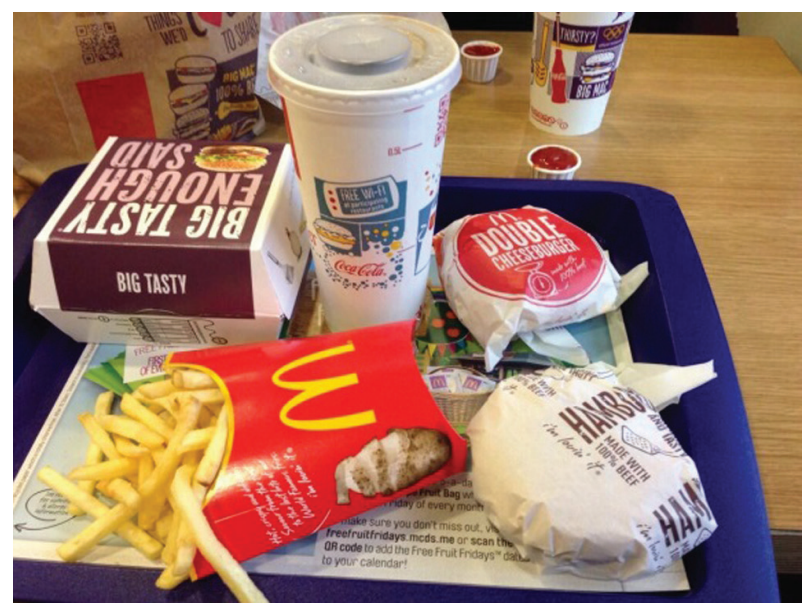

Fig. 3.21 'Joys of knowing someone that works at McDonald's, ordered medium got large plus two free burgers'

Equally common as part of this genre is something commenting upon on your current mood. Those posting such images have clearly spent some time taking a photograph or searching for a meme to express how they are feeling accurately (Figs 3.22-3.24). The more negative mood messages (Figs 3.25 and 3.26) are usually intended to elicit some kind of supportive response from one's concerned friends.

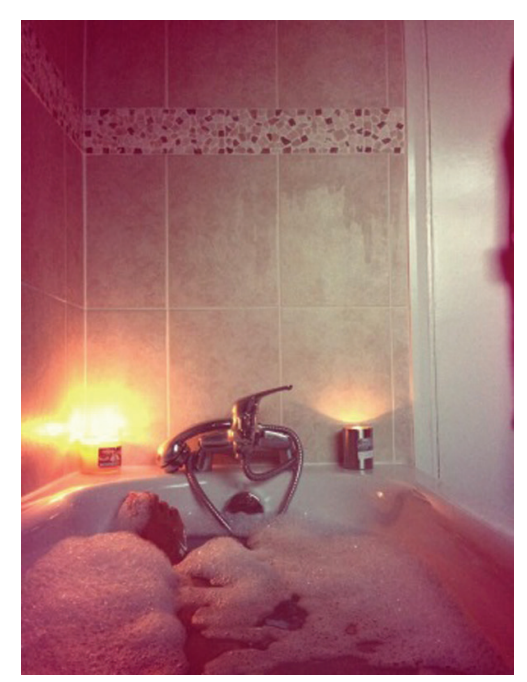

Fig. 3.22 'This bath is just bliss' 


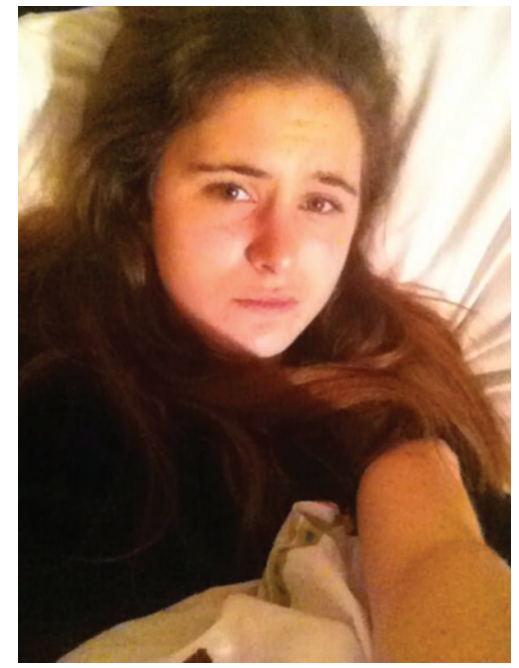

Fig. 3.23 'Can't contain the excitement'

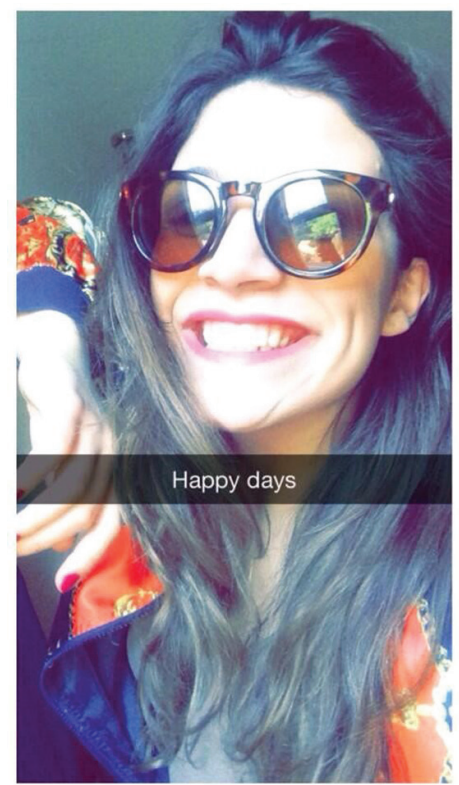

Fig. 3.24 'Happy days' 


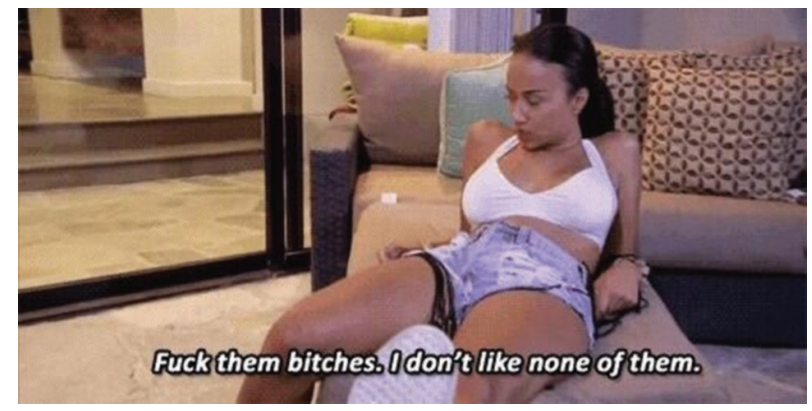

Fig. 3.25 'How I feel'

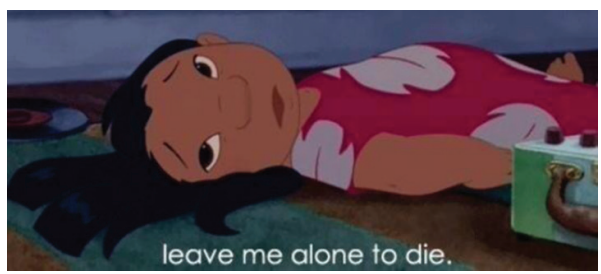

Fig. 3.26 'Bad day'

The categories discussed so far might be found with either gender, but with some other genres there is a degree of gender differentiation. For example, males are more likely to post football-related material (Fig. 3.27), though they are also found among female postings.

Males also have more direct references to sex (Figs 3.28, 3.29, 3.30 and 3.31). Almost invariably these need to be funny, although they may occasionally post sequences of porn directed at other males.

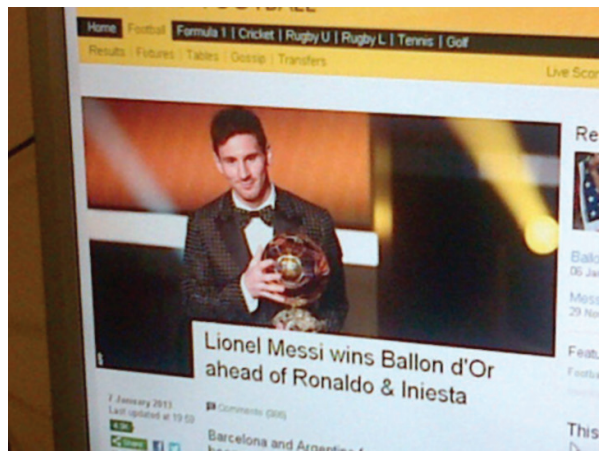

Fig. 3.27 'Even Lionel Messi wears bow ties' 


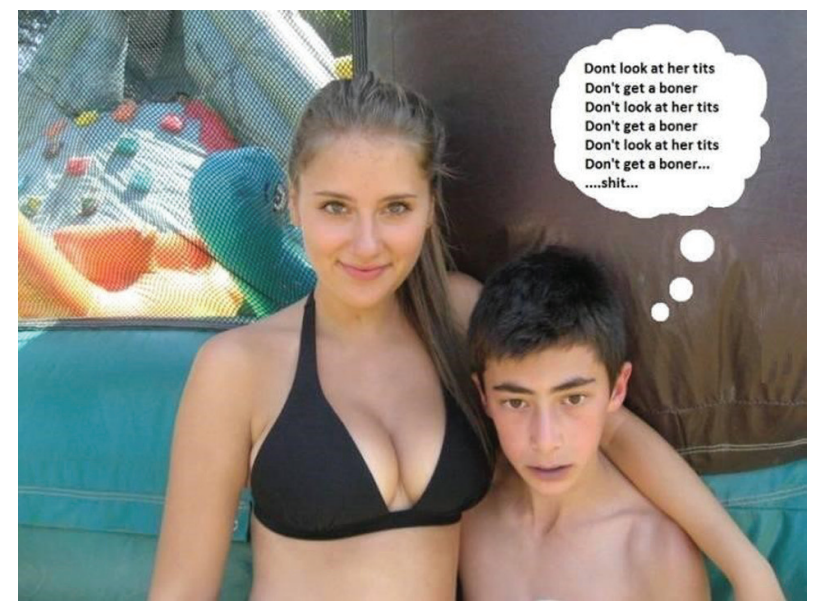

Fig. 3.28 Tweeting involving sexual humour

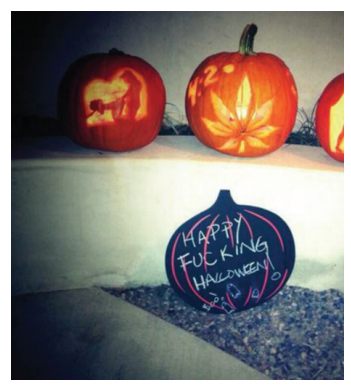

Fig. 3.29 Tweeting involving sexual humour

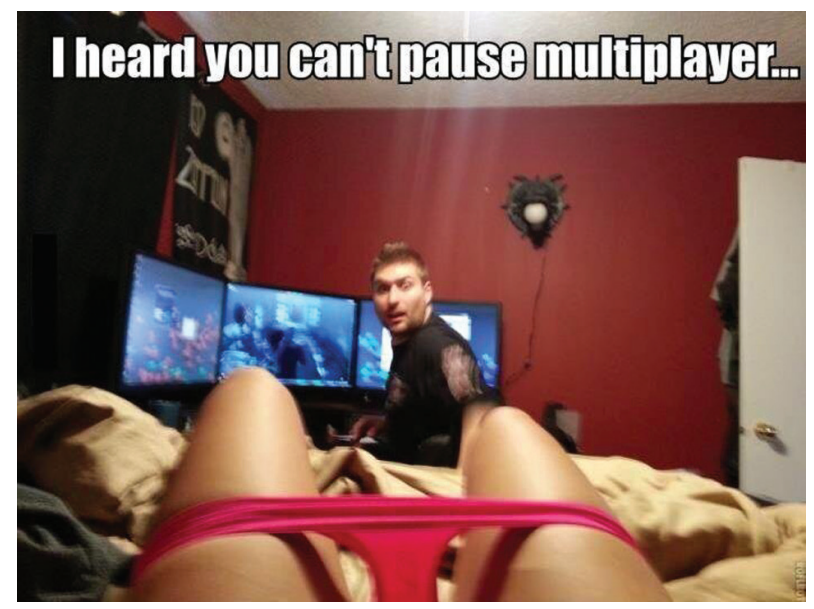

Fig. 3.30 'Dilemma' 


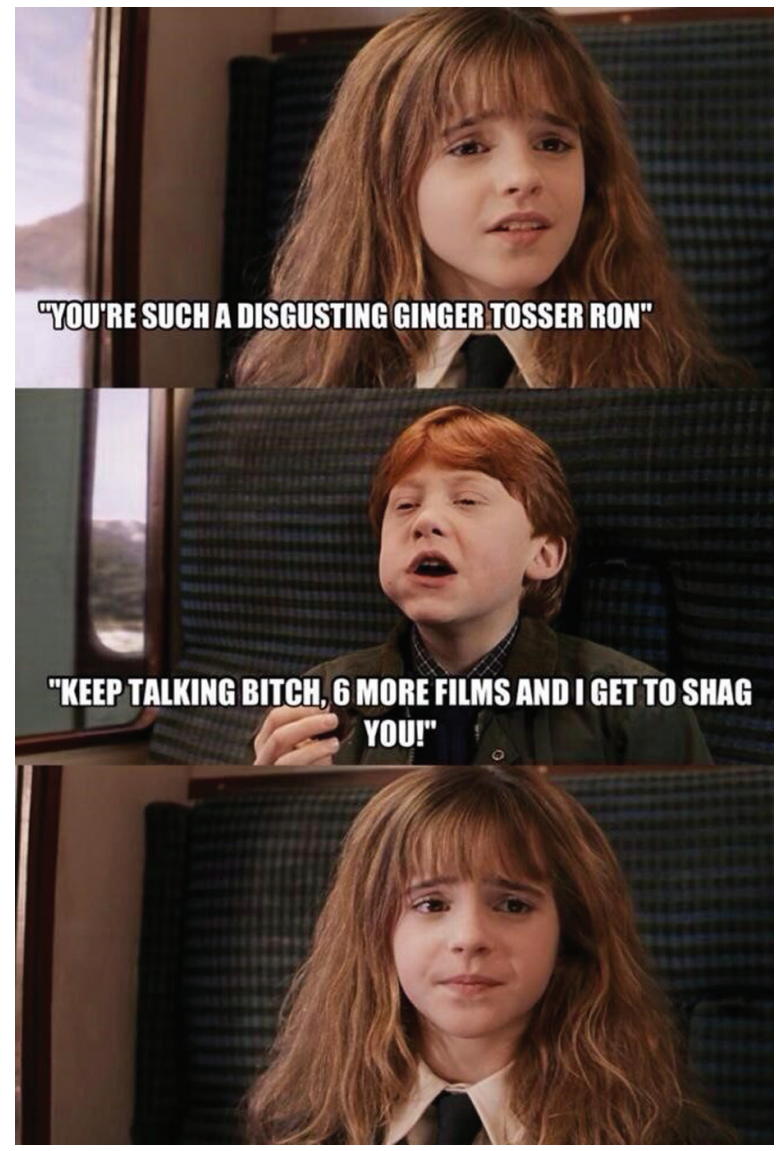

Fig. 3.31 Harry Potter tweet 
Females are equally true to stereotypes so far as being more likely to post comments on relationships (Figs 3.32 and 3.33).

Events as such do not often feature as the subjects of postings, apart from birthdays, though a visual in the form of a tree is often used to celebrate the coming of Christmas (Fig. 3.34).

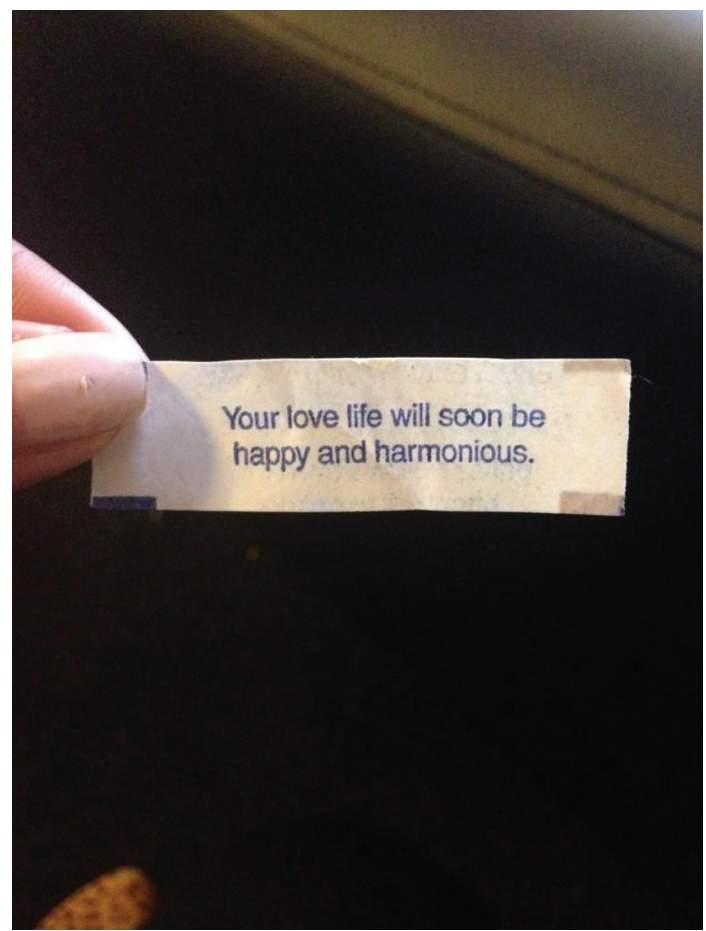

Fig. 3.32 'My fortune cookie is freaky after this week'

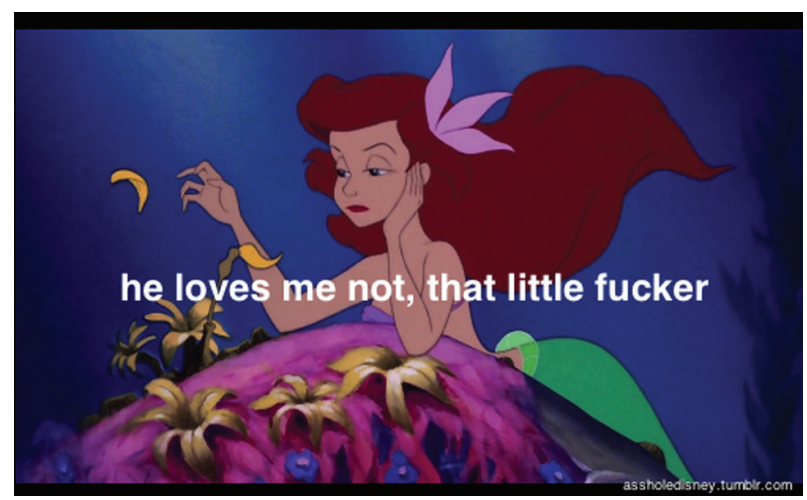

Fig. 3.33 'He loves me not, that little f...' 


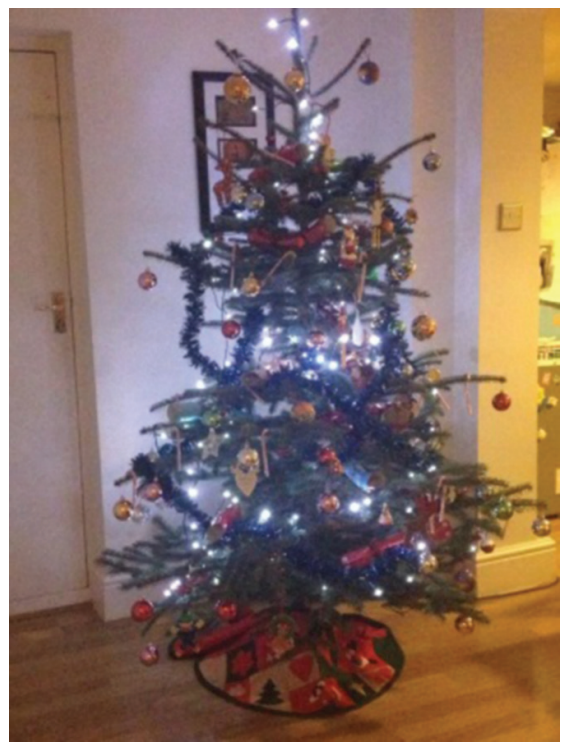

Fig. 3.34 'Feeling festive'

A topic that seems to come out more overtly on Twitter than either Facebook or Instagram is the desire for particular goods or other possessions, perhaps reflecting that currently this is the platform where young people feel comfortable with this kind of overt self-expression (Figs 3.35-3.38).

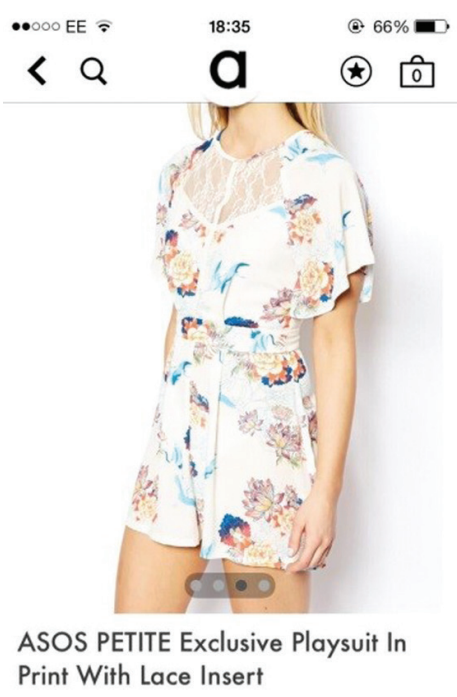

Fig. 3.35 'Someone buy me this please' 


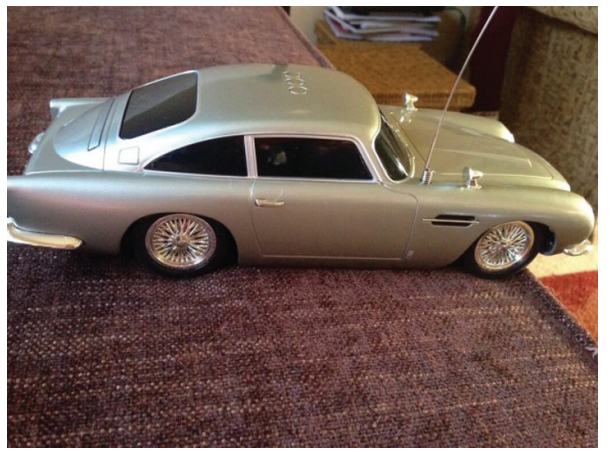

Fig. 3.36 'I got an Aston Martin for Christmas woo woo'

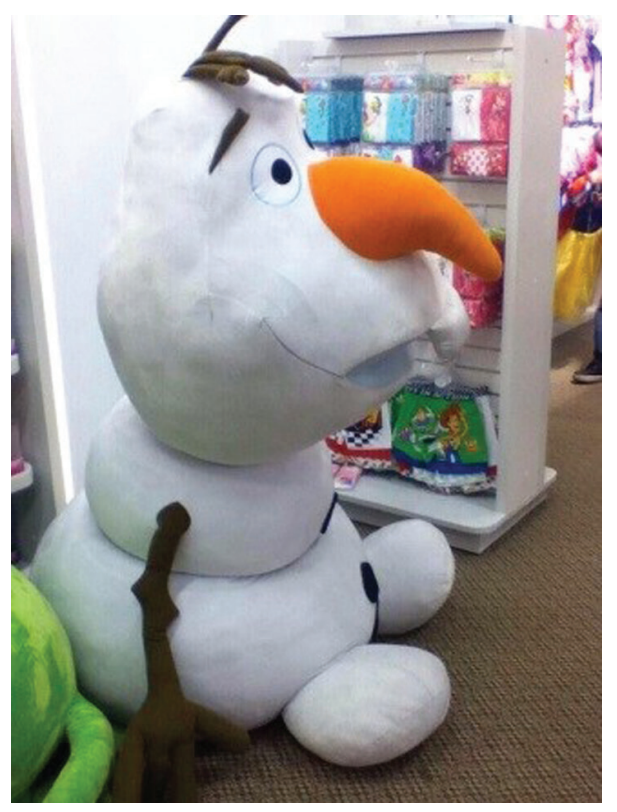

Fig. 3.37 'Anyone want to buy me a...' 


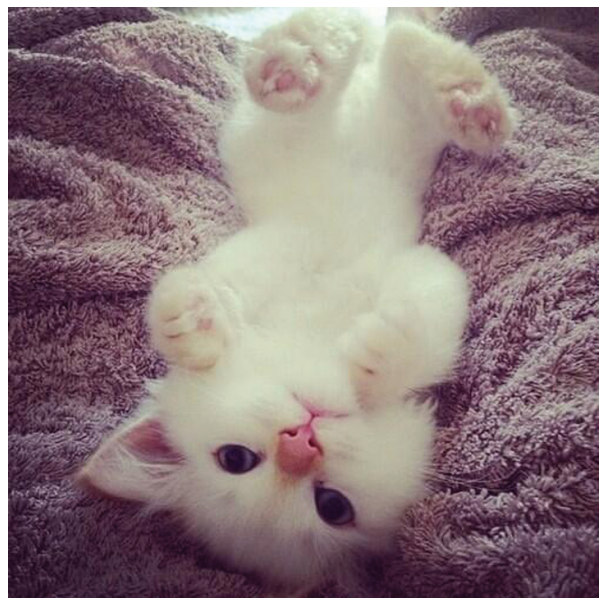

Fig. 3.38 'I want'

Occasionally one may also see a comment on an undesired purchase (Fig. 3.39).

Apart from these core genres there are a series of other, more occasional topics. These may include political or nationalist postings (Figs 3.40-3.41) or school-related postings (Figs 3.42-3.43) - or postings that are considered 'sweet' (Figs 3.44-3.45).

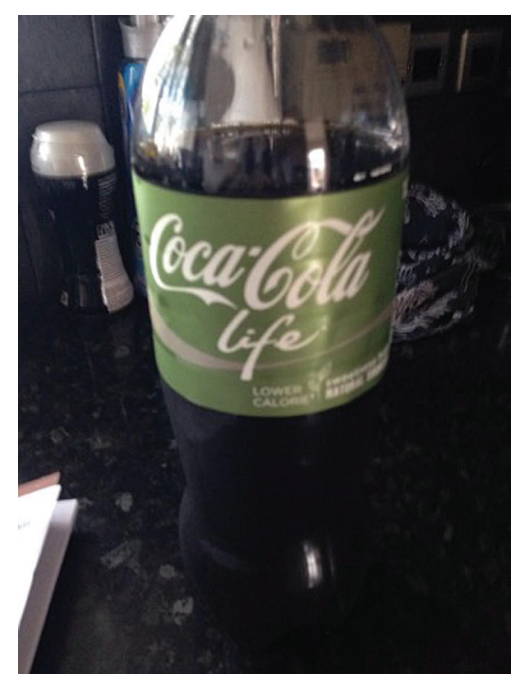

Fig. 3.39 'Wtf is this $\mathrm{s}^{* * \mathrm{t}}$ '? 


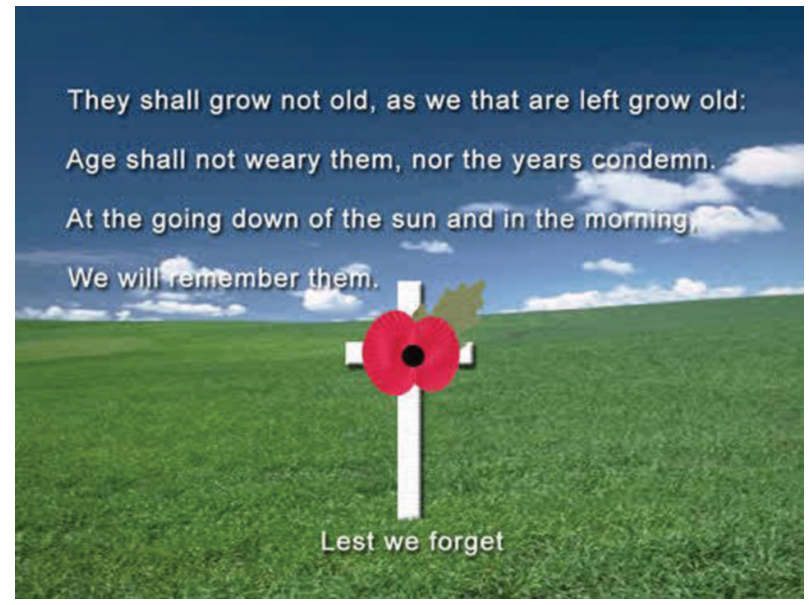

Fig. 3.40 Lest we forget

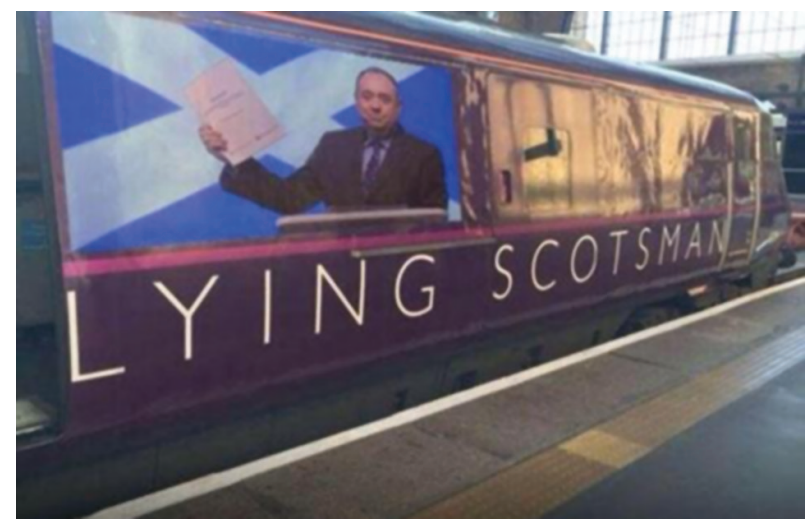

Fig. 3.41 Political posting

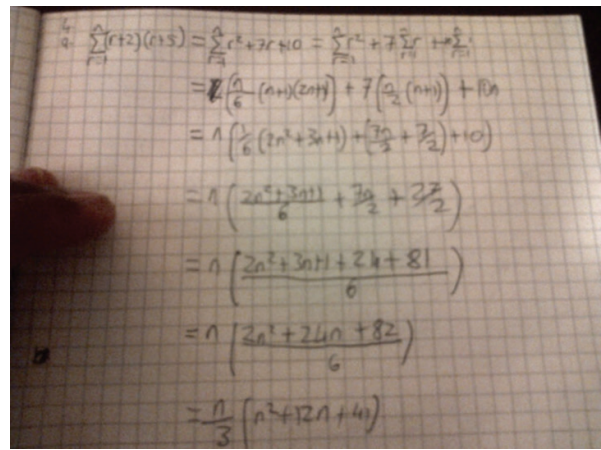

Fig. 3.42 'Hope this hits the spot' 


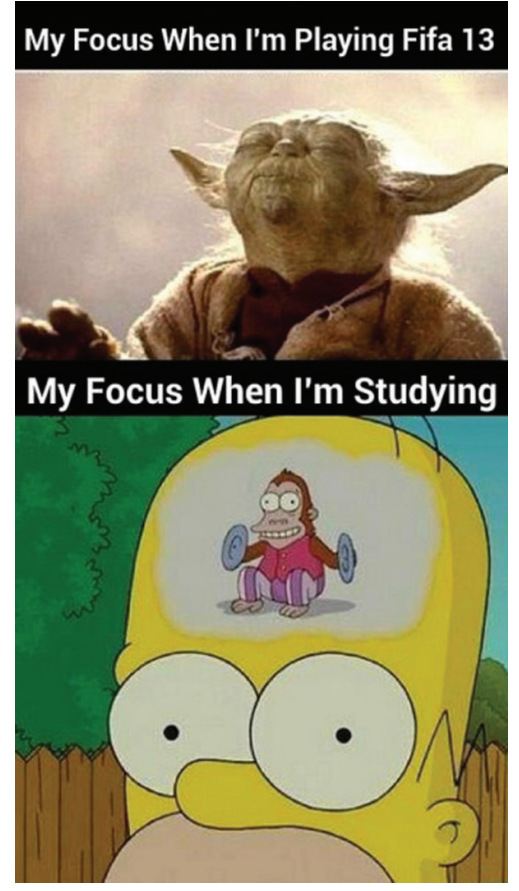

Fig. 3.43 School-related posting

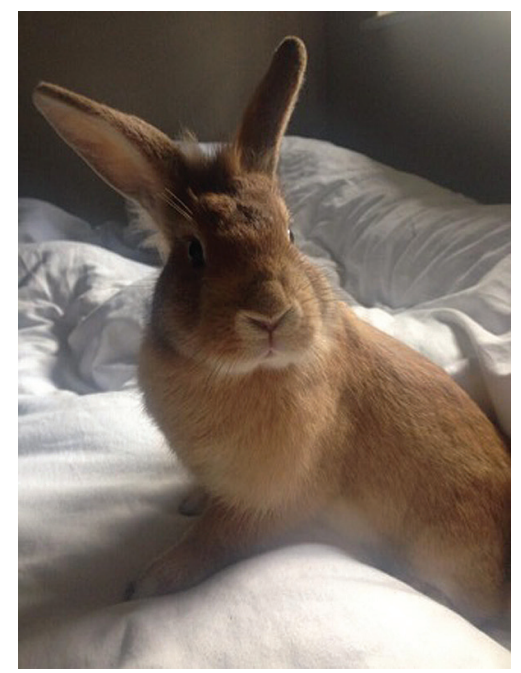

Fig. 3.44 'Good morning Queen of Sass' 


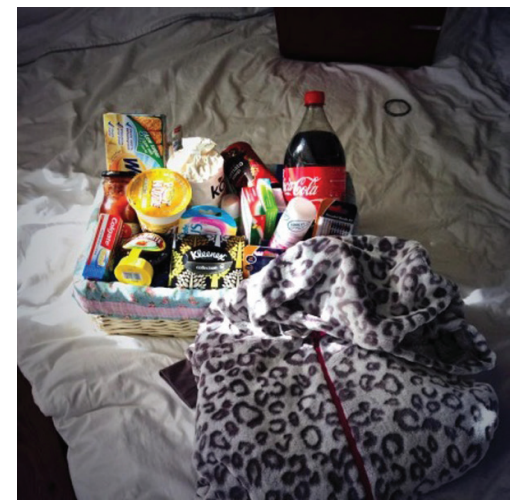

Fig. 3.45 'My mom is the cutist [sic], emergency basket and onesie'

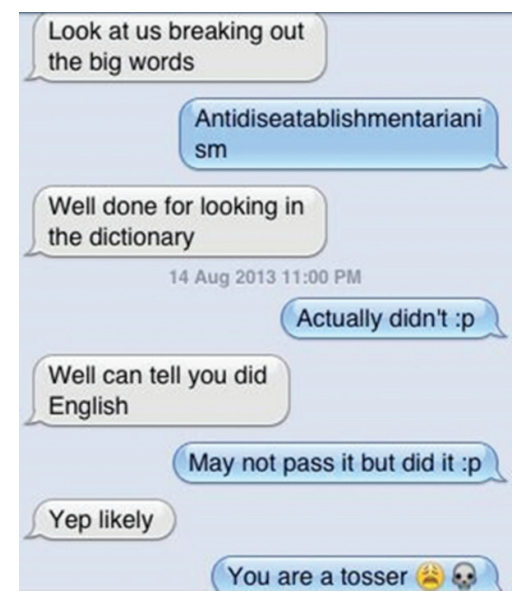

Fig. 3.46 Cross platform visual posting

A final genre is the use of Twitter to re-post screen shots that have appeared on other media; these were originally private, but are now being shared more widely (Fig. 3.46). An example from Snapchat is the photograph that said 'Happy days' (Fig. 3.24), but one also sees screen shots from WhatsApp and from regular texting. The genre illustrated here is banter (Fig. 3.47), but there are others. 


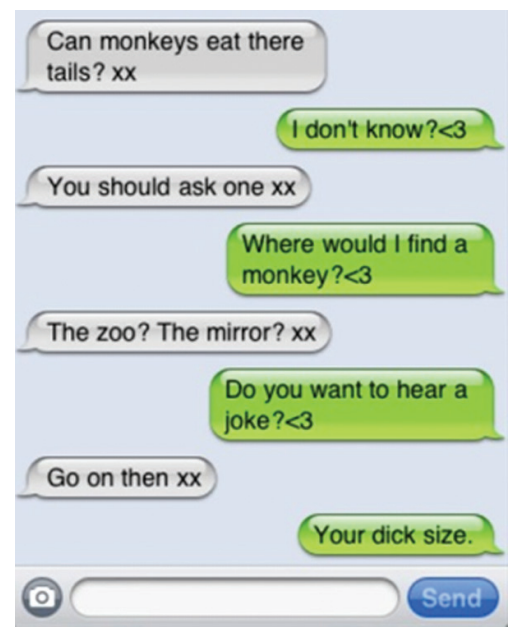

Fig. 3.47 Cross platform visual posting

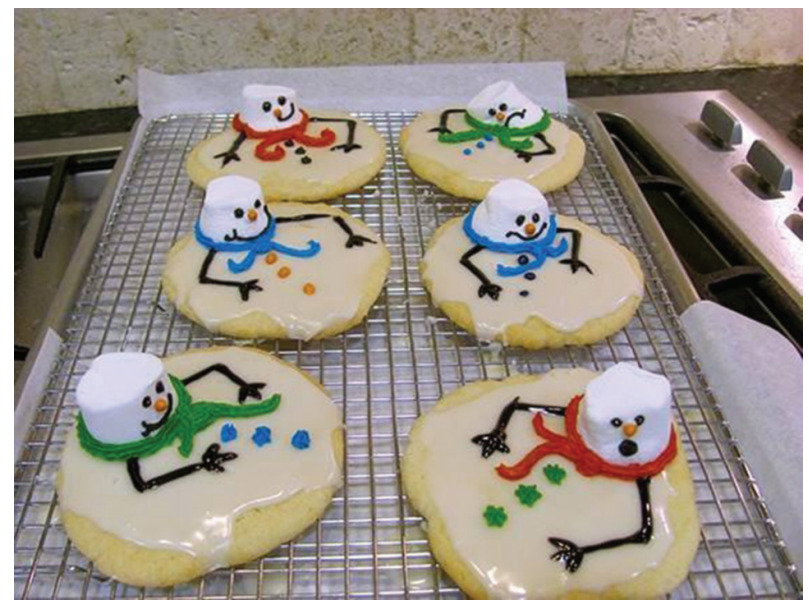

Fig. 3.48 We should be making these

This section has described the main genres of visual posting on Twitter by 16-18-year-olds. The further implications only start to emerge when they are contrasted with Instagram, but this contrast is not absolute. These final examples are the types of visual images that could equally well be found on Instagram (Figs 3.48-3.49). 


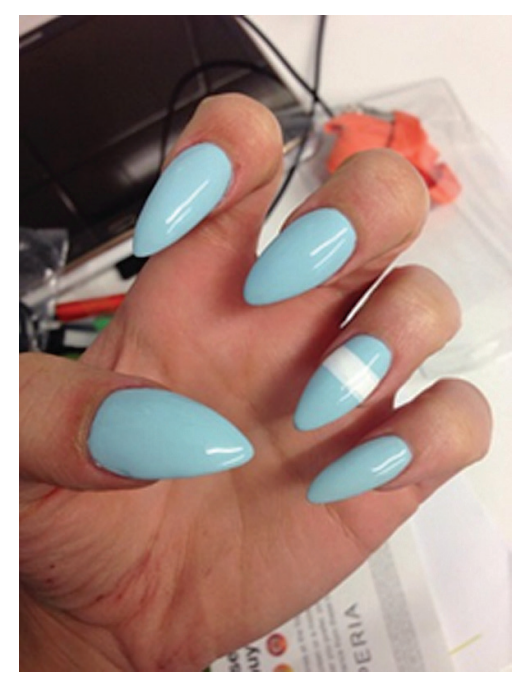

Fig. 3.49 Nails

The same would be true of genres such as the selfie or images of one's besties (best friends) and BFF (best friends forever). Indeed some use Hootsuite and other devices for simultaneously posting certain kinds of image, for example a friendly group selfie, across Facebook, Instagram and Twitter simultaneously.

\section{Instagram}

I followed 12 male and 17 female school pupils aged 16 to 18 on Instagram. The males averaged 33 posts, the females averaged 147 posts each. ${ }^{5}$ Females also do more visual posting on Facebook and send more Snapchats, but do not dominate visual posting on Twitter. Overall I examined nearly 3,000 images. Instagram is like a strippeddown Facebook and also, as one informant suggested, a sort of baby Photoshop. It is almost entirely a site for photographs, though it is now also possible to post short videos. These seemed popular for a while, but may have declined since the novelty has worn off. Instagram posts attract 'likes' and comments in the same style as Facebook, which now owns Instagram. However, there is a greater remove from traditional 
analogue photographs, as while images are retained there is no provision for them to be organised in albums, nor are they tagged. During much of the field work period Instagram was also limited to photographs taken on mobile phones rather than standard cameras.

What Instagram added to Facebook was a more serious engagement with photography itself. The platform comes supplied with a number of filters that allow one to manipulate the image. These photographic techniques would not long ago have been the preserve of professional photographic studios, but Instagram has turned them into simple, highly accessible technologies. The evidence from these schools is that this matters to its users. They have come to regard Instagram as a kind of craft, though a craft that requires minimal effort and competence. This means that while it may be derided by elites or professionals, it is entirely unintimidating to a teenager.

Often the craft element of Instagram is a way of concluding an engagement with some other craft. The moment you finished baking a cake, putting on your accessories or sprucing up your pet, you take the photograph. This relationship to craft has three versions, as illustrated in the food and drink images (Figs 3.50-3.54). Firstly it can be a cake one has baked or a meal one has prepared. Secondly it can be an appreciation of the craft of others: something that one has purchased, been served or just seen in a display. Cupcakes and macaroons are quite common examples. Finally it can be an exploitation of the food to demonstrate the craft represented by taking a good Instagram image

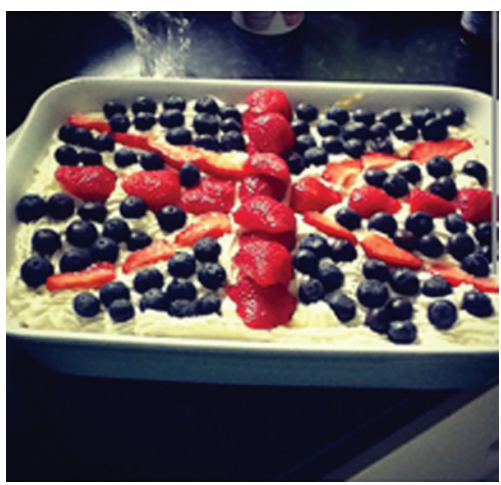

Fig. 3.50 Home-made food 


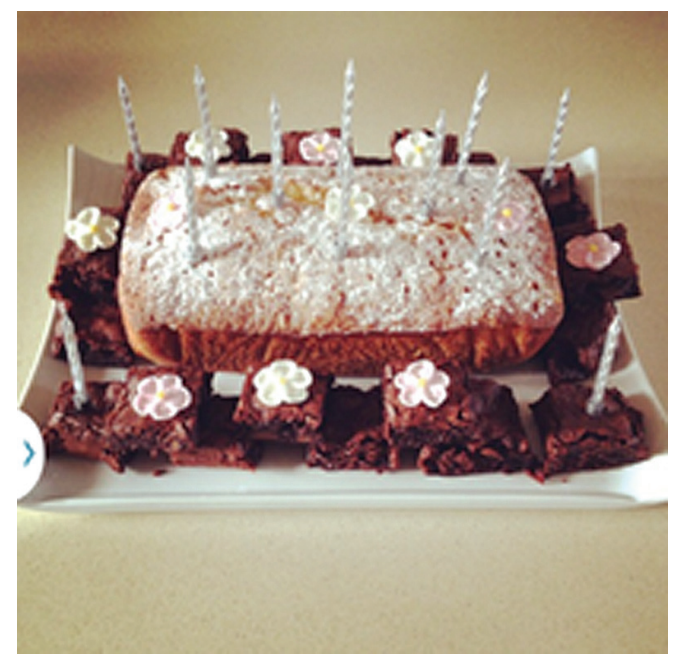

Fig. 3.51 Home-made food

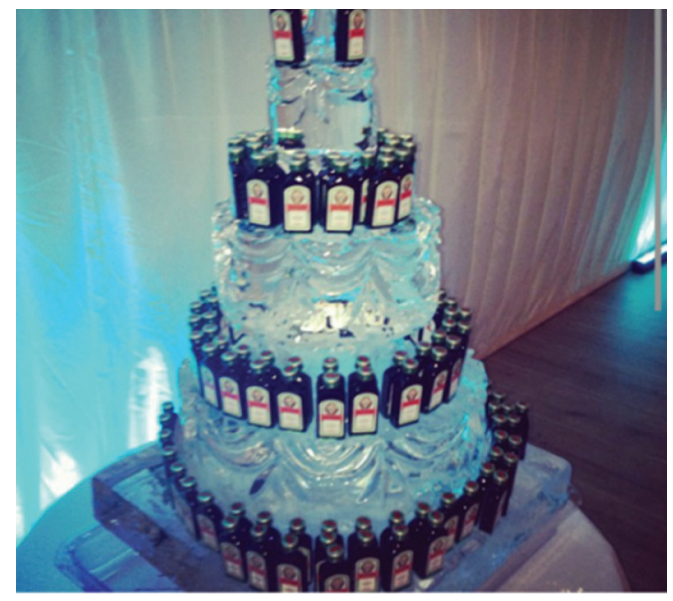

- 23 likes

Fig. 3.52 Commercial drink display 


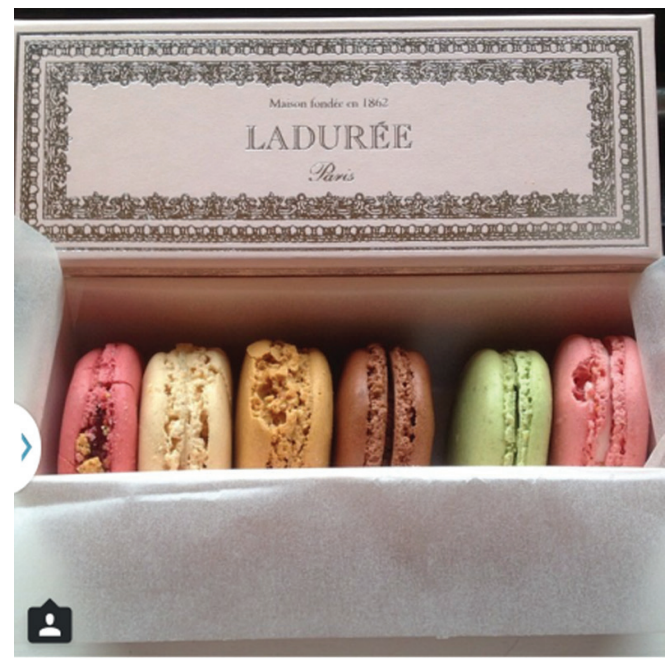

- 57 likes

Fig. 3.53 Commercial food image

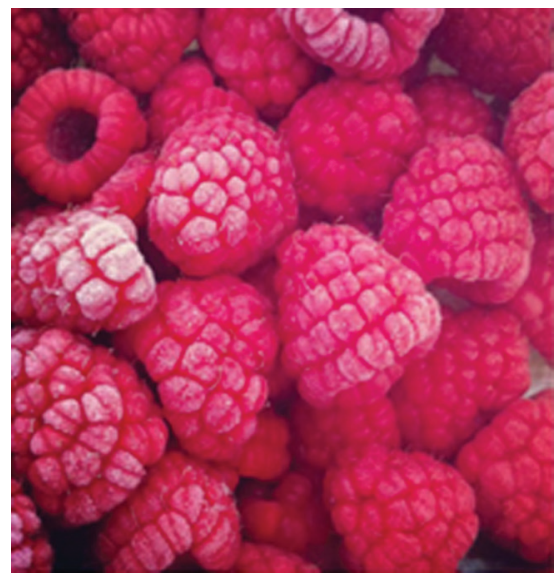

Fig. 3.54 Food as a photographic craft 
of something that otherwise would not have elicited any particular aesthetic appreciation.

The school pupils are quite explicit about Instagram as craft. For example, one recalls how they:

Upload a photo of some books I found which I got really excited about. I found them, put them in a pile, but I rearranged them so they'd look good for the photo ... It is a craft, it's important. You're not going to upload a rubbish blurry photo or something embarrassing ... You have a lot of Instagram pictures that are mostly taken if someone goes out for a meal and they're like 'that looks good' so they'll take a picture and they'll put it on Instagram.

Another student noted: 'Yeah that is a craft. Like baking a cake. I'd rather get some nice flowers in, or a nice cake stand, rather than just taking a picture of the cake. You need to make the whole picture look good.'

There are still plenty of references to more traditional genres of photography. For example, Figs 3.55-3.57 are holiday shots. Yet they are also clearly 'filtered' in the sense that, while a mass of such holiday photographs might have been posted on Facebook, only the more visually arresting images will qualify as suitable for posting on Instagram.

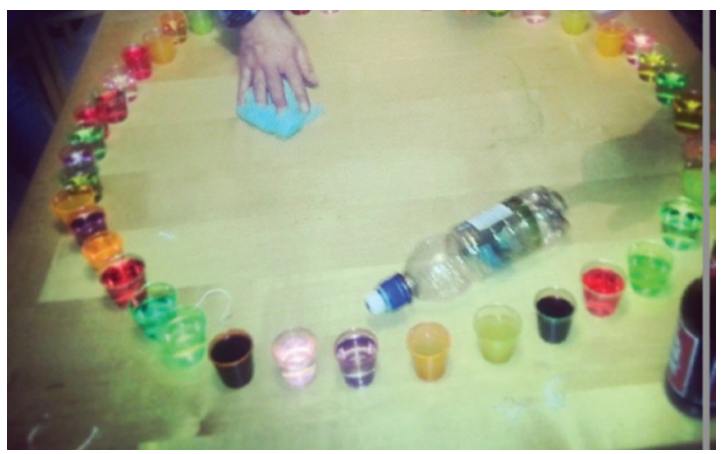

Fig. 3.55 Holiday photograph 


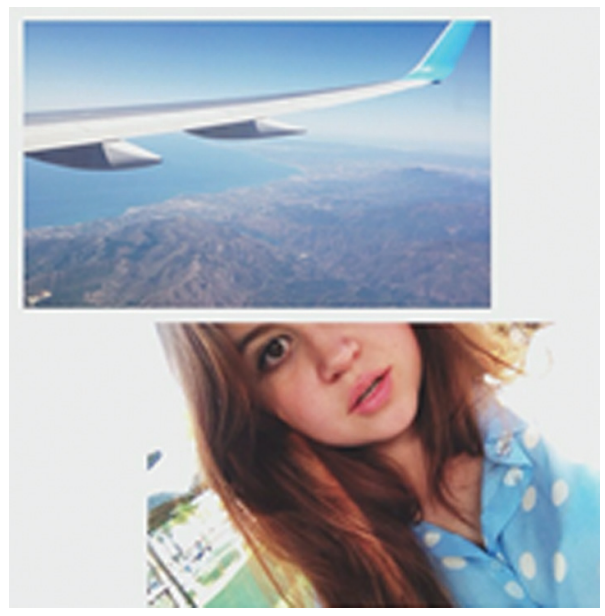

Fig. 3.56 Holiday photograph

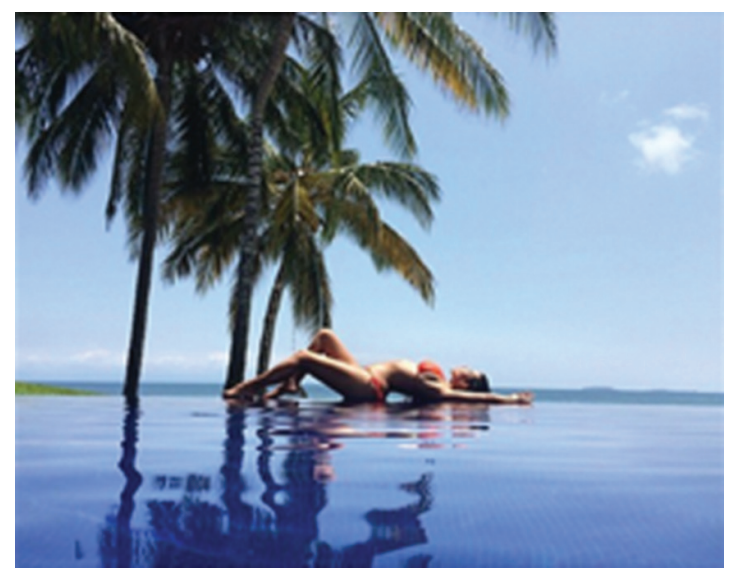

Fig. 3.57 Holiday photograph 
The same would be true of other common and traditional photographic genres such as birthdays (Fig. 3.58), rock concerts (Fig. 3.59) or weddings (Fig. 3.60).

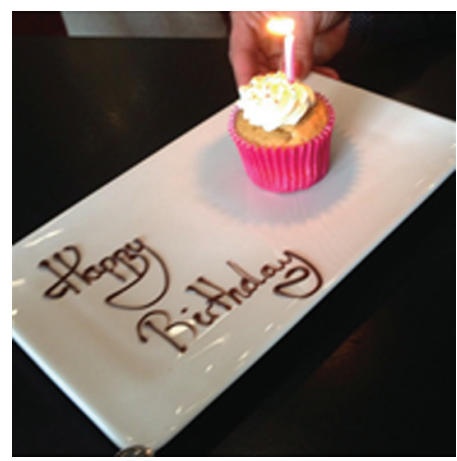

Fig. 3.58 Happy Birthday photograph

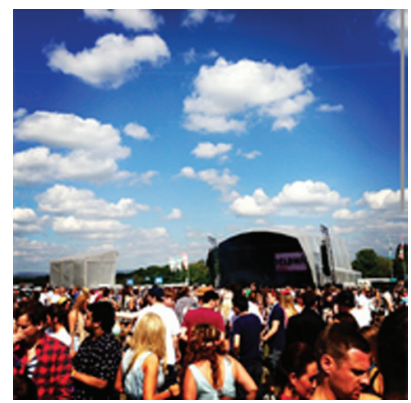

Fig. 3.59 Music festival photograph

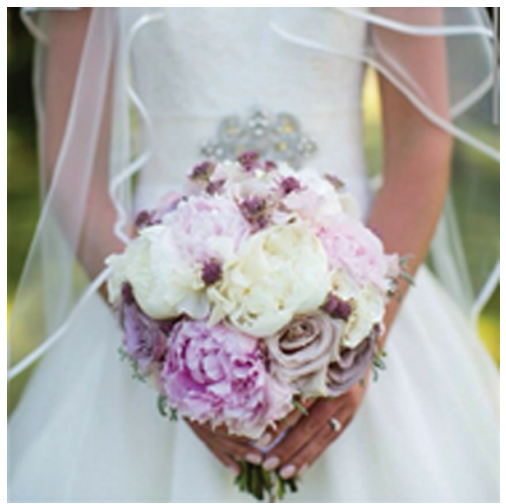

Fig. 3.60 Wedding photograph 
A third example reflects an ubiquitous subject of English photography - that of people's pets (Figs 3.61-3.63). ${ }^{6}$ This sometimes extends to other animals (Fig. 3.64).

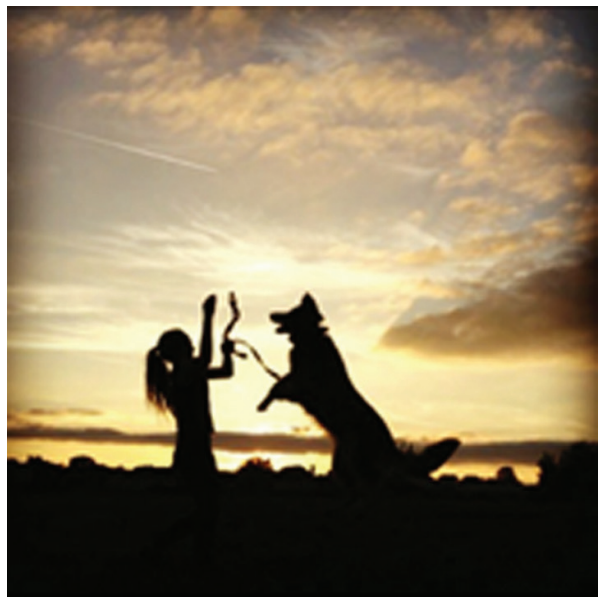

Fig. 3.61 Pet photograph

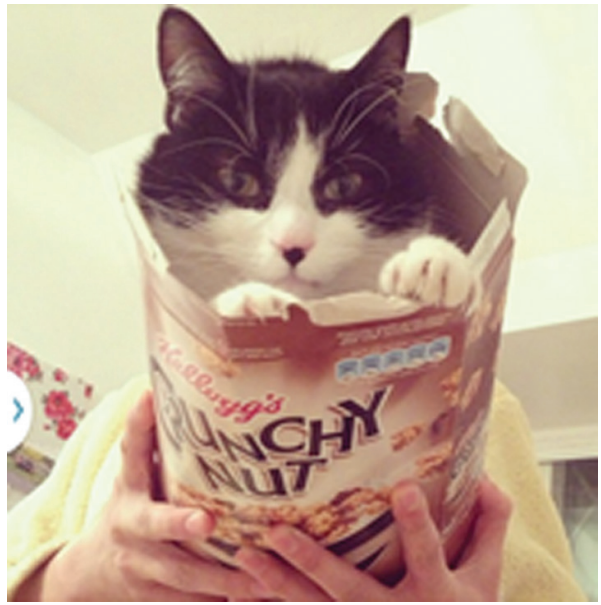

Fig. 3.62 Pet photograph 


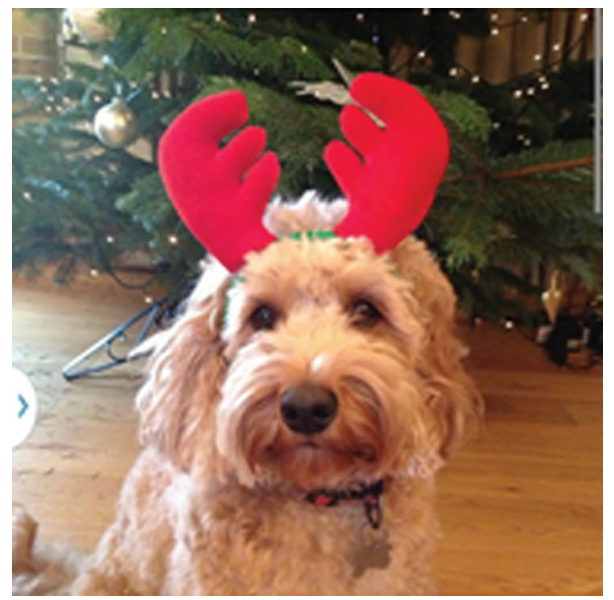

Fig. 3.63 Pet photograph

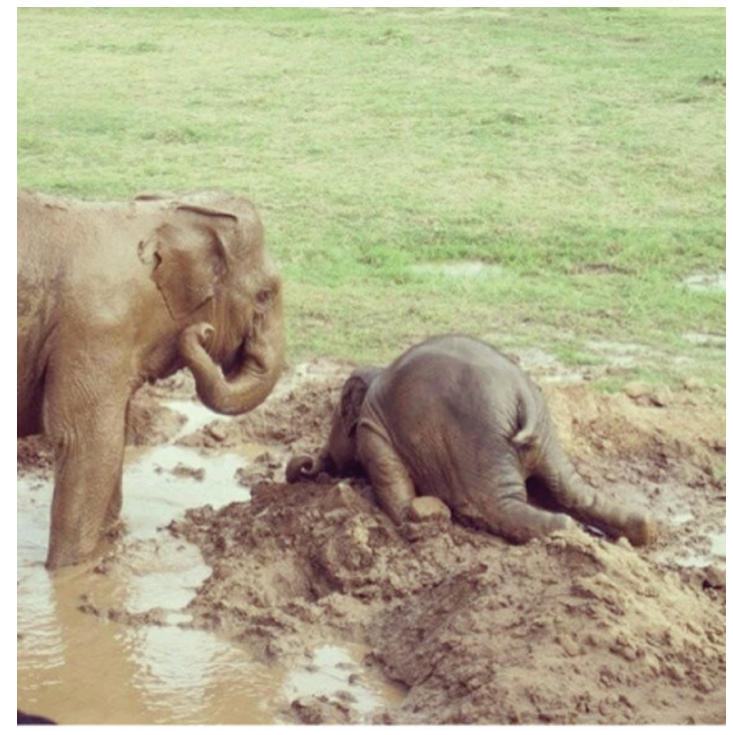

- 23 likes

Fig. 3.64 Animal photograph 
It is consistent with the aesthetics of Instagram that people will also take items such as accessories in their own right as an appropriate Instagram visual, rather than merely as something worn (Figs 3.65-3.66).

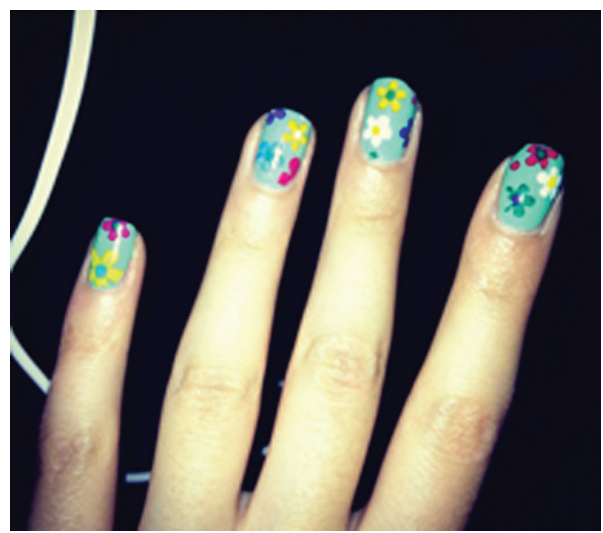

Fig. 3.65 Accessories

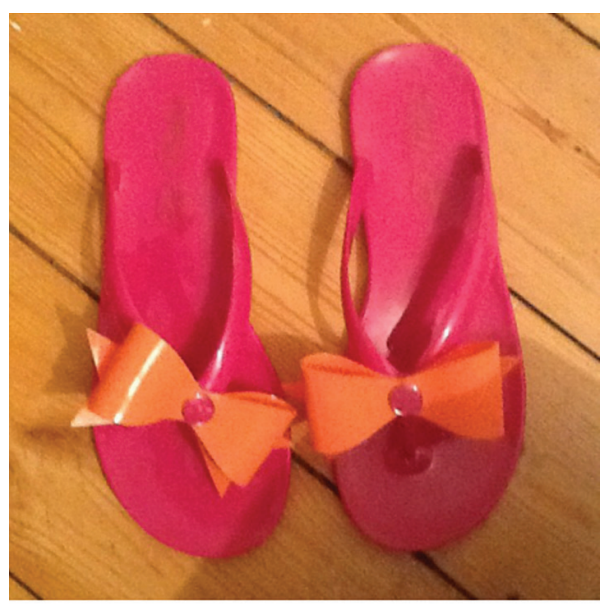

- 11 likes

Fig. 3.66 Shoes 
There are other genres which are largely absent from alternative platforms such as Facebook and Twitter, but which seem to be emerging on Instagram. Perhaps since these are all school pupils, or in some cases now university students, and many of them are quite academic, they respond to the visual possibilities of books and magazines (Figs 3.67-3.68).

Most of these images are crafted as photographs. However, there is a variable relationship between placing the emphasis on photography itself or using the image to share an appreciation of its subject - for instance one's pet or nail art. Some images though have clearly been taken a step further. These have been posted on Instagram entirely for aesthetic purposes, designed to show how stylish the photographer can be. The subject is merely there to be exploited by the craft. This was

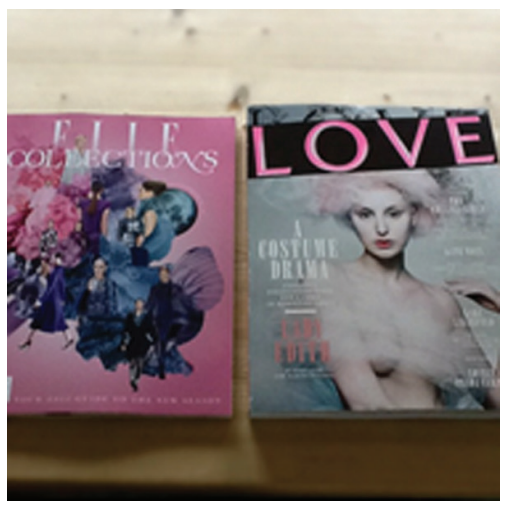

Fig. 3.67 Books and magazines

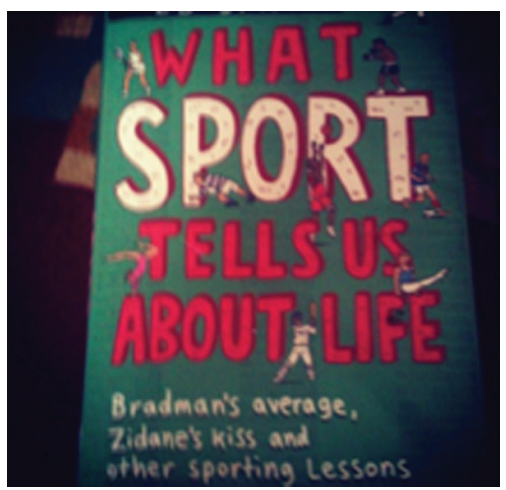

Fig. 3.68 Books and magazines 
noted as the third possibility in food photography. As the anthropologist Pierre Bourdieu pointed out in his work on popular taste, ${ }^{7}$ the highest level of cultural expertise is claimed by those whose photography or painting exploit objects without aesthetic significance in themselves, for example a cabbage or a floor. This avoids the possibility of aesthetic credit going to the subject of the photograph rather than the photographer. The most suitable topics are those generally disregarded, such as tins of Vaseline or even a patch of sunburn; it can also be something denigrated, for instance a Barbie doll (Figs 3.70, 3.71 and 3.72). All of these serve to demonstrate the cultural capital of the person posting. For the same reason these photographers may try to ensure that this claim and message get across through direct juxtaposition with a known style icon, for example i-D (Fig. 3.69).

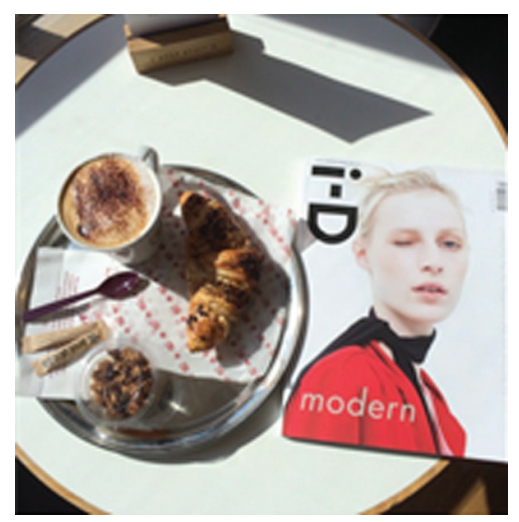

Fig. 3.69 Instagram as a photographic craft

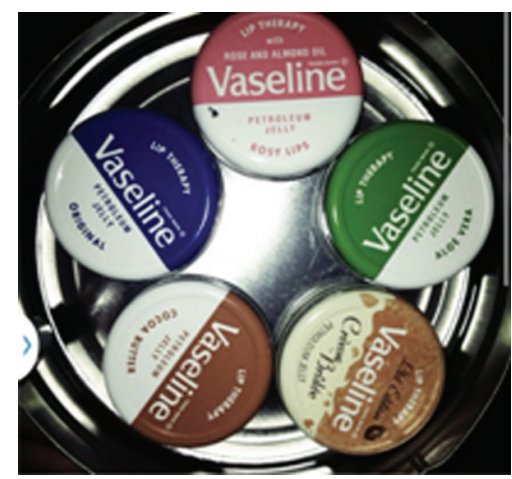

Fig. 3.70 Instagram as a photographic craft 


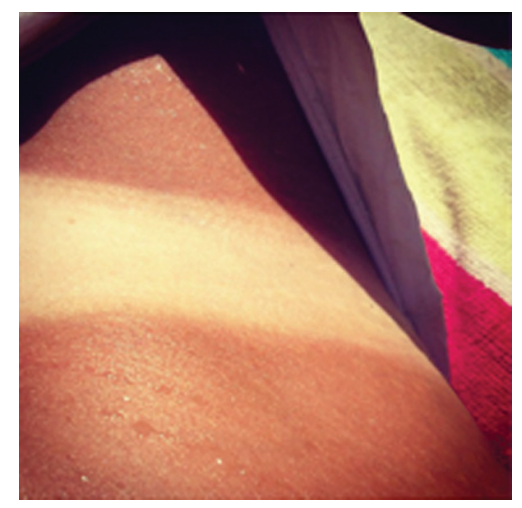

Fig. 3.71 Instagram as a photographic craft

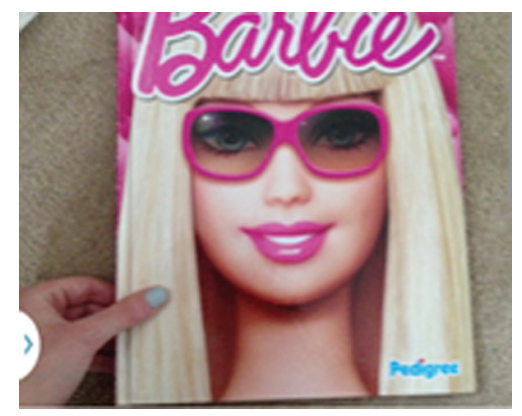

Fig. 3.72 Instagram as a photographic craft

All of these points are relevant to understanding the close connection between posting selfies and Instagram. Instagram is a femaledominated platform, and most selfies within this population are also female. Evidence is given in Visualising Facebook that the vast majority of selfies posted on Facebook by this population are actually 'groupies' that is, expressions of friendship and groups within which multiple people appear. By contrast those on Instagram are usually individuals. They are carefully crafted in two ways. Girls who are generally considered 'fit' express this mainly through looking glamorous and sexy: the enormous amount of time devoted to make-up, accessories and similar matters attests to the status of this activity as a craft. The photographic 
image is just the finishing touch to a long process of creating an ideal bodily aesthetic. In addition many of the selfies posted on Instagram clearly aim to extend that crafting beyond that of the posed subject to the way in which the image has been constructed and altered, thereby simultaneously demonstrating one's style and photographic ability (Figs 3.73-3.75).

Fig. 3.73 Selfie
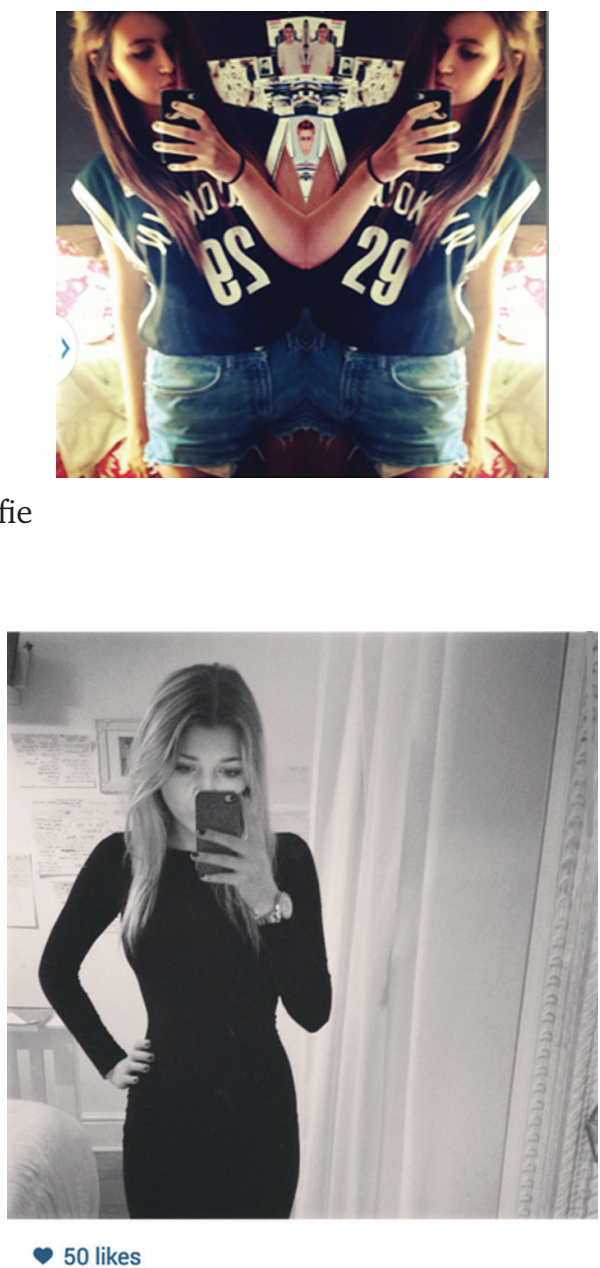

Fig. 3.74 Selfie 


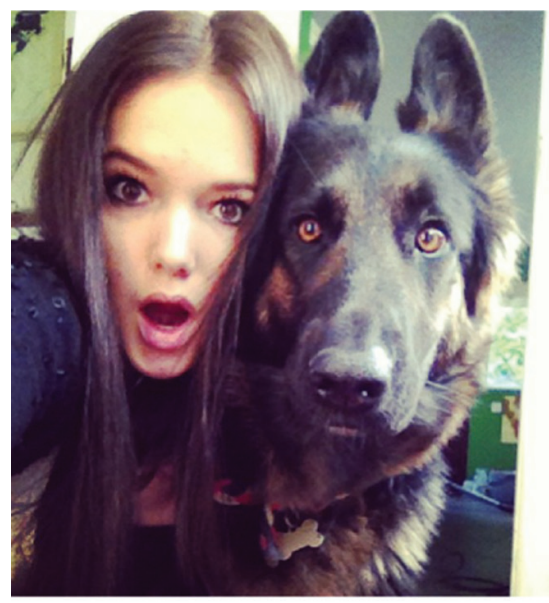

26 likes

Fig. 3.75 Selfie

The final caveat applied to Twitter works symmetrically for Instagram. There are a few people who post on Instagram much the same images as they would post on Twitter, including people at parties, banter and the other genres that were discussed as Twitter postings. In general males are more likely to do this, reflecting the general trend for males to identify more with Twitter and females with Instagram, but they are exceptional rather than typical.

\section{To understand the picture, look at the frame}

These young people now see Facebook as a site incorporating wider social connections, including their own families. As a result posting on Facebook has become far more circumspect. At the time of field work, by contrast, Twitter and Instagram were both directed to peers, since family were rarely present. Where the sites differ is that Twitter is directed inwardly to the relationships between those peers, mainly others in the class or school year. The visual images of Twitter are thus typically an aspect of banter, in which the most important component is humour. By contrast there is very little humour on Instagram. It is quite a serious platform and there is minimal banter, since the images purport to be posted for a different audience than those one already knows. The 
stranger is courted on Instagram for the authentic appreciation of one's craft, especially if they are from another country. In practice it is still mostly the user's peers that view Instagram posts, the same people as see his or her Twitter posts. If it is someone the user knows less well, this is most often because posting is also seen as a way of initiating contact across gender lines. Yet this does not matter because there remains a clear opposition between the idea of Twitter, directed inwardly to the group, and that of Instagram, directed outwardly to beyond the group.

A further piece of evidence for the changes taking place is the hashtag. This is generally associated with Twitter, where it originally developed as a common practice for sharing information. As Twitter is appropriated by this young group for banter, however, the use of hashtags has markedly declined since they are neither addressing nor attracting a wider audience. Hashtags are not that common on Instagram either, but a rather different use has been retained. Although designed to attract the notice of others, the hashtag doubles as a kind of commentary on what you have posted. For example a post of a car is followed by a string such as \#love \#need \#perfect \#dream \#Lamborghini, while the image of a child is followed by \#cute \#nephew \#familyiseverything. A certificate is embroidered with \#driving \#test \#so \#happy and a holiday snap embellished with \#Cornwall \#summer \#happy \#boyfriend \#smile. Some will hashtag every word they use. Girls also often include a flood of emoticons and emoji such as hearts and faces, but a duck or wine glass may be employed for much the same purpose.

The emerging distinction between males and females regarding their respective predilection for Twitter and Instagram may extend to other gendered associations. Twitter is a fast-paced, crowded, quarrelsome space of hyperactive banter, humour and sometimes nasty school playground stuff; by contrast Instagram seems a relatively quiet, contemplative, crafted place for aesthetic delight. Girls in particular recognise that Instagram allows them to escape the rather cold male space of Twitter - but Twitter is also the platform within which girls behave in the rather appalling and nasty ways to each other discussed in Chapter 5. So retreating to Instagram they appreciate:

the lack of sort of anti-social behaviour. It's just nice, Instagram, quite a relief from stuff like Facebook which is constantly people arguing, and Twitter which is just the same ... whereas Instagram is interesting, kind of, you can follow interesting people, might follow artists that I like and stuff like that. 
These gender differences can also play a role in cross-gender relationships. One young girl, clearly quite shy, acknowledged that she was using these visual images in the hope that they would attract the attention of boys, with whom she felt quite unable to initiate conversations directly. As a different informant put it:

If they want you to talk to them (boys), they'll go through some of your pictures, a way of showing you are interested without being over the top. Girls hate messaging boys first, they think, 'Oh I feel too keen, I'll just wait'. So rather than being too keen and saying hello first, they might just 'like' your photos.

Sadly the girls are likely to be disappointed, since the main Instagram images the boys respond to are the glamorous and sexy selfie shots, rather than those that are pretty and contemplative.

Many of the key genres of Facebook postings described in Visualising Facebook - for example endless shots from parties, the close association with drinking and the desire to look silly or, as with Snapchat, ugly - are largely missing from Instagram. Also absent, more surprisingly, are the prom shots from student graduation parties. The latter may be explained by the fact that the focus within Facebook is on friendship and people's social groups and social lives. Polymedia is the crucial perspective here; only in the light of knowing that Facebook covers this wider social field can we understand how Instagram is narrowed to a craft activity and Twitter refined and confined to the purpose of humorous banter. As polymedia it is as though we were dealing with the rapid evolution of a series of Darwin's finches. Each platform colonises an area of expression that complements the other and cedes them their own ecological zone.

In all these respects Instagram and Twitter seem not just different but almost diametrically opposed to each other as funny/serious, banter/craft and so on. Yet in other ways they appear more like two sides of the same coin. As noted earlier, Facebook in retrospect seems like the bridge between traditional photography and something else. There is now quite a bit written about the shift from analogue to digital photography, ${ }^{8}$ but in some ways the shift to social media has been even more radical. It is not simply the decline of the camera in favour of the camera phone - the implications are much wider than that. More generally social media photography has been a repudiation of all that we previously have assumed a photograph naturally is. 
The initial associations of the photograph historically are with memory and memorialisation because this was important at the time photography was invented. The other primary purpose (much commented upon in anthropology) is that of representation..$^{9}$ Over time, however, academics recognised that there was also a trend towards democratisation and the emergence of a mass form, ${ }^{10}$ leading in turn to the snapshot culture and finally to digital photography. Despite all these changes, van Dijck ${ }^{11}$ and others have argued that one could still relate digital photography to these traditional concerns with memory and representation. Yet by the time we reach social media such as Snapchat, this no longer seems viable. An image that self-destructs after a few seconds cannot be considered an aspect of memory, or even of representation. While Facebook still contains albums for looking back at photographs, these significantly do not exist on either Twitter or Instagram; here the emphasis is on transience.

If these images no longer correspond to that which academics have understood as the meaning and purpose of photography in the past, what have they become now? There are two main answers to this question. The first is given merely by situating them in this book about social media. The images are clearly an integral part of communication. The term Snapchat is a pretty concise and quite accurate label for that platform. This chapter is merely the most explicit example of a more general change - which is that, partly as a result of social media, communication today is increasingly a visual and not just a textual or an oral practice.

There is another aspect to this material that may have been comparatively neglected since it is not the one we actually see. In his study of photography Bourdieu ${ }^{12}$ not only examines the long-term shift towards a democratisation of photography; he also introduces the idea of studying photography as what social scientists call 'practice'. We have previously assumed that taking photographs is simply the technology required, and what we actually want are the images that result. What, however, if sometimes the images are really just there to legitimate the taking of the photographs? For example, in Visualising Facebook we argue that the party pictures these teenagers post on Facebook are sometimes so blurry and unfocused that the content is completely obscured. The reason they are posted is to justify the initial taking of photographs during the party itself. Taking a photograph has become rather like holding a drink - a key mode by which everyone acknowledges how much fun they are having. People during a party respond to the raised phone by demonstrating this experience to a camera. As a result, being photographed prompts 
them into having a more exciting time. The very act of taking pictures enhances the vitality of the party itself. In which case it does not really matter if most of the photographs are never posted, or if those that are prove to be of very poor quality.

In her work on the family photograph, Gillian Rose ${ }^{13}$ advocates this perspective of photography as practice. In other words, to understand what a photograph is we need to think about what the photograph is doing. In her case the main point of the family photograph is not really memorialisation nor perfecting an image; it is rather an exercise that plays a role in the creation and maintenance of the family as a unit. Rose's primary concern is therefore to examine how people display photographs, how they share them and the consumption of photography, because all of these can be seen as a means for maintaining and strengthening family relations.

Instagram does more than place a frame around things that have been crafted. It also puts 'frames' around everyday experience. In other words, it may be that the image that is posted on Instagram is largely a legitimation for the far more considerable time some of these young people spend looking at the world around them within the frame of 'what would make a good photograph for Instagram'. They themselves note how they look at landscapes, food and objects differently and in a more focused manner, simply because they now have Instagram in mind. So the significance of Instagram may be more how it impacts upon users' engagement with the world around them, as opposed to merely the images that it creates.

These teenagers are easily bored. The world around them, in which almost everything strives to be special, can thereby become quickly bland and undifferentiated. When everything is trying to be special, paradoxically nothing ever is. Having the task of making something special through selecting it as a photograph, therefore, may become a useful means of making the world less boring and being alive to the things around one. In England there is also a premium on personal creativity and originality that makes this more of a craft. One school pupil noted: 'Yeah. Before if I went out, I wouldn't pay attention, but now I see things and think, "Oh that would make a good photo". Think more about it now (more) than I used to. Use filters pretty much for all of them. I do like it. I find it interesting, all the different effects.' Another informant, now at university, and probably the most incessant user of Instagram within this ethnography, admitted: 'If I'm out for a picnic with my fiancé, I'll say, "Wait, I want to get a photo first". It's always about photos. Sometimes he gets a bit annoyed about it. I'm always desperate 
to capture the moment and still obviously enjoy it, but sometimes I'm almost living through the camera.'

Her site is replete with images of her dog, food and interiors. This use of the image to frame the way people look at the world around them produces some genres that seem to speak directly to this task. It is very evident in these genres of flowers and landscapes, which include not only nature but objects or scenes that users consider have the potential to be further aestheticised by this act of framing within Instagram (Figs 3.76-3.79).

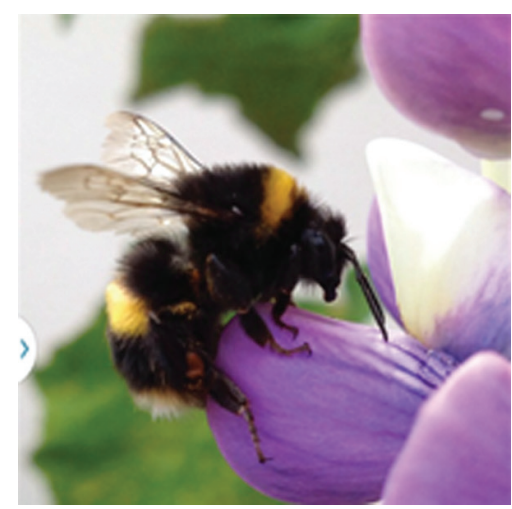

Fig. 3.76 Instagram image

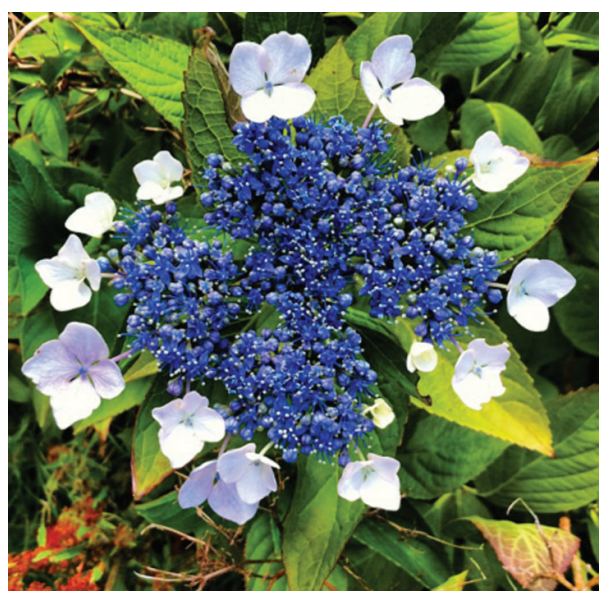

Fig. 3.77 Instagram image 


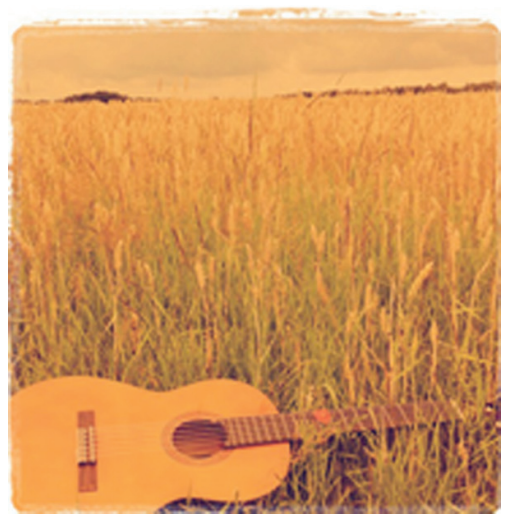

Fig. 3.78 Instagram image

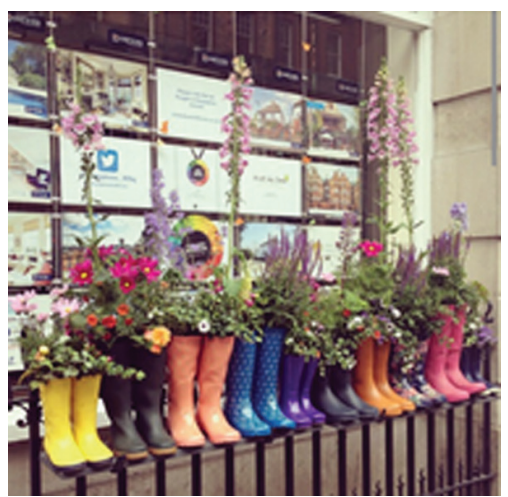

Fig. 3.79 Instagram image

If we regard Instagram as a means for framing experience, we must also realise that for at least some users Twitter shifts from being the diametric opposite of Instagram to becoming an alternative version of the same thing. Some use Twitter only as a constant form of banter, almost a stream of consciousness, but others seem very concerned with how 'clever' or 'amusing' Twitter represents them as being. These people are constantly trying to think up, or come across something, that will enhance their reputation. They are determined to compose the tweet that others really want to 'favourite' or re-tweet 
because it is funnier or cleverer than most. While some users (mainly female) develop a challenge that makes the day more interesting, based on trying to create a really stylish Instagram image, others (mainly male) have an alternative project - to make their day more interesting by coming up with the cleverest or funniest tweet. Both can thus turn their life into a mini project, which literally, in the case of Instagram, gives it focus. This is by no means a daily practice. At least for Instagram many of those we follow only post a photograph every two weeks. Yet in discussion it is clear that they take many more photographs than they actually post, so this framing can be pretty constant.

This chapter began by pointing out that we increasingly refer to visual posting on social media, but have neglected actually to show them and to concentrate on what we then see. It has concluded with the exact opposite point, that when we examine these visual postings there is a danger that we imagine that they are it: the totality of what we study. Through analysis and conversation with those involved we can now see that the visual images are just as important for understanding people's experience of the world around them. This is something we do not see directly, and for which posting images is often a legitimation. Yet even though we can never perceive this 'experiencing the world', it may be among the most important consequences of social media to date. 


\section{4 \\ Social media and social relationships}

\section{Before Facebook we all knew what a friend was. Really?}

I still have in my possession the diaries I kept for three years of my school days when aged 14 to 16. It turns out that I kept a weekly friends list. I would carefully rank my friends, punishing them for slights, rewarding them for shared confidences, all in secret. ${ }^{1}$ We did not have 'besties' or 'BFF' (Best Friends Forever), but there were precursors.

For adults, friends are not as often ranked as categorised. ${ }^{2}$ Typically you consider as one group those people you speak to at the school gates about your children; another group may be those from whom you feel you can request help when you have run out of milk and the shops are shut. There are those people with whom you like to gossip, and those with whom you enjoy sharing memories of your own schooldays. There are also the friends you accrued because they were friends with your partner, dating from the time before you met. There are those who you trust a bit and those you trust a lot. Friends are also categorised by context, as school friends, work friends, Saturday night out friends, football or hobby friends. There are also those who simply do not have friends. There are people who live in a village like The Glades, not a city, and yet turn out to be lonely and isolated - in essence friendless.

In earlier times and in most anthropology the central idiom of relationships was family. The study of friendship often developed around that idiom, so anthropologists talked about fictive kin. Some readers may recall that as a child they were told to call everyone around them aunt or uncle, even though they were the friends of parents rather than actual relatives. Today the ethnographic evidence from The Glades suggests that this may be going into reverse. Instead of modelling friendship on 
kinship, we model kinship on friendship. What a mother really wants to be is her daughter's best friend. There are cousins who are close friends and cousins who are merely cousins. So friendship has increasingly become the core idiom of relationships and family is now beholden to it. In that sense the experience of family becoming friends on Facebook reflects a wider and deeper trend in English relationships.

It seems to be so common as to almost have become a rule that the invention of any new media will have one rather unfortunate consequence. The discussion of the relationship that people can now have online leads them to romanticise and simplify their previous experience of offline relationships. As Facebook spread it was met by a noisy chorus of claims that people on Facebook could not tell the difference between a Facebook friend and a 'real' friend, an accusation that still comes up frequently in The Glades. Yet, as we have just seen, this bland category of 'real' friend is a considerable oversimplification of the many different types of prior offline friendships. Similarly in the early years of the internet, when people could not decide if the various groups being created online represented 'real' communities, we were told that, by contrast, we had all been living in real 'communities' offline, which was not, of course, the case. With each new online development, people still tend to simplify and romanticise its offline precedent - a process rather frustrating for anthropology, which has spent a century trying to show how complex offline relationships such as friendship and community have always been.

Our starting point should be to refute these oversimplifications. Instead we acknowledge that we were previously just as concerned, sometimes obsessively concerned, with the issue of whether a friend was a 'real' friend, and we had strong feelings about what you could or could not trust him or her to do. Would the friend be 'there' for you in an emergency, and could you reveal something wicked you had done because you needed to share it? Such criteria are constantly applied, not just to friends, but also to relatives including siblings - the stuff of many novels and television series. Within the ethnography a good example of the complexity and diversity of offline friendship was found in our study of 'toddler groups'.

Perhaps the key moment in the formation of friendships in The Glades comes with giving birth. New friendships begin with antenatal classes and are strengthened by subsequent baby and toddler groups often essential contacts for new mothers taking time off work to be full-time parents. Traditionally women in this situation relied more on family and varied connections with other women, who usually had 
children of different ages. Today most people are placed into this new version of the anthropological concept of an age-based cohort, where mothers are mainly involved with other mothers who have infants of much the same age. This leads to increased and informed support, but can also foster intense and direct comparison with what other babies or infants are doing at any given moment compared to one's own.

This is the context within which many different levels of friendship may then develop. A mother attending a toddler group may bond with a group of women towards whom she immediately gravitated, potentially becoming friends for life. There may also have been a second level of mothers at the toddler group, with whom she might chat but in a more restrained fashion.

However, there is also much exclusion at such groups. When a mother walks in and sees a group who clearly already know each other very well, it seems impossible to break into that circle and feel welcome - she is already an outsider. So even in this setting, probably more accessible than most life experiences, friendship could still be anxious, difficult and ranked. Sheera seemed to have her revelation about her toddler group friendships through the act of talking with us, a process that tended to make things explicit. She was highly sociable and went to several toddler groups, having in particular a core group of 13 other mothers as friends. Their children went to each other's parties and they sometimes went out as a group, for example to a restaurant at Christmas. The mothers supported each other and provided help if emergency childcare was needed. They understood that when people posted pictures of their kids on Facebook they needed to see 'likes', even more so than when they posted about themselves. Yet what Sheera realised in explaining all this to us was that, in all that time, they had only ever talked about the children.

This was incessant. If the sun was out the mothers would text each other and many would turn up at the park for the children to play together and for the adults to talk - about their children. If it was raining they needed to get the children together at a house to play or they would be bored - leaving the adults to talk about the children. Sheera thus knew all about these other children - but she realised on reflection that she knew almost nothing else about the mothers. Unlike her previous friendships with other women they never talked about relationships, and certainly never discussed 'the bedroom department'. She gives an example of a conversation: 'And I was like - how was your holiday? She was like "yeah alright". I was like "what did you do?" "Oh, just the same old." And it's like I'm not asking for blood here. What did you get up to, 
what were the hotels like, what did you eat? And she's just like "Oh yeah, really good, I'd recommend you to go." And it's like "OK, what's next?" But you throw us together and we will happily talk about kids and playgroups, common things, softplay areas, what we can do together. But in the nights out we'll just talk about kids really. It is really, really weird.'

It would be quite surprising if such demarcations and the variegated nature of friendship offline did not also emerge after a while on social media. In this instance it was only because we were having a discussion focusing upon these interactions that Sheera came to see how strange they had been. But in an analogous manner it may be only when Facebook arrives and makes friendship so much more visible and in some ways explicit that we come to question what we mean by friendship and how it compares to the expectations of kinship as a relationship. Facebook serves to aggregate and expose the often quite haphazard way in which friendships have developed in the past. On the Facebook page there is some family, the cousins that are friends and not just cousins, but these are mixed with the only two people you are still in touch with from school, plus a rather more varied group of university friends, some of whom you would rather now discard. There are the work colleagues who helped you survive an oppressive employer alongside the people you felt especially enthusiastic about because they seemed to acknowledge you when you moved into a new neighbourhood. There are also often idiosyncratic alignments. A woman of 82 mainly has family on Facebook, but when she was younger her family hosted a Pakistani man whom she describes as very spiritual - someone from whom she has learned a good deal. He now lives in Pakistan, and she has found Facebook a good way to renew and maintain that contact. More commonly this applies to people encountered on holidays or when working abroad. Facebook exposes friendship as a bit of a mash-up.

In trying to characterise the way relationships operate in Melanesia (the region that includes New Guinea), the anthropologist Marilyn Strathern $^{3}$ focuses on the events and actions that make relationships 'visible' to people. A core example is the way in which the birth of a child makes manifest the relationship between two other people as parents. She argues that among the people she studied it is this visibility that makes the relationship. In that regard social media, such as Facebook, has the effect of making us a bit more Melanesian, in that visibility becomes also for us a more active component in creating and maintaining relationships. Facebook quite literally makes relationships more visible - which may also make us both more conscious and more selfconscious about our relationships because other people can see them. 
For traditionally taciturn and private English people ${ }^{4}$ this visibility can become a source of embarrassment and anxiety. Constance realised that she had just allowed her Facebook to grow 'organically' when at school. When she left home at 18 and came to The Glades, however, there was no longer that natural flow between online- and offline worlds. She thus became far more aware of who was present on Facebook. This became still more acute when her parents divorced after one of them had an affair. Suddenly there was so much about what one ex-partner might come across with respect to a new partner and so forth that Facebook shifted from being almost entirely thoughtless as a process to an arena of very careful consideration and manipulation. This was because for Constance the continued interaction with certain relatives had now become 'inappropriate' according to other relatives, who thought she should no longer be friends with them.

The brief history of the internet is already long enough for there to have been several distinct phases to this problem. Before the development of social media, the internet had been renowned as a place where people could create new communities around specific interests and hobbies, ranging from fandom of celebrities to extreme politics. These were often anonymous and revolved only around that particular interest. From this perspective social media is not a continuation of the previous internet, but almost its opposite. Where the earlier internet fostered discrete interest groups, Facebook has mixed together groups that would previously have been separated out into family, friends, work colleagues, shared hobbyists and so on. Where the earlier internet created concerns about the consequences of anonymity, we now have the opposite problem of worrying about the lack of privacy.

One solution to this problem has come from the findings of Chapter 2. The development of polymedia and a plethora of different platforms can be exploited to bring some order back to this confused space, making this a third phase within such a history. The internet created dispersed interest groups, while Facebook created a mash-up of everyone one knew. Now social media can be used to organise one's relationships. Within the more formal interviews we often asked people about their use of each media sequentially, and it became quite natural for people to talk about their 'email friends' as opposed to 'phone call friends'. Each group were characterised by what had become their 'natural' mode of communication. This was especially clear for WhatsApp. Individuals were now often part of a family WhatsApp group, a singlesex football or gossip-focused group, and a mixed group who plan their Saturday nights together. One informant discussed the development of 
a WhatsApp group of new mothers on a new housing estate explicitly called 'Wine Women and WhatsApp'; 5 they needed this group to organise the occasions when they would share their experiences and enjoy some wine. Facebook could then shift from being the place where groups are mixed together to a place where one could park some relationships and move others elsewhere.

Katie used these developments to signal her own growing maturity. Previously she had accumulated 2,000 friends on Facebook, which she attributes to her experience of partying in London. Part of having a good night out was meeting some new people and getting on well enough that one decided to become Facebook friends. There was no particular thought to any consequence, to actually looking at them on Facebook: it was the friending that mattered. Rather than de-friending them or re-ordering things, however, she just left her Facebook in abeyance; when she moved on from her London party days she migrated her active social media life to WhatsApp groups. The more mature Katie was defined as someone who now cared about friends, not merely the activity of friending.

In Chapter 2 polymedia was introduced as the complementary relationship between different platforms. However, we can now also see that this can be mapped onto a gradation of different classes of friendship. This was especially clear in the study of the school pupils as one came to look at exactly who was being connected by each of the main social media they used. At the time of the ethnography it was very clear that the most intimate social media platform, despite - or perhaps because of - the fact that it is derided by others, was Snapchat. Most pupils have only around ten people with whom they regularly share their Snapchat images. This is because a primary function of Snapchat is the creation and maintenance of trust as represented by one of its most common genres, the uglies. ${ }^{6}$ Sharing an image where you look pretty awful is a test of whether people keep this to themselves. In practice this is more nuanced. It is almost expected that some uglies will be screen captured and shared among other friends. This is OK as long as it is fun. Yet pupils are also well aware that in the first phase of Snapchat very private intimate shots were inappropriately shared, revealing just how much is potentially at stake in this arena of trust and friendship. By the age of 16 they have a very well-considered sense of trust and betrayal, already honed over many years. Snapchat thus works well for the close bonding of trusted friends.

One level up from Snapchat are WhatsApp groups, which as previously noted mostly include both single- and mixed-sex groups. There 
were similar groups and interplay between more or less private conversations on BBM. The next level up was Twitter. Although hardly any school pupils set their Twitter accounts to private, in effect Twitter was more private than, for example, Facebook because it was rare for adults and others to follow their children on Twitter.7 Twitter had thus become the primary site for semi-public group banter and generally being silly. Facebook in turn had shifted from peer group banter to become the place where one could safely incorporate other groups, such as family and work friends, as young people moved into part-time and then fulltime jobs. Finally there were platforms where people not only did not mind, but actually wanted strangers to be present - mainly Instagram, but also, for some, Tumblr. This was because it was more impressive to have a perfect stranger 'like' and admire the aesthetics of one's posting or collections. Taken as a whole, therefore, we can visualise polymedia as a centripetal force spinning relationships into a series of concentric levels of greater or lesser intimacy; each orbiting around a platform appropriate to that distance. This also provides a clear illustration of the concept of scalable sociality in a series that goes from most to least private and from small to larger groups.

Scalable sociality does not always have to map onto platforms. boyd has pointed out that on social media young people find a situation of context collapse, as audiences they would once have kept apart share the same social media space. Yet teenagers have many ways of coding their messages online, such that only certain groups understand what is being said and others are excluded. As a result, even though it appears that everyone is equally on the same platform, users are in effect able also to create a form of scalable sociality, with different levels of privacy and differentiated groups. ${ }^{8}$

As we move from the school pupils to adults, Facebook is of particular interest because it has now become increasingly important to older people. It is an irony that Facebook was invented by male geeks and originally spread through them. Because when we use the term 'social media', then at least for the English the people who are seen as the natural social mediators are in fact older women - who have traditionally, among other domestic chores, assumed prime responsibility for maintaining family and friendship communications. The long-term future of Facebook is likely to be within this traditional frame of social mediators as a platform dominated by older females.

For example, Jenny has three children aged 26, 31 and 34 who all live in the north of England. She sees postings from them nearly every day: 'S. . . was posting something this morning, saw her post a couple 
of photos. That's my middle daughter K. .., she had challenged me for a movie pop quiz or something.' Jenny notes that she will post on Facebook if her partner (whom she met through Friends Reunited) has done something interesting with the garden. He will also tag his daughter, and 'if we take a picture of the dog we tag her'.

It tends to replace the telephone to a large extent doesn't it, I think. I mean my father when he was alive and he went onto Facebook. He was logged on at 4 p.m. in the afternoon. He was nearly 95 when he passed away. And that was just again a means to keep in communication. He was very with it, as you can probably gather, had his webcam up there as well. He could see the posts of the garden and so on.

Facebook also works well for Jenny because of all the step-dads and step-mums and ex-partners involved. Everyone is in touch, but not too much and they are not too close. 'It's saved me a fortune on flippin' phone calls.' The family is core, but actually Jenny has over 2,000 friends on Facebook: 'most of them I know quite well. They are friends or family. If I put up something, someone might be interested in this, I'll put it up there.' They belong to a gardening group and her partner spends quite a bit of time advising people in a 'hip replacement group', reassuring them on the basis of his experience of having had this operation. Jenny is also trying to get the local retirement home to pay more attention to the internet. Her activities, then, give an example of social media being employed by some very social mediators.

\section{Englishness and the 'Goldilocks Strategy'}

The penny did not really drop until I was writing this chapter and started to realise that, given that this is the English who we are talking about, the proper starting point might be to realise that social media was always going to be as important for keeping people at a distance as it was for coming closer to them. At which point it seemed that Goldilocks, who rejects both the 'too hot' and the 'too cold' porridge in favour of the in-between, 'just right' bowl, in effect represents a perfect English fairy story. For most people in The Glades life is all about avoiding things that are too hot or too cold. What they want are 'nice' relationships. To people from other lands the English nice might seem a rather tepid or a lukewarm version of warm. Social media thus emerges as an ideal way 
of gauging the precise temperature at which English people like to keep their relationships. In fact the word nice as the most common English expression for this balance comes up frequently in discussion:

That's it. A lot of people I have on there, it's really nice to be in touch with, but I don't necessarily want to meet up with them again. There's some I'd like to meet up with again, hope I will stay friends from school, which, again we don't message each other, but we'll comment on the same things about school. It would be nice to see them, nice to see what they are doing. If I bumped into them it would be lovely, but I'd never arrange to meet them. It's nice. They're people that were a big part of my life at some point. But don't have to be a big part of my life now. And like I say, you only share as much as you want to share, and they share as much as they want to share.

This is the 'Goldilocks Strategy' on sociality in action. Social media both keeps people in contact and keeps them at a distance, which is nice.

This is harder for the school pupils, whose relations in any case lurch between someone being on one day best-friends-forever and next day worst-enemies-for-life. Yet Twitter can provide a way to deal with the people in class you dislike but still really want to know what they are doing, while bitchy people are indeed quite entertaining. For example:

Yeah. I guess people that are interesting to like. My friend I mentioned Tracy, ideally I wouldn't follow her on Twitter. She does annoy me, but it's really useful to know what she's going on about all the time. It's quite amusing to us. All I'd do is look at her tweets, I guess like laugh or think 'why is she saying this?' So at the moment a group of my friends are going to Bristol with Tracy who they used to be friends with her, but now they're not friends with her any more. She's just a really horrible person basically. Like she makes up stuff all the time, says she doesn't like any of us. Accused us of bullying her and took us to the head of year ... And when we don't talk to her, that's not really bullying. So we kind of, we put up with her, she sits with us and we'll be polite with her but not particularly friendly with her. So she's tweeting all the time how she's so excited, really looking forward to it, can't wait to go. But behind the scenes she texts my friends being like 'Oh you're going to ruin my holiday, I'm dreading going, we're just going to argue.' Knowing her Twitter is quite useful to think - well hang on, 
she's saying all this. Knowing that, I'd be looking at her Twitter all the time.

After a few years of this kind of intense reflection on one's precise relationships, it is perhaps not surprising that people end up with an aspiration for things to be merely 'nice'. A person who uses that word a great deal is Lucy. Although she is not yet 18 it is clear how far she has moved from this earlier teenage phase. She is very clear that 'nice' is about how social media helped her to achieve what she sees as a decent balance between being connected and being autonomous. This applies both to major and minor relationships. The starting point is her father; he is separated from her mother and she only sees him on alternate weekends. However, he has become quite a presence on her Facebook, 'liking' almost all her posts. She is well aware that he could become too obtrusive, for example in trying to friend her friends, which would cause her a problem both with him and Facebook. As things stand, though, her silly banter is now on Twitter, so she regards it as 'sweet' and appropriate for an absent parent to demonstrate closeness in absentia through Facebook. The platform provides them with a more constant communication than just the bi-weekly visit.

This is just one example of what is 'nice' about Facebook for Lucy. Without it she would have had virtually no communication with her aunt, uncle and their children who live in France, which would have been a pity. When her sister went to university they needed to renegotiate their relationship. Lucy is pleased to know what is going on with her sister in some detail, not least because it gives her some guidance for when it will be her turn to go to university. However, she does not want to be seen as too interested or interfering - so passive observation through Facebook, without ever 'liking' or responding to her sister's postings, seems about right. It's also 'nice' when you get things right in any given act of communication, for example working out how to Skype a toddler nephew aged two and a half, who wants to tell you what he has been doing - although after too long this can get a bit tedious and he gets rather overwhelmed. Half an hour of this, however, is described by Lucy as 'nice'.

Tumblr is in the same sense a 'nice' platform, used by many young people precisely because it does not normally mean active friendship between people even if they are interested in each other's blogs. One girl thinks that it is a bit too distant, so actually 'You can have conversations. There is a little message that most people don't use, but it's nice when you find someone who's got similar interests, that maybe you've 
met once at a party, that you can follow them and you can find out that they've got similar interests, even if they live in Scotland'. Tumblr is also nice for getting to know boys who live abroad, enabling the relationship to be kept at a distance, without awkwardness and ambiguity.

This desire to find a niche that is neither too hot nor too cold seems to apply to all ages, partly because it is just as relevant to family relationships as it is to friendship. An older woman notes:

I've got a couple of cousins, one is in Wales, one is in Blackpool. They have just recently come back into my life 'cos my mum died and they came to the funeral. And we just keep in touch 'cos it's just so easy to put something on Facebook. But I probably wouldn't pick up the phone and talk to them, probably haven't got that much in common to sit and talk for half an hour. But a comment on their Facebook or a text is so much easier. I can now see her daughter, her daughter's children and her other daughter, she's got pictures of my family. We write comments occasionally to each other on Facebook. But I don't think I'd pick up the phone and talk to her. I think as you get older you have less and less family and you grab hold to what you have got. 'Cos she hasn't got parents. Got one brother. And I'm her only cousin. We've all of a sudden, she's got like a friend.

Here again we can see that keeping at a distance can also mean allowing someone to be closer than they were. The balance is not necessarily about being unfriendly: it is rather about being appropriately friendly and, in a very English manner, politely friendly. For English people the best thing social media can do is to help resolve situations that otherwise could be intensely embarrassing, precisely because it is unclear as to just how close or distant it is appropriate to be. Several people noted social media as incredibly helpful in dealing with death for just that reason. A school pupil explained that when recently the mother of his friend died, many people responded on Facebook. These were people who would not have wanted or indeed expected to be part of the formal proceedings of funerals and wakes, but who might feel uncertain what to say in an informal playground setting. In this situation Facebook seemed to provide the right and appropriate distance between the formal and informal that worked well. A similar example had occurred some years earlier in the extremely upsetting circumstance of a pupil at school who was killed. The school ended up encouraging other pupils to see Facebook as the right place to post comments and condolences. It 
was not too obtrusive, but people could make their feelings public and acknowledged - something the school recognised they needed to do.

For young adults the most excruciating moment of embarrassment is often the initiating of a cross-gender relationship, because they have an acute fear of being the person who makes the advance and then ends up being rejected, with all the subsequent damage to their self-esteem. Such experiences then make it difficult for them to repeat the same positive action on the next occasion. This is precisely why Tinder seems to be such a success. Tinder is a 'dating app', but more precisely it is a means to initiate cross-gender conversation - one that does not involve getting so drunk that you feel brave enough to make a move on someone, but in a condition which may lead to irresponsible consequences.

Instead people suggested that Tinder keeps this initial advance light and fun. Tinder consists basically of a few images which can give another person an idea of whether or not they want to make contact. Online Wikihow ${ }^{9}$ offers the following advice:

Avoid pictures of you with a person of the opposite sex, as this can give a bad impression to people looking at your profile. Try to have at least a few pictures of you, preferably from different angles. Use pictures to show off your interests, such as a hiking photo or a picture of you at a beach. A picture of you with a dog may prove to be very helpful, especially if the dog is cute! Smile and act natural!

I have no evidence for this paragraph, but on a speculative basis it appears that much of Tinder may not be interactive. These profiles are simply enough to create an imagined encounter. It allows one to spend time wondering what you might have said to that person, or what sex with them might have been like, which is how much of young people's time is spent in any case. What people did say was simply that Tinder makes things easier. For many Tinder is basically a game. Because it is a game, however, it cuts through the razor wire, the barrier to initial contact. As a result it is very possible that Tinder, along with its various rivals and clones, are creating many new and successful relationships. People claimed that already they knew of cases where this led to marriage and other relationships with depth - even if one route towards those goals may remain casual sex initiated by the Tinder encounter, which is why the site is also considered sleazy. When, however, the main English alternative is drunkenness leading to casual sex as a mode of initial encounter, women in particular may see a good deal of merit in this method of overcoming embarrassment. 
As people get older social media fits within the more general English sensibility of relationships kept close enough and distant enough. A somewhat unusual but perhaps instructive case concerned a whole section of road in Highglade. It started as a quite familiar story. When the residents there had young children, they were more in and out of each other's homes. Later on much of the talk and gossip was conducted, literally, over the garden fence. Now people are older they are less bothered about meeting face to face, appearing instead to have found comfort in Facebook - rather as one might find comfort in an old armchair. Peggy's next-door neighbour is not too well, for example, so it is easier to communicate through Facebook about some weeds that seem to be coming through into her garden, or to have an online chat about a car parked outside the day before which neither of them recognised. In any case since her neighbour does night work they would have difficulty in communicating directly, so Facebook seems ideal as a replacement. Currently there are eight people along Peggy's street with whom she communicates in this way. She notes:

I think Facebook's took over everything now, that's taken over more than the phone. People used to use the house phone. I don't use the phone. I'm more chatty on Facebook ... I tap it in to him, he might not answer till the next morning or whatever and he'll come back and say 'Oh I was working', I mean I know he works, it's not a problem, but sometimes he'll say to me I've got a parcel, but instead of coming round to tell me, he'll tap me and ask me to take it. Little things like that.

She looks at Facebook before work. It is the first thing she looks at when at work and is a key part of her evening. 'I think it's good 'cos you'll tap in to all your friends and you'll be surprised how many friends have come out of the woodwork.'

As a string of neighbours they note who is doing what for the village carnival or who is playing in the local five-a-side football. At the same time Peggy is corresponding with people from her school with whom she had lost touch. Yet it is hugely important that Facebook can keep people at a distance. For example, when her husband was dying 'We had neighbours in, a young couple across the road would come in. They were religious. They were trying to pressurise me and I don't want that'. After he died there were plenty of visitors and condolences immediately after her bereavement, but all these seemed to dry up when really she still needed them. Peggy thus found sharing on Facebook with 
others discussing their experience of bereavement was quite helpful. Living alone, she can watch television for entertainment, but finds she gets itchy fingers and wants to 'tap' away on Facebook. She is careful to explain that she is not addicted to Facebook, but she does wonder what the kids have been doing or if there is any news from her sister. She likes the fact that her brother scans and posts pictures he had found which were kept by their mother, enabling all the family to post about how awful everyone looked. She sees the postings of both her sons, and is not bothered if they are a bit daft on occasion. Knowing what her son is up to enables Peggy to predict when he is likely to come over with a bag of dirty washing, on his way to his girlfriend. Again she does not mind too much. Sometimes she goes a bit further. In fact she quite surprised herself when she posted asking if anyone knew how to put up a trellis for her garden - after all, there is no way she would have gone outside on the street and asked a stranger or even a neighbour that question. The posting brought results, and now a friend of her late husband is going to help her with it. However, she is a bit upset by some of the bad language and people venting in public, and by some quarrels reflected in 'indirects'.

In effect, for Peggy, Facebook replaces the traditional raising of the net curtain - a leitmotif for the assumed behaviour of older women in such villages. But no one sees her raising the curtain and looking out and actually there is a good deal more to be seen on the screen than out of the window. She can browse photographs, whether from her family or others, which she loves to do, and see what people are wearing and doing, and who seems to be friends with whom. As she suggests: 'It may all be rubbish, but it's friendly rubbish.' She does not have a car and cannot go out much. Without young children, not being a drinker and unable to afford the local restaurants there is just no other way she could have found this particular combination of semi-detached relationships. These are exactly what she craves now that her husband has died and her children have left home. For some of the earlier examples, the right temperature of the porridge meant keeping people at a distance and preventing things from warming up. Yet for many elderly people life's porridge had simply got colder and colder, and they were becoming increasingly lonely. Staring covertly through a net curtain was probably never what people of previous generations actually wanted their lives to become. Facebook can help to bring some warmth back to the porridge.

Furthermore, Peggy is well aware of the shallowness of traditional village friendships. People object that Facebook has too much trivia, but what did they think most conversations were about offline? Previously she would greet and chat to people she knows when shopping on the 
High Street, as she still does, but such conversations impart very little actual information. Most were about the weather, and very limited compared to the details of other people's lives that she can now encounter on Facebook. Even when it's the same topic, such as a neighbour talking about the weekend he or she has just spent on the coast, there is much more sustained conversation on Facebook than within the High Street conversation, and on Facebook you can see all the photographs. It is not as nosy as being in someone's house, but it is nosier than meeting them on the street. This group of users can also arrange practical things, for example to take in each other's deliveries from the post office when they are out. For Peggy, that is 'nice'.

As this example also shows, the 'Goldilocks Strategy' is equally adept at dealing not only with the mundane, trivial but sustained sociality that keeps everyday life active, but also with serious and complex issues of death, condolence and forming new relationships. This is particularly clear to Peggy with regard to her most difficult current relationship, which is with her four-year-old granddaughter. Her son is estranged from his wife, to the extent that Peggy has no direct contact at all with her granddaughter. The couple had separated even before his wife realised that she was pregnant. They tried getting back together, but the relationship ended even more acrimoniously and now he will never go round there. Just like Peggy, therefore, her son never actually sees the little girl at all. All his knowledge of his daughter comes through Facebook. Peggy is Facebook friends with her daughter-in-law, and every time a new photograph of her granddaughter appears she downloads it to show to her son. Her daughter-in-law knows perfectly well that this is going on and approves. On the one hand this is all pretty heartbreaking for Peggy, but in the circumstances she feels it is the best she can do. For all concerned it provides an excellent example of social media's amazing ability to keep people both connected and apart at the same time. Given the extent of divorce and the rise of 'complex' families in contemporary Britain, it is now a hugely significant facility.

For some users not as old as Peggy, keeping things apart is often at a premium for a very different reason. This is a period during which people are often working hard and for long hours. An increasing number of individuals in The Glades work at home and work all day on the computer. Since this is more isolated than traditional work locations they appreciate the ability to make social connections. However, these need to be controlled so that they do not interfere with work and can be done at times of convenience - often a ten-minute break from work tasks. For Freddie, who manages a company from his home computer, these breaks 
take the form of reading and possibly replying to posts about some of his various hobbies. A big fan of Frank Zappa and Captain Beefheart, he is an anonymous member of a forum devoted to their music. Freddie also likes to discuss football. Right now, however, between the demands of the business and parenting a young child he hardly has time to meet up with anyone, nor does he really want to. Social media gives him sociality that can be turned on and off at the click of a mouse button.

Such 'middle distancing' is also a reflection of his decision to come and live in The Glades. One of the very few Jewish inhabitants, he sought out The Glades as sufficiently distant from traditional Jewish settlements in London and therefore keeps at bay the intensity of family life that he grew up with, along with endless arguments and debates about Middle East politics that he can follow online at a safe distance. He has thereby established a direct parallel between this choice of The Glades as a place to live, neither too close nor too distant from London, and his subsequent use of Facebook and forums. They are all part of his suburban solution to achieving what people call a 'life balance'.

Similarly Jo has a full-time job, and at the same time she is studying for a legal qualification. She therefore has virtually no time to keep up with people. As she notes when she is studying: 'I don't go out at all ... I don't really interact with people as much as I did before, I just don't have the time.' Jo does not post at this phase in her life, but she is grateful for the fact that other people who are less busy do post their photographs, articles and other things, because at least 'you feel like you are part of something rather than being on the outside, and you can see what friends are doing without having to speak to them about it 'cos you don't have the time to talk to them'.

In addition there is a whole group of valuable uses of social media that are more specific to women. It allows them to develop and sustain a variety of relationships with men, without having to wonder whether or not these men are actually investing considerable time in friendly social banter to further the determined agenda of eventual seduction. Men readily admit (to other men) that they will groom women for years while never wavering from this clear ultimate purpose. Having social media relationships with men in another part of the country or men living abroad may provide women with quite a novel experience of asexual but deep cross-gender relationships.

At other times women also appreciate the way in which social media allows them to engage in relationships to others with shared concerns at a time when previously this was not possible. An example mentioned by many women was the issue of breastfeeding at night - generally an 
immensely tiring necessity. So boring that many mothers use a breastfeeding phone app to remind themselves of which breast they have just fed the child with. At 2.00 am you cannot use the phone since that would disturb a sleeping partner. Today, however, you can cradle the baby in one arm and check who else is currently breastfeeding with a free hand; you can then make contact and at least have some company for the next hour or so. Sometimes, too, mothers may feel anxious about what the baby is or is not doing. Simply knowing that one can get advice or share experiences even at night is hugely reassuring. 'Is green poo normal?' 'How come he wants to feed again when I only just put him down?' 'What exactly is colic?' 'You don't want to disturb the doctor every two minutes.' ${ }^{\text {'0 }}$

Social media usage can be adapted to fit the circumstance. Claudette was able to compare her experience with her first baby, born before social media was common, with her recent experience of having a second child. Her key observation was that the new ability to use social media aligned closely with another difference. Having a first child naturally leads to a huge desire for frequent contact with, and reassurance from, other mothers. In the case of a second child the greater experience of being a parent is to some extent offset by the reduced time available, since the first child also requires attention. For Claudette social media fits perfectly into the current regime where she is spending far less time in toddler groups and face to face meetings; this can be compensated for by interacting with other mothers of second or third children who are also now comfortable with making social media the key to their sustained communication.

Similarly those families who moved into The Glades and have many relatives in other parts of England are likely to be posting reams of baby photographs and anecdotes to keep them up to date - in a way that people with local families would not require. It would be a mistake, however, to conclude that there is a natural geography to social media: that it is only used by people to overcome distance. A toddler group makes intense use of Facebook precisely because they all live near to each other and see each other often. Just as schoolchildren can now extend the playground into their home through social media, a degree of interaction can develop that has its own momentum which no one wants to interrupt. To conclude, it is not just that social media is used consistently either to distance people or to bring them closer; it is equally used to balance people's offline life. As we have seen, it is supposed to make life warmer for those whose social connections have become attenuated, and to create distance from other people when social life has become too full. 


\section{Porridge is difficult to get right}

This last section provides evidence for a specific conclusion, namely that the very definition of social media as something colonising a previously unoccupied position between private communication and public broadcast is particularly well suited to resolve many issues of English sociality. Such sociality is perceived, indeed defined, as a mode as much concerned to keep people at the requisite distance as to develop close friendships. The argument here sounds quite positive. Yet there is at least as much to be learnt from the equally numerous examples where those involved feel that social media has failed, or where social media is subject to the same concerns that prevented satisfactory relationships previously. The first example will illustrate the displacement of established sensitivity to the new media. Then we progress to claims that social media itself creates problematic conditions, something that almost always comes down to the new forms of visibility it creates. The third possibility is a combination of prior and unprecedented problems that we find in concepts such as 'oversharing'.

The starting point is the way in which social media simply makes evident the exquisite sensibility of many English people to the exact state of their relationships, even as this has been transferred lock, stock and barrel to the new media:

So for instance there was a girl; one of my friends. She had fallen out with me and my husband and we're the godparents of her son. So what I noticed was that she wouldn't actually comment or like anything that we ever put on Facebook: our wedding anniversary, photos of Jerry, anything that was of importance to us. But she would do this with friends of ours, who she wasn't even close friends with. So my father-in-law - she's starting commenting on his statuses. He lives in Lincoln and she's met him like twice. She'll comment on all the people round us. But distinctly ignore anything that we'd put on. She's put on like friends of mine she knew that I would be in touch with them. She would put on things like 'Oh my lovely. It was so lovely to see you the other day. We must catch up soon.' It was blatantly obvious that she was declining all of my messages and not taking any of my calls. But incredibly readily available to everybody else.

I was inviting people to a particular group or something and I included all the names and I missed her out by mistake. And then I can't remember what happened but she was like 'oh thanks for 
including me' and I was like 'I'm so sorry' and I think I texted her because I didn't want it playing out on Facebook, but I texted her to say I'm so sorry ... And when she put something on Facebook about how she'd had a really really rough week. My immediate instinct was to take her some flowers and my immediate thought was that she likes the big chrysanthemums. I'll take her some of those, and then I thought no I'm not doing that, we're not friends any more. And then I just thought you know what, I'm not going to be shrunk down 'cos of this whole issue, I don't see why I should change myself and actually not do things that are nice because of the conflict. I don't want her to feel like it's a power thing, and I'm not trying to force her into talking to me, because if I send her these flowers and she has to say thank you while she's being rude. So I thought I'll just take them over one evening and leave them on the doorstep, 'cos you've had a rough week, so I've done what instinctively was the right thing, but I haven't put her in a difficult position. Do you know what I mean? I didn't want her to feel it was a manipulative thing.

The advent of the category 'Facebook friend' was bound both to pose new problems and also throw this general category of 'friendship' into relief. Facebook did not cause this anxiety over how to get things exactly right and to do exactly the right thing. The user would clearly in any case have been able to elaborate these contradictions at considerable length, simply because she is so sensitive to them. Several conversations with young mothers revealed their anxiety and uncertainty over such issues. One talked about whether it is OK to friend some of the other mothers she meets at school; they are much younger than her, and she wants to, but is not sure if they want her to. Another informant felt that she now knows the other mothers too well - the time when asking them to friend her on Facebook would seem natural has passed. In this instance, the 'porridge' is already too warm and it would seem too forced. The point made about Tinder above is that English people are highly sensitive to that precise moment at which a person makes the attempt at friendship in case they are rebuffed. However, there is no Tinder that makes Facebook friending light and fun for mothers. By contrast what works well is when 'we joined the $\mathrm{NCT}^{11}$ and had our four lessons and after that swapped email addresses. And then we hooked up on Facebook and we all met up a lot'. Here the process seemed natural. The same women later joined an emerging group that now has 300-400 mothers in the Treedon area; they use the site to advertise 
and exchange or sell baby goods, but also explicitly to welcome new mothers in the area. Being English may therefore imply an exquisite sensibility to the precise timing that determines whether a social interaction is appropriate or not. ${ }^{12}$

Field work in the village included countless conversations within which individuals were keen to discuss how and why they have friended certain people and unfriended others. In a relatively short time general norms can develop, of which by far the most widespread is the conclusion that a Facebook friend must be someone you have at some time or other actually met. This makes it very different from prior internet connections. In these anonymity was prized on the grounds that people could then share their most intimate secrets and get advice they could not possibly take from people they actually knew. There may also be norms as to the proper size of Facebook:

I used to have a friend who had a rule that she wouldn't have any more than 150 friends on Facebook. Which I thought was a valid rule. I realised that out of the 305 people I'm connected to on Facebook, I don't know 5 of them. As in I don't know them personally. Everyone else I've either worked with them, or they're a friend, or I've met them through a baby group. Or they're a friend of a friend who I've met and then we sent each other Facebook connection requests. Of the 5 people ... I know who they are, but I've never met them. One of them was through an Australian friend. And this was a couple of years ago. She became friends with this chap in Scotland. And then he sent me a friend request. And I thought well Sheila knows him, don't want to be rude. And it turns out that he's friends on Facebook with my friend's cousin. Mutual friends. There's another connection. I've met Sheila's cousin Dennis. Dennis knows this chap. It's a safe connection.

Such conversations may also reflect the remnants of the concern which emerged when Facebook first arose about whether these were 'real' friends. There were several versions of: 'The problem with Facebook is that you cannot be proper friends with that amount of people.' Similarly people explain in detail the logic of their unfriending:

I just did a big cull. People who do glamour selfies and stuff that just annoyed the hell out of me. I just took her off as a friend. Unfriended, annoying, a girl I went to school with 15 years ago. And I think everyone when they went on Facebook they went and 
found all their old school friends, and it's like well, we weren't that close at school, we've had no contact since school, you haven't private messaged me and I have to see pictures of your selfies every other day on my feed. So I took her off. 'Cos I didn't see any benefit. There were some lawyers I had on from Uni and I was like I can't even remember, can't put a face to that name, can't think of anything about you, who you were, or why I would need to contact you in future. Some of them I've kept 'cos it's kind of handy to accumulate lawyers at times.

So once again people are creating an idea of what 'temperature' a relationship needs to be for Facebook friending to be appropriate. As the last example indicates, a key criterion is the actual behaviour of that person online. A term that developed early on with social media is that of oversharing. An older brother worries about his younger sister: 'I have advised her in the past but again, I try and see myself in her shoes. She's 18. When I was 18 I think I'd just got Facebook. I think that was around when it came out. I do advise my sister to not do it, but I remember I was young and have done the same thing. She'll either learn from mistakes or realise that she doesn't want to be sharing that much with 300 people at once.' Another notes that you 'can post something funny about kids like finding a flipflop in the microwave. But a girlfriend posting her husband asleep and not fully clothed seemed wrong, also embarrassing things about kids. I de-friended one who posted pouting selfies.'

One of the mothers shows her annoyance:

There's also a degree of smug-married and smug-yummymummies. People who, you know, get married to the love of their lives. Have this perfect relationship, have perfect children who only ever do perfect things and they just plaster all of this. The girl who has 15,000 pictures on Facebook is very much like this. That's the bit that really annoys me 'cos I don't believe your family is that perfect. I kind of feel when people post that amount of stuff - who are they trying to convince? Other people or themselves? I don't need to put up a thousand pictures and have people telling me 'Oh you're so beautiful, your children are so beautiful, your life is perfect.'

Since the concept of oversharing is now well established people would often discuss it in regard to their own postings. Most parents were fully aware that endless postings of their children's latest activities could 
irritate and annoy some people, but usually argued that they needed to do this to keep family and friends updated. Other people did not have to look at the baby pictures if they did not want to. Sometimes there are deeper concerns:

Funnily enough I always get an instinct, when it's the anniversary of my mum's death. Because I don't have wider family. It's the kind of day that can go by without any reference to my mum ever having existed. It's like, I always feel tempted to put something. Like it's 8 years since my mum died. But you know when you think it's such a public setting. There's 136 people here. This is the kind of thing I'd talk to my friends about but I don't necessarily want the world and his wife to know. It's too precious to have it spread across 136 acquaintances who I haven't seen for years and some of them that are just school friends. ${ }^{13}$

One of the most common reasons for people to refuse Facebook altogether is that they want to avoid wasting their time on what they regard as trivia. In effect they are thereby judging social media as a kind of 'news' site, while those who do enjoy Facebook see it as more analogous to chatting, an activity that would in any case largely concern everyday trivia. Another woman who lives in a social housing area she calls 'Jeremy Kyle street' (after a daytime television programme shown in the UK and notoriously full of scandal) refuses to go on Facebook precisely because she feels she has enough gossip already. There is a common logic which was discussed in a story in Tales from Facebook. ${ }^{14}$ In effect if you feel isolated from gossip then Facebook can help add something that is missing, while if your offline life is already 'overshared' you have reasons to avoid an additional online burden. However, this logic is very partial. In the ethnography we encountered plenty of people who simply prefer to be equally private both offline and online, or equally public both offline and online.

Oversharing is an example of what turns out to be by far the most common problematic issue with social media such as Facebook, and which may account for much of the movement to alternatives such as WhatsApp groups. It is simply the level of public visibility - clearest when it is most extreme, perhaps because of what is being made visible or whom it is being made visible to:

I was on it, quite happily on it, but then had a lot of family issues last year, and there was a lot of bickering going on. Sort of doing 
with my dad and my niece. My brother left my sister-in-law, went off with somebody else and my niece, his eldest daughter, was causing a lot of trouble. She's 20 now, was 19 at the time. It was all on Facebook, all really public. Kate was doing stupid things, she was the sort of catalyst, was doing stupid things. And it got to a point where I was just like - I can't be doing with this, 'cos I was saying - now can everyone just calm down. This is supposed to be a social site not an anti-social site. And it was really weird 'cos my nephew, her brother, came off exactly the same night, just lost it, lost the plot.

She was dissing the new girlfriend and slagging her off basically but nastily. None of us wanted, none of us were happy with the situation that he'd gone off with her. And then my dad got involved and started telling Kate off which is fair enough, but then it became a slagging match between them all. Then my youngest niece who is only 16 now, she got involved, and my nephew who is in the middle bless him, stayed quite calm. He tried to say to my dad - look you know the girls are really upset about this, we all did. Thing is we've got a lot of joint friends. Obviously we are all family and we have friends that are all the same. So even if I was to block them, it would still come back through. At the time I was just looking at it and getting more and more irate and in the end I just went - right I'm off, this night I'm off, and I deleted myself off.

There are other cases where the impact is simply and quite obviously problematic, for instance people discovering that a partner is having an affair: 'It went to his wife's sister by mistake because they have the same name. And I won't say anything else, but it was one of those things where an accident with too much alcohol.' Rather more common were the suspicions and jealousy to which social media gave rise. To put this in perspective, both were far less common in this field work than in my previous study of Trinidad. ${ }^{15}$ Having said that, such a conclusion would be disputed by a hairdresser who claimed that, based on her conversations with clients, The Glades is rampant with inappropriate relationships, jealousy and break up, all because of social media. Being more interview-based, my ethnography was also more shallow than my previous study in Trinidad, and I may have simply been less exposed to these more difficult private issues. It was clear, however, that in comparison to Trinidad there is far less gossip in The Glades and people are much more discreet. 
Working in the Caribbean I had found that in Jamaica there was strong evidence that mobile phones made sexual infidelity that much easier and more common, whereas Facebook - being more public and eliciting tagged photographs - actually made it more difficult. ${ }^{16}$ The information in The Glades was insufficient to make such generalisations, but it is clear that both more traditional texting and the rise of WhatsApp meant that private assignations are now easier than ever to arrange. Yet also, as a group of men noted, it used to be that 'what goes on tour stays on tour, the old saying, girls have the same saying. But that's not true these days, is it? You're sitting round a pool taking pictures. Everyone has Wi-Fi, uploading stuff straight away.' In effect extramarital relations have had to become significantly more discreet or complications can swiftly arise: 'but then she used my laptop in the afternoon to go on Facebook, and halfway through her using it, the battery went flat. So she was in bed. I was lodging there, so was in a different bed at the time, put my laptop on, and her Facebook was there, and there were messages between her and this other guy. Had been going on for about five months. And then safe to say it was pretty obvious what was going on. So that broke us up. Some guy she was at Uni with.' The fact that stag and hen parties are now favoured occasions for posting photographs does not always sit well with the number of married males and females going abroad for such parties where things may happen.

A divorce lawyer noted that social media can be used in court as concrete evidence, which might be helpful. Far more often, however, she finds it an impediment to clients coming to terms with the divorce settlement: people can go back to something posted a year before which reignites their animosity. For this divorce lawyer Facebook is strongly associated with stalking, jealousy and obsessive concerns with someone about whom you have negative feelings - precisely because you can go back to Facebook and view the evidence again and again.

Perhaps the single most problematic consequence of visibility encountered during this ethnography concerns foster parenting in England. What was already a very difficult role has become far harder because of social media:

One incidence of Facebook was a young boy sees on Facebook that his birth mother has started slagging him off on Facebook. And to the fact of that she's named another female that his father is having relationships with. The son, having all these emotional upheavals 'cos he's in the thing, promptly trashes the foster carer's 
house. Windows, doors, and just goes crazy. 'Cos he's, he's within the group of all these. There's no privacy within the internet. For instance, one young lad had a smartphone, the parents said well where are you. Google map, Oh I'm here dad. Twenty minutes later the father is at the front door at the foster carer's banging the heck out of the door saying give me the kid back.

More common were feelings of a kind of negated 'Goldilocks Strategy', where it seemed that Facebook made the wrong people either closer or more distant. Parents who are not on Twitter or Facebook, for example, find that a distant relative is; he or she thus knows all about what their own children are doing, but of which the parents are unaware. As a result the parents become beholden to this relative for keeping them informed - a situation some find deeply troubling, suggesting that it harms their direct relationship with the child. For others it was essential not to be on Facebook, as in the instance of a woman suffering from longterm postnatal depression who came to appreciate that Facebook was clearly impeding her recovery. In another case a woman's relationship with her sister was deeply damaged through information on Facebook, which revealed that the sister had visited England but had failed to contact her.

An incidence of this unwanted visibility, though it came up only once during the ethnography, was the sense of Facebook as a ghost. A man felt very uncomfortable when a person who had died but still retained a Facebook profile would appear on his wall - even though he thought he had unfriended the deceased, which he felt was the most appropriate thing to do. 'Didn't know him well, I worked with him, he was one of my friends, younger than me so a bit of a shock. His face kept coming up and it just didn't seem right.'

More common are cases in which it is harder to see the visibility of social media as causative; it rather feeds into a pre-existing issue of visibility. In the previous section there were several examples of how social media has assisted new parents in creating relationships. However, it was also noted that the offline movement towards antenatal and then toddler groups has changed parenting. The fact that everyone has children of very similar ages makes direct comparisons inescapable: 'Some people, yeah. I've maybe got one friend who would kind of post it to the world that their child has just done something, to kind of shout and say "isn't my child clever".' This may continue into later stages when young people post their exam grades and say which school or university they have got into, though by that time most of the peer baiting is done by the 
children themselves. For the new parent there was even much embarrassment about the more positive uses, as this mother notes: 'You know I still kick myself about some early posts I did when Cressida came along, saying ridiculous things, like help why does my child do this ...? And then you feel so stupid 'cos it's just a normal child thing, but at the time it seems like such a big issue.'

Finally we also need to acknowledge cases where increased visibility does not have the consequences that one might have predicted. Perhaps one of the most surprising findings of this research is how the 'Goldilocks Strategy' is achieved when the meeting point is between two quite extreme polarities. Prior to social media grandparents and greatgrandparents tended to meet the very young in situations where the latter were expected to behave appropriately. One would have assumed that the elderly might be quite distressed if exposed to the actual behaviour of a free-ranging modern teenager, complete with incessant swearing and silliness. Social media is probably the first time for a long while that this older generation has immediate access to the materials young people are sharing with each other, rather than those intended for consumption by an older generation. I conducted many interviews with quite elderly people who had recently become exposed to this extreme adolescent behaviour, and while they did show some concerns with the level of swearing or the lack of any attempt by young people to protect themselves from the consequence of sharing, they were on the whole quite relaxed and unfazed by this encounter. This was one of the findings that completely contradicted my own expectations. They may not like all that they see, but at least in The Glades there was a general liberalism among the elderly about accepting that 'young people will be young people' - possibly combined with gratitude that they are not quite as excluded from younger age cohorts as they used to be. In several cases I was interviewing people in their nineties.

As an example, how does an elderly woman respond to her granddaughter's cohort who happen to have a close relationship to death metal bands?

Well the one thing that's helped me is she's 16, and she can go from angel to Satan in about .5 of a second and I'll tell you what heartened me is seeing the others. They're all just as confused and immature and naïve as she is. So in a perverse kind of way that's comforted me. It's mostly bands and 'I'm gonna die if I don't see them' and 'I feel like cutting my wrists today'. 'Oh My God' you know. And they seem to have good days. If one of them is down 
generally, one of them will pitch in. I've noticed that one girl in particular is often down and I think for Christ's sake I want to slap her, pull yourself together. You can't say that but actually my granddaughter did once. She told her to get a grip and I thought good for you. I was so impressed, I was quite proud of her 'cos it was going against the mainstream. Everyone was like 'Oh I love you babes don't do this, don't do that.' It is funny.

\section{Making and breaking relationships}

So far the discussion, apart from that of Tinder, has been mainly about family and friendships of a general kind. Yet social media is now often an integral part of the process which leads to intense relationships and long-term partnerships. This is hardly surprising in that people naturally use any evidence they can to discover who this person that they are developing a serious relationship with really is. There were many instances where social media seemed to be instrumental in both creating and breaking people's key relationship. Perhaps the most publicised result is that now known as 'revenge porn'. Revenge porn certainly happens among the school pupils, making things particularly difficult for the schools since it is usually the younger pupils who behave this badlywhich means that it is technically illegal. However, teachers are well aware that such conduct is mainly symptomatic of immaturity, which means that these schoolchildren need a considered response rather than a heavy-handed legalistic response from the police. The police themselves are in a quandary in such situations since they appreciate this, but are legally bound to intervene if asked.

More commonly for adults, social media is simply an integral aspect of getting to know someone:

We used to work together. He was my point of contact at work, had to ring him on a daily basis and stuff, and we had this little banter about something, and he used to called me Keleeeeeee. And one day we were just chit chatting and I was basically really foul with him over the phone. I was having my own relationship problems before I got with him. That evening he sent me a Facebook message saying what's wrong. He's always added me on Facebook to see what I would look like and thought - Oh yeah she's whatever. I didn't think that, he was just a work colleague, thought 
I was never gonna 'cos with me, pictures and real life is two different things to me. I didn't fancy him from his Facebook. I didn't even look into that, didn't bother. He sent me his friends request and I accepted it and just left it at that. That's it. Right now, you know if someone send me a Facebook message, obviously I'll stalk them first, but back in them days just accepted it. One evening he Facebooked me asking why was I so down at work and stuff like that. Next day, carry on with work, sent me a Facebook message how are you? And from then every day he sent me a Facebook message. 'Cos we didn't have each other's numbers. Private message was the only way to speak to each other. Then it led to every night before bed. Then sneaky texts. But with him it was like ding dong that picture was nice. Or like fiiiiiit! Was very very flirty ... One day he said he wanted to come and see me. This was by Facebook as well, I said Oh yeah that's fine.

Sadly this is the start of an extended story, which, in brief, is: meet, drink, sex, end of other relationships, move in together, have child, regret and finally acrimonious break up. The stories are rather shorter when there is no growing symmetry. For example, a male in a toddler group found it very uncomfortable when one of the mothers started flirting with him through WhatsApp, and therefore made the whole relationship to the group a bit more problematic.

While there is nothing to support the common idea that offline relationships are more real, the discrepancy between online and offline may still be significant. A relationship can become quite complex when people feel they are dating two people - one offline and one online. For example in a lesbian relationship Joyce was at first attracted because her new partner was shy and introverted when face to face. On Facebook, however, the same person seemed to reveal a different and more communicative side to herself which made her more interesting. Yet the very same factor led to the couple breaking up because after a while the sheer openness of the online self, with its political venting and strident opinions, became an aspect of this woman that Joyce eventually found quite unattractive. She had hoped that her partner was using Facebook to give herself a public confidence that would then emerge in her private personality, but came to realise that the opposite was true. The more extrovert she became online, the more introverted she was offline.

Couples may or may not feel that their screen lives need to be similar in order to be compatible. One woman may be just fine with the fact that she can get on with stuff for hours while her partner is on World 
of Warcraft, but in another case the fact that a man's partner is always on her phone when they are in company is given as the reason why he decides to break up with her. Finally a common and highly problematic consequence of social media's visibility occurs when a relationship break up is played out on that media. This experience is quite common for school pupils, though these are usually quite transient. As people get older the issue may become more serious:

I think social networks are absolute poison to relationships. They just don't help any situation, people get involved, write nasty indirects. Was going out at Uni, didn't work out, he broke up with me. But when things turned sour, we're going out for 10 months. Indirect tweets, you just know it's about people. It's just immature isn't it . . . Yeah, a lot of my friends got involved with things, they go out on nights out, pictures get uploaded which could cause tension, just all of those things.

\section{How Facebook became discretely English}

Writing a chapter on personal relationships is always frustrating for an anthropologist. We know that a good novelist can write several hundred pages and still only partially present the nuances and contradictions of a single relationship. ${ }^{17}$ To try to generalise about a whole population and every type of family and friend-based relationship feels ludicrous. As already noted, certain key topics such as humour and modesty were missed out entirely, as they will be discussed elsewhere. Instead examples were chosen in order to try to make a few points in detail, rather than try to be comprehensive.

This chapter is also the point at which certain themes are emerging which have been alluded to and which will provide the foundations for the wider conclusions of this volume. One is that the rise of social media has allowed commentators radically to simplify the discourse around offline relationships - is a Facebook friend a real friend? The reality is that, if anything, social media has made an already incredibly messy area of sociality (how do you tell if someone is a real friend offline?) even messier. The solution analytically was to turn this around and instead use observations of relationships on social media to remind ourselves of the complexity of relationships more generally. 
From here the discussion moved to observations that are less generic and point to a more specific alignment between social media and English sensibility. Such a perception gives rise to the coincidence noted at the start of this book. The definition of social media as scalable sociality between the private and the public just happens precisely to fit a definition of Englishness as an embarrassment with everything that muddies a clean distinction between the private and the public, creating a desire to keep the middle area under tight control. This led to what has been presented as the 'Goldilocks Strategy', marking how people calibrate relationships on this 'temperature' scale to get the exact degree of warmth with which they feel comfortable. A section showing some of the ways in which social media facilitates this task was followed by another showing some of the ways in which it makes this task more difficult or problematic. It was noticeable that the latter section, but not the former, focused above all on the consequences of increased visibility. This is because the traditional means through which English people dealt with this potential for embarrassment and anxiety in relationships was often by not making things explicit or evident. So the increased visibility, especially in situations where 'people's dirty linen was being washed on Facebook', was always likely to cause new problems for an English population.

However, not all social media has this effect. The particular platform that was almost always cited for the way in which it increased visibility was Facebook - the same platform cited for the way in which it mixes up different categories of relationships, for example workplace colleagues and family, thus making social relationships more difficult to order. This observation will be taken up at greater length in the conclusion to this book. Why in so many cases did Facebook become a problem - to which platforms such as WhatsApp then became a possible solution? What can be learned from the trajectory of polymedia that has emerged so far, brief though it may be? As it happens, elements of both Chapter 5 and Chapter 6 serve to parallel the findings of this chapter. It is therefore better to accumulate all this evidence before drawing some more general conclusions in Chapter 7 . 


\section{5 \\ Making social media matter}

Across all nine volumes in this series we decided that Chapter 5 could be used for whatever purpose the individual researcher chose. In most cases this is to highlight a particular interest or finding, but in my case I have decided to use this chapter to demonstrate a potential in our work that is otherwise sometimes assumed to be absent. I am referring to the practical use of our research results to inform and change policy or practice in applied areas - suggestions intended directly to improve the welfare of populations. In short, can our work be useful? For this purpose I have taken two areas from opposite ends of our research spectrum: learning from our observations regarding the impact of social media upon young people at school, and the potential of social media for the hospice movement, which deals with people who have a terminal diagnosis - mostly, but not always, older people.

In the first case this potential is simply drawn from our findings, since there was no initial intention of making the work with schools an applied study. These policy-related issues emerged unbidden as we carried out research with young people. By contrast the study of the hospice was always intended as an applied project, undertaken at the request of the hospice director. This request was accepted on the grounds that I felt a project of this scale ought to include a component whose primary purpose was to assist the welfare of our informants, even if this was never part of our research proposal or our grant application. The advantage of the first case is that it illustrates the way in which research that was not carried out with the aim of applied usage often still has that potential. 


\section{Learning about education}

This section effects a transition from pure research to practical application through several routes. The first involves what is often called 'best practice', that is, simply reporting an exemplary case so that it can be copied by others. A second example is through collecting information that was not previously available, but may prove a useful foundation for informing future policy. The third and final example will examine a case in which the evidence we collected could be used to change the terms of a major debate about one of the most concerning aspects of the impact of social media on schools - an aspect generally referred to as 'cyber-bullying'.

The first example, that of best practice, was encountered in one of The Glades' primary schools. ${ }^{1}$ The attraction of this case study will be evident to most parents, who at least in this region will usually confess to a common experience of frustration as a parent. When their children are at primary school, it becomes almost a daily ritual to try to find questions to elicit information about what pupils have done that day at school. Underlying this is the probability that most parents find the increasing autonomy of their children's school lives difficult to come to terms with. Going to school is for many parents the first instance where a whole section of their children's lives is completely out of view. Typically parents want to acknowledge and congratulate the subjects of their love on their achievements and build their confidence, as well as to be alerted as early as possible to any problems they face - many feel this is something of which the teachers themselves might not be aware. Parents of course are not a uniform group: some are happy to cede authority to teachers, while others cannot believe that anyone other than themselves can properly understand the child's needs (including the child). While academics may perceive this as a problem about granting autonomy to children, parents are most likely to see this retained concern as a natural manifestation of the depth of their love for their children.

The problem is that almost inevitably the children's answers are laconic in the extreme. When asked what they did at school that day they typically reply 'nothing' .. . 'can't remember' ... 'what's on television?' This drives parents to distraction and also leads them to devise all sorts of strategies and even threats, such as 'you are not getting any tea until you tell us at least one thing that happened at school today'. Given that this is such a common experience, and one that parents frequently discuss with each other, I confess to being completely entranced when 
Ciara and I first heard about a primary school blog - not at the school, but from teachers and parents whom we happened to come across during the general ethnography.

The story really starts from the appointment of a new headmaster who gave all the teachers Wi-Fi enabled devices for taking photographs of the children's work. This in turn was posted on a blog page for each class, linked to the school's website. After the blog received thousands of hits in the first month, the headmaster sent letters asking all the parents of the approximately 400 pupils for permission to post the blog, to which all but a few agreed. From then on each class not only set up a Twitter account, but was also expected to post detailed visuals of its activities on a daily basis.

The parents reported that this made a huge difference to their interactions with their own children; they could praise and discuss specific pieces of work undertaken that day, for instance a drawing or a poem. It also made the general relationship between schoolchildren, teachers and parents less formal, with less reliance upon authority or knowledge held by only one or two of these three. Parental anxiety about what was happening to their children, about which previously they had had no knowledge, was significantly reduced. Within the more general ethnography perhaps the single major expansion of social media use in recent years was among new parents. Such an inclusion of school material fitted easily within their home-based online activities, and children's work could in turn be shared with interested relatives such as those living abroad - many villagers seem to have relatives in Australia in particular.

The development of this blog may also have fitted in quite neatly with a possible shift in childcare. Women in The Glades typically expected to spend at least a year on maternity leave. ${ }^{2}$ This made the subsequent break from their children that much more difficult, and in the ethnography women seemed subject to feelings of guilt and loss, which made the blog still more cathartic. The brevity of Twitter and the very nature of primary school activities meant that the character of postings tended to be focused around the idea that everyone was having 'fun' just as much as being educated. There did not seem to be any evidence that the children resented this intrusion, possibly because the reaction of their own parents appeared almost entirely positive and congratulatory. This may be partly because a duty to foster one's children's self-esteem is pretty much the mantra of contemporary parenting. One caveat that would require further investigation, however, is that extended studies in the US have noted a worrying trend in which new media has been 
used for 'over-parenting' and reducing the autonomy of children with negative consequences, though this may relate more to an older cohort. ${ }^{3}$ It is possible that this blog also may be merely kicking the problem of childhood autonomy further down the track, but it is too early to tell.

If the later experience of the children confirms this overwhelmingly positive response from the parents and teachers, as well as Ciara's ${ }^{4}$ evidence of the way in which this facilitated a less formal relationship between school and home, then the ethnography has encountered something which bureaucrats could reasonably term a 'best-practice' innovation. The role of our research is then to attest to this result. As we were independent from the school, and in any case deeply involved with these parents as part of our ethnography, we can provide additional evidence and support. Through writing our account we hope to promote this example as something potentially easy to emulate at primary schools in the UK and elsewhere.

The second way in which our project was able to contribute in an applied fashion to contemporary education was through the collection of data. Initially we assumed that this would emerge directly from our ethnographic authority, which came by virtue of studying in the village for 18 months. This assumption was naïve, as we discovered through an unexpected incident. At the time of our field work most people assumed that Facebook had become the dominant, almost monopolistic platform for social media among the young, having seen off prior alternatives such as MySpace, while Twitter was assumed to be used mainly by professionals and journalists. As soon as we started field work, even before we worked within the schools themselves, it was obvious that young people had radically changed their relationship to Facebook. Facebook had previously been a primary site for 'cool' sharing and peer-to-peer banter, at which time children and youths assumed this to be 'their' medium. They were consequently quite shocked at that iconic moment when 'my mother has just asked to friend me on Facebook'. Previously adults had in general looked askance at this social media, being mainly concerned to deter their children from spending any or at least much time on it.

Our research showed that this tipping point, when parents sought to friend their children on Facebook, was if anything more profound than either had realised. It precipitated a massive change in perspective, which did not mean that young people's presence on Facebook diminished. Indeed the contrary was true, since adults who had once discouraged this usage now insisted that their children remain on a site where they could share materials increasingly with grandparents, relatives living at a distance and others, as well as with 
the parents themselves. As a result the status of Facebook as the primary 'cool' peer-to-peer medium between young people could now be pronounced 'dead and buried'.

When I published this finding on our project blog ${ }^{5}$ I did not anticipate the response, which was that the 'news' went viral. Reports, often wildly inaccurate, appeared on literally hundreds of news sites all around the world. I was surprised partly because working in the schools made this not seem like news at all. It was something that nearly every teacher and parent already knew very well. All class information went through Twitter; there was no instance of a teacher using Facebook in the hope of informing pupils. Something so blindingly evident hardly felt like a discovery. Yet somehow this shift had remained almost entirely unknown at the level of formal news and journalism, as well as to the general public or in countries where this trend was not yet evident. Indeed some journalists refused to accept these findings, despite the fact that they only needed to ask a few children to have it confirmed. In some cases a failure to read the original posting meant some assumed I was claiming a decline in Facebook itself. It also became evident that journalists were not familiar with the kind of authority claimed by anthropological work. Because the blog post did not include statistics, tables and more general quantitative material, they tended to dismiss these findings as anecdotal, ignoring what was by then already many months of intensive study.

By 2016 it is unlikely that anyone would still doubt these findings. In fact almost immediately some journalists in countries such as the UK, Australia and the US reported a similar loss of cool, but the heated discussion that followed from this blog post showed that to gain authority research may need to include other kinds of data than are normally included in anthropological work. My immediate response was to conduct a survey of 2,500 pupils (actually we ended up with 2,496 ) initially, to be honest, partly to show that I could. ${ }^{6}$ Fig. 5.1, for example, is a chart showing the presence on the main social media for each age group which confirms the growing presence of Facebook.

This confirms that there is no loss of presence on Facebook, but the same survey also asked these school pupils to name their top three favourite platforms. Only 12.7 per cent picked Facebook as their favourite social media, 8.4 per cent as their second favourite and 9.7 per cent as their third favourite. This was certainly vastly different from assumptions made prior to this study, which saw Facebook as basically a young person's platform now dominant in their lives and with which they entirely associated themselves. At a mere 12.7 per cent Facebook is clearly no longer the dominant 'cool' platform for social media. 


\section{PRESENCE ON SOCIAL MEDIA PLATFORMS \\ FOR 11- 18 - YEAR-OLDS IN SCHOOL IN ENGLAND}

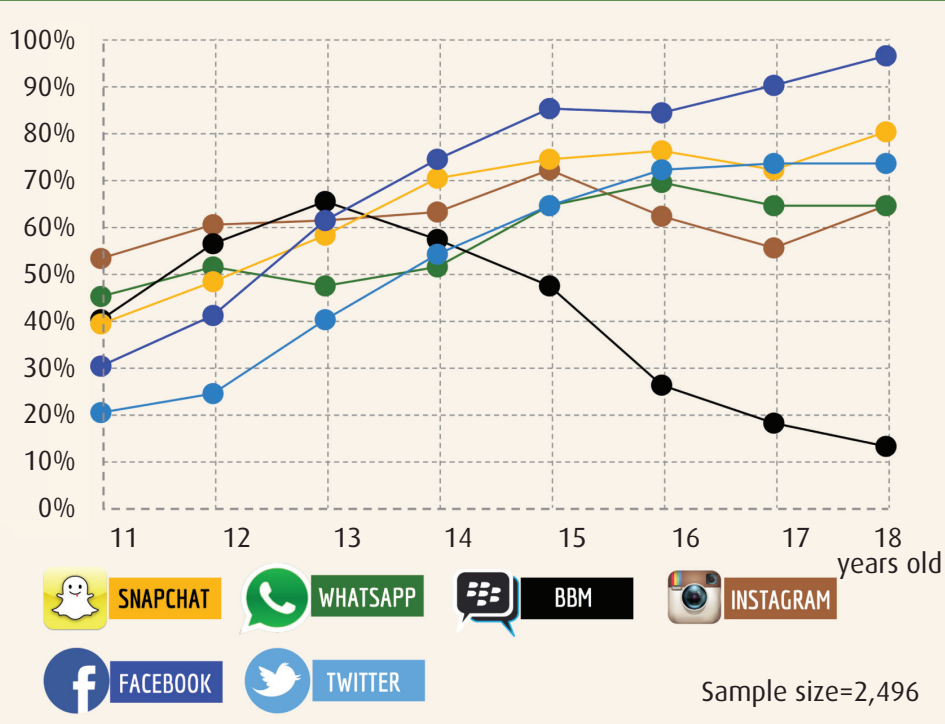

Fig. 5.1 Presence on social media by age at four secondary schools close to The Glades

More work will be carried out on this survey later, but it can already be used to demonstrate, for example, a statistically significant tendency for females rather than males to use visual media such as Instagram and Snapchat. It also confirms the general contention of Chapter 2 that most teenagers work now in a situation of polymedia where they employ several platforms simultaneously. It was also striking that these six platforms were far more prevalent than a whole host of others that are often discussed but are simply not that common. Tumblr would come next, and there is some usage of game stations, but others barely register. Mostly the statistics merely reproduced observations that were in fact evident from early on in the field work and do not seem to merit the time involved in their collection. Yet in addition this survey gave some guidance to usage for those under 16 with whom no ethnographic work was carried out - for example, demonstrating the continued importance of BBM for the younger group. So this represents a second route towards more applied consequences, the provision of evidence. 
It is, however, the third route that probably represents the main strength of an anthropological contribution and is precisely the kind of evidence that not only does not lend itself to quantitative investigation, but also exposes the misleading consequences of approaches that come top-down from policy-driven research. There was no original intention of contributing to policy concerned with the problem of cyber-bullying.? In general the aim was similar to that of a recent excellent ethnography of a school classroom, ${ }^{8}$ which was merely to observe the use of new media with an open mind. It was only subsequently, on reading the background literature, that a marked discrepancy became apparent between the way in which behaviour was reported and explained in that literature as compared to what was encountered during our study. It also became clear that the main reason for this is that the policy-directed literature was derived from research with a specific agenda and set of interests that seem to have influenced its findings. The main advantage of ethnography here is that, without any specific focus, it tends to see behaviour within a much wider context, thus changing our understanding of what is being observed.

The issue of cyber-bullying is less pertinent to the age group of 16-18-year-olds, but during discussion these school pupils talked at some length about the previous two years. For them, coming into the sixth form at 16 was seen as generally marking a decline in the incidence of this kind of behaviour, but the memories were fresh and traumatic; they seemed to be something the pupils really wanted to discuss further in retrospect. Several examples have been presented in previous chapters to illustrate how school pupils use social media for a wide mix of arguments, banter, gossip and conflict that may sometimes spiral into abusive and destructive interactions. Early on it seems that the primary platform for these was BBM; for a short period this migrated more to Facebook and its current manifestation is mainly within Twitter beef. The topic emerged immediately because the start of field work coincided with a recent suicide of a 15-year-old girl in a nearby district. This had been widely reported in the newspapers as a case of cyber-bullying, though both the police and the child's parents argued the cause was otherwise. We decided to follow up this story and travelled to that district in order to interview those associated with this event. All of her friends that we spoke to supported the newspaper claims:

I know for a fact when I was friends with her, it was social media that was getting her down. All BBM. Or MSN. Facebook inboxes. They don't understand the impact it has on someone, getting those 
messages. Think 'Oh it's just nasty messages between girls'. It's not, not for someone like Tricia who took everything to heart. She really cared about people and took it all to her heart. They won't accept that. Calling her a slut, saying she's disgusting. All stuff like that. It must have been horrible. But never really understood the impact it would have. Especially, we've grown up around it. We understand it. Onlookers don't really get it.

One of the reasons parents and police may have been less aware of what was going on was that much of this took place on BBM, a heavily encrypted platform where material generally goes under the radar of adult surveillance. However, the same friends helped provide the wider context to this event. They did not seem to regard Tricia as a passive victim of cyber-bullying: rather they framed this tragedy in terms of the ubiquitous presence of arguments and abuse circulating among girls of that age. Tricia would find herself in conflicts with peers in which she would argue back as much as she would receive. In other words, there were likely to have been other encounters in which she might have been framed as the cyber-bully. As one friend put it, 'Tricia had a mouth on her. She knew how to argue. People used to not like her for no reason. Even people in my year ... She had her group of friends. She was constantly on Facebook and Twitter'. The sense seemed to be that Tricia would equally send and receive negative messages with her peer group, pretty much as the rest of her peer group did. Rather than defining people as perpetrators or victims, therefore, the pupils saw certain people, for example Tricia, as taking a more active role in these exchanges, while others prefer to stay aloof. The issue of suicide is not seen in terms of the interactions themselves, but rather in terms of the underlying vulnerability and volatility of emotional states that girls of around 14 and 15 seem to experience. Among these are potentially devastating losses of self-esteem where things that would otherwise not have major consequences may at that particular instance be severe enough to be considered a reason for suicide. It is worth noting that this is the age group in which anorexia, bulimia and especially 'cutting' are prevalent.

This is of course an extreme case, but it confirmed a more general trend that emerged from the 80 interviews we conducted at these four schools. The term 'cyber-bullying' was hardly ever used by pupils, and we realised it mainly occurred when we had introduced it or in reference to news coverage. In some ways it was the news that made this a topic in its own right. In another case a girl in the village on several occasions presented herself as considering suicide from cyber-bullying. 
However, this was done in such a manner that it seemed more likely that she was using the anxiety created by the news in a conflict of power with her own parents, rather than a situation emerging from her own experiences at school.

As boyd notes, 'When adults reframe every interpersonal conflict in terms of bullying or focus on determining who's at fault and punishing that person, they lose a valuable opportunity to help teens navigate the complicated interpersonal dynamics and social challenges that they face'.. The problem is that there are many books on cyberbullying, ${ }^{10}$ and because of the focus on policy much of the discussion seems to be dependent upon the definition of clear categories. If one can identify individuals simply as either bullies or victims it may be possible to characterise the demographic and other parameters that correlate with this categorisation. Such a simplification makes advising school and parents a good deal easier. People are told to look for the 'signs' of victims and bullies and to be aware of where they are likely to come from.

However, our evidence suggests that this advice may be quite misleading and therefore possibly ineffective in dealing with these problems. It ignores the wider context - a pervasive culture of what might be better termed endless banter and taunting, or, as suggested in another paper, cyber-drama, ${ }^{11}$ which most young people participate in and which at some level occurs nearly every day in passing slights, insults and innuendoes. The problem with policy discussions that equate quantitative evidence with data is that often these papers suggest that we have not properly understood cyber-bullying because we do not yet have enough data, or that the data has so far produced inconsistent results. ${ }^{12}$ This approach also claims that the problem could be resolved if only we had a more precise and consistent definition of terms such as 'harm'. ${ }^{13}$ Our conclusion is that this desire for precision, and similarly the desire for quantitative data, is generally at the expense of understanding. The problem is not lack of consistency in semantics, but lack of contextualisation in research. In the experience of these children there is simply no clear line between abuse, insult and banter and bullying. From an ethnographic perspective the first stage would be to try not to frame this and narrow it to specified categories, but rather to open up the enquiry so that this behaviour is understood to be just one end of a wider spectrum.

In this instance the potential contribution of this research was to give a more detailed answer to one specific question: how precisely has the advent of social media changed and impacted upon a situation 
that was clearly fully fledged prior to social media? The interviews and online observation suggested three ways in which social media itself has actually changed the nature of these interactions. These were firstly indirects, secondly the erosion of distance and thirdly the concept of hiding behind a screen. There is no inference that these were necessary consequences, deterministically caused by the technology. It is rather that these are the ways in which social media have been exploited in this instance.

\section{Indirects}

An indirect is simply a comment or an accusation made on social media that does not specify the name of the person, or people, at whom it is directed. Students reported indirects to be the most common form of 'negative' usage of Twitter, which was also evident from following their accounts. Students would often see an indirect and worry that it was directed at them. The prevalence of indirects was shown to affect both personal confidence and the relationships in female friendship groups; often a girl would suspect that someone they believed to be their friend was in fact publicly venting about them.

Indirect tweets are horrible. They are horrible. And everyone assumes it's about them. Everyone. The indirect thing is a nightmare. Had one the other day 'Fake friends, I can see you'. Now, this is one of my friends, we were all sat there like 'What?' Got a text from one friend saying 'Is this about me?' . . . I text back saying 'Is this about me?' Because none of us know, so it just sends everyone off against each other.

Asking the person that posted the tweet who the tweet was directed at may only serve to worsen the situation:

You've got two or three girls saying "Oh is that about me?" Then someone else tweeted "Oh, this isn't about you, but obviously you've done something wrong ..." I think Twitter ruins everything. I really think it does. Like with friends and stuff, 'cos you're always wondering "like is that about me?" ... And I just think if it wasn't for all the social networking I reckon things would be so different. Like good different... 
On the other hand, an indirect may be posted in a situation where many people, including the person at whom it is directed, know precisely who the tweet refers to. This is intended to create embarrassment and anxiety for the individual accused due to the wider reach of people who would be witnessing the tension, in comparison with offline equivalents. The 'known' indirect could be re-tweeted by those who support the tweeter, thus generating further anxiety for the accused, or it could provide an opportunity for those in support of the accused to defend them.

These are two entirely opposite but complementary problems created by the indirect: those caused by everyone knowing to whom it refers and those caused by no one knowing. An indirect can be a means of harassing a particular girl and encouraging others to do the same. In such cases there are no doubts about the target, and the indirect may simply be a way of avoiding the 'evidence' that is these days far more easily recorded since this material is online. Pupils are well aware that platforms such as Twitter have the consequence of making them quite transparent to each other, in contrast to Snapchat and WhatsApp. Often a particular class group or year group is seen as divided into several smaller sections, which comprise close friends of varying constancy. Such groups may be quite transient, and it seems as though indirects could be as much used within what was previously a close group as outside - those who are already friends know more about each other, and have more ammunition and possibly reasons for competition and jealousy. Outsiders thus need to confirm the current state of these dynamics, as one pupil noted:

I try and stay neutral with quite a few people, 'cos then if something is said, I'll be like 'Oh is that about me?' and they'll be like 'No don't worry', OK fine. Which happens quite a lot. Like 'Oh it's not about me is it, what have I done?' They are like 'no no no, not you, another person in your group'.

Another key factor is that indirects can also be a side effect of something rather different. On Twitter English schoolchildren are generally competing over how clever they can be in terms of wit and banter. An indirect can be appreciated and gain recognition in the form of 're-tweeting' or 'favourites' - not because it is abusive, but because it is creative and even stylish. The primary drive may be an opportunity to be funny, and the suffering is secondary to that purpose. This would be especially true of male uses of insult that would lower the perpetrator's reputation unless other people regard it as funny. On the other hand, one easy way to seem 
funny is to be outrageously acerbic. Such a comment can be especially cutting, with the situation compounded by the fact that the recipient, in being hurt, thereby demonstrates that they cannot take a joke.

\section{The erosion of difference}

Much of the literature on cyber-bullying emphasises the way in which digital technologies have eroded the boundary between school and home. Home no longer exists as a refuge, since in many ways the main arena in which social life is lived is now online - irrespective of whether the young people are physically at home or in school. These exchanges can now continue $24 / 7$. While there has been much academic discussion on how the internet brings the public realm into the private, for example networked privacy, ${ }^{14}$ social media is in addition seen to bring the school realm - where 'traditional' bullying took place - into the home: 'They don't have the decency, let them have their home, somewhere safe to be. Now there's nowhere to go. People say "just log off Facebook", but if you $\log$ off you have the voice in your head like she's posted six things about me and I can't see it ...'

While parents may think that their children are safe and asleep in bed, or studying at their computer, they may in fact be engaged in conflicts with their peers online. A family psychologist who served the area of our field site commented on this: 'They keep [their phones] on all the time, that means they are hyper-alert all the time, they don't relax, it keeps the tension up for the young people. They have to reply, they get anxious, they are quite private so they can't talk to their parents about it.' Arguably issues of physical abuse would create more visible evidence for parents that their child had been suffering at school. However, teenagers reported their own resistance to parental requests to view abusive materials due to the fear of losing their offline privileges. Teenagers very much want to continue their social interactions on evenings and weekends, especially as opportunities to play outside the home are being restricted. Yet this desire clearly leaves them vulnerable to persistent assaults that sometimes grind down their already fragile self-esteem.

\section{Hiding behind a screen}

The third problem we found that corresponds to the rise not just of social media but also of new media more generally, is the consistently asserted 
proposition that teenagers, especially girls, say things in the evening from behind a screen that they would never say face to face in the classroom. Screens appear to act as a point of engagement which allows a thought bubble to burst into text. Other girls then tweet responses using the similar protection/mediation of the screen.

People can hide behind their computer screen. They are not face to face with someone. They don't have that shame, they don't have that remorse for someone. If they are gonna be rude or say a harsh comment, they've just got a screen in front of them rather than an actual person, they are more inclined to say exactly what they think rather than hold back.

'Cos it's so easy. On Twitter people don't think before they say. Twitter is a form of speech now, you just think and tweet. Before you had to think about what you said, you could see people's reactions.

Pupils assert that migrating from Facebook increases the incidence of conflict because of the use of re-tweets, though there were earlier equivalents on BBM and then Facebook.

Another reason for focusing upon these three factors is that they seem to support each other. The problems caused by indirects are exacerbated when they have the ability to cause distress outside of the hours of the school day, the time at which those experiencing only traditional offline bullying would have been able to escape from further harm. Similarly the prevalence of indirects could be partly explained by the confidence acquired by being behind a computer screen.

\section{Direct boys and indirect girls}

One of the consequences of this degree of specificity is that it also helps us to understand why the pupils clearly saw gender as such a critical component of these changes. ${ }^{15}$ The term 'indirect' is actually quite helpful in understanding how these pupils stereotype gender. For them, males in general are seen as the natural directs. They suggest that males are just as capable of saying nasty, horrible things, but they tend to say these directly and respond immediately. Young boys will fight physically and be directly aggressive. As a result it is dealt with then and there, rather than rankling and occupying their minds in the same way. By contrast it is suggested that the natural mode for girls is indirect - a situation in 
which issues of unfairness and imagined revenge go constantly round and round in the head, evoking recrimination and (usually) temporary bouts of hatred.

At the same time, while girls are seen as more likely to be directly involved in this kind of online behaviour, boys are indirectly seen as the cause of much of the quarrelling - partly because they enjoy egging the girls on and 'stirring' issues and partly because the quarrels are often about them. A typical quote would be: 'Guys tend to just say stuff, say it and get it over and done with, but girls, we're not like that, probably just beat around the bush a bit.' There again many of the accusations concern relationships with boys: 'Yep. Always around different boys ... There was a comment made like so and so is trying to steal my friend, or "hate it when a girl flirts with someone else's boyfriend", and we think "Oh I wonder who that's about?" Might be about us. . '

Boys clearly regard major quarrels between girls, especially those that blow up into Twitter beef, as a form of entertainment, and are happy to find ways to incite girls into these or to extend them. In the case below, girls had kept party photographs private, but a boy then used them to make mischief:

But then one of the boys got hold of a picture by mistake, took someone's phone and sent it to himself. Put it in his group chat, and they were like 'urgh that's disgusting why would you get with her?' And they like tweeted indirects about it. And we were like 'We would never do that. She's embarrassed to have got with you as well, but we aren't gonna openly put it on, we knew what it was as well.' And they think they are just so big and 'oh we're year $12 \mathrm{~s}$ now.' But they aren't, still act like year 8s. They get really nasty with each other.

With some exceptions, this is a fairly consistent view of gender. Boys are not more benign: they are happy to stir and publicise quarrels, to betray girls through postings about their ex, to lie, cheat and slander others. They suffer less, however, because the results are more short term. Girls find it harder to confront each other directly, or perhaps confront themselves. They are therefore more likely to retain the hurt and live in a world of anger, regret and low self-esteem.

If we then reflect back on the specific ways in which new social media seems to impact upon cyber-drama, each of them can now be seen to have a strong gender component. The rise of the indirect is associated 
particularly with females and is opposed to the stereotype of males as being more direct. Yet this is also true of the sheer emphasis on social interaction as the overwhelming concern, all day, every day, which now continues through to the evening. This commitment to constant social interaction is also seen as intrinsically female. Males are viewed as more likely to turn away and be content with more autonomous activities, for instance playing games on computers. Furthermore, the erosion of distance is also closely associated with a shift from physical dominance to an emphasis on verbal assault. Males would be expected to dominate physical abuse or similar forms of offline bullying.

So in all three ways the shift to online cyber-drama means that females are more closely associated with the perpetration of such abuse, nullifying the advantage accruing to males in traditional bullying because of their physical capabilities. In effect females have attained new capabilities and exploit the potential of social media more effectively than males. This would make these changes a clear example of what could be described as an 'attainment'16 - that is, an ability of young women to achieve something previously latent, since it arose from a frustration with their lack of strength relative to males and their subsequent vulnerability. So in these three specific instances we could conclude that social media has empowered female school pupils, recognising that there are many others such as revenge porn where it has not. The fact that they may subsequently use these attained advantages to harm each other does not make this less of an empowerment: as with other fields such as military hardware, new forms of harm are one of the tasks for which new technologies are commonly employed. The problem is that the glib use of terms such as empowerment seems to have neglected even the possibility that power is not always a good thing. ${ }^{17}$

As a summary to this section, these instances were provided to show how our research on social media might have an applied and welfare usage with respect to the field of education. A primary school blog was argued to be an example of best practice, while a survey of social media usage provided new information and a study of online banter and taunting suggested a revision of the standard literature on cyber-bullying. What all three have in common is that the interpretation depends upon the wider context of ethnography. The significance of this will be considered alongside a second example of this more applied perspective - the work with a hospice. 


\section{Social media and the hospice}

Around the time when the larger project on social media began I was approached by Dr Ros Taylor, director of the Hospice of St Francis in Berkhamsted, who suggested I carry out some research alongside Kimberley McLaughlin, one of the senior managers at the hospice. This would be the first time I had carried out research whose primary result would be a consultative and practical rather than an academic report. The work involved interviewing over 90 individuals, of whom 50 were patients and the rest carers, relatives and hospice staff. Some of the patients were interviewed just once, others several times. Most of the patients had received a terminal diagnosis of cancer, although some other illnesses were encountered, and while a few have recovered almost all of the patients have now died. ${ }^{18}$

I agreed to volunteer for this work because I hugely admire the hospice movement. My subsequent experience from this research has entirely surpassed even those positive expectations. It is really quite hard to convey just how effective the hospice movement has been. In my past I had encountered dying people as mainly angry, frustrated and largely unreconciled to their situation - not conditions in which you expect people to provide positive acknowledgement. Yet in two years of hospice research I did not meet a single patient who was not fulsome in their praise for the Hospice of St Francis and the difference the hospice has made to this stage in their lives. To their lives, not to their dying, since the ethos of the hospice is to transform a situation in which the focus has been on death to one in which a terminal diagnosis is regarded as a stage in life that should be made as positive as possible.

Why would a hospice be interested in the potential of communicative media? While in some countries a hospice is largely the place where people go to die, in England, where the hospice movement was invented, ${ }^{19}$ this is only a small part of its function. The Hospice of St Francis cares for hundreds of patients at any one time, mostly for months if not years, but the average stay in the hospice itself is only nine days. Most people want to be cared for in their own homes and so, while they may come to the hospice for support services such as pain control or counselling, mostly the hospice staff spend their days visiting patients in their own homes. As a result communication between the patients and the hospice is hugely important, and provided the initial focus of research. Eventually it became the first half of the research and 
culminated in a report to the hospice advising them on how they could use new media to improve their services. ${ }^{20}$

As the work progressed, however, it became clear that because patients were in their own homes an equally important dimension in terms of the potential for social media was the communications between them and those relatives, neighbours and friends who comprised their support network. Social media is already becoming an integral part of these communications, both for patients and also for having an impact upon bereavement. ${ }^{21}$ By expanding the study to the patients' social universe the applied project dovetailed with the simultaneous ethnography of The Glades as a study of people within their entire communication network. Indeed the hospice research became one of the most comprehensive parts of the larger ethnography; we were able to understand any impact or potential impact of social media within the frame of all other forms of communication, including face to face and traditional media such as the telephone and letters. This in turn helped to expand the work on polymedia and other issues central to this volume.

In the report to the hospice the first section examined the immediate potential for each new device in tandem with the others. Take webcam as an example. Given the English cultural norm of responding to the question 'How are you?' with, 'I'm fine, thank you', webcam was seen as providing access to patients' current physical conditions and wellbeing. It could resolve nurses' frustration at their inability to convey visible support to a patient sobbing on the phone. Staff envisaged webcam as useful for an immediate appraisal of symptoms, helping to decide whether a home visit was required and for demonstrating devices or regimes for taking medicines. It could also be valuable for dementia patients, who find it easier to recognise a person's face rather than his or her voice. Nurses also suggested that webcam could provide an interim assessment as to whether an elderly patient who had suffered a fall, for example, needed the additional trauma of going to the hospital's Accident \& Emergency unit. Webcam might increase trust between medical professionals, who otherwise may meet only as a voice on a phone, and could also substitute for staff meetings requiring an additional two hours' travel and petrol costs. Patients suggested webcam could facilitate a virtual presence at a wedding or funeral that they were too ill to attend, and enable relatives abroad to attend the patient's own funeral. Each new technology in turn revealed similar advantages, such as the potential for texting between nurses and patients, the use of iPads or tablets for taking notes and the incorporation of specialist phone Apps. 
In addition to considering the potential of each new media, the report made 11 practical recommendations. For example, there was the potential for digital legacy Apps in which patients could leave voice recordings and other material to their descendants and a scheme for 'kite-marking' medical information that is found on the internet. The research on polymedia became a direct challenge to the way in which doctors have previously assumed a knowledge of the appropriate media for each kind of interaction. This research showed that patients differed considerably in their responses to medical communication about something as sensitive as their own terminal prognosis. Some preferred to write emails late at night. As one put it:

I would never have come into a hospice to see a counsellor or anything like that but to let out how I was feeling, on my terms, in the moment I wanted to and then press the send button felt very cathartic. I didn't feel like I was bothering anyone and knew they would respond when convenient to them - this kind of support really fitted for me.

By contrast, others preferred more face to face contact. The idea of polymedia thus turned into a recommendation for an initial consultation as to which media any given patient preferred for each of the different kinds of communication in which hospice staff envisaged they would become involved.

Potentially social media could be at the heart of these recommendations. The wider problem has been a disastrous history of a UK National Health Service spending vast amounts of money on bespoke computer services, including ideas for telemedicine and other services, most of which have failed. In the past a researcher might have suggested a new scheme or device. If accepted this might be developed by a major corporation such as Microsoft, then tested and sold back to health services at considerable cost. The issue is not just these costs, but also the fact that a new device, for instance a bespoke Videocam, will inevitably appear clunky and dated by the time it is established in usage. All of this reflects a history of healthcare which has tended to operate in a topdown fashion.

Today we live in an unprecedented time with regard to new media. Every six months the smartphone gets smarter, new Apps appear, internet sites are established and social media goes through another change. Even more important is the evidence that the creativity is moving from producers to consumers, allowing several of our routine technologies, 
such as texting, to spread to populations as unpredicted appropriations by ordinary users. It is even more likely that those with special needs and their families will, from now on, be the vanguard in adapting ordinary commercial media to their specific requirements. Typically it was an elderly patient's grandchildren who knew about some recent App or who could research a voice-activated system for a patient who could no longer type - or who could turn a device into remote surveillance so that their mother could keep an eye on their grandfather. ${ }^{22}$

The report proposes a social media group around 'Patient's IT Initiatives' in which healthcare professionals, while assuring the anonymity of their patients, post short descriptions of their observations of patients' use of IT devices, specifically outlining the positives and benefits of these devices to the patient's welfare. Other clinicians who read these postings would be able, in turn, to repeat them as suggestions for their own patients with similar issues or problems to solve. This could be a useful site to report on failures as well as successes, giving feedback and relating other experiences that people in similar situations might learn from. Such a scheme bypasses all forms of bureaucracy and all those seeking to make profits out of this sector. In effect it adopts the 'peer to peer' and 'open access' initiatives that have become the vanguard of our new digital age. ${ }^{23}$

These initial proposals were aimed at healthcare professionals as ways of making their work more effective. The second half of this research was concerned to find out how palliative care patients themselves used social media, and their subsequent experiences. This usage was going through remarkable changes. At the start of our project most people believed that social media, such as Facebook, were a young person's prerogative and doubted that older people would ever be attracted to these new digital worlds. By the time of the hospice ethnography the fastest increase in Facebook usage was among the older population: around half of the over-65 year olds encountered in the general ethnography were now using Facebook. As already noted, the evidence from this ethnography suggests that the longer-term outcome for Facebook may well be a general migration to older people. They will increasingly appreciate the functionality of being in touch with family and overcoming issues of immobility, while younger people will migrate to newer platforms better suited to their interests.

During this period of transition, the situation usually encountered was an older population just starting to use Facebook, and very occasionally other platforms, but still regarding them all with deep suspicion. For example, Elaine has three children and several grandchildren; she 
was separated from her husband. At various times she had been a social worker and home care helper, and then had taken an Open University course. She had previously had breast cancer, but retired in 2012 when her current cancer had made ordinary work no longer viable. Unusually I came to know her within the hospice itself, where she had come for respite and pain relief. Like many older people she distrusts Facebook. However, the way that she reported her ambivalence towards social media also seemed to implicate the very 'English' nature of this distrust, which encompassed both social media and several other relationships.

For Elaine her increasing engagement with social media has coincided with the various stages of her cancer. Earlier on, when she first experienced breast cancer, she had used one of several Facebook sites called 'bosom buddies'. One of the most important features of this site had been its supposed anonymity. Elaine was then faced with what she describes as 'a bizarre coincidence', when she recognised the person living on the other side of the street as someone with whom she had been communicating through this site. What this story brought out, however, was the way in which her many concerns with privacy and potentially also embarrassment in her use of social media were actually a migration of a pre-existing set of concerns formed in relation to offline social situations. Elaine has many stories that relate to concerns over face to face relationships, for instance neighbours not knowing how to respond to the news of her cancer. Another example was her not knowing whether a particular neighbour had actually seen the card that she put through the letter box - and if he or she had then been unsure how to interpret the lack of response. This was the kind of instance that informants used to highlight the advantage of WhatsApp, where one sees if the message has been read.

Elaine also provides examples that fit with what in the last chapter was termed the 'Goldilocks Strategy'. She described how her sister had used Facebook to organise her mother's funeral. Elaine noted that when it came to responding to the news of this death, people who were really close to the family would not have said anything on Facebook, nor would those who felt too distant and were therefore probably not on their Facebook anyway. However, Facebook was used by some people who did not feel close enough to make personal contact, but still wanted to make some sort of response to the news of the death.

For her own part Elaine distrusts Facebook and will not use it to discuss her illness directly. Indeed she worried for some time after a friend used direct messaging for that purpose in case all the other 'friends' on Facebook had seen this. Despite her ambivalence, however, 
Facebook has an important if indirect role in dealing with communication about her disease. As she put it:

We went on holiday, and I was trying to get pictures of me looking happy, and reasonably well, 'cos it says a lot doesn't it. A picture says a thousand words and it saves me having to keep saying this that and the other. If you just do a picture and put it on Facebook then everyone can see I'm having a great time in Spain and I don't have to explain myself ... . we went to France before that, and I took more pictures and I got other people to take pictures, and I did get an awful lot, I think a lot of people didn't really know how I was, at that point, I got huge amounts of likes, like 30 likes, because I think it was a way people were genuinely pleased to see me having a nice time. It was nice, it was good. Yeah.

At the same time her 'Englishness' comes to the fore when she contemplates the falseness of this kind of self-representation. As a result she is very tempted to turn this into ironic humour, and especially black humour, that typically English idiom. What she wants to do is post a pastiche of that message related to her present condition: " ing a lovely time in the hospice". It would be quite funny really wouldn't it? . . . I could do that I suppose. I don't think I've got the nerve to be all "Oh here I am having a jolly old time at the hospice". If someone posted that I'd just laugh, so maybe I should.' She also notes that social media becomes especially important partly because otherwise lying in bed is so boring. Yet she also sees a negative side.

I do look at Facebook, but I think it is one of those things. I have heard it can make people depressed, Facebook. If everyone seems to be having an incessantly happy time, and you're not. It can be a bit. It's the other side of it really. I've experienced both. And I had to stop Facebook for a while. I don't want to see about other people's holidays, I don't know, it does lend itself to showing off, Facebook, it is about that. It's not a place to put your innermost thoughts or your dark thoughts or things like that really. It's that sometimes, I don't know, it's just a time I got a bit low. I don't think you should look at Facebook when you're low. It just makes you feel...

This ambivalence emerged recently when there was something Elaine felt she really needed to communicate. The problem was that she had 
become increasingly upset by one particular phrase. Many patients struggle with the dominant conversational conventions about 'fighting cancer' or that one should 'be strong'. When her surgeon had finally told her that her cancer was inoperable he had ended the session with exactly that phrase: 'Be strong.' Elaine saw this advice as absurd, implying as it did that she had some control over these events, when in fact personal fortitude would do nothing to prevent this cancer from killing her. She contemplated Facebook, but then actually used text, to tell people that the one thing she did not want to hear was to be told to 'be strong'. The reason she chose text was she felt that this gave her more control over who saw this message.

Facebook has thereby become part of a wider polymedia. Sometimes it is better to text, sometimes to post. Elaine remarks on how nice it is to receive a physical card, but also how someone including their mobile phone number within such a card gives her the option of renewing a relationship. Each media has occupied its own niche within a complex situation. On the one hand she is dealing with profound and consequential communications, but on the other she wants to retain her English sensibility in controlling how people respond, and to keep humour as an integral part of such communications. As she notes, a physical card is great, although for a terminal cancer patient the conventional 'get well soon' greeting is not really appropriate. As usual she finds this funny.

There were many such personal stories about an individual's relationship with social media which reveal the way that scalable sociality, as part of polymedia, gives the ability to craft a repertoire of communicative channels; these are aimed at different groups of acquaintances to help the patient to deal with the issues arising from living with a terminal condition. However, as the research developed, the links between this experience and the wider ethnography of Englishness became stronger. What emerged strongly as the hospice research progressed was the evidence of isolation and loneliness among elderly people, especially elderly men. This would not have been at all surprising in an urban study, but had not been anticipated in a context where most of the hospice patients lived in villages much like The Glades. At the same time as this hospice study was demonstrating the consequences of isolation, the ethnography of The Glades was inching towards an explanation of the cause. ${ }^{24}$

As already noted, the preferred mode for English sociality was always in the public domain, for example greeting others in the street or when out shopping, socialising at village events such as the annual carnival or going to a performance of a cultural society. Some people used 
the sports clubs, others preferred the pub. There was evidence of widespread philanthropy and the hospice itself, which is one of several in the region, has over a thousand volunteers. This friendliness in the public domain and commitment to public welfare is contrasted with a powerful normative rule respecting the autonomy of the private domain: it is reflected in traditional sayings such as 'an Englishman's home is his castle'. Especially for working-class informants, people avoid going into each other's homes if they are not related. There is a consistent fear of imposing oneself upon the time or interest of others, and especially of being viewed as a nosy or inquisitive neighbour. The English assumption is that other people have better things to do than be interested in oneself, complemented by a fear of being thought boring or boorish if one imposes oneself upon someone else. The core characteristic is reticence. ${ }^{25}$ As a result social networks developed in the pub or on the golf course did not follow people back home when they became ill and unable to go out. People who regularly volunteered to work for institutions such as the hospice in order to provide private care to strangers found that they were embarrassed to offer that same care to friends and neighbours, and sometimes even to family.

The result of this propensity to social embarrassment is highly problematic. We found hospice patients who were born, schooled and lived in a village, but today as elderly cancer sufferers know only two other people in that same village. Neighbours cannot be presumed to know one another. Perhaps most shocking are reports from both patients and staff that relatives and friends actually stop contacting the patient, reflecting a deeper avoidance of acknowledging terminal sickness. In some respects kin relationships seem to be following the pattern of friendships in this regard, rather than the other way around.

This reflects the general point in Chapter 3 that friendship is becoming the idiom of kinship, while historically the opposite had been true. Grandparents take huge pride in claiming that they are not 'a burden' and have very limited contact with their descendants, so the reticence often derives as much from patients as it does from family and potential friends. It is the patients themselves who back off, not just friends and relatives. While this is hugely variable, the overall evidence is that the social universe of the elderly can often be remarkably small. This is especially true of older males who often choose to back off rather than become a burden. Institutions such as the church serve relatively few congregants. The problem is exacerbated once a patient is ill and loses their faculties, whether from immobility or dementia - at this point their social universe can shrink to nothing. The evidence is there with 
hospice patients, with staff reporting that in the most extreme examples even children may be absent from the funeral. ${ }^{26}$

This leads back to the fundamental point of this book with regard to social media itself. Into an English situation, which strongly contrasts a charitable public face with a defensive private space, comes a new set of platforms called social media. These have been defined here as media that do not fit traditional concepts of public and private media, but which occupy a space in between. As noted in previous chapters, the result is social media reconfigured to manage a space that is often neither too close and intimate nor too distant. As older people have migrated to Facebook, this has been one of the principal reasons for its success. They can, in effect, be inquisitive without being intrusive. It is early days, but there are already many instances where it seems that Facebook has enabled people to retain communication that otherwise would have ended when he or she retreated to the home. Because they remain in active contact they are also more likely to engage in active support, at the very least in the form of continued social communication - something that people suffering from loneliness and isolation desperately desire. If this proves to be the case in the longer term, then it will be because the very nature of social media, as located between the private and the public, addresses this very specific problem of English sociality: how to overcome the boundary between the two.

In my report to the hospice this conclusion needed to be set within the current situation of hospice care. As hospice staff noted on many occasions, the moment when a person is diagnosed as terminal or when a spouse loses their lifelong companion is the worst time to try to introduce new media to facilitate social contacts, as people may also have lost hope and confidence. The staff can predict this, but the patients cannot. As one nurse put it: 'I have been a nurse since 1980, and I can honestly say that out of all the ways in which this can help it is with the unbelievable loneliness of people. It is so tragic seeing patients who have lost someone they have lived with for 60 years once they have died because they have nobody going into that house, except once a year.'

For this reason it seems vital proactively to foster wider social relations that can turn into social support later on in the trajectory towards death and bereavement, and this should be done at the initial assessment. An older person who can Facetime on an iPad, or a younger person active on Facebook, has unprecedented means for retaining connectivity with others. Yet teaching new media takes considerable patience and commitment from the trainer, as well as confidence and ability in the learner. This may be easier when partners are still present or the cancer 
is in a relatively early stage, when there is a reservoir of hope and selfconfidence. Clearly there should be no pressure to impose new media on the unwilling, but there are grounds for explaining to new patients, who have never used a computer but might be less intimidated by a tablet such as an iPad, why this may become a very useful tool later on, even if this is not something in which they particularly want to engage.

Again social media works here within a wider context of polymedia. As already noted, webcam, with that additional comfort of visual encounters, often works best for patients. A nurse talked of a patient who now can only move one finger and her eyes, but has retained remarkable autonomy through her iPad. She remarked how fortunate it was that this skill with the iPad was already in place, since it could never have been introduced at a later stage. Apart from the iPad, however, the platform that seems already to have the most positive and sustained impact when elderly people take it up is probably Facebook. There are the extreme stories, such as someone whose life was saved through being able to communicate while still on Facebook that he was having a stroke, enabling the recipient of this information to call for an ambulance. ${ }^{27}$ More routinely Facebook may be having a considerable impact on grandparent to grandchild communication. Where WhatsApp is accepted, this is developing as a key platform for sharing photographs of new family members such as babies and infants. Because social media goes to groups, it can save a person constantly having to repeat updates about their condition to each individual..$^{28}$ It can also be valuable to carers, whose problems of increasing isolation are almost on a par with patients and who also need social support to alleviate their sense of anxiety and frustration.

Overall we found that there are grounds for advocating both the development of specialist internet sites such as 'bosom buddies' as well as general social media platforms. People with particular types of cancer often feel they do not want to discuss intimate issues to do with parts of their body with anyone other than those who are undergoing the very same and directly comparable changes. At the same time patients undergoing chemotherapy, and who are thus susceptible to infection, or patients who feel disgusted and ashamed by changes in their own appearance, find social media the only way to retain contact with others.

Finally the research encountered cases where patients are using Facebook cathartically to discuss openly both the experience of having cancer and the situation of knowing that they are going to die..$^{29}$ This can also help overcome the reluctance of other people to engage with the topics of death and dying. In one case posting and receiving responses from a growing body of relatives and friends helped to bring a patient's 
estranged family back together. As a result she argued that Facebook had been instrumental in transforming this period of her life before she died, allowing her to use her experiences to educate and uplift others. A man in his forties who worked in IT carefully considered how to use Facebook to keep friends and relatives informed as to the progress of his treatment. However, he also saw these postings as instrumental in his own acknowledgement of such developments. ${ }^{30}$

\section{Why breadth is depth}

Many people would expect that an academic project funded through the taxation system, as opposed to commercial funding, comes with certain social responsibilities. A rather simplistic version of this would be the idea that it should be shown to have demonstrated 'impact', viewed as practical and applied consequences. There is a danger that a chapter on applied consequences could be read as a narrowing of that kind, but actually the contents of this chapter lead to a very different and much broader conclusion. Firstly such a criticism ignores the most important of all the benefits of this kind of academic research. These are the contributions to knowledge and education which are equally ways of contributing to public welfare. Hopefully all of this book is worthwhile and matters - not just this chapter.

However, the real danger of such an argument is that it would lead to a similar narrowing down of research. Already research grants are increasingly trying to pre-empt the research that they fund, to the extent that the proposed 'impact' is specified from the start. This consequently influences the proposed methodology, increasingly conceived in the language of correlations and specified relevant variables. The conclusions of this chapter are diametrically opposed to such logic. It is hard to imagine that the sheer volume of knowledge and insight that should arise from the scholarly commitment of ethnography would not ultimately be relevant and helpful to applied and practical projects conducive to the welfare of populations. However, this is actually much less likely, and the evidence base would be far shakier, if this were done at the expense of the rather special and distinct quality of ethnography as open-ended and broad-based holistic contextualisation. The response by the ethnographer to the request for consequences should not be a narrowing down to selected topics, presumed likely to be the key variables prior to that research. Ethnography rather shows how this is likely to lead to mistaken and misleading results. 
The two examples described in this chapter make this same point in very different ways. In the first case this argument follows by default. The ethnography of The Glades was not intended as an applied project, and the enquiry always retained an open-ended commitment to breadth, so that the study of taunting and negative interaction, for example, was merely one component of the research on schools. The ethnography equally contributed to the evidence for the opposition between visual materials on Instagram and Twitter, presented in Chapter 3, with no applied intentions. It was this breadth of ethnography that suggested there might be a problem with the more policy-directed research that had already predetermined categories of bully and victim. It was because the ethnography encountered these issues equally through engagement with parents and pupils in their home context, rather than just at school, that the analysis could be more precise in delineating exactly how social media transforms these negative encounters as indirects, the erosion of distance and hiding behind a screen. Ethnography is the only approach that tries to engage people in all their varied contexts, as opposed to presuming in advance which will be relevant to which. Taunting could be revealed to be part of a wider culture of negative interaction rather than an expression of predefined roles.

The same point emerges when we start from the opposite trajectory in the second example. Here the initial enquiry was narrower, since the hospice is not situated in The Glades and the study was a response to the request by the hospice director for some applied research. This meant first interviewing patients in their homes and then speaking to staff and carers at the hospice. Only subsequently did it became apparent that the results and recommendations would be much richer if this study were combined with the simultaneous and wider ethnography based at The Glades, because one of the core problems that emerged from the hospice research was that of isolation and loneliness. Yet it was not simply the interviews with patients that helped shed light on this; it was actually the primary research project directed at social media in The Glades. A patient who implied that their only social contact was their gardener was backed up by our interview with a gardener in The Glades; he noted how elderly people increasingly employed him for tea and company, not just for gardening.

It was also the wider ethnography that helped to highlight the specific issues of Englishness and the problem of separation between the private and the public, and this in turn helped to explain the prevalence of isolation and loneliness even within a village setting. The hospice study might have been both less successful and produced less useful 
suggestions for application and policy had it remained true to the initial project, focused on the hospice itself. In social research breadth is the prerequisite for depth.

In examining these two studies that target either end of the age spectrum one can see another reason why breadth matters. Often we see things in a narrower compass because of institutionalisation. Young people are studied in schools, those with terminal conditions in the hospice - but people do not live only in schools, nor in England do they only die in hospices. In both cases people spend time there, but they mainly live and often die at home. The same assertion would be true almost irrespective of our topic. Anthropology has become ever more essential to the study of modern life partly because more and more of that life takes place at home - which means we have to understand and engage more closely with these private worlds. It is only ethnography that feels 'at home' in people's private homes. Yet without understanding the lives of families and homes, we miss the fundamental context for so much else. The same lesson is likely to follow as social media itself becomes more significant in people's lives. If social media is where we increasingly live, then this is where research will increasingly need to take place. 


\section{6 \\ The wider world}

As we reach beyond the more personal use of social media within friendship and the family we encounter a large number of institutional settings which are increasingly exposed to new social media, each with its own patterns of usage and consequences. Two of these, education and healthcare, were encountered in the last chapter. This chapter will examine three more examples: religion, politics and commerce. With five cases considered it should be possible not only to gain a sense of what lies in common across institutional usage, but also how social media needs to be considered with respect to each particular context. Here the three sectors are first examined in their own right and the results then compared. ${ }^{1}$

\section{Religion}

Religion is very much a minority pursuit in The Glades, as it is in England more generally. A survey in $2005^{2}$ suggested that only 6.3 per cent of English Christians regularly attend Sunday services. Of these, 28 per cent are Anglican, 28 per cent Catholic, 9 per cent Methodist, 9 per cent Pentecostal and 8 per cent Baptist. The main Anglican church in Leeglade may have less than a hundred people for a Sunday service (the average in England is 54), although around 1,600 people attend at least one of the various Christmas services. The two ancient Anglican churches occupy prominent positions and are traditionally associated with the leading citizens who dominated their respective villages. The vicar is still expected to serve on several village committees.

In England the Anglican movement represents the established Church, while Methodists and Baptists developed as 'nonconformist' movements that migrated still further from the original Catholic church. 
There are active Methodist and Baptist churches in both Highglade and Leeglade, and the biggest weekly congregation is at the Catholic Church in Leeglade. Recently things have become much more ecumenical with a thriving 'Churches Together' group; this includes all these denominations and the cooperation represented by 'Messy Church' directed to parents and children. Some prayers, for example the Palm Sunday worship which takes place at the Leeglade village green, include all the denominations.

It used to be that people generally died within the same denomination that they were born into. This was likely to reflect class lines. The 'posh' section of the village who could afford housing near to the village centre tended to dominate the Anglican church. Lower-income villagers living on the periphery were more aligned with the Baptist and Methodist churches, while those of Irish Catholic descent mainly remained with the Catholic church. Today, however, individuals are much more likely to find a church that suits them personally and to migrate to that church. The main spectrum of choice is from the more evangelical churches found outside The Glades in places such as Treedon through to the traditional Anglican churches of the village. At the same time the churches realise that they cater to a number of different niches and have started to differentiate services, encouraging the elderly to attend one service tailored to their needs and the young to another.

\section{Informational use}

For the churches, social media is first thought of as an additional means for the dissemination of information. As such it builds upon two established modes. All the churches now find email central to their communications, but because they largely work with more elderly villagers they cannot assume that everyone has internet access. So the Anglican Church in Leeglade still prints around 600 parish newsletters a month, around half of which are distributed for free. In addition, a perhaps surprising number of people still pay for these, buying them at the local shops which stock them. On the other hand, the Methodists have realised that texting these days can reach pretty much everyone, since most elderly people who may not use the internet do now possess mobile phones. So if, for example, the church cannot be used on a severe winter's day there is a texting equivalent of a 'telephone tree's to ensure that everyone gets to hear about this, including congregants in their nineties. 
Email has now become the natural form of information dissemination for many other matters, though it is generally not seen as suited to theological discussion.

Each church will already have a website, and this was the initial template for the use of Facebook sites which have now become common. It is recognised that Facebook lends itself to a more dynamic interaction and is a more natural place for daily postings. In turn this dovetails with the increasing use of social media for the internal circulation of information. A Methodist minister, for example, might go to national websites and download prayers for the day, or indeed use a phone App for that purpose. The Anglican curate re-posts a diocesan thought-for-the-day email onto the church's Facebook site. The church's Facebook page was mentioned by several of the villagers in the course of other conversations; it seems to function quite well for disseminating information and as a reminder of events for those already closely associated with church activities. However, there was no evidence that other people, less involved with the church, were likely to view such postings.

The Methodists are perhaps the most adventurous in regard to the wider potential of new media, but within limits. They regularly employ a PowerPoint in their youth-directed service but never in that for the elderly, even though it is mainly the elderly who may struggle to hold heavy hymn books or have impaired sight, and thus would most benefit. When using new media such as texting Methodists explicitly cite the precedent of John Wesley, who founded the Church through developing a more direct and open form of preaching. Similarly for a more evangelical lay preacher the use of Facebook is legitimated as continuity with the Christian tradition of 'getting the word out'. Part of the acknowledged mission to expand the Church's reach, a precedent is the effective evangelical use of prior broadcast genres such as television.

\section{Group use}

One effect of new media is to expand the potential group associated with a particular church, previously limited to those who live in the immediate area. One of the most active members of The Glades Methodist Church actually lives in Girming, for example; he practically never comes to The Glades because of impaired mobility, but uses online media to participate in their activities. A woman in The Glades prefers 
a church in Treedon and therefore makes use of their women's prayer group which is on Facebook:

So there's a prayer request you can put it on there. Just say 'hi ladies, I'm struggling with this at the moment' and as the day goes on there are 125 people who say 'seen'. The church itself probably has 1,000 people. I would say some of the ones that have been lovely have been through private messages. One mum on Facebook who I know from the Treedon church, I don't know her that well at all, it's just that we would say hello if we met each other, but we never hung out in the same friendship group. And her daughter, again I wouldn't know at all, is probably about 15, but she's quite severely disabled and she put a status on Facebook and she always amazes me about how cheery she seems to be despite the fact that she's so knackered from everything ... And my heart went out to her 'cos I just thought - bless you that you've put this on here.

She argues that people will make a genuine plea for camaraderie when someone is ill or at the end of their tether. Yet she suggested that even in those cases there is often an element of humour or banter involved, usually in England a means to prevent people becoming embarrassed by not being sure how best to respond to serious events. Here, then, we see a close engagement with the norms of social media as a group-based activity alongside the sense of belonging to the Church.

An initial use of Facebook to disseminate information commonly develops into this group interaction, as postings attract comments and Facebook becomes seen as a place for discussion. The Baptist Church helped to develop a general 'Churches Together' Facebook page for the village, while the Methodists developed the Facebook page for 'Messy Church'. They also run a small group called Agnostics Anonymous, which is a discussion forum that links with a local pub. By contrast the Catholic Church, which has the largest congregation but an elderly one that seems destined to decline, has set its face against the use of new media for pretty much any purpose at all. Social media is starting to become an idiom for discussion of more theological issues, but only slowly. A lay preacher discusses at length the way in which the person one encounters online may not reveal the 'truth' of that person - a typical criticism of social media. There are more common references in sermons to people's attention to screens getting in the way of real life and concern for other people. However, there is also some recognition that social media has provided examples of community and support. 
The most common assertion about the impact of social media in The Glades is by clergy. In the main they wish to imply that organisations such as the Church represent genuine communities, but that these are being undermined and replaced by social media such as Facebook which represent a kind of 'community-lite'. Yet these same villagers suggest evidence entirely contrary to this claim. As one parishioner noted, 'The church put on a Facebook page, a lot of people then did become friends with the church. Then I realised how many people are actually on there that I know and I see every Sunday. [Have you got to know them better now through Facebook?] Yeah. A lot better. Normally, you don't really discuss what jobs they do or what social activities they do. You meet them in a church setting, talk about church-related things'. She then notes that thanks to Facebook she has come to realise who is related to whom and who she knew about through other channels. Another villager noted, 'When my husband had his heart attack last year I put on that he'd had a heart attack, it was amazing how many people sort of commented on it, wanted to know how he was, when he had his heart operation, quite a few of them were praying for him, that sort of thing. That's nice 'cos I thought I've only ever known you through Farmville, interested enough to comment and think about it. A lot of the people I know are Christian people.'

On many occasions people who might once have come directly to the clergy for support post about feeling depressed or betrayed by a friend on Facebook. It is only if the clergy have personally friended them on Facebook that they come to hear about these problems and can respond by calling round. A third woman likes the fact that her Facebook mixes the people she knows from church with others. She finds it much more effective than going on websites as a means not just to remind her about church activities, but more importantly for her to share some of the church news with others and possibly get them to thereby become more involved in church activities, since she works on several committees organising such events. This is something she hopes will be accomplished through her personal Facebook site. One way she does this is by periodically posting a hand-knitted Christian lamb to pose by religiously related images such as festive meals (Figs 6.1 and 6.2).

More generally there was a core group to each church that was very close to one another and accord with our ideals of community. For most of those who just attend services, however, it is the church rather than Facebook that has in some ways been community-lite, because interaction was limited to church-related issues. By comparison Facebook is 


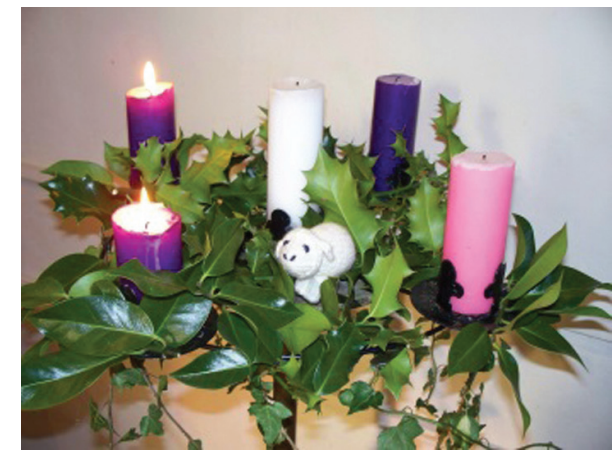

Fig. 6.1 Festive meals

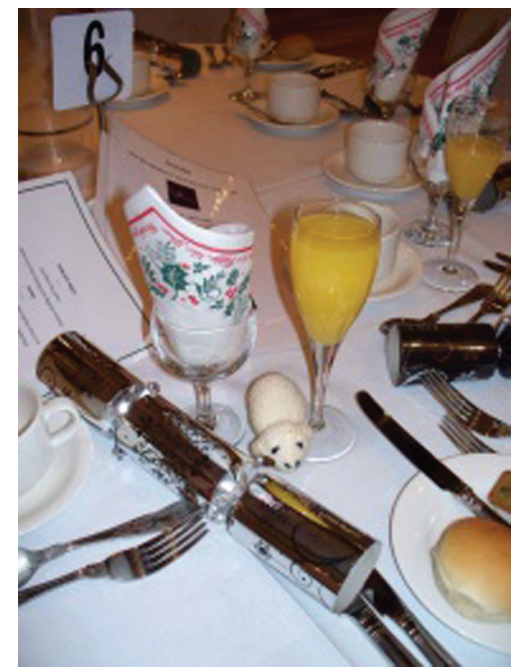

Fig. 6.2 Festive meals

much more holistic and makes visible the interconnectedness of people, especially people living in the same village, linking to other aspects of their lives. More than that, these quotations suggest that for most people neither is sufficient, but the two work in tandem surprisingly well. If one is looking for interaction that approximates our idea of community, then it is the way Facebook builds upon going to church that seems most effective. This conclusion would not be true for the more evangelical church in Treedon, however, which is an example of more intense community in its own right. 


\section{Personal use}

There are more dilemmas when it comes to the personal use of social media, not only for the priesthood but also the involvement of the laity. A Methodist minister has a blog which is not problematic since it is in effect still just a form of dissemination, although consisting of more personal reflections. The Anglican curate, just starting out in his work, finds that it is very helpful to remain in contact by Facebook with the other clergy that he trained with, who may encounter similar issues and dilemmas. They also continue to celebrate their respective developments such as carrying out their first baptism. Some but by no means all the clergy have accepted that new media does not preclude a deeper spiritual engagement. One regularly uses a Jesuit site based in Ireland which takes them through Ignatius Loyola's Spiritual Exercises in a daily, cut-down version.

The issue that is increasingly faced by all the clergy is the degree to which they should allow congregants to friend them on their own personal social media. A Methodist minister noted that at first she eschewed the idea of having church members on her private Facebook, but has since relaxed and includes a few. She now realises that this may cause problems since Methodist ministers are rotated after a few years. Having built close relationships, it would be an obvious use of Facebook to remain friends. Yet this militates against a smooth transition, potentially making it harder for the new minister taking over in the village, and leading to further problems of distancing and dependency.

She also uses texting for pastoral care, so 'if I know someone has got something going on - tends to be with the youngest age range I will give them a quick text. I will say thinking about you today, prayers and hugs, hope everything is OK'. Where clergy are on Facebook with congregants it opens up the likelihood of seeing posts which are hard to interpret as other than calls for support. Clergy showed me directly (anonymised) postings on their Facebook by individuals who were clearly in considerable distress, feeling depressed or bereaved or betrayed by a friend. These are things which once may have led them to come direct to the clergy, but the clergy now come to hear about them through Facebook. In some cases one can see personal messages of support and comments put there publicly as a direct response by these same clergy, which in a way also advertises the way in which clergy support people in need. At the same time they are likely to send 
out a private message asking if they want to chat or simply to visit in person. The Anglican curate notes:

I think where it is useful, in terms of how the village communicates. If I pick up from my feed that a friend of a friend is terminally ill or suffered a bereavement or whatever, that does open the door and I would be very happy to contact those people and say you know, please don't think, this is not private, I've seen it on here. You know where I am, is there anything I can do? And that's, perhaps that's the sort of fringe benefit of being on, you hear those things, in a slightly quicker time.

The contrast is with a lay preacher who reflects on his very personal dilemmas with this more intense contact through Facebook. He is struck by the way the contradictions of Facebook reflect those of his own life. As an individual, along with many people in the church, he would clearly much prefer to have a very private personal life. At the same time he now has a public responsibility which includes developing the power of charismatic delivery in public performance as a preacher. Things became complicated as a result of a recently developed relationship with one of his congregation. Some of his church congregation, who tend to be elderly and highly conservative, turned out to be not at all happy when aspects of his private life, including this particular relationship, became more widely known, partly through the new partner's postings on Facebook. These critics were not slow to come forward, and both he and his new partner have suffered quite some distress through other critical social media postings that subsequently followed.

So it is not surprising that he reflects theologically upon the same contradiction. On the one hand he claims social media represents this positive potential for spreading the gospel and inclusiveness, where he can remind his flock that 'God loves you' and embrace the natural sociality of congregations.

But also, there's a dark side to our humanness. We love to judge. To see what the other human is doing. We love to hide sometimes behind that anonymity. And that's really horrible. And nowadays they get what you call 'trolls'. They'll attack someone. Like glad that person died ... When they crucified Jesus, very akin to Facebook, a majority of people turned against. One week they welcomed him in, hosanna hosanna they cried, and the next week 
that same group cried 'crucify him ... I've had people, I've had Facebook used against me in that way. In relationships. Jealousy. Envy. But to discredit. To bring about a fall.

As noted, this individual is a lay preacher. It is less likely that a fully trained member of the clergy would find themselves in a similar dilemma, for reasons that are especially evident when it comes to the Anglican Church.

\section{The Anglicans}

The Anglican Church faces a problem, as all churches do, in that much of the appeal of the Church itself is that it represents a rock of tradition and custom, something to which people may hold on to while a flood of changes take place all round them. They look to the clergy for protection from change and reassurance about the values they have always held. For this reason such parishioners do not particularly welcome the idea that the Church itself could be an instrument of such change. This would be particularly true of the Anglican Church (and Catholic Church), both of whose roots are closely associated with conservatism in both political and general terms. There are many additional grounds for avoiding new technologies, most especially the sense that some people are thereby likely to feel excluded.

What this amounts to in practice includes a kind of political agnosticism. As the curate says about social media, 'I think it's a very good place to note events. And try and offer comfort, support, etc. I think one has to be sensible and restrained about opinion. And simply because it's a particularly Anglican understanding of church that our understanding of ourselves is that we are here for all the people of The Glades. Whether they come to our church or another church or none. And you know, I will certainly not be drawn on my political opinion for instance.' One reason for this is that, as he further observes: 'I think also, there's a distinction with the clergy, who are the last probably professionals required to live on their own patches. Most doctors, lawyers, teachers don't live anywhere near the places they work.' If anything then, the clergy will be more circumspect and wary of voicing opinions. Having said that he also notes that 'everything that can be public about you ought to be'. ${ }^{4}$

The key point with regard to the wider arguments of this volume is that in listening to the debates within the Anglican Church, in 
particular, we see that this reticence is focused largely upon the issue of how far social media should be allowed to breach the traditional distancing between the public domain and the private domain. In short, the established English Church provides a crystal-clear example of what seem to be English sentiments about the public and the private. As one vicar said, 'If I had a new curate coming who is into all of this I would need to caution him. He's about to get ordained and I think he's really got to learn the boundaries about what's public and what's not appropriate in public.' Indeed, as the actual curate noted: 'Some people are scared I think of social media because it's this putting in the public sphere what used to be private. It is not that they cannot see the potentials of new media.' Email is preferred to telephone since people can reply at their own time and it is not imposing on that particular moment. This curate is already very sensitive to the accusation of imposing himself. He comments that 'certainly I've had it since I moved here, numerous times been going to see people and knocked on the wrong door, for whatever reason. And people do seem to treat that now as an invasion of privacy. If they weren't expecting someone, it's an affront almost. So I think, that's an unfortunate part of our culture, but it is where we are now.' He does not make his mobile number public.

A further example comes from discussion about a project to send people text messages on a daily basis. People who come to baptism are handed little cards so they can subscribe to a week of texts. The clergy recognise that with services only taking place weekly people want to receive something every day. That's the way the church operates. The texting is the church service. Now there are email links for daily prayer, morning and evening.

'Meditations, daily meditations, that's becoming very popular. Saw people there sitting with their iPads, I'm saying my prayers today.' Yet the clergy seem terrified of sending these texts to people who do not actually want to receive them, who feel perhaps that it is too intrusive. I attended a special seminar of Anglican priests in the region to discuss the use of new media and, although there was some enthusiasm, it was heavily tempered by this fear of intrusion. Historically the English Church was not something that imposed itself upon the private domain; it was rather a resource to which people could turn in need. In a way it reflects the personality of those involved. As one member of the clergy admitted, 'I'm a complete introvert, I want to be able to choose when I contact people and when I respond to people'. 
This caution is evident also with respect to even more innocuous text messaging:

We have a toddler group twice a month for parents, carers, recently baptised new babies, might be quite interesting if you want to talk to new parents. It's only twice a month. People might forget when it is. I was thinking text first of all. Then it took a long time to see if people would welcome that and not find it intrusive. I think we are probably of the generation where texting and mobiles is more for private use and chosen personal use. I wasn't sure if people would want to have the church muscling in on their texts. But having established that, then we've had to look at how we send text messages. People have been really quite pleased to have a reminder, and it doesn't seem to be out of order to have the church sending texts to people's phones.

This sounds mild and reasonable, unless you have carried out anthropological research in half a dozen other societies where this fear of intrusion would be so unimaginable, so extreme, as to be completely bizarre. It is the comparison that identifies just how English this is. After all, as made explicit in the conversation, this is not even about texting that could be called religious. It concerns texting just as a simple reminder to parents. Listening to this vicar, one is reminded of so much English literature from George Eliot's Middlemarch to the novels of Trollope. These words seem to have come from a centuries-old sensibility; the Anglican Church's quiet, respectful reticence in the face of the parishioner's private life. The fact that these clergy are also very uncertain of whether, for example, one should publicly announce a funeral or a wedding would again astonish the people of our other field sites around the world. In many of those sites religion is tightly integrated into people's family and social life - it barely leaves them alone. Clergy expect to be opinionated and interventionist. In respect to the topic of this book, the conclusion must be that the increasing evidence presented by this ethnography for the Englishness of social media makes more sense when set against the much more established Englishness of the traditional English Church.

\section{Politics and political views}

The term politics can refer to the narrow field of party politics, the entire infrastructure of the state or, as in the term 'politicised', a 
dimension regarding the political implications of pretty much anything. The larger ethnography covered a whole swathe of areas that have a political dimension. Chapter 5 discussed the school system, but the ethnography also covered issues of local policing, transport, the health service, social housing and housing policy more generally, the incidence of poverty and forms of welfare provision. There is also a vast amount of public service carried out by this population which covers areas that might otherwise have been the responsibility of the state, such as extensive involvement in care and welfare services including the hospice. ${ }^{5}$

In this section, however, the focus is limited to those people actually referred to as politicians, and references in social media to what could be called Politics with a big P, as well as the discussion of such politics in private social media. There is a general consensus that people in England are disillusioned with and alienated from politics. One constantly hears statements by villagers that all politicians are the same; they all make promises which they break, all are self-serving and so forth. The problem may be less that politics has failed the electorate and more that it is in some ways the victim of its own success. In a site such as The Glades, with decent housing for the majority, good schools, free healthcare and little crime, for most people the institutional operation of the state has become so taken for granted that it receives little credit. People can therefore afford to withdraw from any personal responsibility to help determine political action and instead exploit politics largely as an idiom or a discourse to create a stance popular among their peers. In other words what people say about politics may today be more intended to position themselves relative to their peers than act as a reflection on real political opinion. ${ }^{6}$ In short they see more benefit in making fun and bonding through often quite glib or superficial criticism of politics rather than actually taking it seriously. Certainly this is what dominates 'politics' as it appears on their social media.

The situation of actual politics was very different. Although the villages may be visited a couple of times a month by their local Member of Parliament (MP), who also writes a column in the monthly village magazine, mostly the interaction will be with local councillors who are themselves villagers. Partly because the popular stereotype of politicians is so negative, it is hard to see these individuals as motivated by self-aggrandisement or a desire for power. Rather political involvement tends to emerge as a form of community service. So a local politician has most likely come into that role having worked as a school governor 
or secretary of a residents' association, or to have served on a church or sports committee. Most of these are pretty tedious contributions, mainly concerned with village facilities such as community centres, planning applications, sports centres, gardens and footpaths.

This work is largely unacknowledged and requires a high degree of altruism and sacrifice of personal time. As those who serve on such committees observe, these days most people want to constantly complain about services, but very few are willing to put themselves forward for community or political roles. The self-description of the most successful local politician was 'if you want something done, ask a busy woman'. She is both extremely busy and extremely effective at getting things done. So the actual experience of these caring, highly involved, largely altruistic and devoted local politicians was the precise opposite of the popular image of self-serving, power-hungry and detached ogres.

In Highglade almost all the local councillors were middle aged with grown-up children. On the one hand they lacked experience and confidence in the use of social media, but sometimes they also imagined social media as some kind of panacea with regard to a generally acknowledged problem - the lack of involvement of young people in local politics. In practice 'old-school' politics was still possible, in as much as the people who tend to run and attend local organisations are a relatively small proportion of the village population and it is possible to know pretty much all of them on a personal basis. One of these older councillors is very affable and popular and one constantly sees him around on the High Street.

There was very little evidence suggesting much potential for social media. A parish council ${ }^{7}$ Twitter feed is unlikely to be followed, people consult the parish website only on a need-to-know basis and a Facebook page has very little appeal, being less effective than a regular website for the provision of information that would be its main purpose. Social media might be effective if there were some major campaign issues that could see the local population fired up and concerned. However, these are very rare. This is an area of very low crime and the main 'political' issues that arose during the ethnography were concerns over the fate of particular buildings on the High Street. It is also hard to see how social media would ever deliver the youth to civic concerns in the way these politicians imagined. These conclusions are reinforced in discussions with the local journalists about their use of social media. Certainly Twitter saves them a good deal of time in terms of keeping up with news from various local organisations. They are among the few who would take note of such information. As with the politicians, they find email is still the main way people 
contact them, while Facebook can be useful in the dissemination of news or for quite specific local campaigns. Yet all of this remains quite limited.

One politician who works at the district level is perhaps the most active in trying to involve new media. She has a reasonably successful blog, and receives a few relevant emails in a day which she regards as helpful, such as a picture of a new pothole in the road. She puts political news on Facebook and Twitter. She feels that social media seem to garner much more attention in other parts of the country than in The Glades, and regrets that there is little point in trying to use it for election campaigning. As a more active user, she is also the most realistic about its limited potential. Twitter is useful as a news source, but to actually get messages through to the community she finds email far more effective, having gradually accumulated the email address of perhaps a quarter of the village households. Even then she typically only gets 20 responses to a question, unless it's a very clear option, for example whether the High Street should have a lower speed limit (which garnered 300 responses). She encourages people to text her, but they rarely do. Thirteen of the 15 council members have email, so this has helped their internal organisation.

The one way in which social media does have an original impact relevant to a local politician is that it crosses over between the domains of the private and the public. In a village, showing distress about some welfare issue on one's personal Facebook can impact upon other people's conscience. The same politician reports that she may get 70 'likes' for a personal Facebook posting on a local issue. She feels it helps to remind people that she participates locally, that her children are at village schools and that she uses the same services, especially if she makes a comment about waiting times for doctors or someone not getting the place they hoped for at a local school. It makes her less of a 'politician' and more of a local representative, which is precisely the perspective that she seeks.

However, there are boundaries to this local involvement that return us to the sensibilities of Englishness and people's dislike of intrusion. They do not want to have others knocking on their door or texting them without permission. What a politician regards as a leaflet with local information may be regarded by the recipient as unwanted junk mail. A politician has to solicit support actively, however, since they depend on being re-elected. So to be successful she has to be quite circumspect, but also sensitive to people's doubts. 'I don't actually like asking people anything, votes, money anything. I think if I'm knocking on their door I should be offering something not asking.' This works because whatever their views on 'politicians' in the abstract most villagers will 
acknowledge the altruism and importance of these individual local villagers as politicians.

This property of reaching directly to people that gives social media its main positive potential at a local level makes it problematic when one is an MP for the region. Previously there was a relatively clear hierarchy, such that people went to local councillors for local issues even if they were not too sure about the relative responsibility of parish councillors, district councillors and county councillors. Today if they have a grievance with a local garage or pretty much anything else they just try to seek redress from anyone they can find who will listen to them - and that increasingly includes their MP, so the distinction between political levels has disappeared. Complainants feel they might as well start at the top rather than the bottom of the political tree. As a result the MP's predecessor received 20 letters a week, while the current MP may get 80 such emails a day, mostly on matters that previously would have been dealt with locally.

On the other hand the MP finds social media rather more effective than local politicians because he is working at a level where he may want to mobilise a wider population around larger issues. He was impressed when recently he spent $£ 250$ on a Facebook advert for a jobs fair, which was viewed by 36,000 people and resulted in 5,000 attending. He views Facebook as much more effective than a website for organising volunteers. He has an email list of 13,000, but claims to be careful to only convey local information and nothing that could be seen as party politics. By contrast he is sceptical of his Twitter account, which he suspects mainly consists of journalists hoping he will say something stupid.

Very little of this has any bearing on the politics found on most people's social media. Visual postings such as memes with a political inflection are not uncommon in ordinary people's Facebook or Twitter, but the vast majority of these are there for comic effect. Politicians are seen as fair game for humour in much the same way as celebrities. Simply swearing at a well-known politician by calling them a ' $\mathrm{f} * * * * * *$ ' this or that is viewed as a genre of humour in its own right. There may be occasional reference to a serious political concern, but this is more likely to be about some international crisis such as hunger in Africa or Middle Eastern conflict than anything local. An exception would be the lowest income population living in social housing, who may post or indeed vent about right-wing issues such as anti-immigrant concerns. They are also the most likely to post serious nationalist sentiments on Facebook, for instance support for the armed services. ${ }^{8}$ 
While visual posting is largely based around humour this is less true of textual posting. As a result Facebook sometimes makes people more aware of the political stance of acquaintances such as work colleagues. This was almost always mentioned by individuals who considered themselves liberal or left wing, who referred to unfriending or being made uncomfortable by postings that they considered illiberal or right wing. Most common were overtly racist postings, but a Jewish villager was offended by his family's unqualified support for Israel on Facebook (a view he did not share). Others were offended by people posting anti-immigrant sentiments. One example was the class of a local secondary school where pretty much everyone had been Facebook friends with each other while still at school, but within a few months of them leaving one group de-friended about a dozen of their class after the latter had shared a set of postings that they considered racist. It seemed unlikely that Facebook or other social media are sites that would particularly influence or change people's political views. Instead it seemed that - as Pierre Bourdieu has argued ${ }^{9}$ - the overt expression of politics has become one element of the way in which people express their personal taste, akin to the clothes they wear and food they enjoy. It rather serves as an instrument by which people decide the people whom they like and dislike rather than as a conduit for discussion of the policies themselves.

Not surprisingly a university student provided a good example of this kind of concern. She noted:

You see a different side to people, things that they've liked, you could think 'I don't agree with that' or comments they've made that you find offensive. Things you would never have heard them say in real life and there's people agreeing with them so you've got a whole pool of people who have completely different views to yours. Sometimes I unfriend. A whole bunch of people gave very racist homophobic comments you know after the RAF base, the guy who was wearing his help-for-heroes T-shirt, the guy that was killed. Anti Islam, death penalty stuff. People in Highglade and the surrounding areas. Other people around the same sort of time deleted the same group of people that I did, 'cos you see everything and there's people's comments and say what the hell you talking about I don't agree with that and they were mostly girls who got rid of them. I can think of two girls that got rid of the same group that I did. 
Given the growing liberal consensus on most social issues people were increasingly comfortable about 'going public' on Facebook as a means to garner support. An Asian woman exasperated by her family's response to her marrying a non-Asian male and in giving birth prior to the marriage itself used Facebook to demonstrate how her friends would support, rather than condemn her. Individuals seemed comfortable in posting with regard to issues of sexuality, though this varied from one gay male who was strident and very funny in the way he did this to a female who did not hide that she was a lesbian but did not proclaim it either. There are also people in The Glades who regard themselves as personally 'activist' around certain political issues, of which by far the most common are 'green' concerns; these tend to be associated with the most affluent households, especially in Highglade. Some of these are associated with the 'Transition Town' movement that proselytises for local and green issues, but the same group may be ambivalent about new media. In some ways their green concerns dovetail with a deep conservatism, such that they do not tend to use social media to the extent that might have been expected. Indeed some seem to believe that social media and all such innovations represent an unwelcome increase in 'energy expenditure'.

\section{Social media in commerce}

When I was first introduced to social science it was a period when a very general critique of something called 'capitalism' was fashionable. As a result we tended to assume that pretty much all commercial and economic forces worked effectively together to promote a combined sectional interest. Later on I spent years studying both commercial companies and state institutions and found them to be a complex mix of different interests that often worked in contradictory ways - and to a surprising degree ended up with practices that could be destructive as well as productive of their own interests. ${ }^{10}$

As noted in Chapter 2, one of the first major results of new digital communications, so far from facilitating capitalism, was to undermine and then demolish the work of nearly two centuries. During this time commerce had tried to isolate the work environment so that during working hours employees would not be distracted by family, friends and wider relationships. Social media has seen huge commercial successes, but failed investments in companies such as Murdoch's MySpace and Google's Orkut show that capital is only one of many factors in understanding the nature of social media today. 
Commercial companies are constantly reminded that they 'have to be on social media' which is now crucial to their survival and profitability. This is because there are many management consultants and now specialist social media companies whose interests depend upon persuading firms that this is the case. When the research on The Glades began it started with a survey of any online activity by village companies and services on Facebook and Twitter, websites and so forth - enough to make clear that pretty much every company had tried to initiate some kind of online activity. However, the sheer number of sites that had been started but were no longer maintained indicated that for many companies it had proved hard to see exactly how social media would help them develop. This common disillusionment was confirmed in subsequent conversations with local businesses.

By the end of the field work most companies had enough experience to form a more realistic appraisal of the potential and value of spending time on social media for their particular concerns. They also knew better how to deal with the intrusion of social media into the internal working of their companies. A small industrial estate between the two villages includes companies ranging from around 3 to over 600 employees. Most now had some sort of policy that tried to control internal usage of social media. The assumption was generally that social media was a problem rather than a solution, and they were particularly concerned that employees should not discuss company business online.

The situation looked very different when it came to actually talking with their employees. I worked with one company, Sringal, ${ }^{11}$ that had 32 employees. At first most employees saw a positive side to Facebook. They reckoned about half the staff tended to share Facebook with the other employees. As a result:

You just see things that other people post about interests and what they are doing that you wouldn't know about them otherwise, especially with people in other departments in the company. So, for instance, I was putting something on Facebook just about looking at a guitar the other day. And one of the guys from the assemblies department was jumping in and saying have you thought about this one, which is probably not a conversation we'd have here ... I guess it brings you together more as friends within a company rather than just colleagues ... That glimpse into the family life was nice, makes it like Oh Yeah, on daily basis, if we're not the same department ... nice to see what people are up to, their families. Catch up with their lives. When I talk about [her daughter], 
people can actually put a name to the face. I think it's lovely when you talk about children see them growing up, don't see that but do see it on Facebook. A colleague put up some nice picture of the zoo, see the children. That's nice ... In our old (smaller) company we were very much focused with each other, all mixed with each other, knew each other, knew their children. Was quite nice, used to sit and have a cup of coffee in the morning, would discuss what had happened at the weekend, but that doesn't happen now. I wouldn't know one thing about another person now, because we don't communicate like that. I think it is the size. Don't mix like you used to. I mean I do find that very hard in this company now.

For this individual Facebook has allowed the company to retain something of the more personal relationships common when it was much smaller but no longer viable at the office itself. It also meant they stayed in touch with people who had left the company far more than had been the case previously. They had recently met up with six ex-employees, some of whom had left four years previously. On the other hand, other employees noted that Facebook intimacy could have a downside. They talked about one individual who revealed what they saw as an aggressive, right-wing aspect to his personality that put them off working with him. They also found it difficult to refuse friendship requests at work from people with whom they really did not want to share at this level, for example senior management. The employees could also be embarrassed by access to family quarrels. In other areas, however, there was uncertainty. Most were favourable when one of them posted about the death of a brother, but admitted that they had not been sure how to respond. In general the larger companies would try to prevent this kind of office Facebook network, believing that they have more to lose.

Problems can indeed arise for management. At the 2014 Eurovision Song Contest the Polish entry was the most overtly erotic. An employee's Facebook comments about this prompted another of the Polish employees to complain to management. However, the manager had to note that as private correspondence, this was beyond her responsibilities. In other companies there were more extreme anecdotes, ranging from people finding their partners through shared office Facebook pages to almost violent quarrels. In one case a restaurant had severe problems when a manager the company had sacked continued to control its Facebook site and put up many disparaging posts until it could be reclaimed. Nevertheless these anecdotes are not typical. The discussion at Sringal seemed to reflect the more common experience regarding the impact of social media on relationships at work. 
As one learned more about the local companies in The Glades it became evident that a considerable amount of local peer networking exists among the companies themselves. In general this was highly supportive and communal. Contrary to some expectations, there was very little sense of competition between businesses. Most businesses recognised that other local businesses were often either already their customers or potential partners to collaborate with to find new customers. The local Chamber of Commerce was very active. In particular, a local hotel had become known as a place for business people to regularly gather and chat. There was a strong sense of local solidarity, mutual support and identity. Indeed the business people were among the most sociable in the whole of The Glades. Some of these networks were more specialist; for example, people in the building and associated trades tended to network intensively among themselves, but far less with others. Their networking was based on regular attendance at particular pubs rather than chatting at this hotel.

Most of the middle-range companies in activities such as manufacturing, as well as almost all of the High Street shops, had come to the conclusion that Facebook and Twitter were of no particular value in terms of promoting themselves commercially. These platforms mainly had a role only if the business had a concern with public relations, or when the personal relationships with customers were an integral part of their service. For businesses of any size and for most employees in small businesses, however, the one social media platform taken to be extremely significant was LinkedIn. This site was almost never mentioned outside of discussions with commerce, but was increasingly central to the career of individuals within commerce. One manager from a very large company admitted that when he was recruiting, the size of an individual's LinkedIn network was crucial to his or her chances of being hired; once employed they were expected markedly to increase this network in order that outsiders would be impressed by the company's networking capacity. He himself had 15,000 links and expected each of his employees to have over 500 each.

Perhaps the most important and more practical uses of LinkedIn related to the core field of employment for The Glades associated with the term 'white van man'. A high proportion of villagers worked in industries ranging from IT to electricians and similar services, partly because the good transport links of The Glades were a major asset. Many of these were individuals who - as plumbers or local shopkeepers undertaking re-stocking and so forth - did indeed travel in white vans which also carried their equipment. While others see the term 'white van man' as 
a stereotype, most of those involved are proud of the types of labour they are involved in. Furthermore, the building trade is perhaps the most lucrative form of local employment. Several women worked to support these myriad small local businesses in fields such as promotion, advertising or public speaking. They noted how much business is gained through networking, largely by word of mouth and friendship with others in The Glades. As a result if one person heard about some building renovation they could connect to complementary services - for instance a plumber could alert an electrician or a gardener.

Such connections built on other media. For example, a 'white van man' might also have an 'office' at a building in the industrial area which for a fee would deal with phone calls as though it were a traditional company office, in order to impress potential clients. LinkedIn was thus seen as integral to a general propensity for networking vital for the success of these small local services. More particularly, however, LinkedIn was perceived to be important when looking for the next job or in responding to redundancy.

While LinkedIn was used for business to business services, Facebook and Twitter might be used to promote business in which a social component was integral. For example, pubs tended to make more use of social media than restaurants, although the latter were also present. Indeed one Indian restaurant had the highest number of visitors to its YouTube postings of any site in The Glades - simply because they had put up videos showing exactly how they made each of their recipes. In one case this involved six sequential YouTube videos, each of which had thousands of views. Services such as restaurants and pubs today also have to be concerned with online sites such as TripAdvisor; these have become extremely influential in determining the success of such enterprises, particularly for potential customers from outside the village. One incident occurred in which a company in the village had itself posted negative comments about a rival. It had subsequently been unmasked as the source of these comments, but this seemed to be exceptional.

Over time social media has become less generic, as companies have learnt which specific usage serves their specific needs. For example, a pub may increasingly use Twitter in preference to Facebook if putting on gigs and other music events is a major activity. They may then use Facebook to give an impression of being an active and a sociable pub, deliberately posting banter between the bar staff to show the authenticity of this friendly environment. The pub's management may employ social media for promotional purposes based on various 
discount schemes, for instance printing out a two-for-one voucher or free drink voucher.

Some businesses see no point in posting generally, but will post special offers or about new stock. As time goes on, their knowledge about how to do this effectively becomes more refined. One pub noted a big difference depending upon what time of day they post on Facebook. A man who clearly considers himself to be rather good looking and provides a personal service has over 800 friends, mostly women, on Facebook, something he justifies to his wife as essential to the success of his business. She strongly dislikes Facebook, however, and has only five friends there.

Staff are unsure as to the impact of social media on the sociability of the pub itself. At least superficially this can appear negative, when a party of people are all staring at their phone screens rather than chatting with animation over their beer. On the other hand staff are well aware that WhatsApp has become the standard way in which people microorganise their outings. Often when one or two commit to spending time at a particular pub they will be WhatsApping to let other people know, so that they can join them. Social media has also become important to young single people who may feel embarrassed sitting on their own in a pub. They appear to feel much more at ease if they can be engaged with their phones while alone.

Perhaps the best evidence for these developments came, not surprisingly, from businesses established precisely to advise companies on how to use social media. Rupert had been in sales for 22 years before establishing himself in this sector as a local adviser on effective social media use. Most of his clients were businesses from around The Glades, but some were further afield in sites such as Girming. His ideal was to work with some 20 or 30 clients on a monthly basis, with typical clients being restaurants and beauty parlours.

Rupert's advice dealt with the company's wider communicative and digital strategies including media such as email. It would cover ways to obtain links to past and potential customers and how then to use these to retain or attract their custom. This might involve getting customers to subscribe to email lists or 'like' a Facebook page and then to determine the right kind of special offers - for instance $£ 5$ off or a 20 per cent discount or a 'Father's Day Pamper Package'. His primary issue is getting companies to understand that social media is best deployed in developing personal relationships. So he was very happy when customers actually responded with congratulations to a restaurant that 
had announced its 25th anniversary, wishing the restaurant a Happy Birthday:

I deal with [. . .] in Girming and their Facebook page. Just every single post was a sales message. It was just like buy this, buy that. It just wasn't working for them. And I was like 'you've got no personality, all you've got is sales'. I think there's a definite strategy around how much you need to promote your business and how much you need to interact with people.

Rupert generally recommends that 80 per cent of interaction should be non-commercial and friendly, with only 20 per cent making actual attempts at sales.

This message is getting through, as illustrated by the ways in which businesses' online presences changed during the period of our field work. Some companies use social media simply for relaying information, for instance a hair stylist who puts all his styles on Instagram or a fashion shop that posts its new stock on Facebook. By contrast a local pet shop has for years had a rather fat and very friendly rabbit, much stroked and admired by the village children. The 'rabbit' now has a monthly 'blog' on local media, where it comments on village activities. A local DJ who mainly works local events such as birthday parties reported that he gets his business in three ways: through word of mouth, business cards and Facebook. Currently he is finding Facebook the most effective of the three. A comic claims to hate Facebook, but this is partly because in his comedy routines he mercilessly lampoons contemporary 'screen' culture - appealing to a sense of guilt felt by many people in his audience who feel they spend too much time online.

Obviously the use of social media is likely to reflect the particular nature of offline interaction, which is why usage by pubs is so prominent. The social media of one such pub is just full of bad jokes, of the kind that would be employed within the pub. Personal relationships are also absolutely critical to the beauty parlours. The same was true of the local travel agent and gift shop. Prior to social media, however, these are the shops and services that were most involved in local sponsorship, charities, sports events and other offline activity. In order to compete with online shopping they have had to cultivate a more personal, long-term relationship with their customers. By contrast people rarely have the same kind of informal relationship with waiters in restaurants, whose social media is consequently more devoted to customers' enjoyment of their food and its good value. 
Not everything falls so conveniently into place. It seemed likely prior to the research that one of the most obvious uses of social media would be for people involved in 'direct selling' or 'party plans'. This model of business activity follows the success of firms such as Tupperware, Avon and Ann Summers in selling mainly through private demonstrations to groups of women in the home. ${ }^{12}$ This may be true elsewhere, but there was no supporting evidence here from this research. The individual we knew best who made a living from such selling exploited her toddler group friendships and those of her housing estate, but had as yet made little use of Facebook where she only had around 60 friends. In some of our other field sites people expect to start entrepreneurial enterprises through contacts with family and friends. ${ }^{13}$ This was quite exceptional in The Glades, however, where the sense that one is being 'exploited' for commercial purposes can quickly become detrimental to friendships and even family relationships. The vanguard forms of the new digital economy such as crowdsourcing and kickstarting were not much in evidence in The Glades, though Airbnb ${ }^{14}$ has a local presence. These are the kind of digital developments which it is tempting to imagine are now widespread, but in reality we do not find them impinging upon an ordinary settlement viewed in ethnographic terms.

One of the most significant observations - again best articulated by Rupert, although echoed by others - was that negative interaction can be far more potent than positive interaction. In other countries people are more likely to complain volubly if they are not happy with services. The problem is that in England this is rare. Typically English people do not complain - they simply 'vote with their feet'. Once offended they rarely give the firm or place a second chance: they just never return. In the same vein businesses felt that a dozen good reviews on TripAdvisor could be negated by one strong complaint. As a result firms had to be very sensitive about their interactions, leading to a situation not entirely dissimilar from the Anglican Church. Rupert was well aware that many forms of communication could be considered intrusive. One of the reasons social media was suited to this environment was that posting online did not presume any interaction with a given customer, who thus retained the freedom to respond or ignore. This is in essence the business equivalent of the 'Goldilocks Strategy' described in Chapter 4. An email might be welcome, but it could very easily be bracketed as annoying spam. Far worse is the use of either texts or phone calls, both of which pushed commercial firms into the realms of private communication. A single unsolicited phone call is precisely the kind of action 
that could result in a customer never having anything to do with this firm again.

It is this observation that connects local use of social media with a bigger picture. The ethnographic study was able directly to engage with village commercial activity, but this represents a relatively small proportion of the overall impact of commercial social media on the people of The Glades. A far more ubiquitous presence comes through the daily manifestation of commerce on people's private screen encounters, increasingly through targeted advertising. In this there is a major split between Facebook, where targeted advertising has now become an integral feature of the platform (as also with Google), and the other platforms such as Twitter, WhatsApp and Instagram, where it has as yet less of a direct presence. Even with these latter sites, however, people presume that their online activity is now being monitored by commercial corporations and reflected in advertising directed at us not only within social media, but also in much of our general online experience - unexpected advertising increasingly finds its way into routine searching and communicating online. Everyone has noticed how this increasingly reflects advertisers' knowledge of our interests and previous searches, monitored through 'cookies' and other devices. This has developed to such an extent that we now expect these advertisements to be strongly connected with our recent online activity.

At one level this goes to the heart of the modern political economy. Digital media has subverted many traditional ways in which we formerly paid for online content, whether in entertainment, communication or obtaining information. Today we expect much of this to be free. The main response by commerce has been to find companies willing to pay for advertising which uses those same digital technologies to gain more intimate knowledge, enabling them to produce more personalised and targeted advertisements. Along with big data and more sophisticated algorithms, this is becoming more and more feasible. As Goldfarb ${ }^{15}$ notes, the primary impact of online media for commerce is hugely to reduce the cost of targeting advertising and to increase that capability. It has also increased the capacity for measuring commercial effectiveness, suggesting that this depends very much on the precise type and context of such advertising.

Outsiders tend to assume that if commerce is developing a new strategy it is necessarily the case that this follows the interests of commerce and is effective. Having worked for several years in the study of commerce, however, I would not automatically assume this. In many cases new commercial developments occur because of technological 
developments, i.e. companies initially do these things simply because they can and only then convince themselves that this must then also be in their interests. If they can now collect vast amounts of personal data and target advertising more precisely, the argument runs, this must be the better way of doing business in the future.

Yet it is not at all easy to assess the consequences of these developments properly. Traditional advertising was originally directed more at introducing new commodities and persuading us that we wanted them. Targeted advertising appears to be more like a mirror, reflecting back commodities that we already knew we wanted. While it is likely that this may help companies such as Amazon become the convenient and immediate source of purchases, it does not necessarily create new demand perse.

While the ethnography could not obtain evidence for assessing the effect of targeted online advertising on businesses, it was able to monitor the popular declared response to this development - an overwhelmingly negative one. Stephen, for example, is a builder, one of the most common professions in the area. As a 40-year-old male he was also perhaps typical of the demographic that seemed most suspicious of Facebook, constantly describing what he saw as the downside of people's involvement. Stephen hates the idea that his personal behaviour is viewed by strangers mainly as a result of his wife's activity on Facebook:

The fact that people I've never met and would probably never like to meet, have seen me eating my birthday cake on my 40th birthday - seen me sitting in the garden. I can't associate myself with that and be comfortable with that. There obviously are implications. Of course I'm responsible for my children's welfare; what happens in the house. Obviously I'm responsible for their care and looking after them. We live in a horrible and cruel world. But strangers know my downstairs toilet, my garden, seen my kids eat birthday cake. I personally wouldn't be doing what she does. I'm not saying she shouldn't.

Not surprisingly the more clearly targeted the advertising people such as Stephen see online becomes, the more upset they grow about how much companies already seem to know of their personal lives and preferences. A highly targeted advertisement is basically very direct evidence that someone has been spying on you. They therefore find targeted advertising deeply disturbing. As another villager observed: 'Google will change your settings on your cursor, so that every time it goes back and tells 
them what you are using it for. Then they send you certain adverts . . . If you join Tesco's, every time you go through the till it records everything you've bought. And suddenly they start sending you vouchers to buy meat . . . or this person's a drinker. Everything you do.'

However, the people probably most upset by targeted advertisements were the hospice patients, because much of their web activity is related to cancer. As one noted,

I've joined the moving-on group now, since I've finished treatment, try and move on. Sometimes I get a lot of feeds and it does get a bit much. Don't want it in your face all the time, keeps coming up, so I had to stop a lot of the feeds, otherwise every other thing was cancer, cancer, cancer and I'm not moving on. Think I'll get rid of these off my Facebook.

A particularly annoying result was that patients get many advertisments for life insurance - even though, as they report, 'I've said I do not want you calling me. I'm already ill. I will never be able to get life insurance again.'

Opinions of this kind are not in themselves evidence that such advertising fails, merely that the concept is not popular. This aligns with the tendency of firms to attract increasing unpopularity as they grow larger, for example Facebook and Tesco - two of the firms most quoted in such accusations. On the other hand academics who study advertising are now starting to look at this issue more generally, with the initial research indeed suggesting a possible backlash against the firms involved. For example, Goldfarb and Tucker ${ }^{16}$ note that 'while there is a relatively high consumer tolerance to targeted ads because the information is perceived as useful, this tolerance may be overwhelmed by perceptions of manipulation when the ad is obtrusive'.

More recently some marketing researchers have identified what they call 'The Personalisation Paradox', within which 'the findings support the conjecture that when firms covertly collect data from customers and use the information to provide highly personalised advertising, it has negative consequences, such as lower click-through intentions'. ${ }^{17}$ A customer may be less likely to use a firm that seems to know more than it should about them. If more sustained research supports these arguments it certainly challenges one of the major foundations for the modern online political economy, ${ }^{18}$ where advertising has become in effect the default model for funding most internet activity. ${ }^{19}$ This is a major consequence. However, it also, at a macro level, echoes the ethnographic 
findings regarding the tendency of the English to take issue with anything that inappropriately transfers from the public to the private.

\section{For institutions too, it is about how to get relationships right}

It would be quite implausible to suggest that all these findings were predictable. If anything we might have expected the Church to be the institution which seized upon the possibilities of social media to reach further into the intimate and private lives of parishioners. Yet it turned out to be extremely cautious about doing just that - to such an extent that we even find religious villagers suggesting that, partly because of this historical reticence, Facebook in some ways feels like more of a real community than does the Church. By the opposite token commerce might have served its own interests better by displaying a wariness about being too nosy or intrusive. Instead, however, many major firms have launched a no-holds-barred assault which openly reveals their desire for as much intimate knowledge about their customers as they can lay their hands on. As a result people are incensed by commercial predations, and may well be withdrawing their custom from the most egregious practitioners. Yet the political results reveal a more complex equation. A local politician might be quite intrusive, but this may be still acceptable if people regard the cause as legitimate. Meanwhile, political opinions expressed on social media may have little to do with any actual politics, instead becoming a means by which people today establish personal taste and friendships.

Although the original intention in shifting from the world of intimate relationships to institutional usage was to move on to other issues, we have actually rather similar findings in both domains. Whether in relationships to people or in relationships to institutions we find new contradictions and dilemmas mainly focused on the way in which social media conflates previously more discrete arenas of private and public communication. As a result both domains contain a good deal of sensitive contingency in terms of precisely how people try to gain the advantage of closer relationships without the concomitant negative effects. A customer may be completely opposed to receiving a phone call from a commercial outlet, for instance, even though this is a village shop or restaurant. On the other hand there are other commercial outlets in the village such as a beauty parlour where the nature of gossip and friendship may reach a level where the customer might be offended if a member 
of staff refuses a Facebook friendship request. This is similar to the tension found earlier in the discussion of personal connections among staff in a small firm. Office workers generally sought to be friendly on social media - but not too friendly. In short we find with institutions the same dilemma that in Chapter 4 was termed the 'Goldilocks Strategy'. As Rupert noted, local firms, just as much as individuals, needed to use social media to develop more personal relationships that at the same time were neither too close nor intrusive.

In general it is the subtle differences and need for sensitive negotiation that emerge when we deal with specific local relationships such as village commerce or the dilemmas of a lay preacher. Changes in the relationship to more distant and abstract institutions appear coarsergrained. The least acceptable crossover is when large corporations show, through targeted advertising, that they now have deep knowledge about what would be regarded as personal and private matters, such as an individual having cancer or even preferring a particular brand of drink. Yet the same removal of distance between the private and the public can on occasion have the opposite effect of favouring the individual over the institution. So an MP finds that the traditional layers of responsibility have been undermined and now pretty much everyone expects him or her to respond personally to almost anything they may wish to complain about.

In general the problems arise when the presence of an institutional concern in the more private sphere of social media seemed inauthentic or obtrusive or, as in targeted advertising, simply crass. If institutional issues seemed to arise more naturally out of the discussions and friendships of Facebook, this was deemed more acceptable. Local politicians could reinforce the sense that they were ordinary villagers with shared concerns by including local issues on their personal Facebook walls. Similarly a member of a church committee could try to spread interest and involvement in the church through his or her personal postings. A key factor was the underlying ethics. People would be more prepared to accept intrusion where the topic registered was something with which they felt they ought to have been more involved in any case, but had neglected. In general, villagers in The Glades are highly philanthropic and engage in a remarkable amount of volunteer work. They were far more dubious about commercial imperatives.

It might be thought that the reluctance of the Church to use social media would be evidence against this conclusion. Yet actually there was little evidence that people were offended by church usage, this reticence rather seeming to reflect the internal and apparently 
traditional fears of the Church about becoming too involved in people's intimate or even theological lives without a clear invitation to do so. This would also be true in quite another part of the field work. The almost obsessive concern with 'confidentiality' found when working with the health service during the applied project with the hospice seemed to come almost entirely from a fear within the institution, rather than from any concern expressed by the patients about other medical professionals seeing their medical records. In the report to the hospice, evidence is presented that this recurrent fear around patient confidentiality may have now become one of the principal causes of harm to patients ${ }^{20}$ since the result is that relevant medical professionals commonly do not have access to critical information about these patients. In short this is not some new factor, but rather a deeply ingrained aspect of Englishness. The evidence suggests that this has become so internalised by English institutions such as the health service and the Church that the fear of intrusion is now stronger within the institutions than within the public they fear to offend.

So the main effect of this research is to distance ourselves further from blanket generalisations about topics such as religion, politics and commerce. Instead we see a mass of highly specific and contingent variables which depend on factors such as how local the commercial organisation is seen as being, or how traditional a church is supposed to be, or how and when political debate should be introduced into friendship and family. The main generalisation linking all of these together is the observation that almost all the issues presented here have to do with the way in which social media has transformed traditional boundaries and barriers between what were regarded as public domains and private communications and relationships. This is precisely the point at which the discussion of social media in institutional use contributes to our final concluding chapter. 


\section{How English is social media?}

One of my final interviews in The Glades was with a village doctor. People had already told me about this doctor, who was said to be extremely easy to talk to. As a result patients flocked to her as someone who would listen to their problems. These days the decline in infectious diseases means that, despite the rise of diabetes and cancer, there are fewer medical issues than there once were. In England going to see a doctor is free, however, so people increasingly come to the surgery claiming a physical problem, but actually to discuss underlying social issues and anxieties such as those connected with marriage and parenting.

The two hours with this doctor went by quickly, with the discussion shifting between her job and her children. With respect to the former she was often quite apologetic, because on reflection she did not feel she had much to report. Yes, patients talk about social media as an integral part of everyday life such as marital relations and parenting concerns, but they never single it out as a major cause of something. The medical authorities have not been warning doctors to look out for some kind of 'social media syndrome', nor did she have any evidence that they should have done. From the point of view of things that require medical or even psychological attention, behaviours that had become pathologies, for example, social media just did not seem to be that important.

Most of the interest in social media that emerges from newspapers or indeed government funding for research is problem-focused. People want to know if social media is causing new syndromes such as Facebook or smartphone addiction, whether it leads to teenage suicide through cyber-bullying, the break up of marriages through making adultery more visible, new forms of democracy, a loss of social skills, changes in the brain and so forth. The poor doctor was apologetic because she could see no evidence for any of these things. I must also apologise because in concluding this volume neither can I. If headlines are what 
makes something important, then I would have to say social media in The Glades is simply not that important. It is rather a constant presence that has some influence upon a very wide range of issues, especially personal relationships. This volume has much to say concerning the role of social media in 'politics', 'education' and the 'family'. However, our comparative volume will suggest that the impact in The Glades is rather less significant or dramatic than in some of our other field sites. It is rare that it can be isolated as the primary cause of anything much.

This, though, still leaves room for an argument that this absence of headlines may be actually a symptom of social media's significance rather than its insignificance. Given the dearth of exciting things to report or even intriguing anecdotes, the doctor instead talked quite a bit about her children. Here the topic of social media found her more animated and more concerned. She was shocked by the degree to which social media dominated their lives, and seemed indeed to be 'where' they now spend much of their time. She felt her children had no idea how distant that made them from her own experience of growing up, and she worried that it was becoming really quite difficult either to share or understand their lives. For her it was as though her children now live on another planet: 'the social media planet'. This was why she felt social media was significant and why she was as keen to speak to me as I was to her. Since this was a foreign planet she was looking for an anthropologist. Someone to go out and explore and come back and explain to her what life on that planet is like, why people choose to live there and what the consequences may be if we all abandon the earth to live on planet social media.

In one way she was quite right. In truth anthropologists are probably not always the best people to contact if you are interested in a specific problem, for example of politics, or gender, or indeed of medicine, though Chapter 6 discusses some institutional usage and Chapter 5 tries to turn this into practical advice and policy. However, the more general tendency of anthropology is to be holistic. The people we study do not live in 'politics' or in 'health' or in 'gossip' - they live lives that include all of these things together, often simultaneously. The definition of ethnography is a commitment to a length and breadth of encounter such that we come to see our informants in respect to the entirety of their lives rather than only in relation to one context. On the other hand that should make us ideal for exploring these alien universes inhabited by human species - whether tribal, metropolitan or, in this case, on planet social media. What we study best are not things that are important, but aspects of life that are 
becoming ubiquitous, ordinary, everyday, the medium through which more and more things happen. Above all we explore social worlds. So a topic called 'social media' is precisely our purview. Furthermore, we tend to avoid the extreme, the sensational and the exceptional, but are entranced and fascinated by how new things so quickly become ordinary and taken for granted as part of normal life. Our primary work is to show that what seems alien is ordinarily human.

At the same time everything in this book shows that the doctor was wrong in perceiving her children's involvement with social media as resembling another planet. She may not be familiar with what they are doing, any more than she would be with the life of a farmer or a monk, but social media turns out to be mainly the further development of prior and sometimes highly traditional forms of English sociality. We have considered Facebook as a new and better version of the net curtain for adults. Twitter for schoolchildren is an extension of school banter, while Tinder may be a safer alternative to a drunken hook-up. Her own children are in some ways using social media to compensate for increasing parental restrictions on their ability to play together, for example in the street as children traditionally did. Yet basically playing is what they are doing - not living on a different planet, but simply finding an alternative way to play together.

\section{Social media as more than affordances}

Clearly this book has tried to move discussion of social media away from a focus on topics such as platforms and affordances and towards more established social science that studies topics such as genres of conversation or modes of socialising. This is not an easy transition to make. It may seem odd that a book that plays down the role of platforms has based most of its descriptive content on platforms as the core units. However, the point made in Chapters 2, 3 and 4 is that, with an increasing range of platforms available, we now use these constantly to create significant differences - whether to explore contrasts in communication, described as polymedia in Chapter 2, to contrast Twitter and Instagram in Chapter 3 or to map different groups as scalable sociality in Chapter 4. In each case, however, these are cultural exploitations of the range of social media platforms. They are not evidence that the nature of the platform has created or caused that pattern of usage. The switch is from thinking that 'Twitter or Instagram does this or that to us' to realising that these are things we have done to Twitter and Instagram. 
Similarly it is tempting to work from affordances, that is, the propensity to use a platform in a particular way because of a property which it possesses. This is a simpler form of explanation than the vagaries of culture. Twitter has the affordance of brevity, Facebook the affordance of asynchronous discussion. Affordance carries with it the implication of causative explanation. It tempts us to conclude that a platform is generally used in some particular way because of these properties. We have plenty of examples in this volume where such a logic and an explanation seem reasonable.

When I wrote Tales from Facebook I refused to accept the then common assumption that Facebook was inevitably a young person's media. Because Facebook had been invented for the young and was mainly used by academics and journalists who wanted to find some logic that made this a natural relationship, they would therefore pick an affordance to match the case. For example, it was suggested that Facebook lends itself to the cultivation of appearance and young people are obsessed by appearance. The evidence in Chapter 2 has weakened the case for such arguments. Firstly it was clear that whole genres of behaviour, such as banter and quarrelling among young people, could migrate from one platform to another with limited change in the nature and quality of that behaviour. Much of this banter had first developed online through BBM on Blackberry phones. It had then leapt across to Facebook. By the time of this study, however, it was almost entirely a feature of Twitter. At each stage there would have been a temptation to explain the alignment with that platform through affordances. Oh well, they use BBM because it is highly encrypted and below the radar of adults, obviously. Yet today exactly the same behaviour, which remains highly offensive to adults, is now largely on Twitter, one of the most public media. It is simply that at present adults do not follow their children on Twitter. This is more happenstance than affordance.

The same chapter revealed that there was no single Twitter. There are in reality a dozen different Twitters which may represent different groups or different genres of usage by one individual. This should be no great surprise. After all Twitter is just a place where you can post short messages and links. There are thousands of uses to which that might be put. The conclusion is not either/or. Sometimes the best arguments are based on the property of platforms and their affordances, but clearly and commonly this is often wrong. It is often cultural factors that seem poorly matched to the technology which nevertheless determine what the social media becomes. This is even clearer if we add a historical perspective; in this case for Facebook. 


\section{A brief history of Facebook}

Facebook has both a generic global story and then a much more specific English consequence. Most people in most countries believe that society has shifted from a historical experience of community to people becoming part of a more modern but also more individualistic lifestyle. In short most of the world today subscribes to a 'myth' of prior community. We believe that once upon a time we lived in sites such as villages where people knew each other well and gave each other support and company. This is retrospectively regarded as an ideal and is usually employed to critique modern life, especially urban life, seen as isolated, cold, unfriendly and unsupportive by comparison. In this mythical village or community people mixed equally with friends, family and neighbours or the people they worked with.

Initially Facebook was dismissed as something trivial for young people, but after that iconic moment when mothers began to send friend requests to their children, the platform changed into a place thoroughly populated by kinship. This meant that the prior separation of peers from relatives was dissolved. Later other people, such as those who worked together or lived near one another, also felt it was appropriate to friend on Facebook. One of the reasons this may have been acceptable is that at first it may have seemed as though we could now reverse history. The result appeared to be a possible return to this lost world of free, intense and mixed sociality. It felt like we were back in a community of just a few hundred people we actually had met, with whom we could exchange harmless gossip and feel the warmth of common knowledge and mutual interest.

This was pretty much the phase in the history of Facebook which I encountered during 2010 when I undertook the study in Trinidad, now published as Tales from Facebook. ${ }^{1}$ In that volume I argued that social media was best understood not as a bright new modern force following from prior advances in the internet, but instead as a nostalgic and conservative return to this ideal of community, which having been lost as face to face interaction could here be regained online. This nostalgic sense of past community is especially powerful since for almost all peoples around the world the last few decades have actually led to an increasing ability for individuals to create or find distance from the traditional intensity of face to face sociality, whether through new opportunities in education, labour, housing or migration. 
At this very general level the example from England fits within the overall argument. There were many cases within this book that seem to speak to this global sentiment. Recall the woman who remarked that now her business had grown it had lost the intimacy of when it was a small firm, but that Facebook had helped them to return to the older experience of when this was a community, not just a shared workspace. Similarly there are many examples of WhatsApp groups that form around family members now living in different places. There are also attempts to retain the community of the school class when people drift to dispersed colleges and work. In all such cases Facebook seems a bulwark against the potential loss of community.

The problem with all this is made clear in Chapter 2 of Tales from Facebook. ${ }^{2}$ Here we meet Alana, who actually lives in a tiny hamlet in Trinidad based on a few stem families. While people in the town saw Facebook as a place to recover community lost, she saw it as a place of refuge from her actual community, because she really did live in a traditional offline community. Yet she regarded this as no idyll: it was something that gave her no privacy, knew all her business, never left her in peace, did not forget quarrels that had gone on for generations, endlessly gossiped, had nothing new, classified her in certain ways she could not grow out of and basically could drive one nuts - though certainly it could also be supportive and even loving. In England after a short period people thus also came to regret the degree to which Facebook actually achieved exactly what they required from it - a re-acquaintance with all sorts of people with whom they had lost contact, now gathered in the same shared but also terribly awkward and embarrassing space.

Facebook thus has its own cultural history, which may explain why people have turned it into various things, largely irrespective of the plans or intentions of the company that created it. In fact it is worth a brief pause to reflect on whether it would have made much difference to social media if Facebook had never been invented. The world's biggest population, in China, does not use it. Populations as vast as India and Brazil developed their social media through Orkut; their recent shift to Facebook was mainly because of its presence in prestigious foreign counties rather than anything extra it offered as a platform. If Orkut had conquered the world instead of Facebook most people would be essentially unaffected. When people migrate from Orkut to Facebook or from Facebook to WhatsApp it really may not matter much in terms of the consequences for what they are doing on and with these platforms. 
A historical perspective thus seems to confirm our ethnographic view that we may have misled ourselves in thinking that the study of social media was largely the study of platforms as causative. The positive side of this conclusion is that it liberates alternatives. If genres of communication of behaviour happily migrate across platforms it should alert us to the importance of these robust genres; the resilience of young people's quarrelling and banter. All communication is determined by frames and contexts. To understand the English we need to appreciate, as Kate Fox ${ }^{3}$ did, how people talk for hours in a pub without really saying much at all, but thereby effectively creating and maintaining social relationships; or the tensions in parentchild communication, or the way in which people discuss football and soap operas in the office before starting work. In short people have always talked on specific 'social media' platforms - home, office, pub, High Street, telephone, political debate, school, etc. - and have done so in culturally specific ways: as women, teachers, men working in the building trades, the working class and so forth. This is why today we have quite specific Facebook usage by young mothers or specific Twitter usage by school pupils.

It was nevertheless possible to make general claims about social media as media. For example, we see a shift from a textual to a more visual emphasis in ordinary communication represented by platforms such as Instagram and Snapchat. The foundation for Chapter 2 was a theory of polymedia. Instead of treating each platform independently, or social media as separate from other media, we recognise that each occupies a niche in relation to all the others that a person employs. In Chapter 3 Twitter visuals only made sense in contrast to Instagram visuals. Because the range always represents a choice, people are judged on which they use, so polymedia also represents the embeddedness of media in social relations and moral judgements. In turn polymedia forms part of the idea of scalable sociality as a choice not only of which media, but which group of people we are engaged with, ranging from smaller to larger groups and from more private to more public communication. Thanks to social media we can see the way we scale our sociality more clearly. Both polymedia and scalable sociality are in turn examples of a still larger theory of attainment. This recognises that social media enables us to do more or different things, for better and worse, but should not thereby be used to suggest we are any the less human or in any way post-human. ${ }^{4}$ 


\section{Social media as Englishness}

A major conclusion to this book is the claim that it has revealed a good deal about being English. The ethnography was not intended to be so specifically a study of the English shorn of its constitutive minorities, including its Asian and black populations. All my previous English ethnographies are based in London and are concerned with quite heterogeneous populations. For the sake of comparison, however, we organised for all the studies, where possible, to be conducted in smaller communities of around 15,000 to 50,000 people: The Glades was simply one such convenient site that subsequently turned out to be remarkably homogeneous as White English. In fact my previous London studies suggest that populations with black, Asian and other minorities often turn out to become equally characteristic of this Englishness in a very short time. So the main reason why this book has ended up with such a clear focus on Englishness is probably not the homogeneity of population. It is rather, and quite unexpectedly, a realisation that the study of social media seemed to bring out certain key qualities of being English.

It is hardly surprising that Chapter 1 to this volume starts by trying to decide what that topic is. Following our collaborative project, social media is defined as scalable sociality. ${ }^{5}$ Previously we had mainly dyadic private media or public broadcast media, and the innovation represented by these social media was the orientation to groups that were neither as narrow as the dyadic nor as broad as the undifferentiated public. It follows that the primary consequence of social media is likely to be the way in which it disrupts any simple division of communication or sociality into the private and the public.

This would all be true of the study of social media in any of our field sites, but what developed in the course of this book has been an argument that the core of Englishness is in fact an exquisite sensibility with regard to the previous dualistic contrast between the private and the public. This inherent sensibility had led to a superabundance of caution and anxiety around things that seemed ambiguous between these two. Such a perception of Englishness, which formed itself into a sequence largely through the exercise of writing this book, is present as three stages of observation: keeping people at a distance; adopting the 'Goldilocks Strategy'; and appreciating the tragic dénouement of English sociality. 
As just noted, part of the brief history of Facebook was an initial attempt to return to a general ideal of community that combined all the different people we know in a single place. However, this seems to have awakened an ancient form of resistance: a tradition of relative individual autonomy with deep roots in English history. Both the ethnography and indeed historical accounts of relationships, for instance those between neighbours, suggests that over the centuries English people have developed a robust defence against the invasive potential of people who live close by. ${ }^{6}$ They have ferociously defended the privacy of their domestic interior; in traditional working class homes, at least in London, people other than kin were not expected to come inside the home. ${ }^{7}$ Instead those same people could be very friendly in certain public domains such as the High Street, the pub, even over the garden fence, since this was designated as public not private space. There are of course exceptions: mothers naturally follow their children who have not yet learned to respect these boundaries, but these often prove to be temporary.

What is perhaps most unusual among the English is that this sense of privacy and autonomy also extended to family relationships - to the degree that members of the family were seen as more autonomous individuals with more limited expectations of long-term family responsibilities. This was enshrined by law for centuries. Historically in much of continental Europe, for example, people were legally obliged to leave a proportion of their assets to descendants by blood, as in the French Napoleonic code. By contrast the English were free to leave their entire estates to anyone, even a donkey sanctuary, and some did so. ${ }^{8}$ This was characteristic of an early and more general English individualism. ${ }^{9}$

Although English people thus share a myth of the village and community, which has a major role in, for example, the campaigns of both the major political parties, this is indeed a myth. Few things would cause more intense embarrassment and suffering to an English family than belonging to a community that actually lived up to this ideal, as in soap operas where people are in and out of each other's private houses. ${ }^{10}$ The English also traditionally protected their interior from exterior view with armour plating (well - net curtains). Popular culture provides many examples of the English family's anxiety over visibility; putting down the toilet seat and checking the surfaces, for instance, before people come into the house. Historically even the poorest people in slum properties kept the front room 'parlour' free of visitors; the latter only ever came round to the back door, except at Christmas. ${ }^{11}$ A platform that renders people increasingly visible, especially to those they already 
know - which can be even worse than being exposed to strangers - was bound to create anxiety.

English people at first accepted a wide range of others onto Facebook and were often proactive in seeking out all the people they had once been to school with through associated sites such as 'Friends Reunited'. Yet soon, as they remarked again and again during this field work, the main effect was to remind themselves of why they had not kept up those friendships in the first place. Why had teenagers spent years barricading their bedrooms to prevent their parents from coming in, only to watch parents take this back-door route into their private lives through Facebook? So in the writing of Chapter 4 it became apparent that after a while many English adults had come to realise their mistake. Being a generally creative and resourceful lot, however, they then discovered that actually Facebook could be used for a quite different purpose. Instead of making or re-engaging with friends and relatives, social media could be used to keep people at an appropriate distance. You could 'sort of' keep in touch, but without having to face actually meeting up. You could contrive your posting so as to keep up the appearance, rather than any actual commitment to the reality of sharing much of your life with others.

These observations led to the second stage, an argument about Englishness as a 'Goldilocks Strategy'. Here social media such as Facebook could potentially fit in rather neatly as an expression of, rather than a threat to, Englishness. Initially most English adults strongly disliked Facebook as an exemplification of 'dirt', ${ }^{12}$ that which had messed up their neat, clean boundaries between private and public, between the different categories of family, friends and work. Yet now it became a wonderful holdall into which one could dump all those dirty ambiguities of distant cousins, ex-relationships and people you were nosy about but did not really trust. Social media could exemplify the perfect English relationship: porridge that basically ranged from lukewarm through to tepid. Such moderation can be seen as a bit like the English weather, a bit like the English Church and indeed a bit like the traditional English village as it actually was, rather than how nostalgic spectacles perceived it to be.

This was the middle ground that had previously been developed through the more material mode of suburbia - a compromise, neither too warmly rural nor too coldly urban, but which had come to feel just right. As it happens, The Glades is itself the final fulfilment of the suburban ideal as a place that seemed to be genuinely a village surrounded by countryside yet within an hour of the centre of London. For the adult 
population in The Glades, Facebook has turned into a visual expression of these suburban ideals. In Chapter 6 of Visualising Facebook this is made apparent by revealing the visual expression of suburban ideals: the photographs of domestic pets and toddlers and gardens that middle-aged, middle-class suburbanites post on Facebook today.

Gradually people came to appreciate that the more intense and close knowledge of each other fostered by the early experience of Facebook could also be rescinded through adopting new social media such as WhatsApp, which allowed a retreat to more private and circumscribed sharing. A similar trend seems evident in many of our other field sites. The period in which the fantasy of ideal community was realised and then found to be excessive thus was, for most people, little more than two or three years.

\section{The tragic dénouement of English sociality}

The third stage in this argument arose from Chapter 5 as a result of the decision also to carry out more applied research on a population of hospice patients, most of whom were elderly. One of the most concrete forms of evidence that English villages are not at all close to their myth of origin is the fact that the hospice at Berkhamsted dealt mainly with people from villages just like The Glades. Yet that part of the research encountered a degree of loneliness and isolation that we would previously have associated with a metropolitan rather than a rural population.

The problem was that the people in this region have maintained this duality of public and private sociality. Older inhabitants with many friends in pubs and sports clubs had kept those people external to their homes. As a result, when they became ill and more housebound the sociality of the golf course did not follow through to the home and they received no visitors. They also remained extremely proud of the fact that they were not a burden to their family, whom they constantly suggested had more important things to deal with, and as a result received far less family support. It was often the case that patients rebuffed the family as much as relatives neglected the patient. This situation was bolstered by the observation that whereas once friendship followed the idiom of kinship, today kinship follows the idiom of friendship. The balance thus shifts from obligation to choice when it comes to caring for sick or aging relatives.

Isolation was not typical, but it was not uncommon. Yet this very same population is quite extraordinarily philanthropic and socially 
concerned. Almost all the older population of The Glades participated in voluntary work to help strangers. The hospice at Berkhamsted has over a thousand volunteers and is funded almost entirely from voluntary contributions. It thus makes no sense to see English people as either unfriendly or unconcerned. Rather we have to go back to the earlier remarks about cultural genres. Sociality works in very particular and framed ways; people become easily embarrassed and anxious when it is not clear what exactly they are supposed to 'do'. Those who give voluntary time to work for a hospice, for instance, may not know what to say on hearing that their neighbour has cancer, and therefore may actively avoid meeting him or her. However, they do know how to help cancer patients when they are given licence to support them as hospice volunteers.

So the 'coincidence' that determines the conclusion of this book is the meeting point between two ways of approaching this ethnography. Firstly we start with the definition of social media, and find it to be that which disrupts the boundaries between the public and the private and exploits the group space between them. Secondly we explore the context of this ethnography as an English population possessing historically and consistently developed clear boundaries between these domains of private and public sociality. Social media comes into a terrain that had been seen as embarrassing and ambiguous. At first it exposes these anxieties and then becomes used as a tool to resolve the very problem that it had caused. We end up with a very English compromise in the form of the 'Goldilocks Strategy', a midway position in social relations: not too intimate and in your face, but not too cold or distant either.

Anthropology is comparative, but this book is not. In many ways the strongest argument for the Englishness of English social media is provided by the other books in this series, in which it becomes apparent how entirely different social media turns out to be elsewhere around the world. Another perspective would emerge if studies were undertaken in northern England or London; these would make clear how far this Englishness is concerned with a region of the southeast and will vary in other parts of the country. Even within this volume, however, generalisations are tempered by the evident differences in the way older as opposed to younger people, or males as opposed to females, make use of social media. Anthropology tries to balance the necessity of generalisation for analysis with the humanity of the individual stories that also populate this volume. To say something is 'characteristic of the English' should never detract from the character of these people as individuals. 
Social media in this book has been addressed mainly as content. We recognise that some people experience social media as a place they live within, but for most people it is now as integral a part of everyday life as is the telephone. It thus makes no sense to differentiate between online and offline spheres, any more than to separate time at the office from time at home as though these were experienced on different planets. Indeed, if there is one core finding of this book it is that in England there previously existed a strange and consistent separation of the private and the public. The main consequence of social media has not been to create a new or different place, but rather to threaten the prior separation between these two established places. 


\section{Notes}

\section{Chapter 1}

1 In this book the singular is used to refer to social media in general and the plural if the reference is specifically to social media as a range of platforms.

2 There is a necessary overlap between this introduction and our general and comparative book (Miller, D. et al. 2016. How the World Changed Social Media.London: UCL Press), since we cannot assume everyone will be reading both. The latter book provides a more detailed account and defence of our working definition of social media as scalable sociality. The best established alternative definition would be boyd, d. and Ellison, N. 2007. 'Social Networking Sites: Definition, History and Scholarship.' Journal of Computer-Mediated Communication 13(1): 210-30.

3 We will use the word 'platform' for each of the discrete social media sites. These are usually developed initially by commercial companies with specific rules and affordances which may be changed at the whim of those companies.

4 Fox, K. 2004. Watching the English. London: Hodder \& Stoughton.

5 Langford, P. 2001. Englishness Identified: Manners and Character 1650-1850. Oxford: Oxford University Press.

6 A point made very clear by the German sociologist Georg Simmel at the start of the twentieth century. Simmel, G. 1968. The Conflict in Modern Culture and Other Essays. New York: Teachers College Press.

7 Miller, D. 2015. 'The Tragic Dénouement of English Sociality.' Cultural Anthropology 30(2): 336-57.

8 The discussion of the literature that might be expected at this point is to be found instead as Chapter 2 of Miller, D. et al. 2016. How the World Changed Social Media. London: UCL Press.

9 One of the other books in this series (Miller, D. and Sinanan, J. 2016. Visualising Facebook. London: UCL Press) is entirely devoted to a comparison between the visual postings on Facebook in England and those posted in Trinidad.

10 The description given in this chapter is necessarily brief. It is my intention to write a separate book devoted to understanding The Glades as a contemporary English site based on the much richer data that came from a full 18 months of field work.

11 People in The Glades would be mortally offended if one referred to these as anything other than villages. However, their size and proximity to London makes them very different from the more classic ideals of the village found in studies such as Rapport, N. 1993. Diverse World Views in an English Village. Edinburgh: Edinburgh University Press or Strathern, M. 1981. Kinship at the Core: An Anthropology of Elmdon, a Village in North-West Essex in the NineteenSixties. Cambridge: Cambridge University Press.

12 Laski, M. 2007. The Village. London: Persephone Books.

13 Class analysis in contemporary Britain has generally become fiendishly complex. See Savage et al. 2013. 'A New Model of Social Class: Findings from the BBC's Great British Class Survey Experiment.' Sociology 47(2): 219-50.

14 Also a small amount of private rental accommodation. 
15 This difference in class attitudes is also extremely clear in their postings on Facebook for which see Miller, D. and Sinanan, J. 2016. Visualising Facebook. London: UCL Press.

16 For a recent fictional account that shows how typical these issues have become to rural England see Rowling, J. K. 2013. The Casual Vacancy. London: Sphere.

17 Table 1.1, taken from the 2011 Census for England and Wales, shows that educational levels in Leeglade fall between those of London and the rest of England, while those of Highglade are as high as London's. The census boundaries differ from mine.

\begin{tabular}{|c|c|c|c|c|c|c|c|c|}
\hline \multirow{2}{*}{$\begin{array}{l}\text { Education-Highest } \\
\text { Level of Qualification } \\
\text { (over 16s only) }\end{array}$} & \multicolumn{2}{|c|}{ Highglade } & \multicolumn{2}{|c|}{ Leeglade } & \multicolumn{2}{|l|}{ England } & \multicolumn{2}{|l|}{ London } \\
\hline & number & $\%$ & number & $r \quad \%$ & number & $\%$ & number & $\%$ \\
\hline $\begin{array}{l}\text { All categories: Highest } \\
\text { level of qualification }\end{array}$ & 6247 & 100 & 7898 & 100 & $42,989,620$ & 100 & $6,549,173$ & 100 \\
\hline No qualifications & 1028 & 16.46 & 1501 & 19.00 & $9,656,810$ & 22.5 & $1,152,517$ & 17.6 \\
\hline Level 1 qualifications & 777 & 12.44 & 1186 & 15.02 & $5,714,441$ & 13.3 & 702,687 & 10.7 \\
\hline Level 2 qualifications & 999 & 15.99 & 1283 & 16.24 & $6,544,614$ & 15.2 & 775,928 & 11.8 \\
\hline Apprenticeship & 236 & 3.78 & 323 & 4.09 & $1,532,934$ & 3.6 & 107,665 & 1.6 \\
\hline Level 3 qualifications & 723 & 11.57 & 956 & 12.10 & $5,309,631$ & 12.4 & 685,508 & 10.5 \\
\hline $\begin{array}{l}\text { Level } 4 \text { qualifications } \\
\text { and above }\end{array}$ & 2214 & 35.44 & 2378 & 30.11 & $11,769,361$ & 27.4 & $2,470,225$ & 37.7 \\
\hline Other qualifications & 270 & 4.32 & 271 & 3.43 & $2,461,829$ & 5.7 & 654,643 & 10 \\
\hline
\end{tabular}

18 Table 1.2 is taken from the 2011 Census for England and Wales. The census boundaries differ from mine.

\begin{tabular}{|c|c|c|c|c|c|c|c|c|}
\hline \multirow{2}{*}{$\begin{array}{l}\text { Approximated } \\
\text { Social Grade- } \\
\text { All household } \\
\text { reference persons } \\
\text { aged 16-64 }\end{array}$} & \multicolumn{2}{|c|}{ Highglade } & \multicolumn{2}{|c|}{ Leeglade } & \multicolumn{2}{|l|}{ England } & \multicolumn{2}{|l|}{ London } \\
\hline & number & $\%$ & number & $\%$ & number & $\%$ & number & $\%$ \\
\hline $\begin{array}{l}\text { All categories: } \\
\text { Approximated } \\
\text { social grade }\end{array}$ & 2424 & 100 & 2990 & 100 & $16,339,853$ & 100 & $2,658,570100$ & \\
\hline $\begin{array}{l}\text { AB Higher and } \\
\text { intermediate } \\
\text { managerial/ } \\
\text { administrative/ } \\
\text { professional } \\
\text { occupations }\end{array}$ & 876 & 36.14 & 876 & 29.30 & $3,751,684$ & 23.00 & 783,570 & 29.50 \\
\hline $\begin{array}{l}\mathrm{Cl} \text { Supervisory, } \\
\text { clerical and junior } \\
\text { managerial/admin- } \\
\text { istrative/profes- } \\
\text { sional occupations }\end{array}$ & 869 & 35.85 & 1042 & 34.85 & $5,051,687$ & 30.90 & 876,892 & 33.00 \\
\hline $\begin{array}{l}\text { C2 Skilled manual } \\
\text { occupations }\end{array}$ & 422 & 17.41 & 596 & 19.93 & $3,372,058$ & 20.60 & 402,715 & 15.10 \\
\hline $\begin{array}{l}\text { DE Semi-skilled } \\
\text { and unskilled } \\
\text { manual occupa- } \\
\text { tions; unemployed } \\
\text { and lowest grade }\end{array}$ & 257 & 10.60 & 476 & 15.92 & $4,164,424$ & 25.50 & 595,393 & 22.40 \\
\hline
\end{tabular}

Note that the total population numbers for the villages in these tables are not the same as that population regarded as contained within the boundaries of these sites during field work. 
19 The general affluence is evident in people's possessions. Our surveys found that six per cent of homes had one bedroom, 16 per cent had two bedrooms, 40 per cent had three bedrooms, 27 per cent had four bedrooms, seven per cent had five bedrooms and two per cent had six bedrooms. We found 11 per cent of households had no cars, 41 per cent had one car, 42 per cent had two cars, one per cent had three cars and three per cent had four cars. This corresponds with census data which suggests around 70 per cent of people travel to work by car. We found no households without a television: 30 per cent had one television, 41 per cent had two, 15 per cent had three, six per cent had four and three per cent had five. Although we found no households with more than five persons, we did find six per cent with more than five televisions.

20 During field work we also made a series of short videos. One of these describes The Glades, another illustrates the field work methods and the rest show stories or findings arising from the field work. These may be found at www.ucl.ac.uk/why-we-post and it is strongly recommended that non-English readers view these to help them visualise the context for this book.

\section{Chapter 2}

1 Fox, K. 2004. Watching the English. London: Hodder \& Stoughton. See also Saville-Troike, M. 2008. The Ethnography of Communication. Oxford: Wiley-Blackwell and Briggs, C. and Bauman, R. 1992. 'Genre, Intertextuality, and Social Power.' Journal of Linguistic Anthropology 2(2): 131-72.

2 Frow, J. 2013. Genre. London: Routledge. 10.

3 Malinowski, B. 1935. Coral Gardens and their Magic. London: Routledge.

4 Madianou, M. and Miller, D. 2012. Migration and New Media. London: Routledge.

5 Gershon, I. 2010. The Break-up 2.0. Ithaca, NY: Cornell University Press.

6 The messenger service developed for Blackberry phones.

7 Turkle, S. 2011. Alone Together. New York, NY: Basic Books.

8 Parenting and young people's use of social media is one of the more thoroughly explored dimensions of the social consequences of new media. Three key references would be boyd, d. 2014. It's Complicated. New Haven, CT: Yale University Press, Clarke, L. S. 2013. The Parent App. Oxford: Oxford University Press and Ito, M. et al. 2013. Hanging Out, Messing Around, and Geeking Out. Cambridge, MA: The MIT Press. There are also many policyrelated papers with astute dissection of these moral issues by Sonia Livingstone, for example Livingstone, S. 2009. Children and the Internet. Cambridge: Polity Press.

9 Murthy, D. 2013. Twitter. Cambridge: Polity Press. Weller, K. et al. 2013. Twitter and Society. New York, NY: Peter Lang.

10 A film about 'Twitter Beef' re-created by these schoolchildren can be found on www.ucl. ac.uk/why-we-post

11 Broadbent, S. 2011. L'intimité au travail: la vie privée et les communications personnelles dans l'entreprise. Paris: FYP Editions. Broadbent, S. 2014. 'Approaches to Personal Communication.' Horst, H. and Miller, D. eds. 2012. Digital Anthropology. London: Berg. 127-45.

12 Miller, D. and Sinanan, J. 2016. Visualising Facebook. London: UCL Press. 145-9.

13 Hutchby, I. 2001. 'Technologies, Texts and Affordances.' Sociology 35(2): 441-56. Madianou, M. and Miller, D. 2012. Migration and New Media. Abingdon: Routledge. See also Baym, N. 2010. Personal Connections in the Digital Age. Cambridge: Polity Press.

14 Baym, N. 2010. Personal Connections in the Digital Age. Cambridge: Polity Press.

15 Miller, D. 2011. Tales from Facebook. Cambridge: Polity Press. Miller, D. and Sinanan, J. 2016. Visualising Facebook. London: UCL Press.

16 Baym, N. 2010. Personal Connections in the Digital Age. Cambridge: Polity Press. 44.

17 Furthermore, there are many instances where technical means, including algorithms and design, are used with great success to determine our behaviour. An extreme but also very clear example is Schüll's study of gaming machines in Las Vegas: Schüll, N. 2012. Addiction by Design. Princeton, NJ: Princeton University Press. There is also a considerable body of literature on human-machine interaction which configures the complex mix of social, cultural and technological factors in ways that avoid a more deterministic reading, for example Dourish, P. 2004. Where the Action Is. Cambridge, MA: The MIT Press. 
18 Miller, D. and Sinanan, J. 2016. Visualising Facebook. London: UCL Press. 158-61.

19 Graham, M. and Dutton, W. eds. 2014. Society and the Internet. Oxford: Oxford University Press.

\section{Chapter 3}

1 A version of this chapter, which includes a more extensive debate with the wider academic literature that is not reproduced here, may be found in Miller, D. 2015. Photography in the Age of Snapchat. London: Royal Anthropological Institute.

2 For most of the books in this series the equivalent Chapter 3 is devoted to the visual posting on the platform that is most prominent in their study. This is Facebook for most of our sites and QQ for the Chinese sites. However, in my case Visualising Facebook is devoted to comparing the photographs and memes posted on Facebook in The Glades with those posted on Facebook in El Mirador, our site in Trinidad. For this reason Facebook is largely ignored in this chapter. By contrast Instagram and Twitter were omitted from Visualising Facebook since these platforms are not yet common in El Mirador and so could not be directly compared. This is why I chose to focus upon them here. Again certain topics such as their 'Englishness' and the selfie are highlighted in Visualising Facebook rather than here.

3 For the ethics involved and the use of consent forms in following informants see the Acknowledgements.

4 Miller, D. and Sinanan, J. 2016. Visualising Facebook. London: UCL Press.

5 The statistical analysis of our questionnaires, which will be published more fully elsewhere, reveals a statistically significant trend for females to prefer the visual platforms such as Instagram and Snapchat.

6 Pet photography is discussed in more detail in Miller, D. and Sinanan, J. 2016. Visualising Facebook. London: UCL Press.

7 Bourdieu, P. 1984. Distinction: A Social Critique of the Judgement of Taste. London: Routledge \& Kegan Paul.

8 Sarvas, R. and Frohlich, D. 2011. From Snapshots to Social Media: The Changing Picture of Domestic Photography. Dordrecht: Springer.

9 For photography generally see Sontag, S. 1977. On Photography. Harmondsworth: Penguin. For anthropology see Edwards, E. 1992. Anthropology and Photography 1860-1929. London: Royal Anthropological Institute. Pinney, C. 2011. Photography and Anthropology. London: Reaktion.

10 Benjamin, W. 1970. 'The Work of Art in the Age of Mechanical Reproduction' (Arendt, H. ed.) Illuminations. London: Jonathan Cape. 217-52. Bourdieu, P. 1990. Photography: A MiddleBrow Art. Cambridge: Polity Press.

11 Dijck, van J. 2007. Mediated Memories in the Digital Age. Stanford, CA: Stanford University Press.

12 Bourdieu, P. 1990. Photography. A Middle-Brow Art. Cambridge: Polity Press.

13 Rose, G. 2010. Doing Family Photography. Aldershot: Ashgate. Rose, G. 2014. 'How Digital Technologies Do Family Snaps, Only Better.' Larsen, J. and Sandbye, M. eds. 2014. Digital Snaps: The New Face of Photography. London: I. B. Tauris. 67-86.

\section{Chapter 4}

1 I also ranked my music, which never wavered from having Joni Mitchell at number one.

2 For excellent studies of the categories of friendship in contemporary Britain see Allan, G. 1996. Kinship and Friendship in Modern Britain. Oxford: Oxford University Press and Pahl, R. 2000. On Friendship. Cambridge: Polity Press.

3 Strathern, M. 1988. The Gender of the Gift. Berkeley, CA: University of California Press.

4 Langford, P. 2001. Englishness Identified: Manners and Character 1650-1850. Oxford: Oxford University Press.

5 A film about this group can be seen at www.ucl.ac.uk/why-we-post 
6 Miller, D. and Sinanan, J. 2016. Visualising Facebook. London: UCL Press. Chapter 2.

7 In addition, as Marwick and boyd have pointed out, there are various ways in which teenagers construct 'networked privacy' outside of individual privacy settings, in order to be public in their own particular way. See Marwick, A. and boyd, d. 2014. 'Networked Privacy: How Teenagers Negotiate Context in Social Media.' New Media \& Society 16(7): 1051-67.

8 For examples see boyd, d. 2014. It's Complicated. New Haven, CT: Yale University Press. 65-70.

9 http://www.wikihow.com/Use-the-Tinder-App, accessed 13 April 2015.

10 One of the films at www.ucl.ac.uk/why-we-post concerns a woman talking about bringing up a child in the still more isolated conditions of a canal boat.

11 An antenatal class.

12 This is not to suggest that people of other lands do not have even more exquisite sensibilities about this and other matters.

13 Underlying these issues may also be a strong concern with modesty and even selfeffacement. Such concern will not be discussed here, however, since it is the subject of far more detailed analysis and discussion with respect to the culture of being English in Miller, D. and Sinanan, J. 2016. Visualising Facebook. London: UCL Press.

14 Miller, D. 2011. Tales from Facebook. Cambridge: Polity Press. 16-27.

15 Miller, D. 2011. Tales from Facebook. Cambridge: Polity Press.

16 Miller, D. and Horst, H. 2006. The Cell Phone: An Anthropology of Communication. Oxford: Berg. Miller, D. 2011. Tales from Facebook. Cambridge: Polity Press.

17 A fine example would be the series of novels by Elena Ferrante concerning a single friendship.

\section{Chapter 5}

1 We were so struck by this case that it subsequently became the subject of an MSc dissertation by Ciara Green who, as well as working as my research assistant through almost the entirety of this field work, was also taking her degree in Digital Anthropology at the Department of Anthropology at UCL. We also have a short film of this study, available at www.ucl.ac.uk/ why-we-post

2 I have not been able to find figures, but my impression was that middle class women in fulltime employment tended to take shorter maternity leave until recently, at least for the areas of London where I have previously researched.

3 See, for example, boyd, d. 2014. It's Complicated. New Haven, CT: Yale University Press. Clarke, L. S. 2013. The Parent App. Oxford: Oxford University Press. 41-5.

4 As suggested in Ciara Green's MSc dissertation, 2014.

5 http://blogs.ucl.ac.uk/global-social-media/2013/11/24/what-will-we-learn-from-thefall-of-facebook/, accessed 24 November 2013.

6 The more complete publication of these quantitative materials will be carried out by our statistician for publication online in February 2016 to coincide with the launch of 'Why We Post' and these volumes. Detailed material is not available at the time of writing.

7 Much of this case study will also be published in a separate paper: Green, C. and Miller, D. 'The Problem with Cyber-Bullying.' In preparation. Many of our results were similar to those of Marwick, A. and boyd, d. 2014. "II's Just Drama”: Teen Perspectives on Conflict and Aggression in a Networked Era.' Journal of Youth Studies 17(9): 1187-204. See also boyd, d. 2014. It's Complicated. New Haven, CT: Yale University Press. 128-52.

8 Livingstone, S. et al. 2016. The Class. London: Routledge.

9 boyd, d. 2014. It's Complicated. New Haven, CT: Yale University Press. 136.

10 See, for example, Hinduja, S. and Patchin, J. 2014. Bullying Beyond the Schoolyard: Preventing and Responding to Cyberbullying. Thousand Oaks, CA: Sage. Kowalski, R. M., Limber, S. P. and Agaston, P. W. 2008. Cyberbullying: Bullying in the Digital Age. Chichester: WileyBlackwell. For useful summaries of the literature, see especially Livingstone, S. and Smith, P. 2014. 'Annual Research Review: Harms Experienced by Child Users of Online and Mobile Technologies: The Nature, Prevalence and Management of Sexual and Aggressive Risks in the Digital Age.' Journal of Child Psychology and Psychiatry 55(6): 635-54. Tokunaga, R. S. 
2010. 'Following You Home from School: A Critical Review and Synthesis of Research on Cyberbullying Victimization.' Computers in Human Behavior 26(3): 277-87.

11 Marwick, A. and boyd, d. 2014. "“It's Just Drama": Teen Perspectives on Conflict and Aggression in a Networked Era.' Journal of Youth Studies 17(9).

12 Vandebosch, H. and Van Cleemput, K. 2008. 'Defining Cyberbullying: A Qualitative Research into the Perceptions of Youngsters.' Cyberpsychology \& Behaviour 11(4): 499-503 (especially p. 499).

13 Slavtcheva-Petkova, V., Nash, V. and Bulger, M. 2015. 'Evidence on the Extent of Harms Experienced by Children as a Result of Online Risks: Implications for Policy and Research.' Information, Communication \& Society 18(1): 48-62. For an attempt to define the behaviour see Olweus, D. 1993. Bullying at School: What We Know and What We Can Do. Malden, MA: Blackwell.

14 Marwick, A. and boyd, d. “It's Just Drama”: Teen Perspectives on Conflict and Aggression in a Networked Era.' Journal of Youth Studies 17(9).

15 Compare Marwick, A. and boyd, d. "“It's Just Drama": Teen Perspectives on Conflict and Aggression in a Networked Era.' Journal of Youth Studies 17(9).

16 For the theory behind this concept of attainment see Miller, D. and Sinanan, J. 2014 Webcam. Cambridge: Polity Press. 4-15.

17 This celebration of empowerment is especially surprising in as much as academics are likely to have read the works of the French philosopher Michel Foucault, who probably more than anyone demonstrated the problematic nature of power.

18 Their stories and experiences will be explored in my very different, less academic book The Comfort of People (forthcoming).

19 Du Boulay, S. 2007. Cicely Saunders: The Founder of the Modern Hospice Movement. London: SPCK.

20 See https://www.ucl.ac.uk/anthropology/people/academic_staff/d_miller/mil-28

21 For a general view of the impact of digital communications on palliative care see Charness, $\mathrm{N}$., Demeris, G. and Krupinski, E. 2011. Designing Telehealth for an Aging Population: A Human Factors Perspective. London: Taylor and Francis. Sofka, C., Cupit, I. and Gilbert, K. eds. 2012. Dying, Death and Grief in an Online Universe. New York: Springer. Walter, T., Hourizi, R., Moncur, W. and Pitsillides, S. 2011. 'Does the Internet Change How We Die and Mourn? An Overview.' Omega 64(4): 275-302. See Miller, D. 2011. Tales from Facebook. Cambridge: Polity Press. 28-39 for an argument and a case study predicting the potential for older and disabled users.

22 A similar situation is developing with regard to disability. See Ginsburg, F. 2012. 'Disability in the Digital Age.' In Horst, H. and Miller, D. eds. 2012. Digital Anthropology. Oxford: Berg. 101-26.

23 Not being involved in policy means that making a proposal is only that, and I am not aware that this has been taken up. However, healthcare is a vast field, so it is quite likely that other similar initiatives are being developed elsewhere.

24 For more details and the longer-term historical background see Miller, D. 2015. 'The Tragic Dénouement of English Sociality.' Cultural Anthropology 30(2): 336-57.

25 For the historical evidence suggesting this has been the case for centuries, see Cockayne, E. 2012. Cheek by Jowl: A History of Neighbours. London: Bodley Head. Macfarlane, A. 1978. The Origins of English Individualism. Oxford: Blackwell. Tadmor, N. 2010. 'Early Modern English Kinship in the Long Run: Reflections on Continuity and Change.' Continuity and Change 25(1): 15-48.

26 For isolation of the elderly today in the UK see Bolton, M. 2012. Loneliness: The State We're In. Abingdon: Age UK. Victor, C. 2003. Loneliness, Social Isolation and Living Alone in Later Life. Sheffield: Economic and Social Research Council.

27 This story is told in one of the films that form part of the Why We Post website.

28 A point noted by Matt Marshall, a terminal cancer patient, in a film about his use of Facebook to be found at www.ucl.ac.uk/why-we-post

29 This, and many of the other points within this section, will be discussed in more detail through the stories of the patients in my book The Comfort of People (forthcoming).

30 Matt Marshall - see note 28 above. 


\section{Chapter 6}

1 The background to this chapter is described in the introduction to the village presented in Chapter 1.

2 English Church Census 2005: http://www.eauk.org/church/research-and-statistics/ english-church-census.cfm

3 Each person phones several others, who in turn phone several more until everyone is contacted.

4 There is much more in Miller, D. et al. 2016. How the World Changed Social Media. London: UCL Press, which discusses how public-facing social media have become a conservative force in many parts of the world.

5 Politics is also one aspect of what is likely to become the central issue to a wider account of The Glades (forthcoming). This concerns people's concept of 'the village' and the vitality of the High Street and local organisations.

6 Again this finding was common to many of the other field sites, even those such as Mardin on the Syrian-Turkish border which is riven by sometimes violent political struggle. See Costa, E. 2016. Social Media in Southeast Turkey. London: UCL Press.

7 The parish was originally a church community, but the term now refers to the lowest tier of elected local government.

8 For examples, see Miller, D. and Sinanan, J. 2016. Visualising Facebook. London: UCL Press.

9 See, for example, the chapter on politics and newspapers in Bourdieu, P. 1984. Distinction: A Social Critique of the Judgement of Taste. London: Routledge \& Kegan Paul.

10 Miller, D. 1997. Capitalism: An Ethnographic Approach. Oxford: Berg. Also Chapter 5 in Miller, D. 2012. Consumption and its Consequences. Cambridge: Polity Press.

11 This name is a pseudonym.

12 See, for example, Clarke, A. 2001. Tupperware: The Promise of Plastic in 1950s America. Washington, DC: Smithsonian Institution. Storr, M. 2003. Latex and Lingerie: Shopping for Pleasure at Ann Summers Parties. Oxford: Berg.

13 See Chapter 6 in Miller, D. et al. 2016. How the World Changed Social Media. London: UCL Press.

14 Airbnb is an online company that provides a platform for customers to advertise spare rooms or whole properties for temporary rental.

15 Goldfarb, A. 2014. 'What is Different About Online Advertising?' Review of Industrial Organisation 44(2): 115-29.

16 Goldfarb, A. and Tucker, C. 2011. 'Online Display Advertising: Targeting and Obtrusiveness.' Marketing Science 30(3): 389-404.

17 Mahr, A., Grewal, D., de Ruyter, K. and Wetzels, M. 2014. 'Unraveling the Personalization Paradox: The Effect of Information Collection and Trust-Building Strategies on Online Advertisement Effectiveness.' Journal of Retailing 91(1): 34-49. See also Malheiros, M., Jennett, C., Patel, S., Brostoff, S. and Sasse, M. 2012. 'Too Close for Comfort: A Study of the Effectiveness and Acceptability of Rich-Media Personalized Advertising.' Proceedings of the 2012 ACM Annual Conference on Human Factors in Computing Systems. New York: ACM. $579-88$.

18 As always in our project we anticipate cultural variation. For the opposite reaction see an article from the Financial Times (28 January 2015) which reported that Chinese customers of WeChat were offended because they were not included in a targeted BMW advertisement. 'Backlash in China over WeChat's Targeted Ads': http://www.ft.com/cms/s/ 0/0fd1abc2-a610-11e4-abe9-00144feab7de.html\#axzz3lnQ37XuD. For opposition in the US see the Pew Research survey, 'Americans not fans of online targeted ads: survey', 9 March 2012: http://phys.org/news/2012-03-americans-fans-online-ads-survey.html

19 Zuckerman, E. 2014. 'The Internet's Original Sin.' The Atlantic. 14 August 2014.

20 Miller, D. 2014. 'Hospices: The Potential for New Media': http://www.ucl.ac.uk/anthropology/people/academic_staff/d_miller/mil-28 


\section{Chapter 7}

1 Miller, D. Tales from Facebook. Cambridge: Polity Press. 181-4.

2 Miller, D. Tales from Facebook. Cambridge: Polity Press. 16-27.

3 Fox, K. 2004. Watching the English. London: Hodder \& Stoughton.

4 For polymedia see Madianou, M. and Miller, D. 2012. Migration and New Media. Abingdon: Routledge. For scalable sociality, see Miller, D. et al. 2016. How the World Changed Social Media. London: UCL Press. For a theory of attainment see Miller, D. and Sinanan, J. 2014. Webcam. Cambridge: Polity Press.

5 Miller, D. et al. 2016. How the World Changed Social Media. London: UCL Press.

6 Cockayne, E. 2012. Cheek by Jowl: A History of Neighbours. London: Bodley Head.

7 Young, M. and Willmott, P. 1957. Family and Kinship in East London. Harmondsworth: Penguin.

8 In June 2016 the will of Melita Jackson was successfully contested in the UK Court of Appeal.

9 Macfarlane, A. 1978. The Origins of English Individualism. Oxford: Blackwell. Strathern, M. 1992. After Nature: English Kinship in the Late Twentieth Century. Cambridge: Cambridge University Press, has subsequently built on this with respect to the nature of contemporary English kinship. While some societies see society with its relations as the idiom for also understanding the person, in England a relative autonomous individuality is presupposed that is not analogous to society. In this book, therefore, we see an individual elderly person volunteering his or her labour as philanthropy rather than as a duty. The dualism between the private and public highlighted here may then be cousin to Strathern's opposition between the individual and society.

10 One caveat is that The Glades is in the 'home counties', a description of southeast England that has connotations of complacency as well as comfort. In England we tend to assume that people in the north of England are actually friendlier and less 'suburban' in outlook. As noted, any generalisation at the scale of 'the English' is obviously an over-generalisation in hundreds of ways, but is warranted since there are generalities and topicalities that we need to take into account. There is a good deal of contemporary ethnography of these other forms of 'Englishness'. For three recent examples see Degnen, C. 2012. Ageing Selves and Everyday Life in the North of England. Manchester: Manchester University Press, Edwards, J. 2000. Born and Bred: Idioms of Kinship and New Reproductive Technologies in England. Oxford: Oxford University Press and Rapport, N. 1993. Diverse World Views in an English Village. Edinburgh: Edinburgh University Press.

11 Robert, R. 1973. The Classic Slum. Harmondsworth: Penguin.

12 Douglas, M. 1966. Purity and Danger. London: Routledge. 


\section{References}

Allan, G. 1996. Kinship and Friendship in Modern Britain. Oxford: Oxford University Press.

Baym, N. 2010. Personal Connections in the Digital Age. Cambridge: Polity Press.

Benjamin, W. 1970. 'The Work of Art in the Age of Mechanical Reproduction.' Arendt, H., ed. Illuminations. London: Jonathan Cape. 217-52.

Bolton, M. 2012. Loneliness: The State We're In. Abingdon: Age UK.

Bourdieu, P. 1990. Photography: A Middle-Brow Art. Cambridge: Polity Press.

Bourdieu, P. 1984. Distinction: A Social Critique of the Judgement of Taste. London: Routledge \& Kegan Paul.

boyd, d. 2014. It's Complicated. New Haven, CT: Yale University Press.

boyd, d. and Ellison, N. 2007. 'Social Networking Sites: Definition, History and Scholarship.' Journal of Computer-Mediated Communication 13(1): 210-30.

Briggs, C. and Bauman, R. 1992. 'Genre, Intertextuality, and Social Power.' Journal of Linguistic Anthropology 2(2): 131-72.

Broadbent, S. 2014. 'Approaches to Personal Communication'. Horst, H. and Miller, D. eds. Digital Anthropology. London: Berg. 127-45.

Broadbent, S. 2011. L'intimité au travail: la vie privée et les communications personnelles dans l'entreprise. Paris: FYP Editions.

Charness, N., Demiris, G. and Krupinski, E. 2011. Designing Telehealth for an Aging Population: A Human Factors Perspective. London: Taylor \& Francis.

Clarke, A. 2001. Tupperware: The Promise of Plastic in 1950s America. Washington, DC: Smithsonian Institution.

Clarke, L. S. 2013. The Parent App. Oxford: Oxford University Press.

Cockayne, E. 2012. Cheek by Jowl: A History of Neighbours. London: Bodley Head.

Costa, E. 2016. Social Media in Southeast Turkey. London: UCL Press.

Degnen, C. 2012. Ageing Selves and Everyday Life in the North of England. Manchester: Manchester University Press.

Dijck, J. van. 2007. Mediated Memories in the DigitalAge. Stanford, CA: Stanford University Press. Douglas, M. 1966. Purity and Danger. London: Routledge.

Dourish, P. 2004. Where the Action Is. Cambridge, MA: The MIT Press.

du Boulay, S. 2007. Cicely Saunders: The Founder of the Modern Hospice Movement. London: SPCK.

Edwards, E. 1992. Anthropology and Photography 1860-1929. London: Royal Anthropological Institute.

Edwards, J. 2000. Born and Bred: Idioms of Kinship and New Reproductive Technologies in England. Oxford: Oxford University Press.

Fox, K. 2004. Watching the English. London: Hodder \& Stoughton.

Frow, J. 2013. Genre. London: Routledge.

Gershon, I. 2010. The Break-up 2.0. Ithaca, NY: Cornell University Press.

Ginsburg, F. 2012. 'Disability in the Digital Age.' Horst, H. and Miller, D. eds. Digital Anthropology. Oxford: Berg. 101-26.

Goldfarb, A. 2014. 'What is Different About Online Advertising?' Review of Industrial Organisation 44(2): 115-29.

Goldfarb, A. and Tucker, C. 2011. 'Online Display Advertising: Targeting and Obtrusiveness.' Marketing Science 30(3): 389-404.

Graham, M. and Dutton, W. eds. 2014. Society and the Internet. Oxford: Oxford University Press.

Green, C. and Miller, D. 'The Problem of Cyber-Bullying' (in preparation). 
Hinduja, S. and Patchin, J. 2014. Bullying Beyond the Schoolyard: Preventing and Responding to Cyberbullying. Thousand Oaks, CA: Sage.

Horst, H. and Miller, D. eds. 2012. Digital Anthropology. London: Berg. 127-45.

Hutchby, I. 2001. 'Technologies, Texts and Affordances.' Sociology 35(2): 441-56.

Ito, M., Baumer, S., Bittanti, M., boyd, d., Herr-Stephenson, B., Horst, H. A., Lange, P. G., Mahendran, D., Martínez, K. Z., Pascoe, C. J., Perkel, D., Robinson, L., Sims, C. and Tripp, L. 2013. Hanging Out, Messing Around, and Geeking Out: Cambridge, MA: The MIT Press.

Kowalski, R. M., Limber, S. P. and Agaston, P. W. 2008. Cyberbullying: Bullying in the Digital Age. Chichester: Wiley-Blackwell.

Langford, P. 2001. Englishness Identified: Manners and Character 1650-1850. Oxford: Oxford University Press.

Larsen, J. and Sandbye, M. eds. 2014. Digital Snaps: The New Face of Photography. London: I. B. Tauris. 67-86.

Laski, M. 2007. The Village. London: Persephone Books.

Livingstone, S. 2009. Children and the Internet. Cambridge: Polity Press.

Livingstone, S. et al. 2016. The Class. London: Routledge.

Livingstone, S. and Smith, P. 2014. 'Annual Research Review: Harms Experienced by Child Users of Online and Mobile Technologies: The Nature, Prevalence and Management of Sexual and Aggressive Risks in the Digital Age.' Journal of Child Psychology and Psychiatry 55(6): 635-54.

Macfarlane, A. 1978. The Origins of English Individualism. Oxford: Blackwell.

Madianou, M. and Miller, D. 2012. Migration and New Media. Abingdon: Routledge.

Mahr, A., Grewal, D., de Ruyter, K. and Wetzels, M. 2014. 'Unraveling the Personalization Paradox: The Effect of Information Collection and Trust-Building Strategies on Online Advertisement Effectiveness.' Journal of Retailing 91(1): 34-49.

Malheiros, M., Jennett, C., Patel, S., Brostoff, S. and Sasse, M. 2012. 'Too Close for Comfort: A Study of the Effectiveness and Acceptability of Rich-Media Personalized Advertising.' Proceedings of the 2012 ACM Annual Conference on Human Factors in Computing Systems. New York, NY: ACM. 579-88.

Malinowski, B. 1935. Coral Gardens and their Magic. London: Routledge.

Marwick, A. and boyd, d. 2014. "It's Just Drama": Teen Perspectives on Conflict and Aggression in a Networked Era.' Journal of Youth Studies 17(9): 1187-204.

Marwick, A. and boyd, d. 2014. 'Networked Privacy: How Teenagers Negotiate Context in Social Media.' New Media \& Society 16(7): 1051-67.

Miller, D. 2015. Photography in the Age of Snapchat. London: Royal Anthropological Institute.

Miller, D. 2015. 'The Tragic Dénouement of English Sociality.' Cultural Anthropology 30(2): 336-57.

Miller, D. 2014. 'Hospices: The Potential for New Media'. http://www.ucl.ac.uk/anthropology/ people/academic_staff/d_miller/mil-28

Miller, D. 2012. Consumption and its Consequences. Cambridge: Polity Press.

Miller, D. 2011. Tales from Facebook. Cambridge: Polity Press.

Miller, D. 1997. Capitalism: An Ethnographic Approach. Oxford: Berg.

Miller, D. and Horst, H. 2006. The Cell Phone: An Anthropology of Communication. Oxford: Berg.

Miller, D. and Sinanan, J. 2016. Forthcoming. Visualising Facebook: A Comparative Approach. London: UCL Press.

Miller, D. and Sinanan, J. 2014. Webcam. Cambridge: Polity Press.

Miller, D. et al. 2016. How the World Changed Social Media. London: UCL Press.

Murthy, D. 2013. Twitter. Cambridge: Polity Press.

Olweus, D. 1993. Bullying at School: What We Know and What We Can Do. Malden, MA: Blackwell. Pahl, R. 2000. On Friendship. Cambridge: Polity Press.

Pinney, C. 2011. Photography and Anthropology. London: Reaktion.

Rapport, N. 1993. Diverse World Views in an English Village. Edinburgh: Edinburgh University Press.

Robert, R. 1973. The Classic Slum. Harmondsworth: Penguin.

Rose, G. 2014. 'How Digital Technologies Do Family Snaps, Only Better.' Larsen, J. and Sandbye, M. eds. Digital Snaps. London: I. B. Tauris. 67-86.

Rose, G. 2010. Doing Family Photography. Aldershot: Ashgate.

Rowling, J. K. 2013. The Casual Vacancy. London: Sphere. 
Sarvas, R. and Frohlich, D. 2011. From Snapshots to Social Media: The Changing Picture of Domestic Photography. Dordrecht: Springer.

Savage, M., Devine, F., Cunningham, N., Taylor, M., Li, Y., Hjellbrekke, J., Le Roux, B., Friedman, S. and Miles, A. 2013. 'A New Model of Social Class: Findings from the BBC's Great British Class Survey Experiment.' Sociology 47(2): 219-50.

Saville-Troike, M. 2008. The Ethnography of Communication. Oxford: Wiley-Blackwell.

Schüll, N. 2012. Addiction by Design. Princeton, NJ: Princeton University Press.

Simmel, G. 1968. The Conflict in Modern Culture and Other Essays. New York, NY: Teachers College Press.

Slavtcheva-Petkova, V., Nash, V. and Bulger, M. 2015. 'Evidence on the Extent of Harms Experienced by Children as a Result of Online Risks: Implications for Policy and Research.' Information, Communication \& Society 18(1): 48-62.

Sofka, C., Cupit, I. and Gilbert. K. eds. 2012. Dying, Death and Grief in an Online Universe. New York, NY: Springer.

Sontag, S. 1977. On Photography. Harmondsworth: Penguin.

Storr, M. 2003. Latex and Lingerie: Shopping for Pleasure at Ann Summers Parties. Oxford: Berg.

Strathern, M. 1992. After Nature: English Kinship in the Late Twentieth Century. Cambridge: Cambridge University Press.

Strathern, M. 1988. The Gender of the Gift. Berkeley, CA: University of California Press.

Strathern, M. 1981. Kinship at the Core: An Anthropology of Elmdon, a Village in North-West Essex in the Nineteen-Sixties. Cambridge: Cambridge University Press.

Tadmor, N. 2010. 'Early Modern English Kinship in the Long Run: Reflections on Continuity and Change.' Continuity and Change 25(1): 15-48.

Tokunaga, R. S. 2010. 'Following You Home from School: A Critical Review and Synthesis of Research on Cyberbullying Victimization.' Computers in Human Behavior 26(3): 277-87.

Turkle, S. 2011. Alone Together. New York, NY: Basic Books.

Vandebosch, H. and Van Cleemput, K. 2008. 'Defining Cyberbullying: A Qualitative Research into the Perceptions of Youngsters.' Cyberpsychology \& Behaviour 11(4): 499-503.

Victor, C. 2003. Loneliness, Social Isolation and Living Alone in Later Life. Sheffield: Economic and Social Research Council.

Walter, T., Hourizi, R., Moncur, W. and Pitsillides, S. 2011. 'Does the Internet Change How We Die and Mourn? An Overview.' Omega 64(4): 275-302.

Weller, K., Bruns, A., Burgess, J., Mahrt, M. and Puschmann, C. eds. 2013. Twitter and Society. New York, NY: Peter Lang.

Young, M. and Willmott, P. 1957. Family and Kinship in East London. Harmondsworth: Penguin. Zuckerman, E. 2014. 'The Internet's Original Sin'. The Atlantic, 14 August 2014. 



\section{Index}

abuse, physical 133, 136

adolescent behaviour 117

advisers on the use of social media 171-2

affordances 39-44, 183

definition of 31

age-based cohorts 94

age-specific differences in approach to social media 5-6, 42, 126-7; see also older people's use of social media

Amazon (online retailer) 175

Anglican Church 150-1, 158-60

anthropology 3-4, 6, 8, 42, 44-6, 93, 120, $126,128,149,160,181,191$

Apple Corporation 26

ask.fm 25

'attainments' 136, 186

autonomy, children's 124-5

baby care $107-8$

banter 52, 85, 89, 98, 130, 183, 186

Baym, N. 33

BBM 38, 48, 97-8, 127-9, 183

beauty parlours $171-2,177-8$

'best friends forever' (BFF) 29-30, 70, 92

'best practice' 123, 125, 136

birth of children 95

Blackberry phones 38, 183

'bosom buddies' 146

Bourdieu, Pierre 81, 87, 165

boyd, d. 130

breast cancer 40,43

breast feeding $107-8$

Broadbent, S. 37, 39

bullying, offline 136; see also cyber-bullying

business-to-business services 170

cancer 40, 43, 143-6, 176, 178, 191

capitalism 166

carers 190

Catholic Church 151, 153, 158

chemotherapy 146

children, mothers' talking about 94-5

China 185

churches' use of social media 150-9, 177-9

class differences in society 10,151

community, sense of 154-5, 184-5, 188-90

community groups 18

companies' use of social media 166-72, 178

complaining about quality of service 173 complexity of relationships in general 120

confidentiality in health care 179

conversation, normative 19

councillors 161-4

cultural capital 81

cyber-bullying 8, 123, 128-30, 133, 136

data collection as part of research 125

dating sites 26

death, dealing with 102-5, 138, 146-7

Dijck, J. van 87

distance, erosion of 148

divorce 115

doctors' surgeries, use of 180

Eliot, George 160

email 37-8, 42, 151-2, 159, 162-4, 171, 173

embarrassing situations 4, 103, 144, 153, 191

emoji 85

emoticons 85

empowerment of girls 136

ending of relationships 21

Englishness 1-8, 17-18, 44, 99-102, 109, 111, $121,142-3,148,160,163,176-9,182$

social media seen as 187-91

ethnography 16-18, 128, 136, 147-8, 174-7, 181,186

definition of 17

extroversion 119

Facebook 3-6, 24-7, 35-43, 46, 48, 70, 74, $82-7,93-108,115,121,125-8,133$, $140-7,152-8,163-78,182-90$

decline in children's use of 125-7

history of 184-8

parents' use or non-use of 116

used for 'news' or for 'chatting' 113

'Facebook friends' 95, 110-12, 120, 125-6, 184

Facetime 30, 145

family photographs 88,146

family relationships 92-6, 102, 185, 188, 190; see also kinship

festive meals, pictures of 155

'fictive kin' 92

'followers' 36

food and drink, images of 71-3, 155

foster parenting 115-16

Fox, Kate 4, 20, 186 
friends, types of 21, 92-4, 97, 110; see also 'Facebook friends'

Friends Reunited 6, 189

Frow, J. 20

gaming consoles $3,26,127$

gender differences in use of social media 59-62, 85-6; see also women's use of social media

gender stereotypes 23, 134-6

genres 20-1, 35-7, 43-4, 46, 186

Gershon, I. 21

Girming, 10, 12, 36, 152, 172

'The Glades' 8-10, 14-18, 34-5, 38, 41, 45, 92-3, 96, 106-7, 114-17, 138, 143, $148-50,158,163,170-3,178,181$, 187-91

Goldfarb, A. 174, 176

'Goldilocks Strategy' 5, 7, 99-100, 106, $116-17,121,173,178,187,189,191$

Google 26, 174-6

gossip 113-14, 177-8, 184

grandparents 144

Green, Ciara 18, 123-5

'green' concerns 166

Grindr 26

groupies 82

happenstance 55, 183

hashtags 85

'hiding behind a screen' 133-4, 148

'Highglade' 8, 11, 13, 104, 150, 166

'historical' material 37

holiday photographs 74-5

home working 106-7

Hootsuite 70

Hospice of St Francis, Berkhamsted 18, 137, 190-1

hospices $8,18,122,137-49,176$

effectiveness of 137

household composition 13

housing see social housing

humour, use of $47-8,164-5$

Ignatius Loyola 156

Imgur 26

'indirects' 37, 131-6, 148

definition of 131

individualism 188

Instagram 7, 24, 27-30, 45-6, 69-91, 98, 127, $148,172,174,186$

aesthetics of 79

craft element in 71-4, 81-2, 85

as a means of framing experience 89

insults online 55

interaction, positive and negative 173

interest groups 96

introversion 119, 159

iPads, use of 145-6, 159

Jamaica 115

joke tweets $47-8$

journalists' use of social media 126, 162, 164 kinship 95, 144, 184, 190; see also family relationships

Laski, Marghanita 9

'Leeglade' 8, 13-16, 150-1

'life balance' 107

Linkedin 169

local services 170,172

loneliness 105, 143, 145, 148, 190

long-term partnerships 118

McLaughlin, Kimberley 18, 137

Madianou, Mirca 21, 41

Malinowski, B. 20

media

forms of 2

choice of 22

medical communications 139

Melanesia 95

Members of Parliament (MPs) 161, 164, 178

messaging services 38,40

Messi, Lionel 59

Methodism 150-2, 156

Microsoft 26, 139

'middle distancing' 107

mobile phones 141

Morgan, Piers 36

mothers' relationships 93-7, 107-12, 186, 188

MySpace 125, 166

networking 144

among commercial companies $169-70$

'niceness' 99-101, 106

observation of behaviour 17; see also participant observation

older people's use of social media 42, 98, 105, $117,140,144-8,190$

online communities 93, 96, 99

Online Wikihow 103

Orkut 166, 185

'over-parenting' 124-5

'oversharing' 112-13

palliative care 140

parenting 27-32

and children's schooling 123-6

and use of Facebook 116, 125-6

see also foster parenting

participant observation 17

pastoral care by churches 156

'Patient's IT Initiatives' 140

'personalization paradox' 176

pet photographs $77-8$

photographic techniques $70-1,74,80-3,87$

photography

analogue and digital 87

as practice 88

Pinterest 25-6

platforms for social media $1,7,20-2,31$, $39-40,43-4,96,127,182-3$

migration across 186

PlayStation 3, 25-6

policy-related research 122-3, 128, 148

political activism 166 
political opinions expressed as a means of bonding 161, 177

politics 160-6, 177-8

disillusion with and alienation from 161 'old-school' 162

polymedia $7,21-3,26-32,35,40-3,45-6$, $86,96,98,127,139,143,146,186$

and parenting 27-32

poverty 13-14

PowerPoint 152

private exchanges and the private domain 4-5, 17, 144, 149, 159-60, 179

property prices 10

public domain 4, 143-4, 159, 179

pubs' use of social media 170-2

racism 165

religion and church organisation 150-60, 177

research, breadth of 147-9

restaurants' use of social media 170-2

retirement 15; see also older people's use of social media

'revenge porn' 118, 136

Rose, Gillian 88

scalable sociality $3,6,98,121,143,186-7$

school-based research 18

school classes as communities 185

school pupils' use of social media $24,35,38-9,45,97,100,108$, $118,120,128$

school-related postings 64,67

schools, local 10, 124, 165

screen shots, re-posting of 68

self-deprecation 48

selfies 40, 70, 82-6

sexuality and sexual humour 59-60, 166

Skype 40, 101

smartphones 38

Snapchat 7, 25, 31, 86-7, 97, 127, 132, 186

'social dis-ease' 4

social housing 10-14, 164

social interaction, commitment to 136

social media

in commerce 166-77

definition of 191

group-based 2

as an integral part of everyday life 192

integration with other media 27

problems created by $109,113-15$

range of platforms for 22

range of uses made of 20-4

significance of $180-1$

studies of 6-7, 31, 149, 182

use of the term 2

social networking sites, use of the term 3

social networks 144

'social worlds' 182 socialisation 44

sociality $2,8,109,120,145,182,184,190-1$

public and private 190

see also scalable sociality

societies, local 15

Strathern, Marilyn 95

suburbia and suburban ideals 189-90

suicide 129

swearing 117

targeted advertising $8,174-8$

taunting 8, 148

Taylor, Ros 137

terminal diagnoses 137, 145

Tesco 176

texting $29,43,139-40,151-2$, $156,159-60,163$

textual posting 165

Tinder 26, 103, 110, 182

toddler groups 93-4, 108, 116, 119, 173

'Transition Town' movement 166

'Treedon' 9-10, 14, 110, 151, 155

Trinidad 38, 114

TripAdvisor 170, 173

Trollope, Anthony 160

Tucker, C. 176

Tumblr 25-7, 98, 101-2, 127

Twitter 3, 7, 21, 27, 32-70, 84-9, 98, 100, $124-8,131-2,148,152,163-4$, $169-70,174,182-3,186$

'Twitter beef' 20, 36, 38, 107, 128, 135

'typical' behaviour 19, 44

'uglies' 97

'unfriending' 111-12, 165

unsolicited phone calls 173-4

villages and villagers $8-10,14,105,154-5$, $162-4,190$

Vine $26,46-7$

visual postings $7,45-7,69,91,164-5$

voluntary work 191

webcam 138, 146

WeChat 2-3

Wesley, John 152

WhatsApp 2-3, 17, 24, 27, 30, 38, 40, 96-7, $113,115,119,121,132,146,171,174$, 185,190

'white van man' image 169-70

women's use of social media 107-8, 124; see also gender differences in use of social media

Xbox 3, 25-7

YouTube 3, 25, 170 

Daniel Miller spent 18 months undertaking an ethnographic study with the residents of an English village, tracking their use of the different social media platforms. Following his study, he argues that a focus on platforms such as Facebook, Twitter and Instagram does little to explain what we post on social media. Instead, the key to understanding how people in an English village use social media is to appreciate just how 'English' their usage has become. He introduces the 'Goldilocks Strategy': how villagers use social media to calibrate precise levels of interaction ensuring that each relationship is neither too cold nor too hot, but 'just right'.

He explores the consequences of social media for groups ranging from schoolchildren through to the patients of a hospice, and he compares these connections to more traditional forms of association such as the church and the neighbourhood. Above all, Miller finds an extraordinary clash between new social media that bridges the private and the public domains, and an English sensibility that is all about keeping these two domains separate.

DANIEL MILLER is Professor of Anthropology at UCL and author/editor of 37 books including Tales from Facebook, Digital Anthropology (Ed. with H. Horst), The Internet: an Ethnographic Approach (with D. Slater), Webcam (with J. Sinanan), The Comfort of Things, A Theory of Shopping, and Stuff.

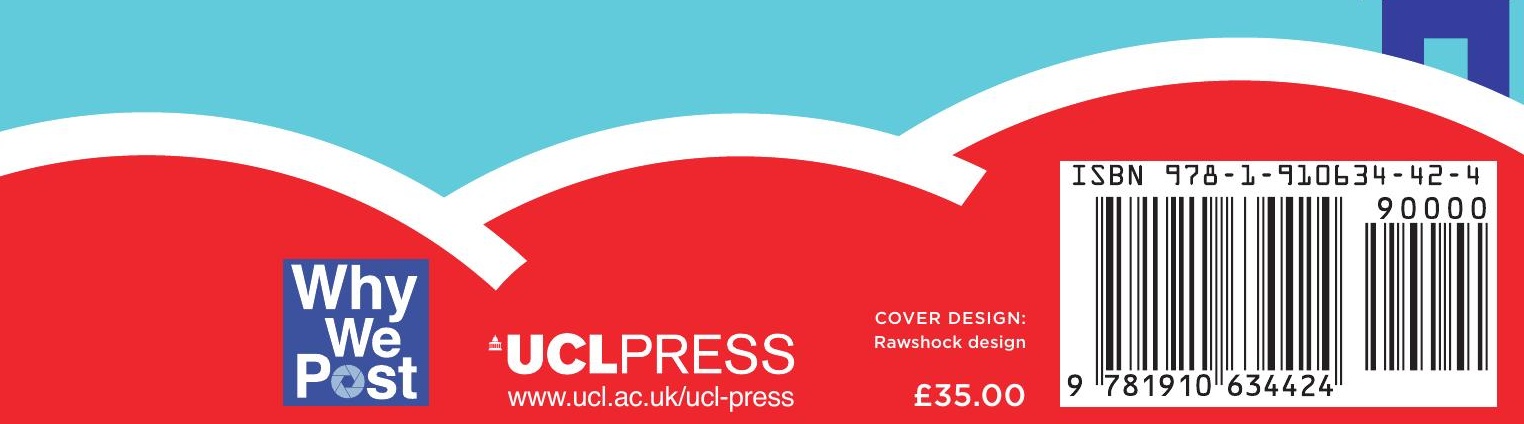

